\title{
Designing Debate:
}

The Entanglement of Speculative Design and Upstream Engagement

Thesis submitted for the degree of Doctor of Philosophy (PhD) 30th July 2015

Tobie Kerridge

Design Department

Goldsmiths, University of London 


\section{DECLARATION}

The work presented in this thesis is my own.

Signed:

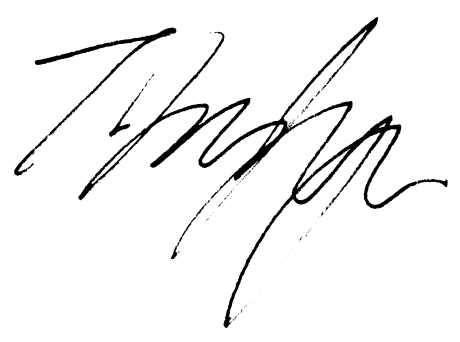

Tobie Kerridge 


\section{ACKNOWLEDGEMENTS}

The supervisory energies of Bill Gaver and Mike Michael have been boundless. Bill you have helped me develop an academic account of design practice that owes much to the intelligence and incisiveness of your own writing. Mike your provocative treatment of public engagement and generous dealings with speculative design have enabled an analytical account of these practices. I have benefited from substantial feedback from my upgrade examiners Sarah Kember and Jennifer Gabrys, and responded to the insightful comments of my viva examiners Carl DiSalvo and Jonas Löwgren in the body of this final transcript.

Colleagues at Goldsmiths, in Design and beyond, you have provided support, discussion, and advice. Thank you for your patience and generosity Andy Boucher, Sarah Pennington, Alex Wilkie, Nadine Jarvis, Dave Cameron, Juliet Sprake, Matt Ward, Martin Conreen, Kay Stables, Janis Jefferies, Mathilda Tham, Rosario Hutardo and Nina Wakeford, along with fellow PhD-ers Lisa George, Rose Sinclair and Hannah Jones.

A huge thanks to those who have provoked rich conversations, which have nourished the subjects and analysis of this thesis. Over these seven years of study I have pursued, and benefited from insight from, Alex Taylor, Ann Light, John Bowers, Tony Dunne, Fiona Raby, Durrell Bishop, Emily Dawson, Kevin Burchell, Gisa Weszkalnys, David Crowley, Adrian Smith, Bjorn Franke, Dave Elliot, Robert Philips, Ros Oakley, Abigail Durrant, Maja Horst, Jo-Anne Bichard, Katharina Bredies, Regina Peldszus, Simon Bowen, Benedict Singleton, Alice Bell, Claire Rocks, Massimo Botta, Louis Buckley, Cristiano Storni, Ana Rita Rodrigues, Luís Filipe de Oliveira Barbeiro, Ramia Mazé, Peter Wright and Matthew Malpass. Your conversations have spurred thought.

Collaborators, partners, supporters and participants of the activities related to the Material Beliefs project are too numerous to mention, I thank you all for the vibrancy of your association. I need to mention and thank Tony Cass, Olive Murphy and Nick Oliver, and fellow designers Elio Caccavlale, Jimmy Loizeau, James Auger and Susana Soares, your contributions to the project have been a source of inspiration and provocation, I hope this thesis reflects the richness of your work.

Finally, my parents Shelia and Martin, my sister Tammy and family and friends will be as surprised as me that this writing is completed. My partner Kate has managed to read not a word of this thesis while endlessly supporting its materialization, Kate you are amazing. Finally, our daughter Irma has only been here for ten months; thanks Irma for being excellent and sleeping well enough for me to get this done. 


\section{ABSTRACT}

This thesis offers a critical reflection of a design practice in which a speculative approach to design became entangled with upstream engagement with biotechnology research. Given that both practices claim to enable a public discussion about emergent technology, what is the nature of their mixing, and how should an analytical account of such a design practice be made?

I start with separate reviews of the respective features of these two approaches, considering practitioner accounts and histories along with analytical literature where those practices are objects of research. Then I take the case of the public engagement project Material Beliefs to develop an empirical account of their confluence. Initially I discuss labs as sites where designers, scientists, and nonexperts come together to discuss and to problematize accounts of biotechnology research. Next, I examine the process of making speculative designs, and here I emphasise the ways in which issues, materials and practices become compiled as exhibitable prototypes. Finally I consider the circulation and reception of these designs in public settings, including exhibitions, workshops, and online formats.

I argue that speculative designs' move on upstream PEST is an imbroglio that goes beyond mixing the formal features of practice, and requires a discussion concerning the actions of the designer in relation to a broader set of accountabilities. Authorship of the processes that lead to design outcomes, the description of design outcomes, and the effects of those outcomes become distributed and negotiated by an extended set of commitments coming from researchers, policymakers, educators, curators and promoters. Ultimately, I contend that this mixing provides an opportunity to foster a reflexive and empirical account of speculative practice, to engage in analysis of the organisations and settings that support a speculative approach, and to provide a critique of upstream engagement. 


\section{TABLE OF CONTENTS}

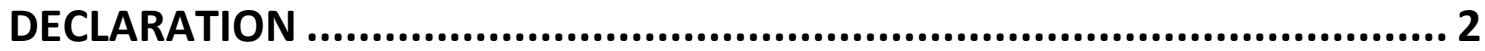

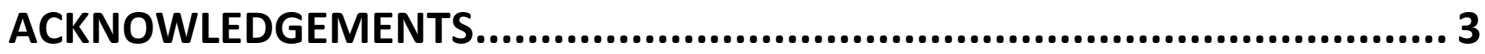

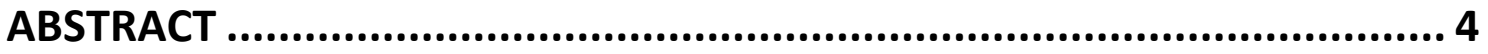

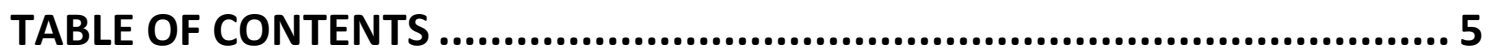

LIST OF ILLUSTRATIONS ........................................................................ 9

CHAPTER 1: THE TOPIC AND APPROACH OF THIS THESIS...................... 12

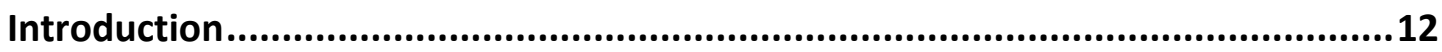

Speculative design and upstream engagement..............................................12

Introducing the project that is treated as a case study ....................................13

A Public Engagement with Engineering Workshop........................................... 13

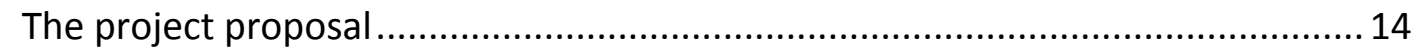

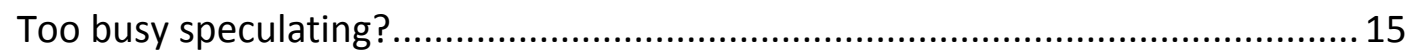

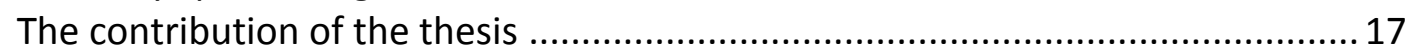

A thesis based in practice .......................................................................19

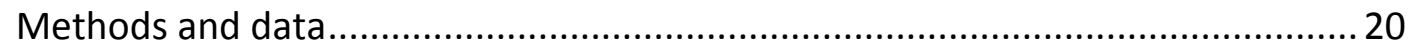

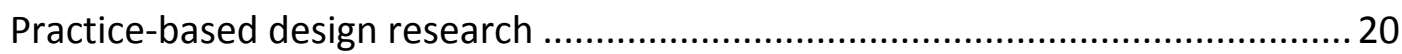

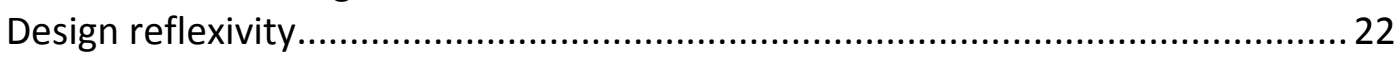

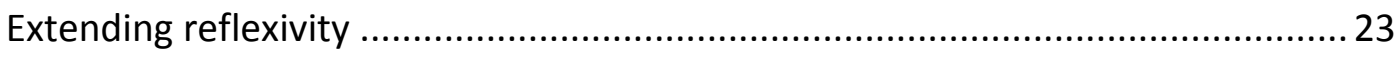

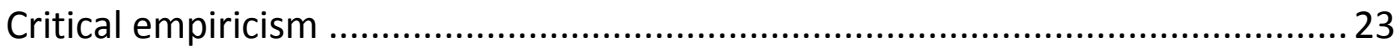

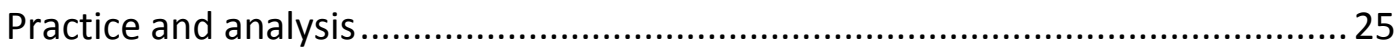

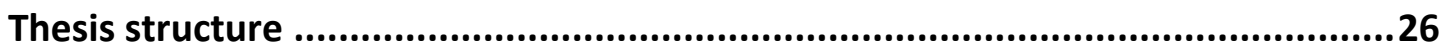

Reviewing Speculative Design and Public Engagement ................................... 26

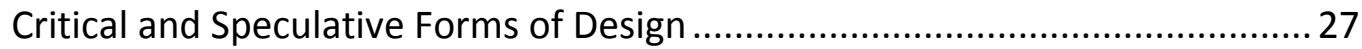

Public engagement with Science and Technology .......................................... 27

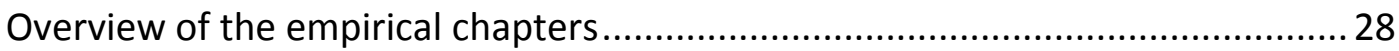

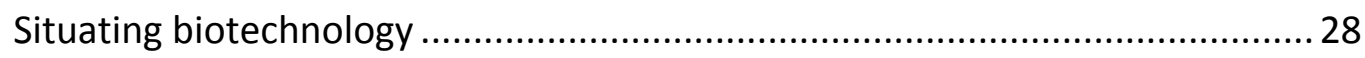

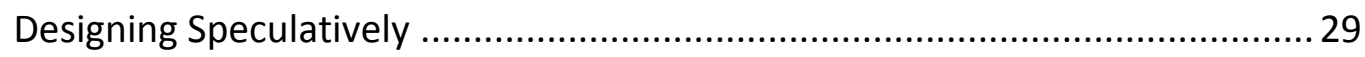

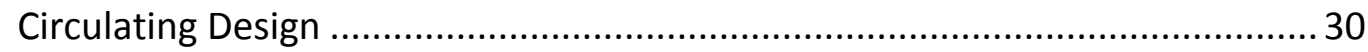

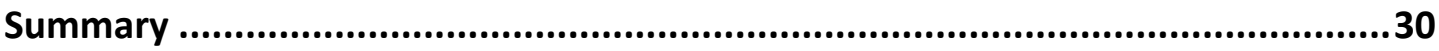

CHAPTER 2: THE PRACTICE AND ANALYSIS OF SPECULATIVE DESIGN ... 32

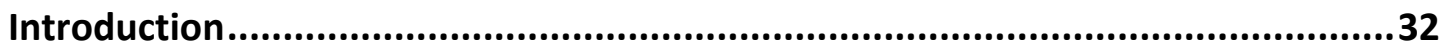

Practicing critical and speculative design....................................................33

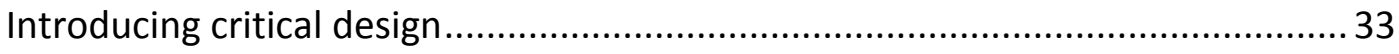

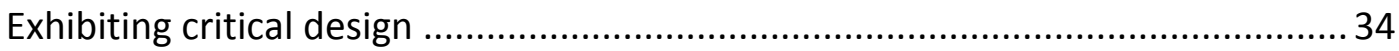

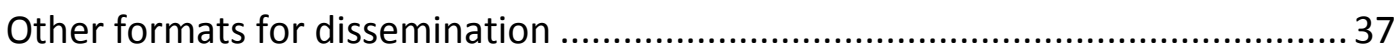

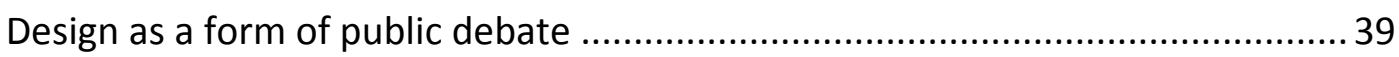

Debate and the Public Understanding of Science.............................................. 41

Funding Design as Public Engagement with Science and Technology .................. 42

Speculative Design and Upstream Engagement .............................................4 46

Considering speculative design as research .................................................51

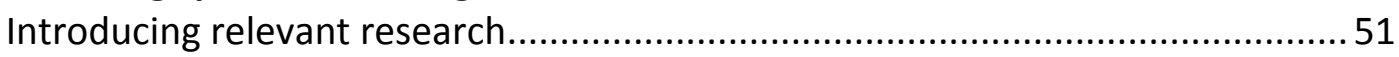

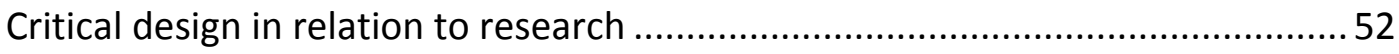

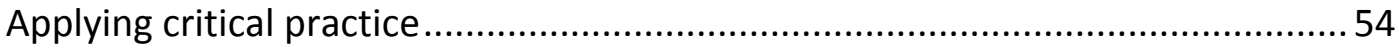

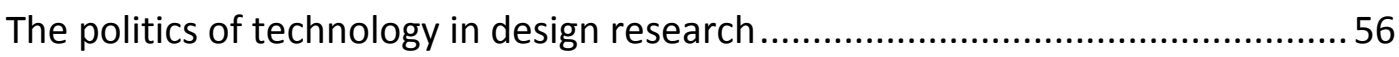

Design participation literature from two archives............................................ 59 


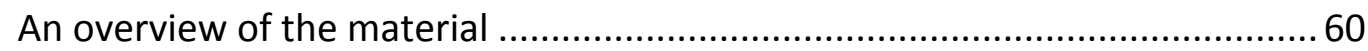

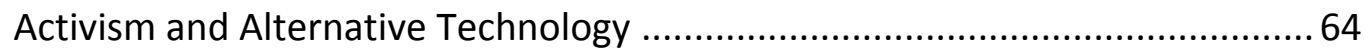

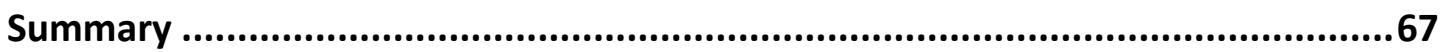

CHAPTER 3: THE PRACTICE AND ANALYSIS OF PUBLIC ENGAGEMENT

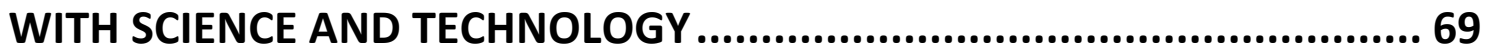

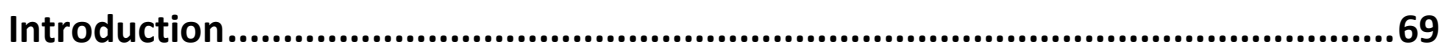

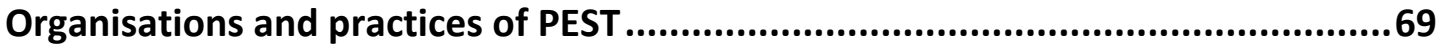

Engagement/Understanding/Awareness, in/with/of,

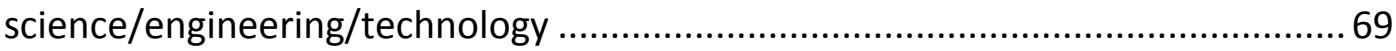

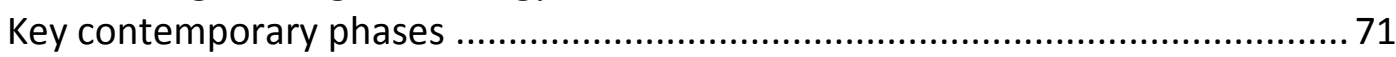

The Public Understanding of Science .......................................................... 71

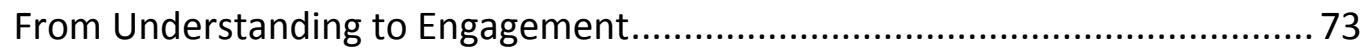

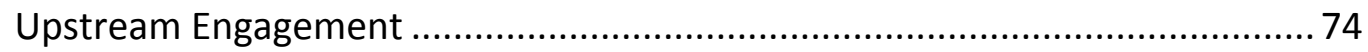

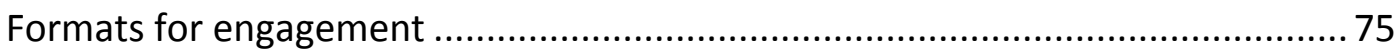

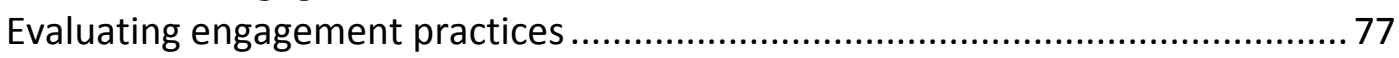

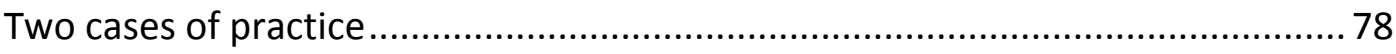

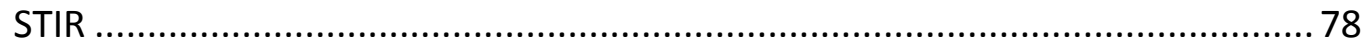

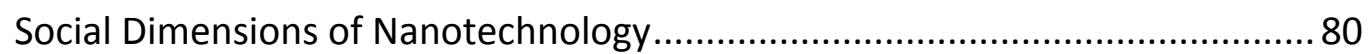

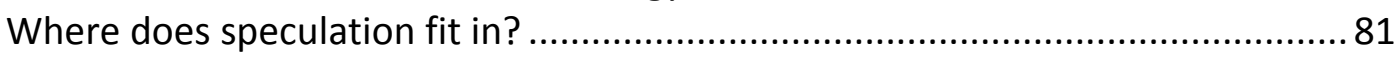

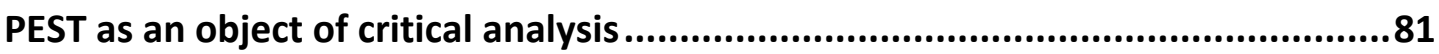

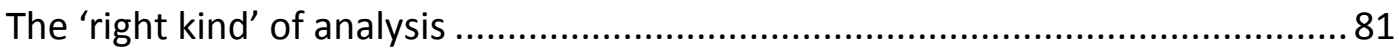

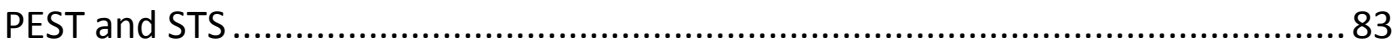

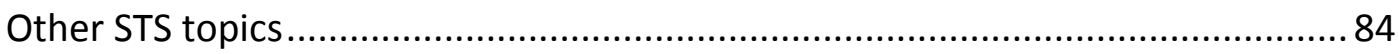

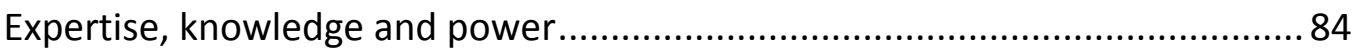

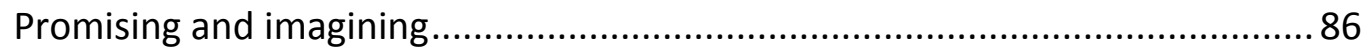

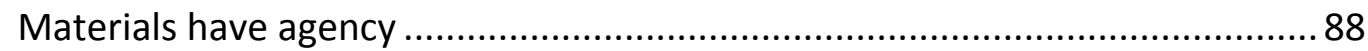

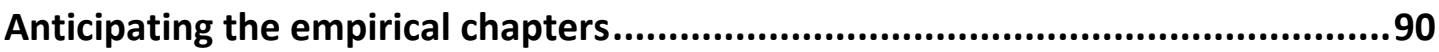

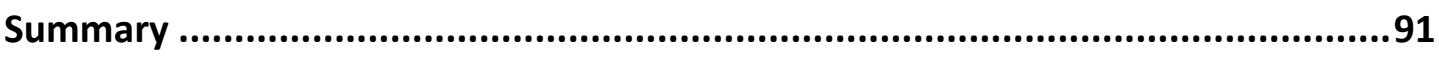

CHAPTER 4: SITUATING BIOTECHNOLOGY ...................................... 92

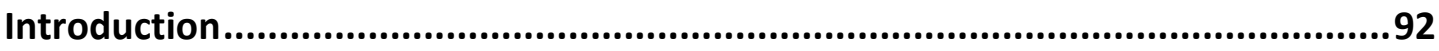

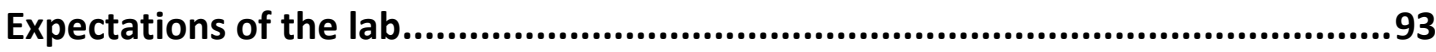

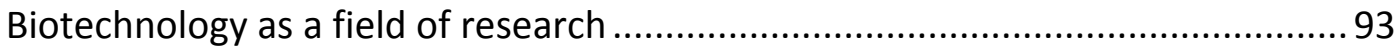

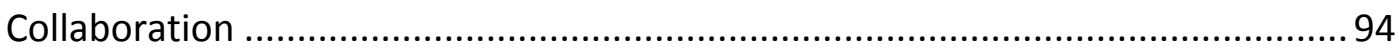

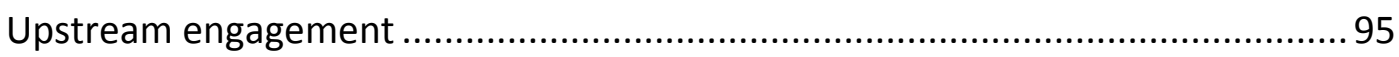

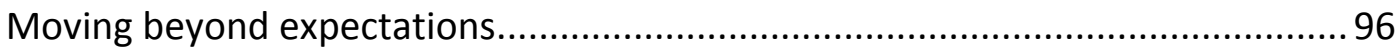

Designers interview biomedical researchers ....................................................96

Interviewing a director of research at a biomedical institute.............................99

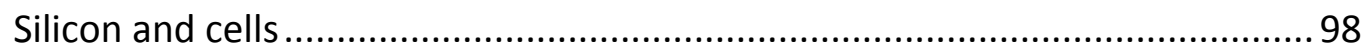

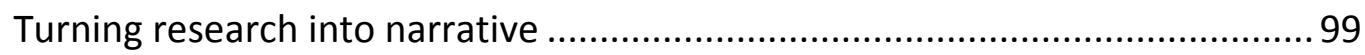

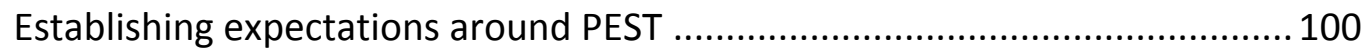

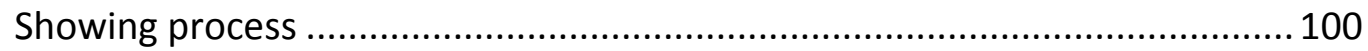

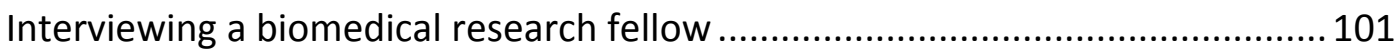

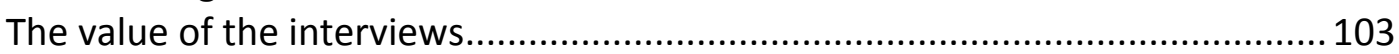

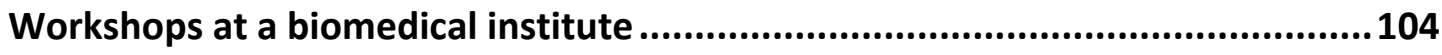

A workshop with biomedical researchers and a patient ................................. 104

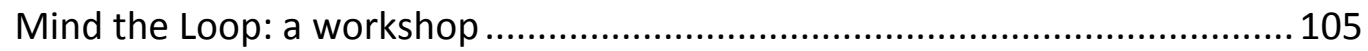

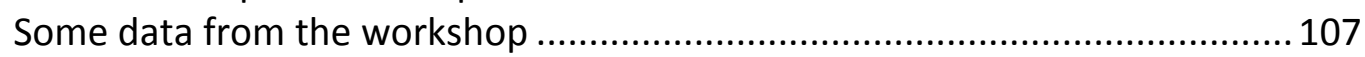

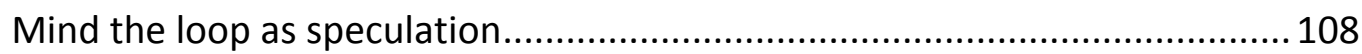




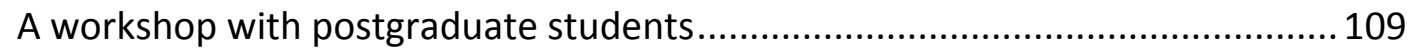

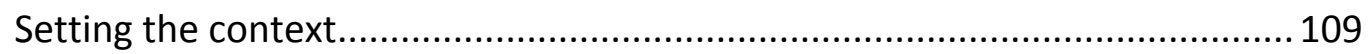

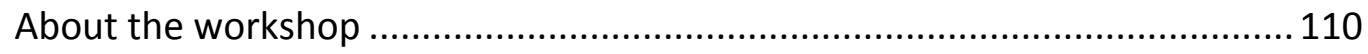

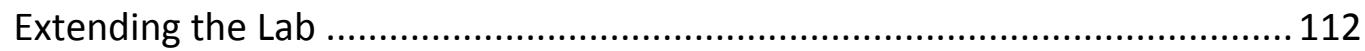

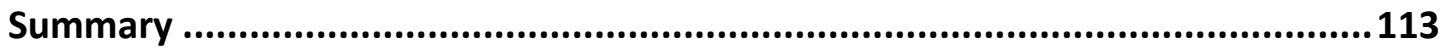

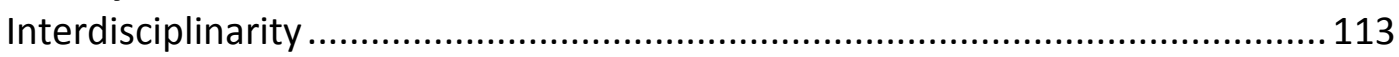

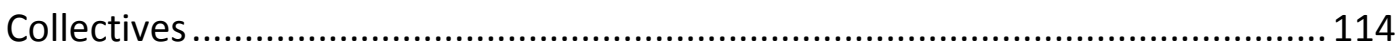

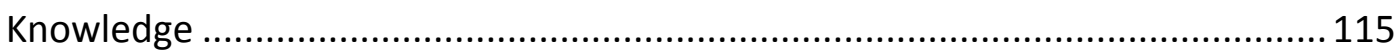

CHAPTER 5: DESIGNING SPECULATIVELY...................................... 117

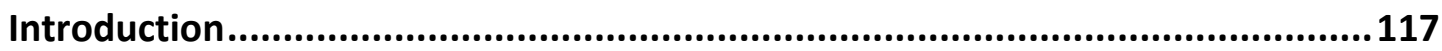

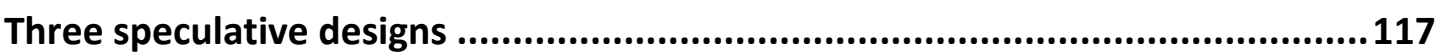

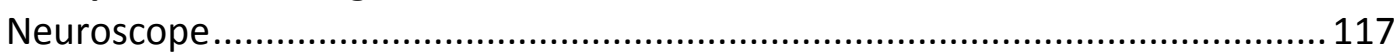

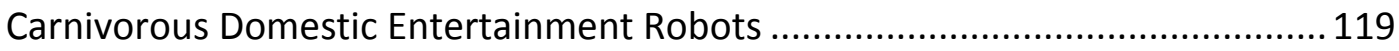

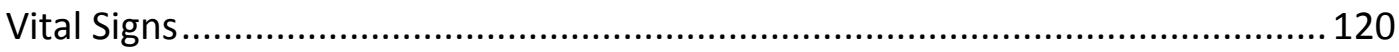

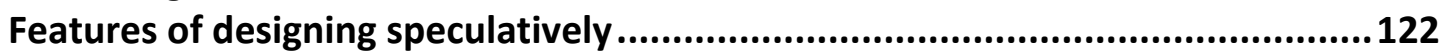

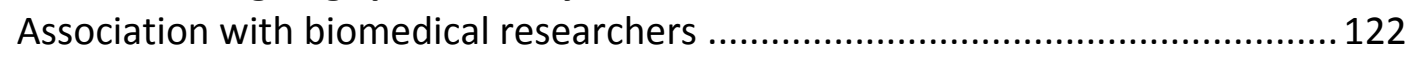

Brainstorming the Neuroscope.......................................................... 122

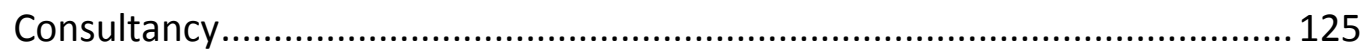

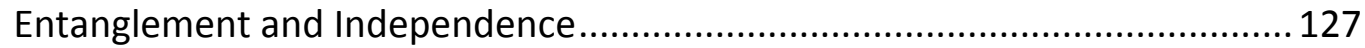

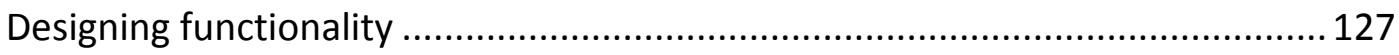

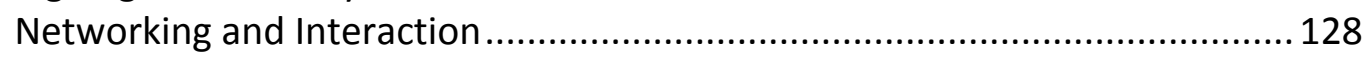

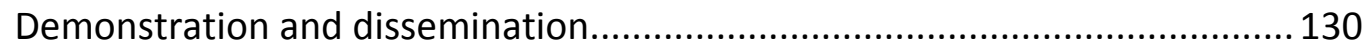

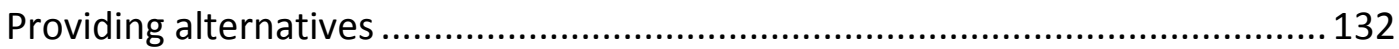

A range of application trajectories for research ........................................... 132

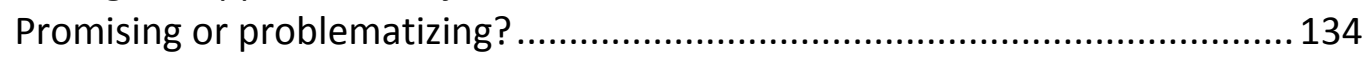

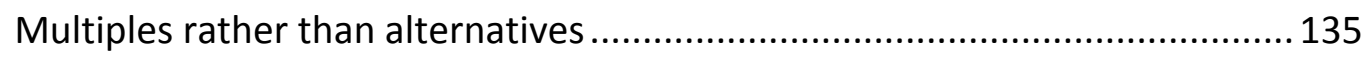

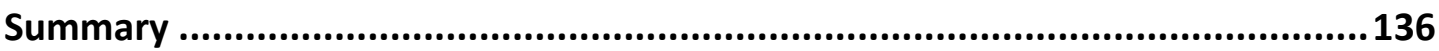

CHAPTER 6: CIRCULATING DESIGN............................................... 138

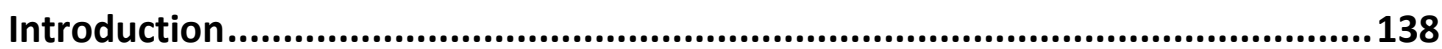

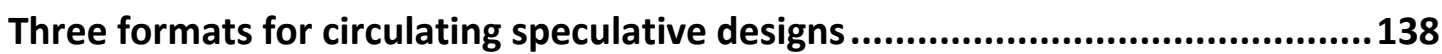

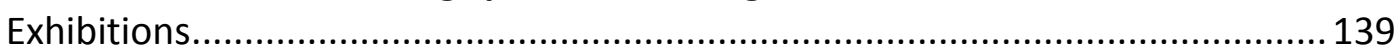

A contemporary design exhibition in Gijón ................................................. 139

Bio-design at an art exhibition in London ....................................................... 141

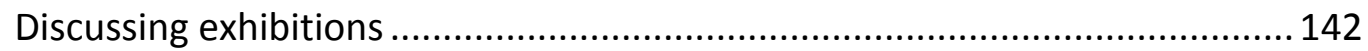

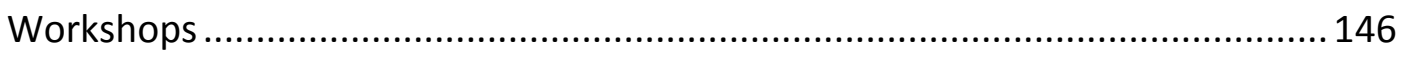

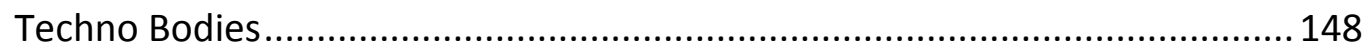

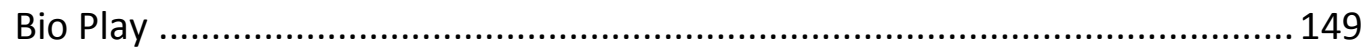

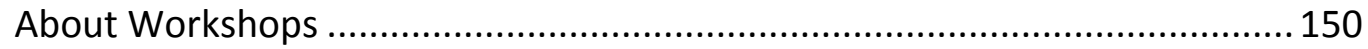

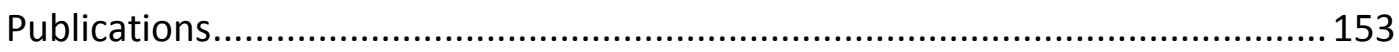

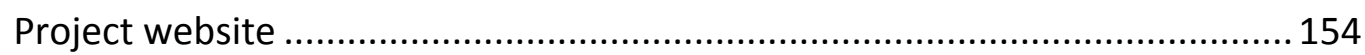

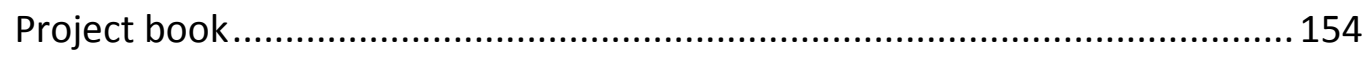

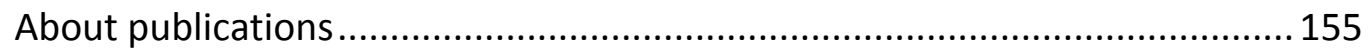

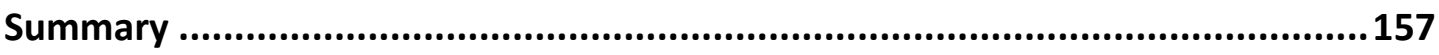

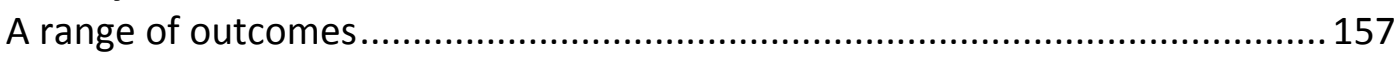

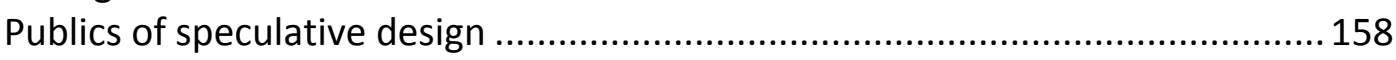

CHAPTER 7: CONCLUSIONS ........................................................... 159

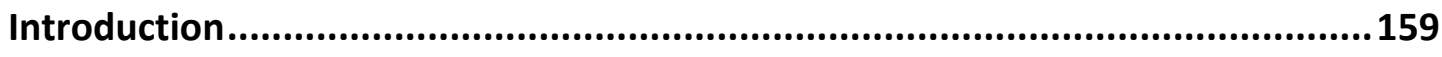

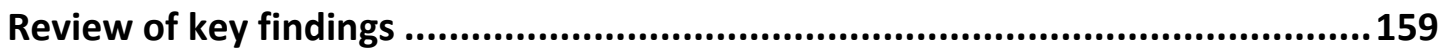




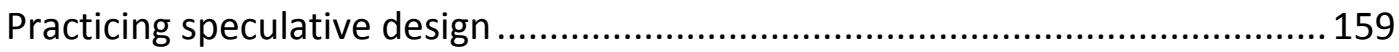

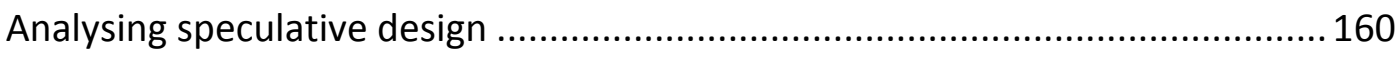

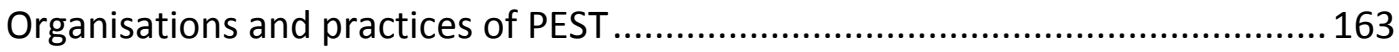

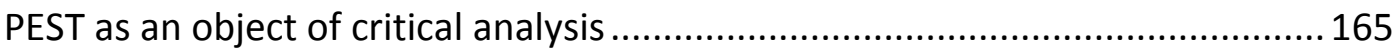

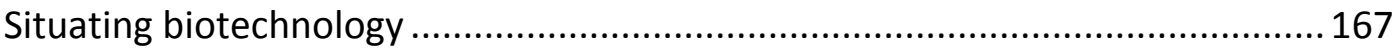

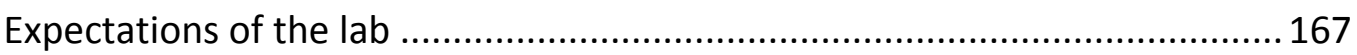

Designers interview biomedical researchers ............................................. 168

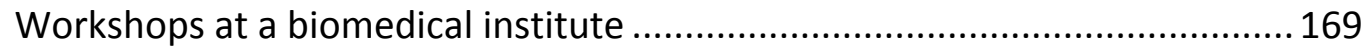

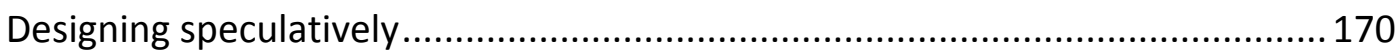

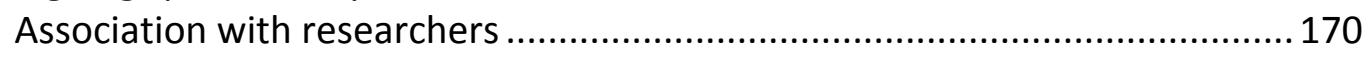

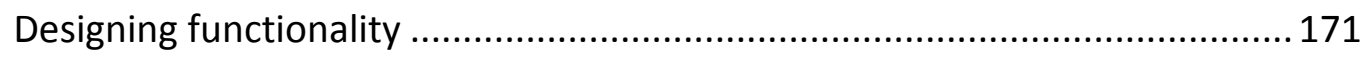

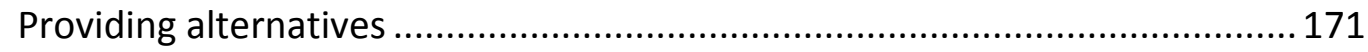

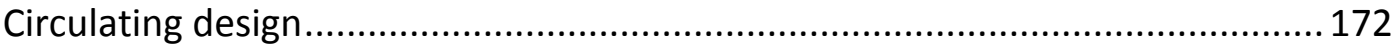

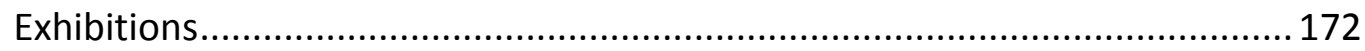

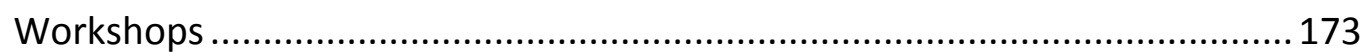

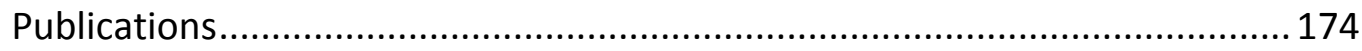

The contributions of empirical speculation......................................................175

Developing the rhetorical claims of speculative design's practitioners.............. 175

Speculative design's enchantment with upstream engagement........................ 176

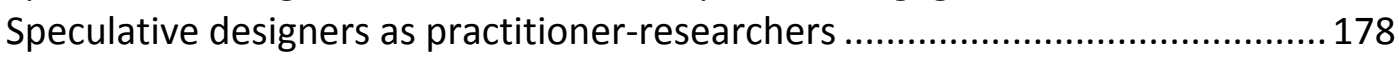

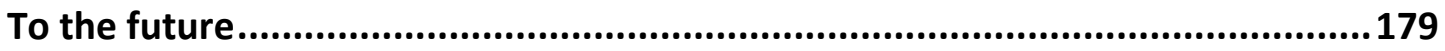

REFERENCES .................................................................... 181 


\section{LIST OF ILLUSTRATIONS}

Figure 1: Workplan depicting project and thesis activity over time 20

Figure 2: Discussing an artificial pancreas, postgraduate students touring a biomedical institute.

Figure 3: Digital rendering of a heartbeat, a live visualisation of neuronal cells 30

Figure 4: Modelling biomedical implants, visiting an exhibition 30

Figure 5: Postgraduate design students hear about biomedical research, a researcher developing an implantable blood pressure monitor

Figure 7: Vertical impact protection jacket and nuisance odour respirator (Auger, 2001), and Auger-Loizeau's Audio Tooth Implant (Auger \& Loizeau, 2001).

Figure 8: Schematic of Bioland and Biojewellery (Kerridge, Stott and Thompson, 2003), a hypothetical product from department 6 - "GM LOVE".

Figure 9: MyBio dolls, an outcome of Caccavale and Ashcroft's Hybrids project 44

Figure 10: Kramer and Papadopoulou's The Cloud Project (2009)

Figure 11: Prof Lord Robert Winston, Imperial College, Lesley Thompson, EPSRC, Prof David Delpy, EPSRC and Andrew Briggs, University of Oxford (left), and Prof Francis Livens, University of Manchester, with Nuclear Dialogues, a collaboration with Zoe Papadopoulou

Figure 12: Facteur Cheval's Garden, van der Dagts “bottoms up”, Parsons and Charlesworth's Adhocism installation.

Figure 13: Rail-Road vehicle proposal from the Lucas Plan

Figure 14: Robin Roy introduces Ways of Seeing the future, Nigel Cross deploys football as a metaphor in Design Strategies and Dave Eliott on The Future of Alternative Technology, three programmes broadcast on BBC2.

Figure 15: An "autonomous" house as an example of soft technology, illustration of a design workshop as a convivial setting. 67

Figure 16: The initial proposal for Material Beliefs at EPSRC Ideas Factory in May 2006

Figure 17: Frames from six of the filmed interviews with engineers and scientists

Figure 18: View of the biomedical institute, still from an interview with researcher 1.98

Figure 19: The central panel of this display for an engagement event at the National Theatre features an transcript excerpt from an interview with a researcher 99 
Figure 21: A rinsed pig heart valve, and a device for mechanically encouraging heart tissue growth from cells seeded onto the valve (Loizeau, 2007). 103

Figure 22: Digital Plaster discussion at the Dana Centre, p1 during and after the session

Figure 23: Participants of Mind the Loop meeting, the test bench for the artificial pancreas.

Figure 24: Summary slide from introductory presentation for students

Figure 25: Workshop for students at IBE, testing an implantable blood pressure monitor

Figure 26: Image of the Neuroscope with a user, and a diagram of the underlying system.

Figure 27: Images of three of the CDER prototypes, Lampshade Robot, Mouse Trap Coffee-Table Robot and Flypaper Robotic Clock

Figure 28: Vital Signs prototypes in blue, a photograph establish a scenario for the devices

Figure 29: A discussion about potential applications for a biotechnology and a diagram of those applications. 123

Figure 30: Potential applications, including 'sophisticated products' and 'extra sensory' are shown moving from the lab to the everyday, towards the far right is 'technological singularity' 124

Figure 31: $r 12$ and $d 2$ at robotics lab, the SlugBot and an image of a vivarium used by the designers to discuss the spectacle of life and death 126

Figure 32: Two drawings depicting the arrangement of cells on the array of electrodes and the branching structure of connections being made.

Figure 33: $\mathrm{d} 2$ and $\mathrm{d} 4$ interviewed by a filmmaker surrounded by CDER prototypes... 131 Figure 34: Frames from r11's visual algorithm to help develop movement of the arm of the fly stealing robot.

Figure 35: Photo depicting a user wearing a digital plaster and monitoring biometric data on a mobile phone, and a description of the application on a health technology website

Figure 36: Layout of d5's We Live What We Eat in the exhibition catalogue 140

Figure 37: Installing exhibition materials at LABoral 
Figure 38: Designers visiting the Library at the Royal Institution during the removal of material to make way for their work, and the opening event for Crossing Over 142 Figure 39: The right-side portion of $\mathrm{d} 5^{\prime}$ s timeline of project activity for Material Beliefs detailing later interviews, projects and events. 145 Figure 40: Techno Bodies, Hybrid Life - event introduction in the main space (left), and breakout discussion with $\mathrm{r} 7, \mathrm{~d} 3$ and $\mathrm{r} 9$ (right). 149

Figure 41: CDER being presented by $d 2, d 4$ and $r 11$ (left), r14 with photography of adult stem cells from the Bonsai Cells project (right).....

Figure 42: Images of project website showing logo and blog post, and screenshot of section featuring interviews with designers about their projects..

Figure 43: Cover (left) and a spread (right) of the Material Beliefs book. 155 


\section{CHAPTER 1: THE TOPIC AND APPROACH OF THIS THESIS}

\section{Introduction}

In this first chapter I introduce the thesis, then provide some background to the project that I take as a case study for its empirical sections. I offer some context to the call for funding proposals that supported the case, and reflect upon the milieu of that call. This allows me to expand on my motives for taking up PhD. studies, and raise some core methodological issues for the thesis. I then introduce the main chapters of the thesis, which includes two review chapters and three empirical chapters, in order to outline the substantive material dealt with in this thesis.

\section{Speculative design and upstream engagement}

This thesis offers a critical reflection of design practice where a speculative approach to design became entangled with upstream engagement with biotechnology research. These approaches will be discussed shortly, though for now it can be said that both speculative design and upstream engagement claim to enable a public discussion around the potential behaviours and implications of the future outcomes of science and engineering research. However, speculation and engagement have very different backgrounds and take different approaches. As a design practitioner who wants to understand these activities as a form of design research, I ask what is the nature of their mixing, what is the value of the activities carried out there, and how should an analytical account be made?

Speculative design and Public engagement are reviewed in chapters two and three respectively, and in each case I deal with practitioner accounts and histories followed by analytical literature where those practices are treated as objects of research. Then in chapters four, five and six I take the Material Beliefs project as a case of speculative design and public engagement, and develop an empirical account of practice and an analysis of its features. Initially I discuss labs as sites where designers, scientists, and non-experts come together to discuss and to problematize accounts of biotechnology research. Next, I examine the process of making speculative designs, and here I emphasise the ways in which issues, materials and practices become compiled as exhibitable prototypes. Finally I consider the circulation and reception of these designs in public settings, including exhibitions, workshops, and publications.

In this thesis I argue that speculative design has adopted the discourse and strategies of upstream engagement in order to extend and professionalise what started as a disciplinary critique of product and interaction design. Additionally I suggest that this entanglement provides opportunities for an analytical account of practice that moves beyond design's adoption of other professional approaches, by 
enabling a discussion about the broader set of accountabilities that attend design action. The case study provides episodes for the three empirical chapters, which are discussed in order to demonstrate how a range of activities that are notionally identified with upstream engagement see a speculative design approach become distributed and negotiated across an extended set of commitments amongst researchers, policymakers, educators, curators and promoters. Ultimately, I hope that this reflexive and empirical treatment of the mixing of speculation and engagement, offers a model of practice-based design research that can be developed and applied by speculative designers working in public engagement and other disciplines.

\section{Introducing the project that is treated as a case study}

I feel it would benefit the reader if I provide an initial impression of the project that provides a case study for the empirical sections of this thesis. Additionally, an account of the conditions under which the project received funding will provide some background to the milieu that motivated me to undertake PhD studies. Following this description of the project and its background, I develop the motivations for the thesis.

\section{A Public Engagement with Engineering Workshop}

In 2006 the Engineering and Physical Science Research Council (EPSRC) issued a call for proposals (CFP) entitled Engineering Ideas in Public Engagement (Nelson \& Jones, 2006). As part of the CFP activity, engineers and engagement practitioners were invited to a workshop to develop research proposals responding to the question of "whether engineering research needed a fresh approach to public engagement" (Smart, 2007, p. 36). I was nominated for invitation by a colleague who had been appointed by the EPSRC as mentor for a previous project called Biojewellery, a speculative design project with a focus on the bioengineering of human bone tissue (Thompson \& Kerridge, 2004). The workshop was part of the IDEAS Factory, an EPSRC programming stream that enabled the research council to respond rapidly and in a risky manner to topics that would support and in some cases seed broader programmes of funding:

The IDEAS Factory has continued to explore research topics that need a new dimension in thinking. Interactive workshops called 'sandpits' are held over five days with 20-30 participants to stimulate highly innovative and risk-accepting research activities. A multidisciplinary mix of participants ranging from active researchers to potential end users is essential. The aim is to spark off lateral thinking and radical approaches to research topics. (Smart, 2007, p. 36)

The aim of the Engineering Ideas sandpit was to fund projects that enabled innovative formats of public engagement around the topics of engineering research, or projects that developed new tools or methods for public engagement 
that could be applied across arrange of research activities. For example, the introduction of the CFP asked how proposals might build a "universal commitment to public engagement by the engineering community" (Nelson \& Jones, 2006). The requirements and motivations of the CFP can be seen as complimentary to the views and lobbying activity of related institutions as that time. A report jointly commissioned by The Royal Academy of Engineering and the Engineering and Technology board describes the public perception of engineering as being traditional and mechanical, focussed on building bridges and fixing engines (Marshall, 2007, p. 12). In this respect the call articulated twin concerns with encouraging engineers to engage the public about their research, while invigorating public perceptions of what it is that engineers do.

\section{The project proposal}

As I saw it then, my invitation to the sandpit was an opportunity to apply the successful features of what had been accomplished with Biojewellery to the themes of the current CFP. The proposal for Material Beliefs identified with the CFP's aim to support risky projects, while also articulating a desire to contribute to the renewal of a shared culture of science and engineering between researchers and the public. The proposal stated:

There is a need to communicate and democratise recent innovation in UK engineering, and with this an opportunity to challenge and invigorate the public's perception of engineering. Unconventional collaboration methods used in PPE projects like Biojewellery and Robert Doubleday's sociological perspective on nanotechnology research are extended in this proposal, and employed to frame a creative and innovative process for representing the technical and sociocultural issues which attend engineering research, to a large and diverse audience. (Kerridge, Custead, et al., 2006)

The proposal is made risky by bringing together a speculative approach to design, as exemplified by the Biojewellery project, with an upstream approach to public engagement, demonstrated by the Social Dimensions of Nanotechnology project 1 . In this case, Biojewellery provided a design approach where prototypes were made and publicly exhibited in order to drive a discussion about biomedical engineering (Kerridge, Stott, et al., 2006), whereas the Nanotechnology project foregrounds the laboratory as a site where social scientists act as critical interpreters of emerging scientific research in order to contribute to the "wider academic and public reflection on the social aspects of nanotechnology" (Welland \& Doubleday, 2005). By embedding speculative design in laboratory environments where biomedical and bioengineering research was being done, Material Beliefs

\footnotetext{
${ }^{1}$ Social Dimensions of Nanotechnology was a project within the EPSRC funded Interdisciplinary Research Collaboration in Nanotechnology, which "appointed a social scientist to be based in a nanoscience laboratory to work together with scientists on the social implications of nanotechnology" (Welland \& Doubleday, 2005).
} 
sought to "open up a reflective and critical space around the role of future technology" (Kerridge, Custead, et al., 2006, p. 4). Additionally, the Material Beliefs proposal contextualises EPSRC interests that relate to its broader Science in Society programme. For example, in a delivery plan contemporary to the CFP, the Council stated it will "Foster public engagement, dialogue and debate around emergent research", and raise awareness of the "societal and ethical implications of research" (EPSRC, 2009, p. 24). In respect of these broader themes, the proposal aimed to take science and engineering from the lab to a "large and diverse audience", as well as aiming to "communicate and democratise recent innovation in UK engineering" (Kerridge, Custead, et al., 2006, p. p. 4).

To summarise, the proposal had two core features. Firstly, it was aligned with the commitments of the funder, both at the scale of the CFP with its focus on reinvigorating public perceptions of UK engineering, and broader interests in Science and Society and public engagement with research. Secondly, the proposal applied features from existing research, including the speculative approach of Biojewellery and the upstream experimentalism of the Social Dimensions of Nanotechnology, in order to provide what are seen to be innovative models of practice. In this way the proposal uncritically reprised a set of discourses and made a rhetorical claim for speculative design's ability to foster upstream public engagement.

\section{Too busy speculating?}

I now move to a second workshop that takes place three years after the EPSRC sandpit depicted above, in order to establish some background to my decision to take up PhD studies. Engaging With Synthetic Biology is a meeting convened at The Royal Academy of Engineering on the 18th June 2009 (Curnow, 2009). The event marks the launch of a pair of publications, a report on Synthetic Biology as an incipient area of interest for this engineering institution, and a report on a study into public attitudes to Synthetic Biology (RAEng, 2009b, 2009a). These publications designate Synthetic Biology as an emerging field of research that is "a prime candidate for significant investment" (RAEng, 2009b, p. 5), and todays presentations and discussions address the relationship between this emergent research area and the public understanding of its features. A panel of invited speakers respond to matters of public interest identified by the report including:

- Do the public know what Synthetic Biology is?

- Is there a sense that this emerging field presents a new range of opportunities for services and healthcare?

- What attitudes are forming regarding the modification of organisms and the creation of forms of life?

- Are there concerns about biosecurity or of rogue microbes being introduced to the body? 
In the room is a network of professional actors from a range of backgrounds who will support a "future engagement strategy" for synthetic biology (Curnow, 2009), taking into account these and other questions. Amongst the policymakers, engineers, social scientists, science communicators and educators are a group of speculative designers, and I include myself in this group. I am in the room because I consider that the questions above, formed during the engagement exercise by a focus group made up of members of the public, would offer potentially rich start points for a speculative design project. For example, rogue microbes and biosecurity are strong examples of the sorts of issues related to expectations about emerging technology that would provide a basis for hypothetical products and services. I see how these provocative designs would provide content that dovetailed into a programme of public events, including exhibitions and workshops, to provoke a public discussion and debate about this emerging field of Synthetic Biology. Such a programme would enable the communicators to evaluate the impact of the scientific researchers work, while social scientists provided analysis for the instruction of more robust policy to ensure national prosperity. The specifics of Synthetic Biology might be unclear to me, but I recognise the nature of the network being formed in this room, and I see potential for my practice to be a part of such a programme. I have worked with scientific researchers in the room, who have previously identified with the label of Biotechnology and then Nanotechnology, and so while Synthetic Biology entails forms of scientific innovation that are currently obscure, there is a strong sense of familiar ground here.

In short, I recognise that what is happening in this room could well support my next speculative design and upstream engagement project proposal, following on from and developing the approach of Material Beliefs, and Biojewellery before that. Except, on this occasion I'm outside of a cycle of proposal writing, because I'm two years into my PhD studies. Therefore, rather than leaving this workshop with ideas about potential proposals that would be co-authored with scientists and engineers, I'll instead continue to write an analytical account of Material Beliefs. And so this event at the Royal Academy of Engineering provides a moment of reflection about my motive for committing to a thesis. First and foremost I have a notion that attending to this particular form of design practice, and providing an analytical account for others, is more valuable than initiating another cycle of that practice. It is my sense that without critical reflection, this cycle of practice repeats a similar strategy time and time again, so that while the scientific research might change, and the approaches taken by practice will inevitably develop, the claim that I make for speculative design bringing about a debate about future technology, remains undeveloped. What are these debates? Who is debating? Where do these debates happen? And so my underlying commitment to this thesis is to move outside of a cycle of practice, in order to deepen and challenge the rhetorical and descriptive 
features of writing associated with proposals and publicity, and thereby offer an analytical account of speculative design and upstream engagement.

\section{The contribution of the thesis}

This is an appropriate moment to provide some sense of how and where the writing that comes out of these personal motivations would make a contribution to research. I have mentioned that modes of writing associated with the practice of speculative design include funding proposals for public engagement projects and descriptions of design outcomes for exhibitions and other forms of publicity. While one feature of an analytical account of practice is to challenge rhetorical descriptions of debate, a related feature is to discuss an association with public engagement as a form of design research that could be useful for other speculative designers.

My sense is that the mixing of speculative design and upstream engagement with science and technology emerges through mutual alignment with an idea of enabling the public to discuss and perhaps challenge the format of emerging technology. However the basis for mutuality is thin. The respective trajectories of designer and engager vary greatly, and broadly put, speculative design is developing a professional territory in which to apply a practice that allows it to move beyond disciplinary critique, while upstream engagement is establishing an additional mode though which it can deliver commitments to public funders, policymakers and scientific institutions. In this sense, speculative design is providing a service for organisations that have resources for a particular activity. It seems that speculative design and upstream engagement is just one example of a speculative approach being applied through professional association with a client organisation, and there have been other instances of couplings since designers who speculate have shifted their energy beyond the disciplinary settings of postgraduate pedagogy. Speculative Designers have found various clients who share an interest in what might be abbreviated as 'scenarios of use around emerging technology', including innovation units, patient interest groups, and technology companies. I would suggest that these diverse types of association, where speculative activity is underwritten by a professional context, would each provide their own specific insights for design research, but that some features would apply across the individual cases. So in elaborating my case of association, one between speculative design and upstream engagement, I hope that there is some general value in a deeper discussion of its features - for example a reflexive treatment of collaboration - that would be transportable into settings where speculative designers are forging links with other organisational entities, and that therefore I am providing some initial approaches that would help others reflect upon and write about their own case of practice.

Another feature of my commitment to an analysis of the mixing of speculation and engagement relates to what I see as a misconception from designers that writing 
about practices that impinge upon another's territory somehow diminishes what is distinctive or valuable about a speculative approach. My sense of this perceived impoverishment is twofold, firstly there seems to be a sense that interpreting dealings with partners necessarily involves the designer 'crossing over' and becoming lost either in the language and aims of the partner, or in the discourse of the analytical frame. Secondly, that the designer is no longer a proper designer because they are not exclusively making things for exhibition. So to be clear, firstly the aim of the thesis is not to establish a speculative approach as a subset of public engagement, for example where speculation would be part of a 'toolkit' for public engagement with key indicators of practice and evaluable features. Nor is the aim to become a social scientist, which, anecdotally, is something that seems to be a particular concern of designers I have spoken to. Rather, I suggest that empirical attention to what happens during a project provides the basis for an elaboration of a speculative approach in a manner that makes practice accountable to partners and designers alike. Secondly, I hope that these accounts provide the basis for progression and development of speculation as a form of practice based research, where making becomes robustly linked to thinking and writing. I see writing as an unassailable feature of a practice that sees debate as its core mode of the designs 'use', and believe that to not make cohesive links to research is to miss an opportunity for developing design capacity.

Finally then, the coming together of speculation and engagement provides an opportunity to discuss features of their cooperation and ambivalence, and to additionally ask some questions about their respective regimes and politics. As speculative design consolidates its move into landscapes of public engagement, it is clear that it becomes entangled in a much broader set of interests. Authorship of the processes that lead to design outcomes, descriptions of those design outcomes, and the effects of those outcomes become subject to a complex and sometime conflicting set of commitments. There is opportunity here, which I have taken in writing this thesis, to experiment with a sceptical discussion of debate and engagement, and to demonstrate a reflexive account of speculative practice.

In the following, empirically grounded account of speculative design I argue that the forms of activity enabled by this design approach are broad and have diverse affects. It is not adequate for a designer to make a claim for the meaning of a design and the nature of the debate that it would illicit. I argue that a speculative design has multiple outcomes; it is a material object in an exhibition, an image on a website, a caption in a catalogue, a proposal during a conversation, a negotiation with a partner. Therefore, I argue that to treat speculation empirically is to challenge the designer's story about what their design is and does. 


\section{A thesis based in practice}

It seems useful at this point to introduce the format of this thesis. Guidelines for postgraduate Design study includes provision for a PhD degree with a practice component, where there is scope for the thesis submission to "include a portfolio, exhibition or other audio-visual display" (DoD, 2010, p. 11). Where there is a practice element, this material "must be original work which exemplifies and locates the ideas which are developed in conjunction with the written part of the thesis" (UOL, 2009, p. 5). Alternatively, examination is by a written thesis viva voce (DoD, 2010). While I initially planned and partly delivered a practice-based $\mathrm{PhD}$, this thesis takes a traditional format, in that it is a written thesis with two literature review chapters and three empirical chapters that reflect upon and then provide an analysis of episodes of design practice. This move to a written thesis does not indicate a rejection of the value of practice. Rather, due to the timeframe of thesis write up and submission, there was a substantial gap between the delivery and documentation of the project work and the completion of thesis writing. In this respect, I felt that rather than contrive to link the practical and analytical elements with the republication and re-exhibition of project work delivered in 2009, it seemed more cohesive and practical to treat the practice as an empirical case for a wholly written thesis.

The case study for this thesis is Material Beliefs, a public engagement with science and technology project funded by the Engineering and Physical Sciences Research Council (Kerridge, Custead, et al., 2006), in which I acted as project lead with a wide set of collaborators who are credited in the end of project publication (Beaver et al., 2009). The project publication should be treated as a companion to this thesis, which in particular extends and supports the visual material included here. Material Beliefs was conceived, proposed and delivered independently of my $\mathrm{PhD}$ studies, nonetheless the project provided an opportunity for a reflexive analysis of speculative design, as described in the introduction above. After discussions with a project manager at the EPSRC and potential supervisors, a proposal for postgraduate study was submitted to the Department of Design at Goldsmiths. In this way Material Beliefs was in progress during the initial period of studies, and project outcomes continued to be delivered beyond the funding period of the grant, due to the relevance to my studies. The workplan below provides an overview of project and thesis activity, and demonstrates periods of overlap. 


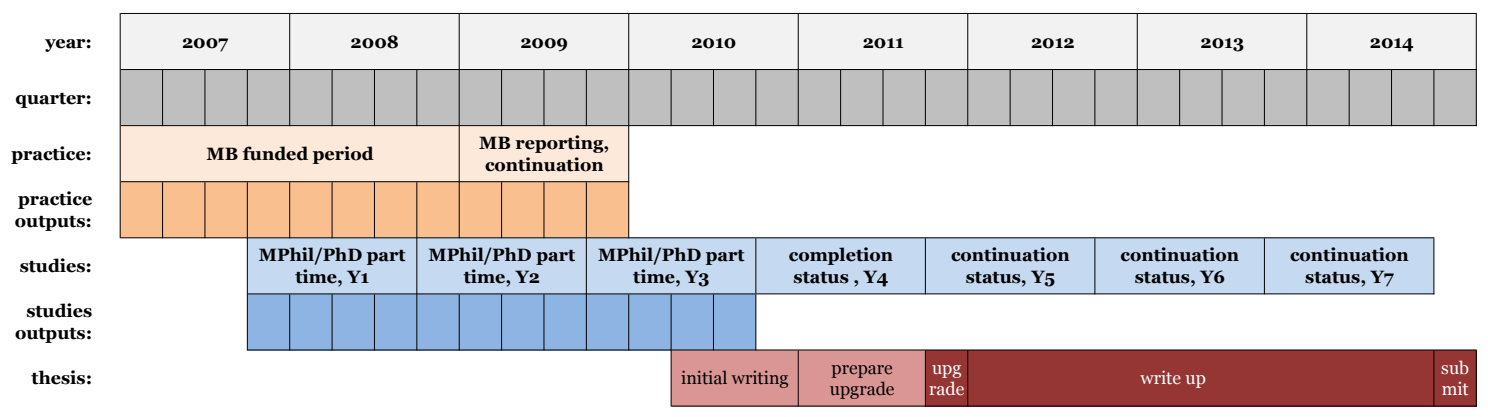

Figure 1: Workplan depicting project and thesis activity over time

\section{Methods and data}

An aim of this thesis is to provide an analytical account of Material Beliefs, where I consider the contributions of project participants, including the roles I took. The thesis discusses a number of episodes from the period of delivering Material Beliefs, where project processes, public events and material outcomes are treated as objects of analysis. To support this enquiry, a range of material generated during the project, including design documentation, photography and notes from fieldwork, emails and interview transcripts, are regarded as data. Thus project episodes and supporting material provide the basis for a reflexive and critical account of a speculative design approach that has become entangled with public engagement with science and technology.

I would like to emphasise the manner in which the material described above is being acted upon in different ways at different times, firstly as a resource for doing design work, and later as data for the analysis of activity. Of course these temporalities are not rigid. During the delivery of the project there were moments of data management that anticipated the later analysis and therefore not of immediate value to design activity, for example the archiving of material. Additionally, there is something to be said about the value of analytical housekeeping for the process of design, in particular I am mindful of the transcription of the interviews with scientists and engineers at the beginning of the project, which certainly acted as triggers for the conceptualisation of proposals, themes and issues that compelled design action. This mixing of the status of materials as support for both doing making and doing analysis, speaks to the methodological challenge of writing about practice, which I turn to in more detail in the following framings.

\section{Practice-based design research}

There is no prescriptive structure for a $\mathrm{PhD}$ that deals with design practice. Perhaps one reason is the breadth of activities, methods and theoretical contexts 
attending the fields of practice that identify design research as a parent discipline 2 . While various models for the scholarship of design practice emerge from the conferences, journals and discussion lists that comprise design research, it is not clear how speculative design relates to this field. As I will discuss in chapter two, writing about speculative design is largely tied to curatorial description and project publicity. More recently, aspects of speculative design have been applied to programmes of research that identify with participatory design and interaction design. Here, these applied forms of speculation are discussed as methods of practice based design research, and I expand on these strategies in the second part of chapter two. However, given that Material Beliefs was a discreet project that was speculative in nature, rather than a work package or a method applied within a programme of design research, I see this thesis as an opportunity to treat the analysis of a case of speculative design experimentally.

So what might an analytical account of speculative design and upstream engagement look like? Here is a brief and imaginary transposition of a project onto a thesis framework, where a speculative design is made for exhibition at a science museum. There is a literature about science and design collaborations for exhibition, and a larger literature within museum studies regarding interaction and display design. Commonly here, design is an instrument for the effective delivery of information to a public audience. Following such an approach, I could start with a description of a brief to design an interactive object for an exhibition about emerging biotechnology in a science museum, emphasising the partial role of design within an interdisciplinary team. There would be an empirical chapter about the design process, from receiving the brief through to evaluating the experience of users after the exhibition has opened, another chapter about the novel features of the interdisciplinary development of artefacts where interaction design and public engagement are brought together. A final chapter might be about the original aspects of design practice as they contribute to more effective engagement of science and technology topics. This would lead into a framework for design and engagement, with some novel methods. In conclusion I would comment upon the relation between reflective practice and design methods in the case of design for engagement, and argue that a rigorous and inclusive design approach brings about rich forms of engagement.

However, speculative design does not align well with the approach described above. It entails a broader set of concerns and does not articulate a discreet problem in relation to a particular context. Specifically, I will later provide a sceptical analysis of public engagement with science and technology, where the implicit assumptions regarding what constitutes engagement or who the public

2 Though currently unpublished, a list of subfields of practices and professions identifying with design-research as a parent field is being put together by members of the Design Research Society, and can be seen in an early form the appendixes of Terrance Love's doctoral thesis (Love, 1997) 
are, become challenged. Therefore, I will question both the role of design in solving specific problems and the role and commitment of engagement practices, and in this respect, while I am working as a designer and committed to contributing to a design research community, there is something of a constraint set up through design methods. Then how to accommodate a reflexive description of design practice, while also affording a critical analysis of the broader scene that gives shape to, and is to an extent shaped by that practice?

\section{Design reflexivity}

Here is a short account of design reflexivity as discussed in design research literature. There is a methodological account of practice that reconciles the creativity of the designer with a positivist framework of problem solving (Cross, 2001; Bayazit, 2004; Krippendorff, 2006). While Cross traces initial ambitions to scientise design to the modernism of van Doesberg and Le Corbusier (Cross, 2001, p. 49), it is through the design methods of Archer (1963), Alexander (1964) and Jones (1970) that a positivist project for design is presented. This science of design is then seen to be broken-up, not least by Alexander himself who suggested we "forget it, forget the whole thing" (Alexander \& Jacobson, 1971). A key argument against design positivism is the 'wicked' problem of formulating design briefs and materialising solutions in the face of social heterogeneity (Rittel \& Webber, 1973, p. 167). This clears the ground for a phenomenological focus on practitioner skills, developed through Polanyi's account of personal knowledge (1969) and integrated in Schön's figure of the reflective practitioner (Schön, 1983). Through Schön the scientist designer is developed into a reflective designer, whom "becomes a researcher in the practice context", and thereby an account of design that is situated and emergent is made methodologically valid for design research.

I see Schön's reflective practice, and Rittel and Webber's notion of wicked problems as providing an opportunity for linking issues dealt with in my thesis back to these broader methodological issues of design research. In particular, a discussion of the features of speculative design might well offer an additional counterpoint to the rationalities of the science of design. However, Schön's notion of reflexivity also provides a point of departure for speculative design to travel to other methodological settings, and so I use this history as a leg of a journey rather than the destination.

Schön depicts design as a conversation with a situation. The extent of the setting that comprises a given situation is flexible, therefore the objects with which design reflexivity engages are determined only by the ways in which the frame of the problem is shaped up, and consequently "there has been a tendency to think of policies, institutions, and behaviour itself as objects of design." (Schön, 1983, p. 77). Though this point is offered as a critique of the potential for the formulation of design problems to get stuck in the recursive specification of its objects, this notion of design reflexivity shows that an analysis of speculative engagement need not be 
limited to the designed artefact. Or rather, what constitutes the design need not be limited to the thing that goes into an exhibition. For design could include formats of engagement, the interactions with the institutions that support that engagement, and an account of the people who are engaged. However, it would still be possible to write a thesis that considered design in relation to such a variety of objects, and not consider political assumptions about the value of engagement, for example.

\section{Extending reflexivity}

An analysis of the broader context within which engineering and design takes place has become an interest for STS scholarship, and approaches informed by Actor Network Theory (ANT) in particular. For example, following Latour's empirical study of scientists in the lab (1987) and Law's account of heterogeneous engineering (Law, 1987), the work of designers has been treated as the stabilisation of a network of "identities, materials, machines, plans customers and ideas" where the biography of the designer is acknowledged alongside the performance of a material in the delivery of a design (Nickelsen \& Binder, 2008). Elsewhere Yeneva looks to "account and understand" the objects of architecture, and in doing so she extends Schön's analysis so that alongside the tools and devices of the architectural designer, buildings themselves have agency, for example they cause plans to change (Yaneva, 2008). Meanwhile Wilkie considers how users of technology products are assembled during the process of design, and thereby builds an argument against notions of users as somehow stable and preformed (Wilkie, 2010). This provides an approach for considering the ways that the engaged public is discussed in relation to a speculative approach to design. Encounters with design can now be seen as generating new forms of agency, and indeed design effects can now be seen as being formatted on the fly, extending the assumed output of design as being the exhibition as a finished entity that would arouse specific issues in the minds of its audience.

As I consider episodes from the project case, I hope to draw on different literatures to conceptualise project activity. I will provide a reflexive account of my role as a designer doing a project, while attending to the ways in which the project comes together and has effects. The literature reviews, one with a design focus and the other concentrating on public engagement, bring together resources to support this approach by dealing with accounts of practice and research into practice, and in this respect provide a framework with which to then develop the empirical sections of the thesis that is sympathetic to this reflexive format that mingles practice and analysis.

\section{Critical empiricism}

I want to further develop what feels like a core methodological concern for this thesis, where a writer treats analytically a case of practice that they are instrumentally implicated in. In his introduction to Virtual Society, STS scholar 
Steve Woolgar opens with a description of the rapid technological changes in ICT that are the subject of a programme of research he is leading (Woolgar, 2002). In the introduction to the text, he foreshadows the profound changes these new technological capabilities will have on institutions including industry, education and government; these social dynamics are to be the focus of the research. Then in a later section, Woolgar's tone shifts and he treats his opening statements reflexively, rounding on his own assumptions:

At one level the main thrust of the rationale seems reasonable enough: it provides the grounds for asking what in fact are the impacts of the internet, $\mathrm{CMC}$, mobile telecommunications and so on. And yet it can be argued that our research on these topics has now reached the stage where we should no longer take this kind of rationale at face value... We now need to understand the manner and extent to which our efforts at researching the social dimensions of electronic technologies are already constrained by the ways we pose the research questions in the first place. (Woolgar, 2002, p. 6)

I would like to draw out two implications for my account of design and engagement. Firstly Woolgar's reflexivity asserts an analytical view of the research as a commentary upon the hubric aspects of the research proposal, a device that I tried to apply to the moment at the Synthetic Biology meeting at the opening of this chapter. For in common with the ICTs of Virtual Society, and the biotechnologies of Material Beliefs, I suggested that Synthetic Biology makes audacious promises regarding change and improvement; novel treatments for terminal illness, systemic improvements to methods of healthcare, intellectual property for universities, economic benefit for UK industry and not least the participation of the public in the intellectual life of these advancements. How to treat such bold statements critically, and how to then make a case for the relevance and value of practices that are not able to leverage such bold claims, particularly when that speculative practitioner is working in such an odd way and for such a powerful client? Secondly Woolgar's reflexivity tenders a strategy in which the assumptions that underlie the research questions are included in the frame of analysis. This would provide a scheme that valued the work of the designers and their partners while treating the work critically, in order to "find a way of both retaining the central terms and assumptions of the problem as commonly formulated, and at the same time interrogating them as we proceed with our research" (Woolgar, 2002, p. 9).

Treating common assumptions interrogatively perhaps presents a particular challenge for speculative design, for beyond the rhetorical nature of proposal writing, the form of the design outcome itself might indeed depend upon arguments that are part of this biotechnological hubris. For example a speculative design proposal might combine the assumptions of an unfinished technology with 
a familiar practice. Take Biojewellery as an example where a speculative design blends a technology with a practice (Kerridge, Stott, et al., 2006), so the technological features of bone tissue engineering is reconsidered through a couple's exchange of commitment rings. Here the interrogation of the institutional claims and technical features of the biotechnology is suspended in order for design activity to be executed. In this respect, analysis can in fact be seen as curtailing the conceptual ordering of assumptions and insights that are entailed in the design scenario, as well as the extensive negotiations and planning required in order for the design to actually come together. Therefore the format of a thesis where practice is treated as an empirical case, rather than a PhD by practice where making and writing become collapsed, might in some cases be a more productive approach. This requires the empirical sections of the thesis to take on a temporal rhythm, back to making and forth to analysing, so that designs can get made, and then the settings in which that making took place can then be discussed.

\section{Practice and analysis}

Separation between the execution of design work and the analysis of the accomplishment of that work is a feature of design research. Cristiano Storni designates 'design time' as distinct from the use of that design in order to emphasise a concern with the "chronological separation between design and use" as it relates to the configuration of designers and the user's knowledge through designing (Storni, 2013). However, I will demonstrate that in the case of a speculative approach, a distinction between design and use is less clear, in that the roles of designer and user, and the chronology of designing and using, are somewhat collapsed by virtue of design and use being muddled by the circular nature of engagement. Nonetheless, the notion of a 'design time' as distinct from the analytical period of writing about design remains constructive, for while making prototypes does entail moments of reflection and analysis, there is a substantial and lengthy set of processes including sketching, soldering, digital layout, filming, coding and writing that bring the prototype together, that would be curtailed or halted were they not performed at a distance to comprehensive analysis.

Reflection upon the contrary accounts that are enabled through positions of practice and analysis is of course not limited to design research. There is a social science literature where STS researchers have crossed over to a field of practice as public engagers. In his account of the Cardiff sciSREEN events, Jamie Lewis describes the effort that goes into producing and delivering a public format that leaves little time and energy to do analysis. This is partly a capacity issue, where the commitments of his participation, and dealing with different actors, makes it difficult to find the time and space to speak analytically (Lewis, 2013). Elsewhere, Maja Horst and Mike Michael have discussed a case where a researcher takes a practitioner role in public engagement practices (Horst \& Michael, 2011). In this 
case, unexpected interactions with the installation from public visitors on one hand provide extremely rich data from an analytical perspective, while in terms of practitioner commitments there is perhaps a sense that their personal investment has become upset, or that descriptions conveyed to the funder might not be met. Horst has commented on her experience making a public engagement installation:

I am much more considerate of practitioners now that I have been one. What I learnt is that I am a researcher, and I don't want to take responsibility for the kinds of effects that practitioners have in the production of persuasive fictions. (Horst, 2013)

Horst applies her experiences of the 'persuasive fictions' of public engagement practice as resources for analytical writing. In crossing over to engagement practice she has challenged and extended her analytical writing. Conversely, as a speculative practitioner I have been somewhat ambivalent to the value of a written analysis. By taking responsibility for rhetorical claims for debate, and in adopting an analytical and sceptical posture regarding practice, I hope to parse critique though an account of practice, and make my writing about speculative design more accountable.

And so as a researcher within a design studio, and having decided to undertake an analysis of practice, I see the design research community as my primary readers. I hope that this analytical treatment of design practice might be relevant to other readers, particularly those who take public engagement of science and technology as a topic, and those who take science and technology as an opportunity for generative intervention. Finally I wish to find readership in those designers who are working speculatively with science and technology, though not necessarily with science engagement partners, and I hope that they find value in this analysis of practice.

\section{Thesis structure}

I move now to an overview of the chapters of this thesis. Following this introductory chapter, there are two literature review chapters, followed by three empirical chapters, and finally a concluding chapter. Below I provide an outline of the review and empirical sections in order to introduce the shape of the content and its core arguments to the reader.

\section{Reviewing Speculative Design and Public Engagement}

The first literature review has a focus on speculative design; the second provides a review of public engagement literature. Both chapters share an arrangement of two sections, where the first section provides a discussion of practitioner literature and histories of practice, and the second deals with writing where the practice is the object of research. 


\section{Critical and Speculative Forms of Design}

Designers have exhibited hypothetical objects and scenarios, providing occasions for discussion and debate about technology and society. Such a strategy has been described by Tony Dunne and Fiona Raby:

Rather than writing papers and seeking conventional academic approval, they could exploit their privileged position to explore a subversive role for design as social critique... Design proposals could be used as a medium to stimulate discussion amongst the public, designers and industry. (Dunne \& Raby, 2001, p. 65)

Here Dunne and Raby suggest that designers can initiate a critical discussion about the long-term implications of emerging technologies. Workshops, exhibitions and publications provide an opportunity for public encounters with design to constitute debate, where discussion flows out of or somehow impinges upon the experience.

In 2004 scientific institutions funded two design-led public engagement projects. Hybrids was funded by the Wellcome Trust (Ashcroft \& Caccavale), Biojewellery by the Engineering and Physical Sciences Research Council (Thompson \& Kerridge). In both Hybrids and Biojewellery there is a clear move from notions of debate rooted in an internal critique of design, to versions of public engagement that share the floor with science educators and funding councils. Here is a move away from a model of practice where the designer is an isolated critic of technology in society, towards an interdisciplinary model where the designer is working with scientists, social scientists and researchers from other backgrounds.

There is now a cohort of designers who in various ways bring together speculative design and upstream engagement. For these designers, this association with public engagement offers a framework for developing disciplinary notions of design for debate, and crucially provides support for their practices. However, while accounts of practice are published in exhibition catalogues and in design blogs, there is a lack of analytical writing where the practice is discussed as a form of research.

\section{Public engagement with Science and Technology}

Contemporary commitments in the UK for scientists to do some form of public engagement are often traced back to Bodmer's report for the Royal Society in 1985, which offers a range of options for enriching public life through the transmission of scientific knowledge:

Better public understanding of science can be a major element in promoting national prosperity, in raising the quality of public and private decision-making and enriching the life of the individual. (RS, 1985). 
Later, the Science and Society report calls for more mutual forms of dialogue, where the values and assessments of non-experts in some way taken into account There is a call for scientific culture to be made accountable:

Today's public expects not merely to know what is going on, but to be consulted; science is beginning to see the wisdom of this, and to move "out of the laboratory and into the community" to engage in dialogue aimed at mutual understanding. (HOL, 2000)

More recently, policy makers and research councils have called for public engagement with science and technology to move upstream (HM-Treasury, 2004b; CST, 2010). Upstream engagement has been proposed as a form of deliberation between scientists and the public that takes place during the initial stages of research, rather than after technologies become products or services (Wilsdon \& Willis, 2004). Nanotechnology is an example of a thematic focus for these upstream modes, and Social Dimensions of Nanotechnology is such a project:

The project envisaged employing a social scientist to work in the nanoscience laboratory at the University of Cambridge exploring the social implications of nanotechnology, teaching scientists about the social and ethical aspects of nanotechnology, and supporting public engagement activities. (Doubleday, 2007).

Robert Doubleday's interest here was the extent to which exchanges between expert and non-experts frame 'responsible development'. He is wary though of expectations from science institutions that social science is in someway preparing society to 'accommodate new technology' (Doubleday, 2007),

While some see these practices as driving democratic models of science and technology decision making (HM-Treasury, 2004b), upstream talk has been critiqued as a repackaged version of top-down research and governance (Wynne, 2006).

\section{Overview of the empirical chapters}

Here I provide a brief description of three chapters to offer an impression of the episodes I will be drawing on, and of the analysis that will be developed.

\section{Situating biotechnology}

This chapter focuses on labs as locations where designers involved in Material Beliefs meet with biomedical researchers in order to hear their work, and have encounters with facilities and equipment. I discuss data relating to a series of episodes where a designer took a role as visiting research at a biomedical institute, supported by material relating to events that took place at other labs. Two interviews are discussed, one with a director of research at the biomedical institute, the other with two researchers at a biomedical lab. I then discuss two 
workshops convened at the institute following the interview. For the first workshop, an artificial pancreas is being developed at the institute is discussed by a patient, a scientist and a doctor and a designer. The second workshop hosts a group of postgraduate design students, who are set a project brief during a tour of the lab. I draw upon literature to discuss the ways in which different kinds of knowledge and technologies come together during these episodes, and then reflect upon how this analysis provides a new understanding of the design practices that are being accomplished here. I argue that these events can be seen as occasions where biomedical researchers have participated in activities that encourage nonexperts to offer alternative accounts of biotechnology research. While there is some overlap between these activities and upstream engagement, I demonstrate that engagement is an inadequate term the variety of ambitions being followed.

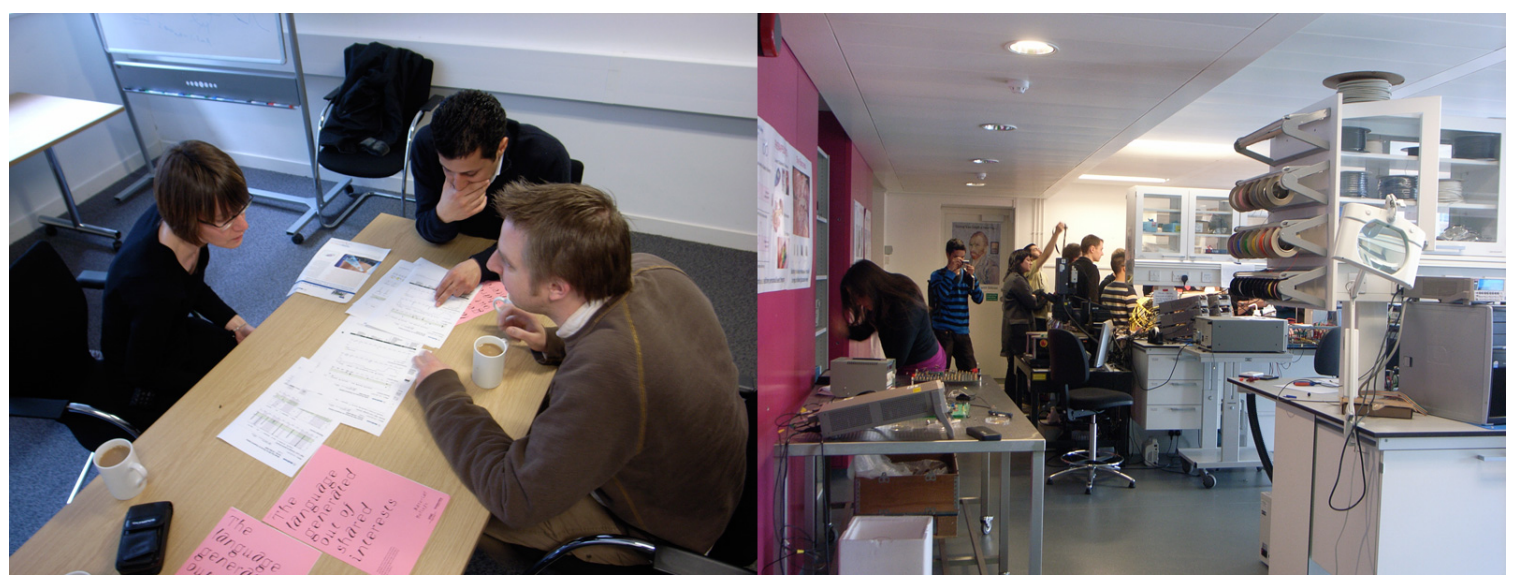

Figure 2: Discussing an artificial pancreas, postgraduate students touring a biomedical institute

\section{Designing Speculatively}

This chapter provides a description of how speculative designs come together in Material Beliefs, emphasising the ways in which issues, materials and practices become compiled through design processes. There is a detailed case study of the design and build of a set of prototypes concerned with biometric monitoring, illustrating how such a design is an accumulation of resources leading up to an object for exhibition. This is followed by a series of snapshots from the development of other Material Beliefs designs, and the aim here is to draw out particular issues for comparison. Such issues include the different ways in which collaboration takes place, and ways in which different degrees of functionality or realism in the designs lead into different experiences for those involved. There is some reflection in this chapter on the ways in which these designs embody and anticipate public engagement, and also some analysis of expectations for the designs that are not commensurable with engagement practices. There is also a discussion here on the forms of agency that are tied into these design processes, for while there are certainly moments of entrenchment in terms of the role specification for the designer, the scientist and the public, there are also situations where roles break down, and accountabilities are more fluid. 

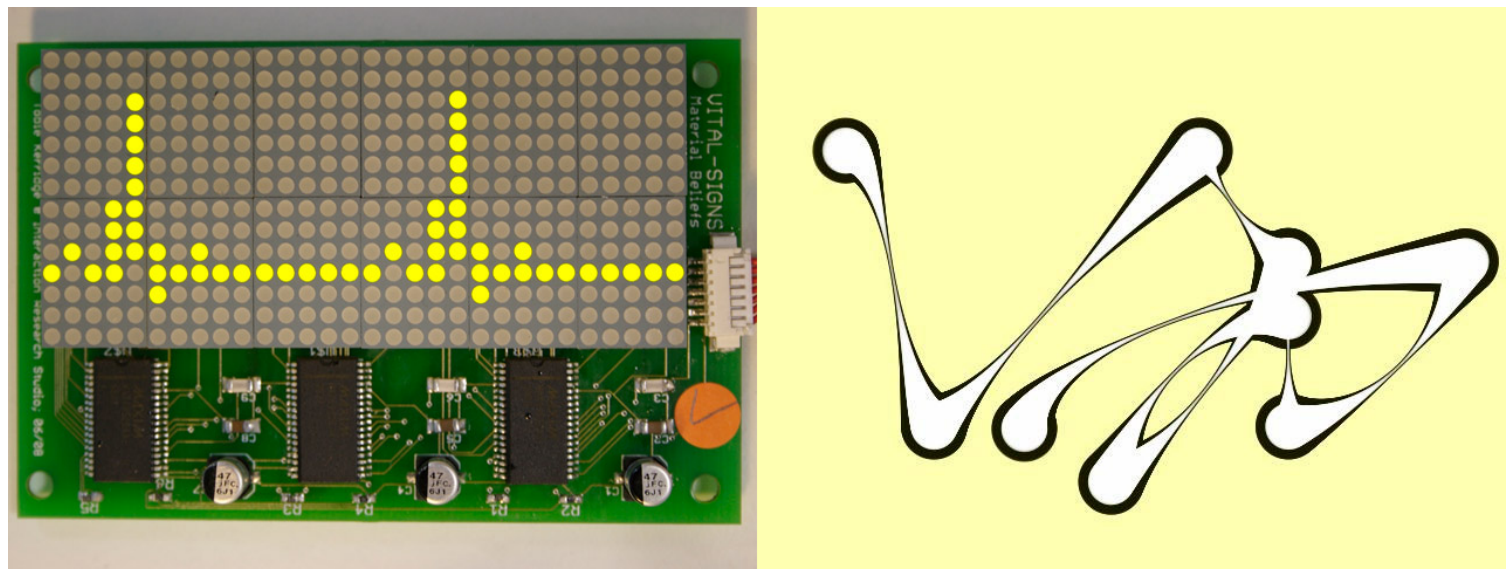

Figure 3: Digital rendering of a heartbeat, a live visualisation of neuronal cells

\section{Circulating Design}

This chapter provides an account and an analysis of the public events that came out of Material Beliefs. While there is a focus on public engagement in the form of exhibitions and workshops, this chapter also takes in online and print media and the communities that form there. One episode concerns an informal evening discussion at a science centre where there is a crisis around the ethics of a speculative design, another is an exhibition at a conservative science Institution where design is confused as art. Additionally there is a survey of the other formats in which the project is made public, and an analysis of the kinds of encounters that take place there in the name of speculative design. Through close attention to the publics that are shaped here and the formats of engagement that take place, this chapter will provide some definition to the more hazy and rhetorical notions of design for debate that are challenged at the start of the thesis.

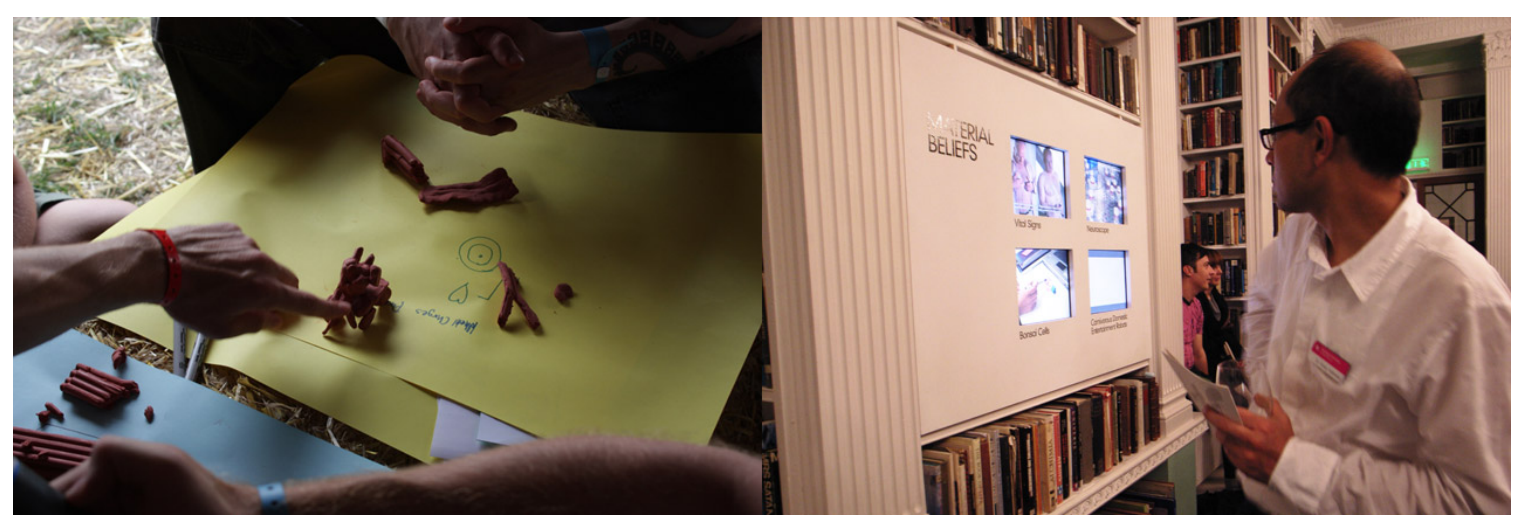

Figure 4: Modelling biomedical implants, visiting an exhibition

\section{Summary}

In this chapter I introduced the topic and the approach of thesis. I opened by introducing my practice as a speculative designer, outlining the association of that practice with the public engagement of science and technology. I described my 
involvement in a funding workshop following which I proposed and received funding for a project called Material Beliefs. I then described a second workshop, where designers and other practitioners were briefed about Synthetic Biology, where conveners at the workshop argued for the urgent need to engage the public about the potential applications and benefits of research within this field. I noted a cyclical nature to the designation of funding to support public engagement activities around emerging fields of science and engineering research. I emphasised that while this cycle allowed for the development of potentially interesting project work, PhD studies offered an opportunity to develop an analytical account of that practice that might better enable a speculative approach to contribute to design research.

I provided an overview of how this thesis takes Material Beliefs, a practice based design project, as a case for analysis, and suggested that while this is a written thesis, the publication that accompanied that project provides a useful companion and extends the visual and descriptive material dealt with here. I introduced the data derived from project work that will be drawn upon in the empirical sections, and provided an overview of practice based design research. While raising interaction design and participatory design as related forms of practice based research, I also introduced STS literature in order to extended a discussion of reflexivity in design. I followed on with other methodological issues, including the tension between practice and analysis.

I then set out the structure of this thesis, providing an overview of chapter content, for the two review and the three empirical chapters. I Introduced the two review chapters, one that deals with speculative design and one that focuses on public engagement with science and technology, and emphasised that each has two sections, where the first outlines practical and historical accounts of the topic, and the second provides analysis of the topic. I described how the empirical sections of the thesis would discuss episodes from the Material Beliefs project in order to provide an analysis of speculative practice. This included an overview of each chapter, where each was shown to cover different stages of generative design practice, starting with interviews and observation largely taking place in biomedical labs, leading on accounts and analysis of making of design artefacts, and completing with the publication of design artefacts and their circulation at engagement events. 


\section{CHAPTER 2: THE PRACTICE AND ANALYSIS OF SPECULATIVE DESIGN}

\section{Introduction}

I would have assumed, "Oh of course this is for everybody's benefit". But you may not want one, you know, people's civil liberties and everything. And it was Nelly who first raised the issue of, well, what if your insurance company will make you have an implant or else won't cover your hospital expenses? (Dawson, 2008)

In the quote above, a biomedical researcher recalls helping a postgraduate design student develop a plausible scenario for faking the biometric data transmitted from an implantable blood pressure monitor. The project is called Cathy the Hacker, and while Cathy's day is spent watching television and shopping, she employs various tactics to substitute false data for her own biometrics so that she appears to be exercising (Hayoun, 2008). Why would a design scenario seek to upset the function of biomedical technology in this way, rather than help deliver an application that would benefit patients? In this chapter I hope to unpack this question in some detail, first by providing some background to the design approach that informed Material Beliefs, and secondly by bringing together some theoretical resources with which to consider this variety of design practice.
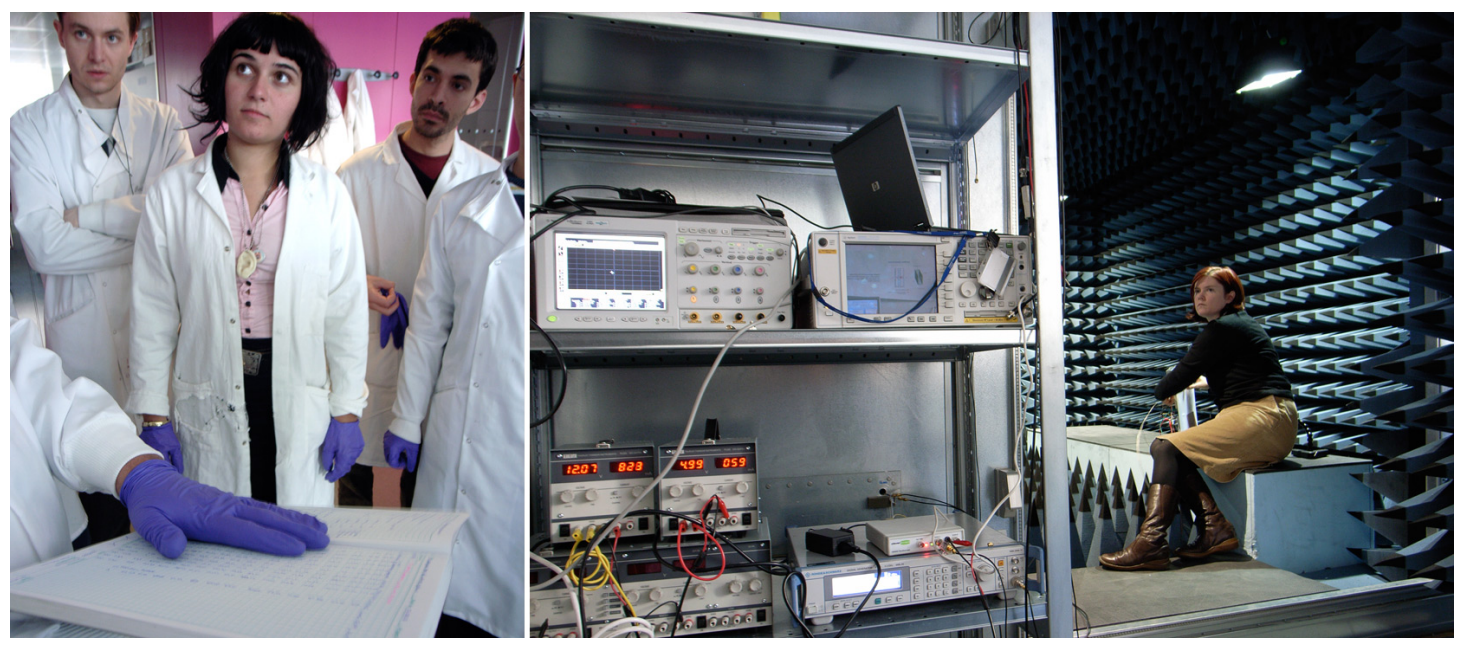

Figure 5: Postgraduate design students hear about biomedical research, a researcher developing an implantable blood pressure monitor

In the first section of this chapter, Material Beliefs is initially aligned with critical design, which provides a basis for asking questions about the embodiment of technology in the material outcomes of product and interaction design. Here I deal with a discursive range of writing about critical design, including practitioner selfpublications and interviews, curatorial statements about designs in exhibition 
catalogues, and discussions about critical design in blogs. I show how this variety of practice has influenced the design approach taken in Material Beliefs. However I will demonstrate that critical design's emphasis on enabling a debate about new technologies leads to an association with the field of public engagement with science and technology, and an extended practice that is described as speculative design.

The second half of this chapter aims to develop some resources for the discussion of speculative design as practice based research. I discuss two practice based $\mathrm{PhD}$ theses that take critical design as a topic, and then consider how speculative approaches are adopted in research. I then discuss how design research deals with the politics of technology as a topic, and how this develops notions of criticality. Finally I develop a historical perspective on participation as a form of public engagement in design research, and link activism and Alternative Technology to the speculative approaches of Material Beliefs.

\section{Practicing critical and speculative design}

\section{Introducing critical design}

"Although I see them as design proposals not artworks it seems that, to hold a design view where electronic objects function as criticism, one must exile oneself from design to the world of fine art because the design profession cannot accommodate such non-commercial research. Objects such as 'Personal Instrument' and 'Alien Staff', with their use of simple electronics and their emphasis on invention and social and cultural content, are rare examples of how product design and the electronic object can fuse into critical design." (Dunne, 1997, pp. 47 - 48)

Describing the artwork of Krzysztof Wodiczko in his thesis of 1997, Anthony Dunne anticipates a form of design practice that is ambivalent to the commercial outcomes of design, and adopts strategies of commentary from fine art. In Wodiczko's technology prototypes, Dunne sees an opportunity for the design of electronic products that "encourage complex and meaningful reflection" (p. 102). These designs are not products to be used, they are design proposals, which "ask questions rather than provide answers" (p. 87). Additionally, Dunne sees critical design as a populist mode of design research, intended for "mass-consumption through publication and exhibition" (p. 87). His agenda for critical design is to secure a infrastructure for its dissemination and consumption, for unlike art or conceptual modes of architecture, "once such work is produced there are few forums for its discussion" (p. 102). In his thesis Dunne commits himself to building an infrastructure to support this approach, and to accomplish this, he describes how design will adopt features of practice from art, architecture, literature and science. Here is a form of design then, which aims to infuse technology with 
narrative, to generate debate rather than provide utility, and to take design research into public spaces.

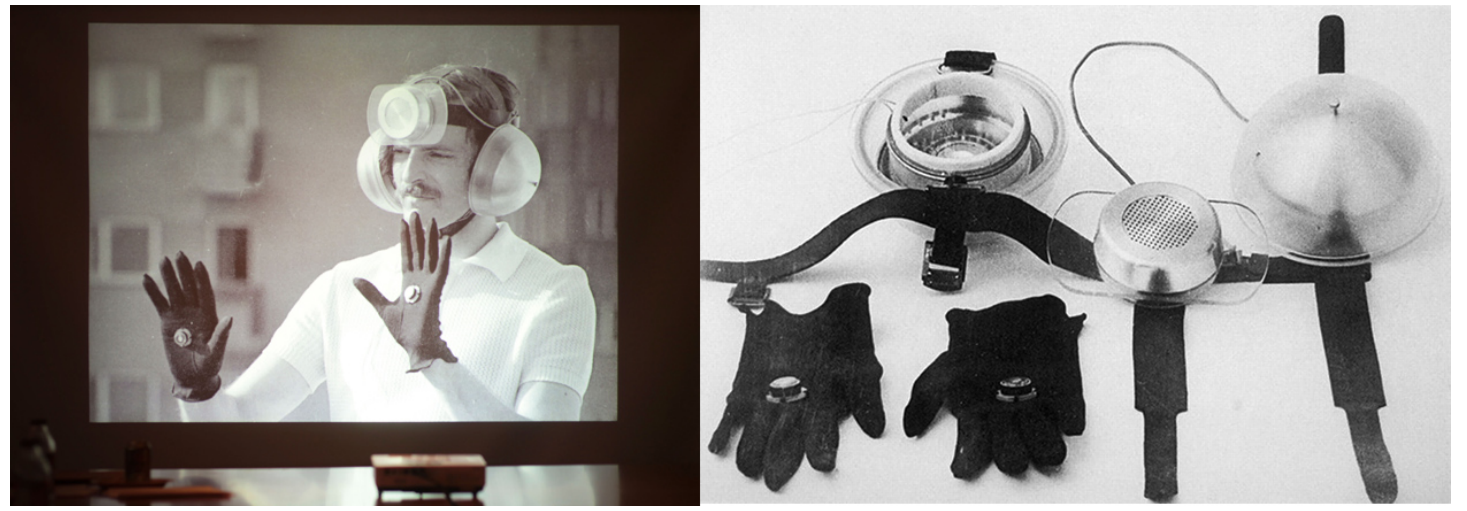

Figure 6: Krysztof Wodiczko, "Personal Instrument”, 1969

The approach taken in Material Beliefs is certainly influenced by these ambitions. Indeed it Dunne's commitment to build a network for practice and publication that sees his students and colleagues, and I include myself here, seek funding from organisations offering programmes of pubic engagement with science and technology. This section provides examples the type of critical design espoused by Dunne, and then demonstrates how this approach is developed through practitioners' self-association with public engagement.

Discussions with peers while writing this section made it clear that critical design is a slippery topic. It means different things to different people at different times, and frequently encourages histories to be drawn upon and opinions expressed. Ramia Maze traces a lineage to Radical Architecture (Mazé, 2007), Matt Malpass to Italian New Wave (Malpass, 2012) and David Cowley to Russian Constructivism (Crowley \& Pavitt, 2008). Elsewhere there are charges that critical design is elitist and colonial in outlook. The aim of this section is not to provide a typology of critical design, or to contextualise critical design historically. Although I cannot avoid doing a little of both these things, the aim of this section is to describe a trajectory of practice amongst a fairly small cohort of designers in order to establish a context for the approaches and settings that inform Material Beliefs. What follows then is critical design as a particular version of the various design approaches that are associated with criticality.

\section{Exhibiting critical design}

Critical designs are "produced for exhibit rather than sale" (Malpass, 2009, p. 1), and so exhibition catalogues provide a distinct set of literature in relation to practice. These publications range from virtual, book-exhibitions, and examples include Design Noir (Dunne \& Raby, 2001), Augmented Animals (Auger, 2001), Consuming Monsters (Dunne \& Raby, 2003) and Self-made objects (Ibars, 2003), along with catalogues from group exhibitions in which critical design has a smaller or larger presence, for example Strangely Familiar (Blauvelt, 2003), D.DAY - le 
design aujourd'hui (Guillaume, 2005), Wouldn't it be nice... (García-Antón et al., 2007), Design and the Elastic Mind (Antonelli, 2008), and Nowhere/Now/Here (Feo \& Hurtado, 2008), through to publications linked to exhibitions that have focused on critical design, including PopNoir (Lopez \& Milliken, 2005), Designing critical design (Zagers \& Warnier, 2008) and WHAT IF... (Dunne et al., 2009) and IMPACT! (EPSRC, 2010). What do exhibitions do for critical design?

Exhibition publications feature accounts of curation and essays that provide historical and cultural contexts for the work featured in the exhibition. The catalogue for 'Wouldn't it be nice...' accompanied an exhibition with eleven participating designers and artists, including Jurgen Bey, Dunne \& Raby, Martino Gamper and Martí Guixé. In her introductory statement as curator of the show, Emily King sketches a body of work where practitioners from the fields of art and design find shared currency in "the potential of new technologies in imagined future markets", she continues:

Common to both is the business of envisaging a different scheme of things, one that is imagined in spite of, or maybe even because of, harsh realities... these scenarios might not be entirely pleasant. The interaction of market and technology in the world that they envisage can take a distinctly dystopian twist. (García-Antón, et al., 2007, p. 46)

King establishes an identity for the work, design as material fiction. Elsewhere in the publication, histories are established. For co-curator Katya García-Antón, the selected work blurs disciplinary identities while demonstrating continuity with the past. García-Antón raises Bruno Munari as an archetypical figure in the development of a non-utilitarian form of design that is "critically engaged with culture":

The artists and designers in Wouldn't it be nice... are tracing alternative paths in their fields that reject old notions of 'applied' design or 'pure' art. Instead they treat their work as an investigative and explorative process, building on the experimental legacy of 1960s and 70s culture, and questioning in their wake the role and place of art and design today. (García-Antón, et al., 2007, p. 61)

If the character of critical design is determined by the themes and histories that it becomes linked to, this identity shifts depending on curatorial ambitions, for example where the exhibition might seek to rehabilitate the role of design (Zagers \& Warnier, 2008, pp. 63-65), or draw up strategies of practice shared between art and design (Betsky, 2003). Despite these variations, critical design is consistently seen to offer a form of postmodernism as a critique of design modernists (Ward, 1993). Mazé and Redström trace a recurring critique of "capital, industry and technology" (2009) to the Critical Theory of the Frankfurt School, including Ardono's critique of mass culture (1991) and Marcuse's account of capitalism 
(1991 (1964)). Critical Theory is frequently deployed, for example a publication accompanying Designing critical design aligns the selected work with Radical Design of the 60s, and its ambition to "oppose prevailing ideologies" (Zagers \& Warnier, 2008, p. 68). So despite difference in curatorial ambitions, exhibitions that feature critical design establish an identity for the practice by making certain associations more durable by establishing a network of institutions and literature.

A core feature of critical design in exhibition literature is its combative relationship with design that is not critical. Here the object of critique for critical design is design itself. In an essay accompanying the PopNoir exhibition Dunne writes:

Design generally falls into two very broad categories: affirmative design and critical design. The former reinforces how things are now; it conforms to cultural, social, technical, and economic expectation. Most design falls into this category. The latter rejects how things are now as being the only possibility; it provides a critique of the prevailing situation through designs that embody alternative social, cultural, technical, or ethical values. (Lopez \& Milliken, 2005, p. 15)

This distinction between affirmative and critical approaches provides a strong statement of identity for critical design. But who is responsible for establishing a boundary to distinguish conformity from resistance? Who provides a sense of what alternatives are available, and what their implications are?

For Paola Antonelli, it is designers whom "have the ability to grasp momentous changes in technology", and "the ability to help people deal with change" (2008, p. 15). Elsewhere we are told that "designers raise critical questions with their work", questions concerning "contemporary society or the society of the future" (Zagers \& Warnier, 2008, p. 65). The role of the designer as a provocateur is described at length in an interview with Feo and Hurtado about their exhibition Nowhere/Now/Here:

What designers think today is the vision for tomorrow, but the future is not only about the objects that will be available in shops. Everything around us has been designed and whatever will surround us in the future will have been designed. This is why exhibitions like Nowhere/Now/ Here are so important. They present possible future scenarios, some are already here and available, some will be there soon and others will never happen, but the fact that they have been brought to live as prototypes has already influenced and changed the future... Creating narratives and exploring alternative scenarios introduces elements that we could not anticipate and takes your thinking to places that you did not foresee. (Feo \& Hurtado, 2008, p. 19) 
While this is a compelling narrative, I would argue that the discourse engendered by these exhibitions and the accompanying publications is primarily a disciplinary one. In particular, putting focus on the agency of the designer provides a resource for product and interaction design pedagogy. Then what is the value of this conception of design when such exhibitions become aligned with other professional programmes? For example do these forms of agency and these critical arguments about technology and society hold sway when the designs are exhibited as part of a programme of public engagement with science and technology? I believe that in cases of collaboration, design supports additional ambitions, including the depiction of science as a creative pursuit, promoting scientific research as providing social benefit, and educating the public about scientific matters. Where critical design mingles with other practices, while the designer may well retain an interest in the capacity of the work to generate critique, catalogue texts and other written accounts of the exhibition and the designs included there will be shared with the partner and therefore promote the aims of their programmes.

\section{Other formats for dissemination}

Encounters with critical design are not restricted to exhibitions and catalogues. Other tangible outcomes of practice include transcripts and video recordings of seminars and symposia linked to exhibitions, interviews with designers, exhibition reviews and features on critical design in magazines and journals, and discussions about the individual designs on blogs. While there is a great deal of repetition here, these additional outcomes also transform designs, by focussing on sensational aspects, by inviting experts to comment on related issues, or by discussing a designer's approach.

Critical designs usually leave the studio initially to be exhibited. Often this occasion is supported by the publication of a pamphlet and a website. For example James Auger produced a self-published book on the occasion of his graduation show at the Royal College of Art (Auger, 2001) and the project is also documented on a website he shares with his colleague (Auger \& Loizeau, 2001 - 2009). The project, Augmented Animals, conceives of technologies designed for animals rather than humans, "tending to some of their specific needs"; survival, traumas of domestication, and status enhancement (ibid. , p. 3). A dog wears the nuisance odour respirator to filter out intense household smells, and a mouse is fitted with an impact bar for protection from a sprung trap. In this case a critical design can be considered to be a package of three elements, including a descriptive title, a persuasive image and a provocative description. While these designs are combined in a thematically related set for publication and exhibition, they are individually selected and syndicated by publishers. For example, two designs from Augmented Animals feature in the design blog, We Make Money Not Art, which reproduces the designer's description and images (Debatty, 2005). A search for "James Auger" and 
"Augmented Animals" using Google provides over 600 relevant URLs that reproduce images and text derived from the initial format. These blogs and discussions provide currency for the designs and generate more exhibitions: Augmented Animals was published in 2001 it was five years later that physical prototypes were shown at the exhibition Bêtes de Style at the Musée de Design et d'Arts Appliqués Contemporains, Lausanne (Prod'hom, 2006). Rather than being restricted to the designer's graduation exhibition and publication, Auger's animal designs proliferate across a series of events, at a variety of scales and in a range of formats and over an extended period of time.

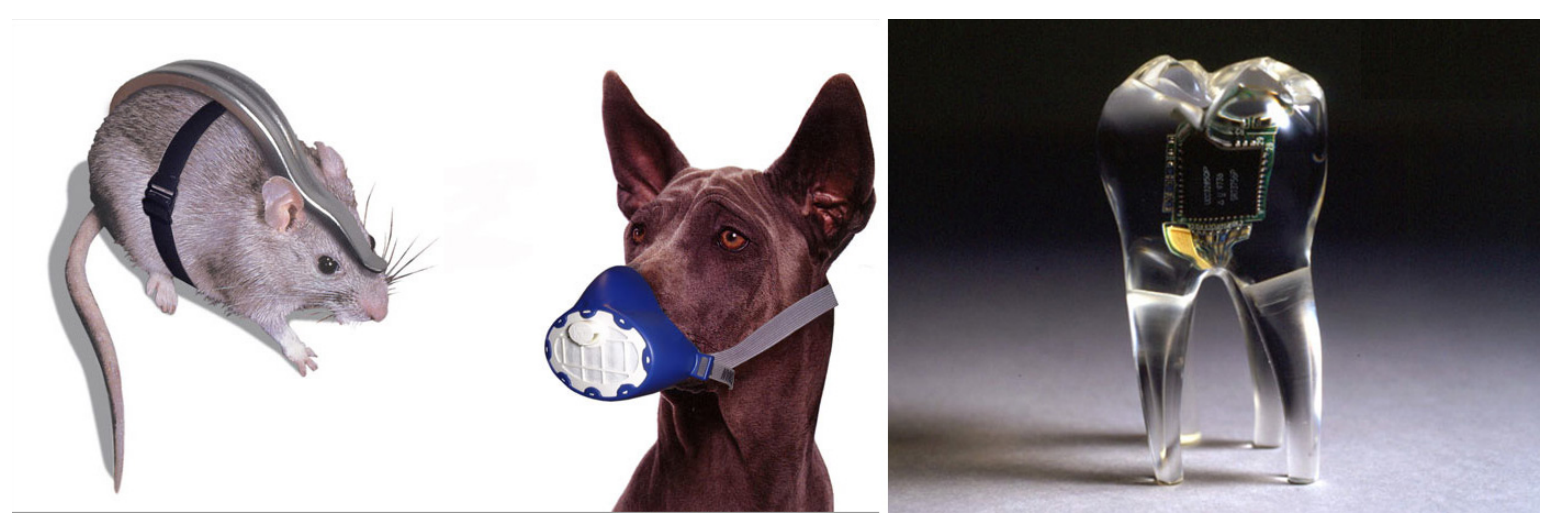

Figure 7: Vertical impact protection jacket and nuisance odour respirator (Auger, 2001), and Auger-

Loizeau's Audio Tooth Implant (Auger \& Loizeau, 2001)

It is through this process of syndication that the design also becomes transformed. The readership of Debatty's blog is largely a design community, and here Augmented Animals is understood to be a set of playful technological concepts, Auger describes a "comic book with each of the concepts existing as a one-liner" (Debatty, 2007). Elsewhere the designs are treated as authentic, or as authentic proposals that warrant further forms of analysis beyond the playful discussion associated with scrutiny amongst peers. For example an article in Wired, a monthly technology and culture magazine, animal augmentation provides the basis for a journalistic discussion. Animal behaviourist Jeffery Harrow is interviewed as an expert, and he warns that "we must be exceedingly careful or we might change our biosphere in ways later generations might abhor" (Sandhana, 2010). In this way the journalist extends Auger's initial scenario by activating a set of issues that include technological determinism, the biosphere and ethics in relation to human treatment of animals.

The critical designer can cultivate the design's authenticity by encouraging journalists to validate the work. Auger and his colleague Jimmy Loizeau describe a "public discussion" about their Audio Tooth Implant, a miniaturised mobile phone implanted in the tooth of the user (Debatty, 2007):

Jimmy and myself were conscious that for the project to instigate a wide public discussion the concept had to exist on the borders of contemporary reality, too 
extreme and it would be seen as science fiction, too conservative and it would just blend into the plethora of current technological gadgets available on the market. Initially we were honest about our motivations but it soon became clear that the press weren't too interested in technological debate so we changed our methodology and went down the surreptitious route; by suggesting that it was a real product and would be available on the market at some point in the near future they took the bait... We perhaps spoke personally to around 20 individuals; the rest is copy, paste and exaggerate. New media such as the web have enabled news and stories to spread like viruses, mutating as they weave their way around the world.

Auger and Loizeau contend than their design brings about a public discussion, and to accomplish this the design is optimised to encourage journalism, as this is assumed to be equivalent to an expanded public debate. More press is seen to support more public discussion. However, I argue that in this case, and other cases where the effects of the design are not developed empirically, there is no attempt to develop an account of what kinds of discussion these news events enable. Rather, it seems that the designers' intention to drive a technological debate has become conflated with a desire to successfully promote their designs. Here are forms of dissemination that can be better characterised as publicity and promotion, which support the designer's ambition to develop a professional profile, and potentially do more exhibitions. This seems like good practice. But the question remains, why is there such a knotty conflation of professional development and a desire for debate about the implications of technology?

\section{Design as a form of public debate}

The network for the distribution of critical design described above can be seen as an alternative to academic publication. For Dunne, while academia provides an environment for "developing ideas and approaches" outside of commercial practice, the outcomes of critical design demand "contexts in which the design thinking can be encountered by the public" (Dunne, 1999, pp. 75-76). One concern here is that design should reconnect with the "everyday reality" which comprises the habits, identities and objects that provide the very basis of its critique (ibid, p. 74), though it is not clear why the setting of an exhibition would be seen as more everyday than that of a university. Exhibition and catalogue publication also offer forms of recognition and value that are seen to be excluded from the research community:

In short, as a result of what might be called "methodological intimidation", research work carried out in colleges of art and design stand a very real risk of losing those qualities of originality, iconoclasm, energy, style and wit which have characterised the best of art school culture science the 1950s.

(Seago \& Dunne, 1999, p. 12) 
These arguments are more fully articulated in Design Noir, where Dunne and Fiona Raby propose that the role of critical design is to "stimulate discussion amongst the public, designers and industry" (Dunne \& Raby, 2001, p. 58). This requires not only new modes of practice - critical design, conceptual design, design noir and designing for complicated pleasures are some suggestions - but new institutions to support those modes:

One way this could happen is if the design profession took on more social responsibility and developed its own independent vision, working with the public to demand more from industry than is currently on offer... Perhaps they could follow the lead of some architectural institutions, and focus on the need to encourage diverse visions through competitions and workshops for practising designers, as well as trying to engage the public through more challenging exhibitions and publications... rather than writing papers and seeking conventional academic approval, they could exploit their privileged position to explore a subversive role for design as social critique...

(ibid., p. 65)

Workshops, exhibitions and publications provide an alternative for the dissemination of design, redirecting the work away from academic audiences. A key move for critical design then, is the adoption of modes that anticipate public readership. Furthermore, there is an ambition for these public encounters with design to constitute debate, where discussion flows out of or somehow impinges upon the experience of an encounter with critical design. Auger has described how the design becomes a tool to translate inaccessible scholarly argument into public debate:

We're sometimes inspired by words from the likes of Neil Postman, Marshall McLuhan, Jacques Ellul and Martin Heidegger but these can be a little inaccessible and remain within the confines of academia, we feel that the language of products has a much broader appeal and can therefore take the debate on technology to a wider public audience. (Debatty, 2007)

What is accomplished by emphasising public settings as the key site for the outcomes of design rather than academic publication? I argue that Dunne and Raby, Auger and Louizeau, and other colleagues and students create an environment in which they are able to develop a variety of design approaches, some which focus on delivering exhibitions, others on providing experimental formats for workshops and other public events. However, while these designs format technologies in unorthodox and playful ways, it is certainly not clear what issues are then debated, or indeed who is having that debate. These forms of publicity imply and inscribe the public within their discourse, and do not require an empirical examination of the forms of public engagement that then occur. I also argue that rather than make design practice somehow more accessible, a move 
from academic publication makes the designs inscrutable. One task for the thesis will be to present the kinds of discussion that are activated by encounters with speculative designs.

\section{Debate and the Public Understanding of Science}

It is perhaps at this point that the term critical design, compromised as it already was by my opening caveats about competing varieties of critical design, becomes less useful as a marker of what these practices offer. I have argued that as these designs become more successful and therefore more widely distributed, the intention of the work is no longer restricted to the critique of design for and by the design community; the designs aim to encourage a broad public debate about technology. This development is accompanied by a shift in the designers' gaze, from the electronic landscapes of Hertzian Tales and Augmented Animals that are the focus of the work towards the end of the twentieth century, to emerging fields of science and technology, initially biotechnology, and later nanotechnology and synthetic biology. This thematic shift provides the basis for association with forms of public engagement incumbent upon those fields of science, that compel a transformation in designerly commitments to public debate. For example here is Dunne introducing the work of his students and colleagues that appear in Cluster, a design publication with a one time editorial focus on biotechnology:

Although there is a relatively high awareness of biotechnology in the public sphere, there is very little actual understanding of it and, as a result, public discussion is very limited. Much of the current debate is presented through newspapers and specialist reports. The flow of information is one-way - from the experts to the public. It is only when something goes wrong that the public get to express their concerns, for example the GM food debate in the UK. (Dunne \& Raby, 2004, p. 78)

Set against a background of public ambivalence towards biotechnology, such as public concerns about genetically modified food, the designs that follow are described as providing an opportunity to "explore public perceptions of different biofutures before they happen" (ibid., p. 79). So where does the impetus for this rearticulated design for debate come from?

Bioland is an unpublished research project offering a selection of designs curated as an "existential department store", where products and services are brought together within a consumer environment (Dunne \& Raby, 2003). In an introduction to the project the authors cite Biotechnology in the Public Sphere, a publication of the Economic and Social Research Council's Public Understanding of Science programme (Durant et al., 1998). Here is a moment when design for debate and public understanding of science coalesce. Through a commitment to design as a driver for public debate around science and technology, an association 
is made with sociological accounts of science and society in the name of supporting public interest in biotechnology.

\section{Funding Design as Public Engagement with Science and Technology}

Durant et als' Public Understanding of Science publication offers arguments and language that allow Dunne and Raby to reconsider the nature of the debate that design can provide. A description of a set of designs responding to biotechnology reflects this approach:

This project will shift the discussion from one of abstract generalities separated from our lives to tangible examples grounded in our experiences as members of a consumer society. In this way, we hope that we can involve people in the debate earlier and set up a dialogue between the public and the experts and researchers establishing policy and regulations which will shape the future of biotechnology... and make a contribution to the design of regulations that ensure the most humane and desirable futures are the most likely to become reality. (Dunne \& Raby, 2004, p. 79)

Here is a network around the design that brings together the public, scientific experts and policy makers to evaluate the social value of scientific applications, where regulation itself is seen as a design outcome. Alongside the curatorial features of Bioland, which establishes a cohort of projects dealing with biotechnology, it is a tool to "bring very different communities together", and it names those communities; "scientists, ethicists, museum and arts organisations, the public and designers" (Dunne \& Raby, 2003, p. 3). While Bioland is never executed as an exhibition in the format discussed, here is a blueprint for speculative design's association with public engagement. When individual designs included in Bioland are then developed into funding proposals that are granted support, the networks anticipated by Dunne and Raby become established.

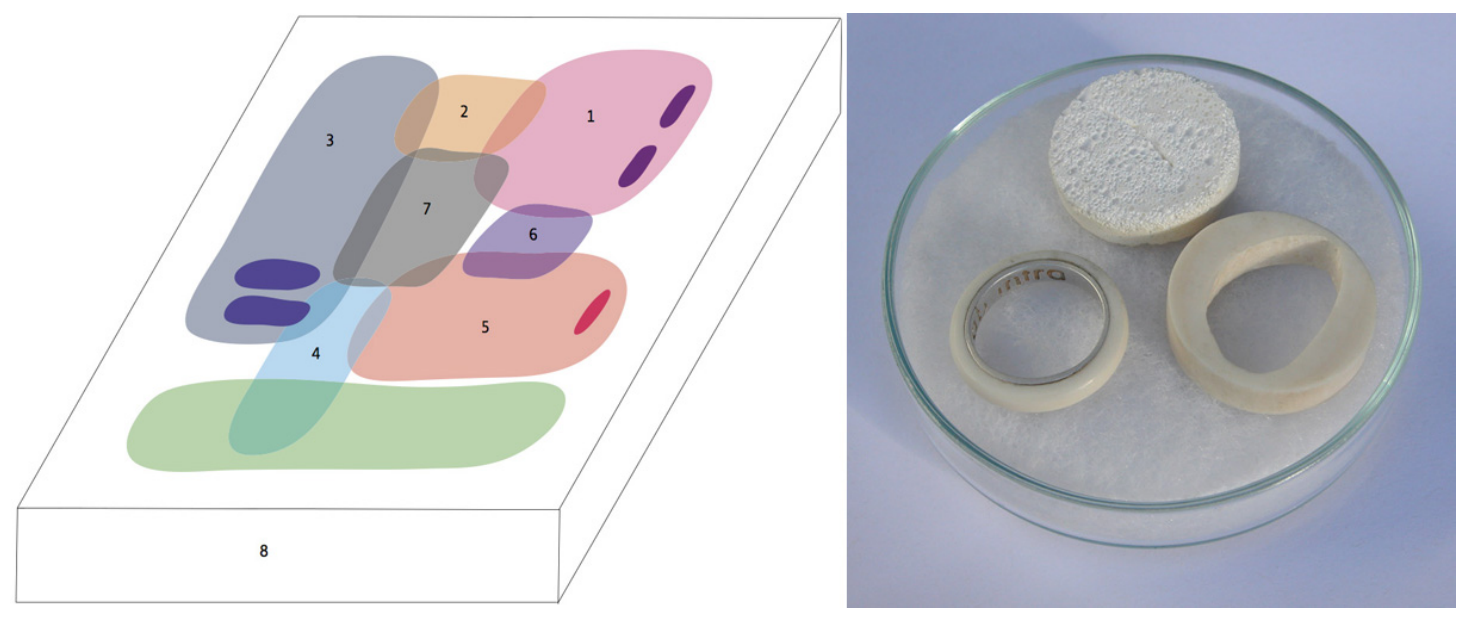

Figure 8: Schematic of Bioland and Biojewellery (Kerridge, Stott and Thompson, 2003), a hypothetical product from department 6 - "GM LOVE". 
In 2004 Richard Ashcroft and Elio Caccavale's "Hybrids" was funded by the Wellcome Trust through a Sciart Production award, and Tobie Kerridge, Nikki Stott and Ian Thompson's "Biojewellery” was supported through the Engineering and Physical Sciences Research Council's (EPSRC) Partnerships for Public Engagement (PPE) programme. These funding programmes offer distinctive platforms for public engagement with science and technology through collaborative practice. Sciart funding was initially conceived as resource for "the emergence of new knowledge through transdiciplinarity" (Arends \& Thackara, 2003, p. 10), where the outcomes aimed to "engage with diverse audiences on the social, ethical and cultural issues that surround contemporary biomedical science" (Turney, 2006, p. 26). In contrast a broad range of science and engineering subjects are eligible to apply to the EPSRC programme. Here partnership is strategic rather than creative, where public engagement is outsourced to "people who can help you to deliver a better and more professional product" (EPSRC, 2003, p. 30). The respective identities of these programmes then give rise to differences in how design for debate becomes rearticulated as public engagement, either through the auspices of Sciart's transdiciplinarity or the professional partnerships of PPE. Both programmes have now ended, the Sciart award replaced with the Arts Awards (Glinkowski \& Bamford, 2009, p. 17), while the remit of the EPSRC's PPE programme has ceded to a cross council "application and assessment process" entitled Pathways to Impact (RCUK, 2010). Such transformations reflect a rapidly shifting landscape in which engagement practices are continually remade as the agendas of funding bodies respond to the shifts in government policy.

An aim of Ashcroft and Caccavale's Hybrids was to encourage discussion about biotechnology through its expression in hypothetical product typologies. Caccavale's project partner Richard Ashcroft outlines this ambition:

The idea of the present project, then, was to collect instances of challenging biotechnological products and other human products which invoke to transgress the human/animal, or more generally the species/species boundary, as occasions of ethical and philosophical reflection. (Ashcroft \& Caccavale, 2004, p. 9)

An initial phase of the project gathered together material with which to generate these opportunities for reflection, and this phase included a survey of products developed as a result of biomedical and bioengineering research. Products here include transgenic ornamental fish, low fat pork, featherless chickens and bioreactor cows (Ashcroft \& Caccavale, 2004, pp. 23-29). Such products provided a landscape of actual bio-hybrids products in which to situate design proposals. Ashcroft and Caccavale comment (Ashcroft \& Caccavale, 2004, p. 15): 
The interaction of design, science, and society is the main objective of the project, providing a way to explore and envision possible biofutures. Like other cultural arenas, numerous issues of controversy are open to exploration. And contemporary design is the ultimate means for exploring biotechnologies.

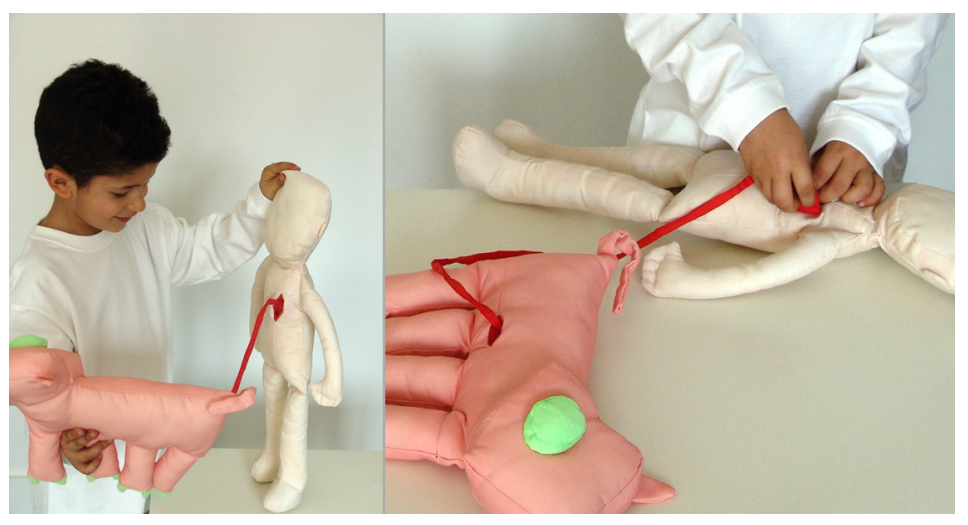

Figure 9: MyBio dolls, an outcome of Caccavale and Ashcroft's Hybrids project

MyBio was a series of children's toys that embodied potential biotechnology products in various animal and human forms, interconnected by fluids and organs. MyBio goat, for example, has a spider's web attached to its udders, "demonstrating one animal making the natural product of another" (Ashcroft \& Caccavale, 2004). While some technologies alluded to in the dolls are on the market, others are in development, and others are more promissory. As designs the MyBio dolls collapse any distinction between products and ideas, and dramatize new technologies through their forms. The photos of the child with the designs depict an alternative everyday, where such technologies are mundane, reduced as they are to teaching aids for children. It is perhaps through their everyday strangeness that a particular form of curiosity arises:

You could see this as public engagement with science and technology. But I prefer to see it as an exercise in democratic practical philosophy. By engaging with these objects and concepts you are figuring out something about the world, and its interrelationships, and our place in it. (ibid., p. 9).

Elsewhere, the expectation of an audiences' engagement with the design is conceived differently. For Michael Reiss encounters with MyBio provides educational rather than philosophical effects:

Such practices help learners explore the moral and social implications of new technologies and enable all of us to reflect on what is possible and what is desirable. (Levinson et al., 2008, p. 49): 
These variations can be ascribed to the different professional identities that have a stake in the project. This was also a feature of Biojewellery, a project that comprised an interaction designer, a jeweller and a tissue engineer (Thompson \& Kerridge, 2004). Here the participants grew rings of bone tissue, cultured in labs using cells donated from lovers, where the couple would then wear material from the body of their partner as jewellery. Biojewellery deployed a strategy discussed earlier, where an image and a description of the design scenario were disseminated. In this case a science writer was employed to write a press release which invited couples to apply to the project, which was circulated to editors and agencies (Reed, 2005). The following extracts are from New Scientist, a weekly popular science periodical, and Bizarre, a monthly fetish title:

The tricky part is that the lucky couple will have to provide bone cell samples, for which the team will get ethical approval only if both people already need surgery... interested couples can apply through the website. (Hogan, 2005)

This is romance - you undergo a tiny little biopsy to create a sample of bone cells for propagation... They're looking for couples bored by cubic zirconias who are willing to participate in the whole Flintstoney bone-harvesting bonanza and it could be you... (Wiseman, 2005)

The New Scientist article is read by a bioethicist, who writes a paper on "Body art and medical need" for the Journal of Medical Ethics (Brassington, 2006). A couple who subscribe to Bizarre magazine send an email offering to donate cells for Biojewellery, describing that they "have tasted each others blood" as "our bodies are the most precious thing we could give each other". These are strong and idiosyncratic statements, and substantially develop the designers' initial, simple scenario about love and marriage. Such developments are folded back into the project, which is committed to working with others and dependent upon volunteers. The Ethicist is invited to discuss ethics at a public workshop, and the couple become donors who undergo surgery and make decisions about the design of their rings.

How do these events relate design practice to public engagement in a manner that gives additional depth to notions of debate? The readership of journals and magazines can be profiled and counted, which presents an additional method for accounting for engagement in Biojewellery. Such an evaluation certainly satisfies the research council guidelines for effective public engagement (RCUK, 2002). Moreover there is also something distinctive being done through an extended form of design. Incomplete designs are circulated, and as they become subject to responses external to the designers' studio, the value of the design is shifted. The design accrues additional implications; ethical arguments and individual tastes. This is in contrast to designs that are broadly resolved at the point of exhibition, which are complete in a formal and material sense, and by virtue of the supporting 
statement and the exhibition publication which prefigure the terms of the debate to be accomplished through the design. Somewhere in between these approaches is a design that anticipates a response from the press, and builds capacities that enable the design to be extended through journalism. It is clear that different design approaches imagine different kinds of public, and entail engagements of different sorts, and I mention these issues briefly here in order to prefigure the ways they will be developed in the empirical chapters of thesis.

In both Hybrids and Biojewellery there is a clear move from versions of debate rooted in disciplinary notions of criticality, to versions of public engagement responsive to the interests of science educators and funding councils, and which also invite the vicarious demands of individuals. This supports a move away from a model of practice where the designer is an isolated critic of technology in society. While such a move is imagined in Bioland, an unanticipated and more substantive outcome is that design no longer has the authority to set the terms of the debate in which the public, scientists and policy makers are then engaged. Rather design becomes more of a ground for staging these encounters, and of building formats through which the outcomes of these encounters coalesce.

\section{Speculative Design and Upstream Engagement}

Speculative design is an appropriate title for the approaches taken in the projects Hybrids and Biojewellery. The phrase has been used to denote the material outcomes of critical design (Dunne \& Raby, 2007), and more broadly to describe a form of design practice that emphasizes "inquiry, experimentation and expression" rather than "usability, usefulness or desirability":

Within the context of technology goods and services, speculative design can be defined as the deliberate configuration of technological systems to explore future-orientated scenarios, conditions or consequences of technology use... such interactions and experiences suggest the potential of extending the range of engagement with and effect of speculative design beyond the common audiences of other designers and critics. (DiSalvo \& Lukens, 2009, p. 2).

Like DiSalvo and Lukens, where I speak of speculative design, I am concerned with not only the material outcomes of design process - the prototypes, the films and images that stage scenarios - but with a range of activities associated with design as a form of public engagement with science and technology, including workshops and exhibitions. Additionally, through an emphasis on process, there is also an opportunity to develop a discussion of the fieldwork, which is an integral part of speculative design, including visits to the labs where science and technology is an object of research.

Speculative design is clearly informed by notions of debate developed in critical design, and remains focused on framing emergent science and technology as 
hypothetical products and services, but responsibility for materializing issues and values is taken away from the designer and distributed across the network that has come together through a process of public engagement. While critical design adopts the language of public engagement in statements about practice, Speculative Design associates in deeper ways with public engagement where it is necessarily involved in activities that effect design processes, and encouraged to account for design processes in different ways.

While the next chapter will focus on public engagement literature, now is a good moment to introduce some precision regarding the forms of public engagement with which designers identify. What I have so far been describing as public engagement is not a stable field, but an entity that comprises a range of institutional programmes, that are carried out using methods from various disciplines. Like Dunne and Raby before them, Caccavale and Ascroft cite Durant, Bauer and Gaskell's quantitative assessments of the public perceptions of biotechnology (Ashcroft \& Caccavale, 2004). Elsewhere, a pamphlet to accompany an exhibition of Biojewellery at Guys Hospital reproduces an extract from a publication from the think tank Demos:

'My role', explains Doubleday, 'is to help imagine what the social dimensions might be, even though the eventual applications of the science aren't yet clear.' Communication is a big part of his work: 'A lot of what I do is translate and facilitate conversations between nanoscientists and social scientists, but also with NGOs and civil society.' (Wilsdon \& Willis, 2004, p. 55)

Here the authors reproduce an extract of an interview with Robert Doubleday, a social scientist conducting fieldwork at a nanotechnology lab in Cambridge. By reflecting on the potential "social and ethical aspects" of the nanotechnologies he encounters in the lab, Doubleday is seen by Wilsdon and Willis to be taking engagement upstream, that is to the early stages of scientific research (ibid. , p. 55). Biojewellery identifies with this upstream mode of engagement and with Doubleday's comments; its "approach was broadly similar", with an ambition to "excite the public imagination" with early stage biomedical research around tissue engineering (Kerridge, Stott, et al., 2006, p. 11). Upstream engagement, as exemplified by the Demos pamphlet's formatting of Doubleday's Nanotechnology project, becomes related to speculative design elsewhere. In an introduction to the 2007 yearbook for the Design Interactions course, as department head Dunne responds to the question, "Many of the projects seem to deal with science rather than technology, why is that?":

We are interested in ways of using design to support debates about what kind of future people desire... if we move upstream and work with scientific concepts we can explore future applications of technologies through hypothetical products before they happen. (Burton et al., 2007, p. 9) 
Similarly a workshop convened by Dunne and Sandra Kemp in 2008 conceptualises such strategies as research methods for art and design:

What types of research tools and methodologies and what models of multidisciplinary engagement might facilitate well-informed 'upstream' public participation in scientific and technological advance at the intersection of biology, art, design and the public sphere? (Dunne \& Kemp, 2008, p. 2)

This model of speculative design and upstream engagement becomes embedded in the work of a cohort of designers. Kramer and Papadopoulou's The Cloud Project converts an ice-cream van so that it becomes "a catalyst for interesting dialogue" where "new audiences experience and imagine emerging scientific developments and their consequences" (Papadopoulou \& Kramer, 2009). With their E.chromi project, Daisy Ginsberg and James King collaborate with a group of young scientists involved in an international competition for innovative uses of synthetic biology. Echoing Doubleday's role as an interpreter of scientific research, the two designers help their scientists "think outside the petri dish while we got to think about how synthetic biology meets design" (Ginsberg \& King, 2009). Elsewhere, King describes himself as a "Speculative Designer", and says of his design approach:

By creating a dialogue between design and the lab work, and the lab techniques that go into making these technologies, I think it can create a much more interesting type of science... there's also a social aspect to it as well, because the imagined possibilities can be made public, and they can raise debate in public and scientific forums. (King, 2009)

Ginsberg too identifies with upstream forms of engagement that relate to Doubleday's approach. The Synthetic Aesthetics project in particular associates speculative design approaches with laboratory research, pairing creative practitioners with scientific researchers working in the field of synthetic biology (Endy et al., 2010). While working with scientists in this area, and specifically graduate students competing in an international competition to develop synthetic biology applications, Ginsberg has commented:

I propose that design can engage with science and technology in new ways, bringing the designer's skills of functionality, synthesis, collaboration and tangibility to allow us - biotech's ultimate consumers - better access to question and consider alternative futures. (Ginsberg, 2010, p. 266) 


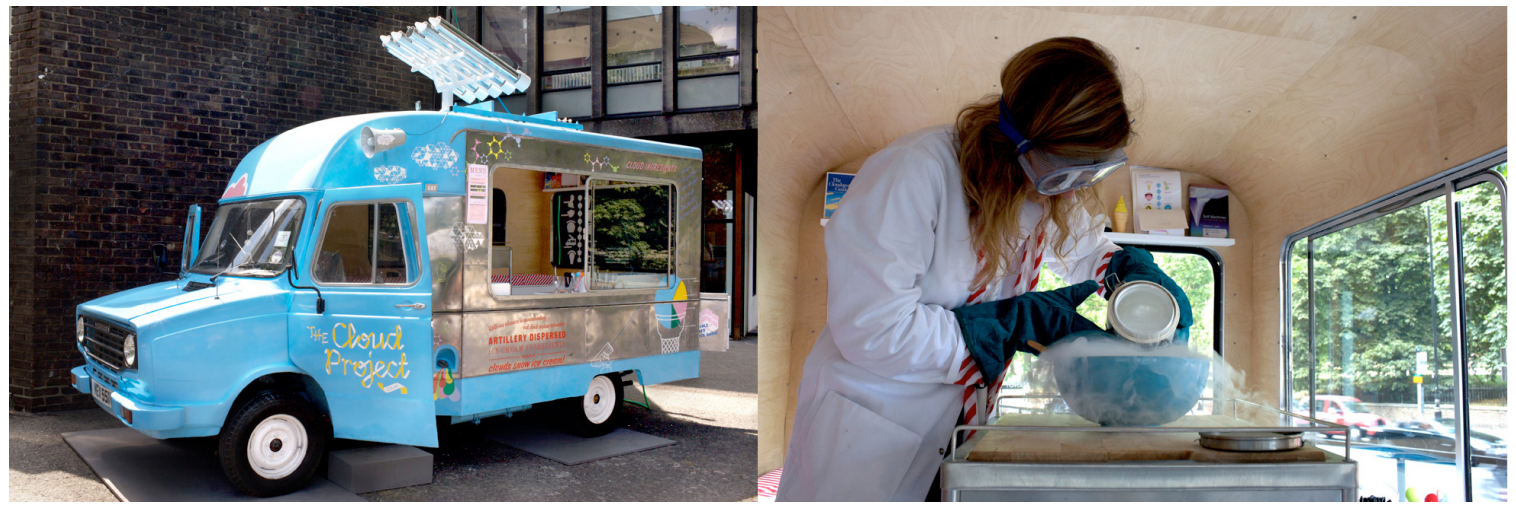

Figure 10: Kramer and Papadopoulou's The Cloud Project (2009)

Elsewhere, non-designers take up accounts of the upstream mode of speculative design. Richard Jones discusses Kramer and Papadopoulou's Cloud Project in the journal Nature Nanotechnology:

The reactions of artists and designers to the possibilities of new science and technology are sometimes playful, but sometimes unsettling and disturbing, and one should not expect uncritical enthusiasm. The outcomes of these interactions are not so much visions of the future, as glimpses of possible futures; if they are not utopian visions, neither are they dystopias. Instead, they are ways of beginning conversations about all the complicated and messy ways in which societies might, in the future, interact with technological change. (R. A. L. Jones, 2009)

Here is a cohort of designers and others who describe a practice that brings together speculative design and upstream engagement. In this practice, the envisioning of hypothetical futures through design alternatives provides an opportunity for dialogue about early stage scientific research. For these designers, the idea of the upstream sanctions a generalised and hazy sense of public engagement, and also offers something of a progression from the quantitative measurement of public attitudes that we see in the work of Durant and colleagues (Durant, et al., 1998). The upstream offers an opportunity to unpack and rearrange science within a process of design, and indeed this is a core aim of the upstream as detailed by Demos, "to expose to scrutiny the assumptions, values and visions that drive science" (Wilsdon \& Willis, 2004).

While there appears to be accordance around the commitment of these designers to speculative design and upstream engagement, there is less agreement about what the work itself does when it is exhibited. For example, the IMPACT! exhibition at the Royal College of Art in March 2010 includes work by many of the designers mentioned above. The exhibition is the outcome of a programme of partnerships between "conceptual design and science", which linked designers with engineers and scientists whose research is funded by the EPSRC (EPSRC, 2010, p. 5). While individual design practices might identify with upstream 
engagement, the programme is presented quite differently. David Burrett Reid, head of marketing and communications at the Engineering and Physical Science Research Council (EPSRC), writes in an introduction to the exhibition catalogue:

The impact of the work we fund is often hidden or difficult to explain. And yet it is vital to engage the public and help create a society which is aware, involved and excited about research, and supportive of government investment in the science base. (p. 8)

Reid is not an advocate of the progressive ambitions of upstream engagement. Here he espouses a form of public engagement, which emphasises the value of science education. Indeed this is the core function of IMPACT! WORLD, an EPSRC programme of which the IMPACT! exhibition is an element. The role of the programme is for the EPSRC to "demonstrate the impact" of its "world-leading research" (Wagstaffe, 2009, p. 6). To support the exhibition, an EPSRC blog offers photographs of the opening event, including portraits of scientists pictured next to the designs, and group photos with key figures from the EPSRC and science policy institutions. In this way the exhibition, and the 16 projects that comprise it, are mobilised by the EPSRC to communicate and to promote the research of the scientists it funds. These ambitions for the exhibition have no equivalence with the designers' ambitions for their work to bring about a deliberative engagement with unsettled technologies.
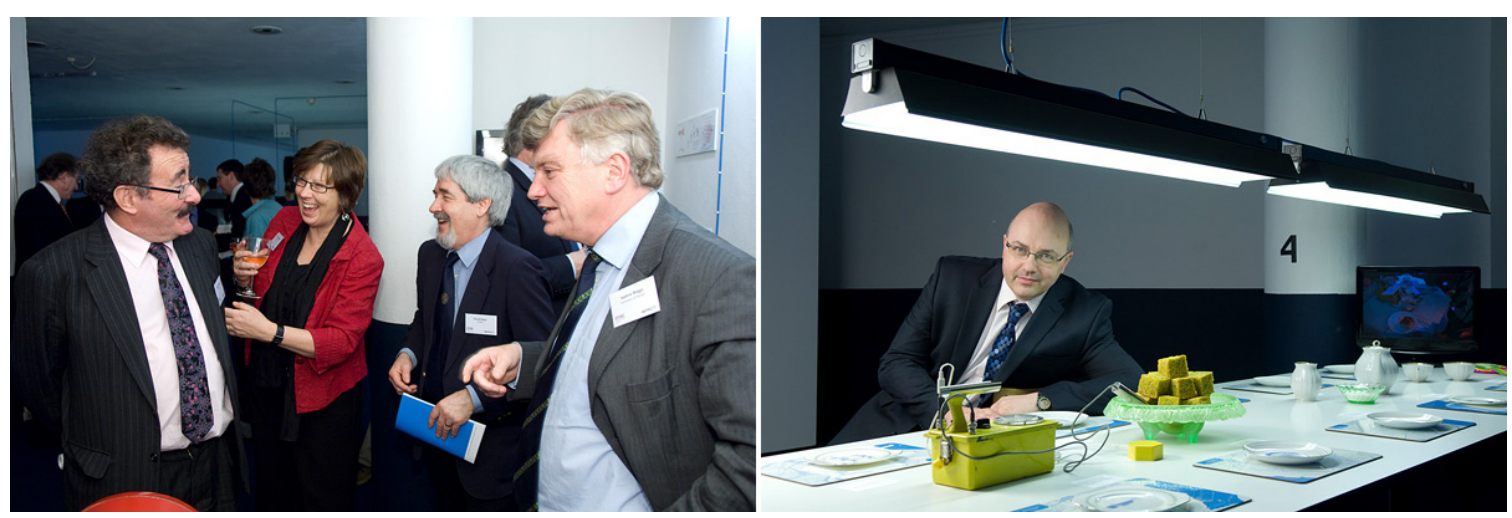

Figure 11: Prof Lord Robert Winston, Imperial College, Lesley Thompson, EPSRC, Prof David Delpy, EPSRC and Andrew Briggs, University of Oxford (left), and Prof Francis Livens, University of Manchester, with Nuclear Dialogues, a collaboration with Zoe Papadopoulou

To articulate the issues with the case above more strongly, I argue that rather than providing debate, due to an under articulation of practice, critical and speculative design in fact supports the forms of power in technoscience that it would seek to examine. Speculative design has been discussed as providing a hegemonic impulse, providing succour for a network of institutions it works alongside. Drawing on the topic of her PhD studies, Luiza Prado's polemic on "the blind privilege that 
permeates most Speculative Design projects" establishes the possibility of a nonnormative form of speculative design, she continues:

I do believe that design is a powerful language, one that it is perfectly positioned to provide relevant social and cultural critique, and that envisioning near future scenarios might just help us reflect on the paths we want to take as a society. In order to truly achieve these goals, however, SCD needs to be held accountable for its political and social positions; it urgently needs to escape its narrow northern european middle class confines; it needs to talk about social change; it needs more diversity, both in its visual representations and in the practitioners in the field. (Prado, 2014)

For Prado the key issue is the accountability of the practice. In the case of speculative design and public engagement, there is certainly a requirement for reflectivity. Divergences between the designer's account of practice and the work that their designs then accomplish in exhibition settings are common to the exhibitions of Biojewellery, and the workshops of Hybrids, and other forms of speculative design and upstream engagement. There is very little literature that discusses speculative design as a form of public engagement, and a key task for the thesis is to bring about an analysis of what takes place in these settings. I believe it is a problem that present design discourse does not provide a rigorous account of what is accomplished, because while there are undoubtedly problems with these forms of practice that are not being articulated, there is also an underdeveloped sense of the value of speculative design in delivering formats where technology, people and issues are brought together in experimental ways.

\section{Considering speculative design as research}

\section{Introducing relevant research}

I have discussed the coming together of speculative design and public engagement, and suggested that by offering an analysis of what is accomplished through this association, I hope to contribute to scholarly discussion regarding what is valuable and problematic about such an approach. Currently though, it is not clear how to go about such an analysis. This is due to the lack of clarity about how design research might grapple with public engagement, compounded by an underarticulation of speculative practice as research. Speculative Design regards exhibitions as the hub of a network for distributing designs, and so designers have focused on doing exhibitions and getting their work into catalogues, rather than providing an analysis of what it is that these exhibitions do. As such there is an opportunity to bring to the thesis a set of literature that resources a translation of publicity into analysis.

In the following second half of this chapter I establish some links between speculative design and a relevant set of literature. I discuss two practice based PhD 
theses that have critical design as a focus. I then discuss how notions of criticality and the politics of technology play out in the broader context of design research. I then take a historical perspective on participation as a form of public engagement in design research, and finally I link activism and Alternative Technology to speculative approaches. In doing so I hope to assemble a framework for discussing speculative design as a form of research through design.

\section{Critical design in relation to research}

I have suggested that speculative forms of design develop a notion of criticality initially established in Dunne's Ph.D. thesis. Drawing substantially on Critical Theory, designers and curators have mapped ideological accounts of society onto designs. For example a helmet with an embedded display is a depiction of consumer passivity in a mediatised space (Debatty, 2007). Theory is deployed here to elaborate the designer's intention for the design or to establish the curator's criteria for the selection of designs for an exhibition, rather than develop a reflexive account of what the design entails. Reflexivity would provide an opportunity to follow the processes through which the design is put together, the situations in which the design is encountered, the people who encounter the design and what they do with it.

While there are some earlier analytical accounts of critical and speculative design, including Natalie Jeremijenko's writing on voice chips (2004), and a paper on the Iso-Phone (Auger et al., 2003), there is an emerging literature around critical modes of design within the design research community. Here critical approaches are treated as a form of research, where empirical data leads to a discussion of practice-based methodology. This has occurred comprehensively in two completed theses, firstly in Ramia Mazé's account of critical design as a ideational tool for interaction design research (2007), and in Simon Bowen's description of a methodology for deploying critical artefacts in innovation workshops (2009). Other academic accounts of critical practice include an account of critical making by Matt Ratto (2009), and a PhD offering a taxonomy of critical design by Matthew Malpass (2009). More recent developments include a discussion of events in practice based design research to conceptualise the integration of critical approaches with co-design (Lenskjold \& Jönsson, 2013), an analysis of the formal approaches adopted in a design for debate project (Mollon \& Gentes, 2014) and a feminist discussion of normativity in speculative and critical design (Prado de 0. Martins, 2014). I discuss Mazé and Bowen's theses, as these were the more substantial pieces of published writing when I embarked on this chapter. I summarise their literature reviews, before taking a closer look at differences in their versions of critical practice, then consider in what ways these reflexive accounts of practice might deepen my own discussion of speculative design.

Mazé and Bowen provide distinctive literature reviews to provide accounts of critical design for their respective methodological positions. Bowen's route 
includes a detailed investigation of Critical Theory as it is associated with the Frankfurt School (Geuss, 1981; Calhoun, 1995; Crotty, 1998; Dant, 2003) This leads to a fairly combative assessment of critical design as elitist, largely through a reading of Geuss, which characterises critical theory, and so critical design, as taking "an intellectually and morally or superior position" through tasking itself with the "enlightenment and emancipation" of oppressed subjects (Bowen, 2009, p. 121). For Bowen, these notions of criticality are also supported by educational literature on critical thinking (Facione, 1990), as a desirable "style of reasoning" for students to learn (Bowen, 2009, p. 112), and also through a discussion of critical pedagogy, which is represented as a politically motivated style of learning and teaching where students "become aware of the nature of their oppression" (ibid., p. 115). I believe that Bowen's assessments overstate both the relevance of Critical Theory for critical design going forward, and its ambition to deliver a political agenda, while underplaying the aesthetic and practical concerns of its practitioners. However, the absence of clear statements from those practitioners clearly leaves critical design exposed to such an analysis.

Mazé also includes an account of Critical Theory, but situates it in a broader discussion of social theory as it relates to design practices, particularly "how to relate to theory in architecture" (2007, p. 214). Mazé elaborates her account of theory within practice with a discussion of the conceptual design of Droog Design (Ramakers, 2002) and Kristina Niedderer's performative objects (2007). In both of these cases the function of a product is transformed through sometimes violent modifications to its form, either by the user or the designer. For Mazé, to practice critical design is to materialise social critique, and these critiques are often based in accounts of future society. These visions become the basis for "subversion, diversification or even celebration" (Mazé, 2007, p. 223).

Each author outlines a practice based research methodology, using the terms critical practice (Mazé, 2007, pp. 208-232) and critical design practice (Bowen, 2009, pp. 84-125). To provide a model of critical practice Mazé sketches three design prototypes linked to a research programme called Static! (pp. 233-254). This involves a discussion of the project work in order "to loosely frame some reflections" (p. 247), which provides a theorized evaluation of the prototypes. For example the Energy Curtain uses embedded solar cells to generate energy when it is drawn, providing a dilemma for the user as to whether to let daylight in or save energy, in order to "stimulate reflection on the costs and effects of consumption"(p. 235). This user is established through studio photography, rather than drawn out of empirical data from a prototype deployment. In contrast Bowen instrumentally deploys critical artefacts within workshops in order to bring about the "development of innovative, human-centred product ideas" (p. 160). Bowen describes a critical artefact called the Ripple Rug, an "ornamental rug with pressure sensors embedded within it to send signals to a picture in another 
location". The design is introduced during a workshop activity to initiate a discussion between designers and users. This discussion informs the designer of various proposals that are "more relevant to stakeholder needs as we understood them" (pp. 132-134). Mazé's version of critical practice sees the prototype as part of a platform that has much in common with the critical design exhibitions, though she treats such events reflexively and admits more variety in terms of where the work goes, for example the Energy Curtain was exhibited at Wired Magazine's NextFest and the Swedish National Energy Convention (p. 252). In contrast Bowen's critical design practice is part of a structured and iterative design process. Here, an analysis of empirical material is used "to broaden designer's and stakeholder's view of possibilities", leading into what Bowen describes as a more relevant design proposal in terms of providing a solution to a particular design problem (p. 211).

Mazé and Bowen have provided two very different accounts of critical design that align with and support distinct methodologies for critical practice. In this respect these authors have evaluated practitioner approaches in order to inform methods for design research, and put their versions of critical practice to work within a research community. In Bowen's case design criticality is initially a reified and patronising exercise that is then put to constructive work solving real design problems as a form of participatory design. Meanwhile Mazé expands an initial focus on product design with histories of radical architecture, and shows how design artefacts can go into a wider range of settings to act as prompts of discussion between designers and users. Both their approaches develop critical practice as a form of research through design, and in this respect they demonstrate how speculative design might be treated empirically to bring about a deeper account of what goes on there. However, in both their approaches a reflexive analysis of practice does not extend to sceptical treatment of the settings where the practice takes places, and so both authors adapt criticality and speculation as part of a normative design practice. In this respect, while Bowen's empiricism and Mazé's attention to events other than exhibitions offer some traction on my own topic, the authors deploy criticality as a discussion about technology in order to solve specific design problems.

\section{Applying critical practice}

I turn now to Mazé and Johan Redström’s Switch! (2008), and Carl DiSalvo's speculative exhibitions and workshops (2009) to develop a discussion of applied criticality. Mazé and Redström present Switch! as a programme of six practicebased design-research projects where "critical and ecological thinking could be applied to energy issues" (2008, p. 60). The authors continue:

We believe that design research offers the possibility to act as a sort of curation in the development of a mature debate about environmental issues by materializing diverse - and perhaps even conflicting - values in forms and 
formats that people can relate to and participate in. (Mazé \& Redström, 2008, p. 66)

This strategy is evident in Energy Futures, a performance and workshop event where an invited group "speculates on forms of energy consumption in the future", following the introduction of design prototypes and scenarios into this setting. For example, as a member of the project team, Thomas Thwaites designed Socket Bombs as the weapon of an imaginary energy activist group:

The concept of Energy Security is as much an issue as global warming in some political discourses around energy. This implies that energy use could become a highly charged political issue. The politicisation of energy fed in to our 'creation' of the Socket Bombers, imagined as an activist group of the near future. With this scenario we wanted to draw attention to the physical interconnectedness of the electrical distribution network, and our strangely unguarded access to it in many public buildings. (Thwaites, 2008)

The Socket Bombers plug an electrically disruptive device into mains sockets, "purposefully causing a short circuit in a buildings' electrical mains". This scenario is seen to initiate a discussion around energy practices, where the narrative features of the proposal provide a prompt for debate. In their paper Mazé and Redström provide descriptive overviews of six case studies, largely comprised of statements regarding the terms of the debate embodied in their proposals. However, there is no analysis of the discussions had amongst attendees of the events where the design proposals are introduced. While an empirical account of the nature of the debate might not be a core concern for the authors - their paper is primarily an account of the methods through which the designs of critical practice can be introduced to public settings - there is an opportunity for such an approach. In this respect the empirical chapters of this thesis will reflect upon the effects of speculative designs in public settings, above and beyond the intention of the designer.

In common with Mazé and Redström discussion of energy practices, Carl DiSalvo makes a case for emergence of issues during public encounters with speculative representations of technology. Additionally, DiSalvo makes an argument that publics come together through the process of eliciting issues, and so he asks, does speculative design form publics? He includes the work of Dunne and Raby and Preemptive Media as case studies, and he identifies "projection" and "tracing" as characteristic of their respective approaches. Projections are described as prototypes or scenarios that embody potential technological outcomes, and here DiSalvo makes use of Dunne and Raby's Poo Lunchbox, a scenario that anticipates a future where human waste is treated in the home as an alternative source of energy. Meanwhile, tracing refers to design processes that "creatively express the histories, discourses, and techniques that constitute an issue", and Preemptive 
Media's Zapped project provides a case where RFID technology is subject to such an approach. While DiSalvo tentatively marks out some ground for the evaluation of these approaches ${ }^{3}$, it is the generative features of these approaches that interest him:

Problem definition, as commonly conceived, implies the identification of a matter that can and should be addressed by design. However, within the context of the construction of publics, the role of design may stop at the discovery and articulation of the issue... It is sufficient and complete for the projections simply to be proffered. (2009, p. 60)

Design becomes a resource for "motivating and enabling political action", where the identification of issues and controversies around technologies, and the concurrent formation of publics in and around those issues become a primary goal, rather than deploying design as a problem solving process. DiSalvo explicitly invites more work here, where "integrating and collaborating with other fields would broaden and bolster the enquiry" of design. So, like Mazé and Redström, DiSalvo does not develop an empirical discussion of the effects of these practices in public settings, he anticipates and invites such a discussion. There is an opportunity for the empirical sections of this thesis to extend the account of speculation so as to include something more than the designer's intended topics. One way to support this is to move away from forms of evaluation that might be incumbent on speculation through its adoption of public engagement. Not having to evaluate Material Beliefs as a case of effective upstream engagement would allow a more experimental account of what takes place. And so the review of engagement in chapter 3 will look to STS to provide alternative conceptualisations of debate, and offer something in line with DiSalvo's call for collaboration with other fields.

\section{The politics of technology in design research}

Through their respective discussions of critical practice and speculative design, Mazé and Disalvo suggest that design activity acts as a resource for political action. The review of critical design practice revealed a focus on the designer, who saw their exhibitions and catalogues as material manifestos for their critiques of technology. In the following section I look to expand the conceptualisation of politics by designers, and to do this I initially draw on Design Studies literature. The term Design Studies is used by a number of design researchers including Disalvo (DiSalvo, 2009) and Bayazit (Bayazit, 2004), and is discussed at length by Fallman who summaries that activity of those design researchers as "contributing

\footnotetext{
${ }^{3}$ For example, where DiSalvo suggests that asking oneself "if the form of expression was appropriate for the audience" might be the basis for assessing success, he loses enthusiasm, and moves onto the suggestion that STS in particular might be "well-equipped theoretically and methodologically" to discuss what is being done in such settings (DiSalvo, 2009)
} 
to ongoing discussions about design theory, design methodology, design history, and design philosophy" (Fallman, 2008).

In his reflexive treatise of the design profession, Norman Potter asks "Should a designer be a conformist, or an agent of change?" (2002, p. 14 [1969]). In tackling this initial question about the social responsibilities of design, Potter explores a range if issues including the motive of professionalism, the value of self-expression and the relationship of design with other industries. Here is a model of political identity that is pervasive within Design Studies. For example Victor and Sylvia Margolin outline a social model for design studies where they ask what a socially responsible designer might be doing when they are not focused on producing "dazzling lamps, furniture and automobiles" (Margolin \& Margolin, 2002, p. 28). They suggest that designers can instead look more carefully at the situations where such products are used, and identify and, contribute to solving, problems of social need, including poverty, age, health or disability (ibid., p. 25). Meanwhile Whitely looks for alternatives to what he describes as market-led design, offering sustainable, socially responsible and feminist approaches that drive more enlightened forms of practice (Whiteley, 1993, p. 167). Elsewhere Fuad-Luke has proposed and mapped a range of practices and philosophies under the rubric of design activism, where "Design activists can contribute to dialogic discourse about new social goals" (Fuad-Luke, 2009, p. 196). In these accounts the politics of design are deeply related to a model that sees society as determined by the technological choices that are made, and where it is the responsibility of the designer to consider how their role can contribute to choice making.

In order to examine the mixing of speculation and engagement, I believe it would be constructive to articulate a less direct relationship between design and society, and take into account forms of agency other than that of the designer. In the subsequent chapter on public engagement I will discuss other ways of considering the relationship between people, technology and society, drawing on literature from Science and Technology Studies. However, at this moment a model where technology determines the social, and where the designer's political agency is emphasised, warrants further discussion. This is not only because it underwrites so much Design Studies discourse; I believe that a deterministic model of technology and society is foundational to critical and speculative forms of design.

The positions of Margolin, Whitley Faud-Luke and also Potter outlined above are revisions of political forms of accountability that have their origins in the design methods movement. From the early 1960s design research sought to establish a methodological account of practice that reconciled the sensibility of the designer with a positivist framework for understanding the design process (Cross, 2001; Bayazit, 2004; Krippendorff, 2006; Cross, 2007). While Cross traces initial ambitions to scientise design to the modernism of van Doesberg and Le Corbusier 
(Cross, 2001, p. 49), it is through the writing of Archer (1963), Alexander (1964) and Jones (1970) that a positivist project for design finds momentum. This first wave of design methods additionally incorporates concepts of usability, engineering and build quality focusing on the user (Dreyfuss, 1955; Alexander, 1964), with a focus on Herbert Simon's science of design, so that design is seen in relation to a system that incudes user requirements and goal identification (Simon, 1969). This first wave of design methods is then challenged by its proponents (Broadbent, 1984). When Alexander suggests in an interview about design methods that we "forget it, forget the whole thing", his objections are about the absence of practising designers within a field he characterises as promoting method for method's sake (1971). Elsewhere, Jones objects when the rationality of design methods become applied to inappropriate contexts such as urban planning, arguing that "as you take more and more of life to be part of the problem you don't get a more stable problem you get a less stable problem" (1977, p. 332). A key figure in design studies, Nigel Cross summaries this period:

Where the first generation of design methods was based on the application of systematic, rational, 'scientific' methods, the second generation moved away from attempts to optimise and from the omnipotence of the designer (especially for 'wicked problems'), towards recognition of satisfactory or appropriate solutions (Herbert Simon had even introduced the notion of 'satisficing') and an 'argumentative', participatory process in which designers are partners with the problem 'owners' (clients, customers, users, the community). (Cross, 2007, p. 4)

Cross provides some historical context for this participatory turn in design methods, noting the "campus revolutions, the new liberal humanism and rejection of previous values" of the late 1960s (2007, p. 4). Broadbent expands upon this scene, suggesting that advocates of first wave methods then found themselves in a situation where "their ingenuity ensured a constant increase in the efficiency of factory production". He then goes on to sketch the impact of this on the sensibility of the designer:

They refuse to be a party to any activity which inhibits the potential of other people to grow into what they conceive themselves to be. So increasingly we find designers who do not want to make design decisions, who believe, at most, that their task is to encourage other people to determine what they themselves want. That explains much current interest in citizen-participation.

I argue that industrial and architectural design's turn from rationality to participation from the late 1960s offers a lens through which to consider the ways in which critical and speculative design currently marks its own difference from "affirmative" and "commercial" design. In this way, literature from the adoption of participatory commitments in design research during late 1960s to the early 1980s, provides an opportunity to reconsider contemporary predications for 
debate and public engagement, a mode of design which I have argued is not articulated as research, and as such would benefit from acknowledging and revisiting these progenitors. Additionally there is vitality in the commitments of this previous generation of practitioners to push design as a medium for discussion and activism into a broad platform of public formats that has much to contribute to a consideration of speculative design's emphasis on exhibitions and workshops.

\section{Design participation literature from two archives}

To discuss this participatory turn in design research, I draw on conference proceedings and academic archives from a fifteen-year period from 1969 to 1984. The conferences include Design Participation (Cross, 1971), Design for Need (Bicknell \& McQuiston, 1977) and Design Policy (Langdon \& Cross, 1984). Additionally the Open University's Man-Made Futures course and the Royal College of Art's Department of design research, acted as hubs for research, pedagogy and related activity during this period. Members of staff including Nigel Cross from Man-Made Futures (MMF) and Bruce Archer from the Department of Design Research (DDR) were key figures not only in terms of their contributions to syllabi, but also as prominent academics, conference organisers and members of various design policy groups. Archives from MMF at the Open University (OU) Library in Milton Keynes include course material at various stages of revision along with BBC OU television and radio broadcasts, while a vast archive of DDR material including a full set of departmental minutes, design research and commercial design work folders, syllabus and audio recordings of visiting lecturers are held at the Victoria and Albert's Art and Design Archive at Blyth House in London.

Here I am dealing with a specific set of literature that offers a version of design participation rooted in UK academic programmes. My ambition is to find precursory methods and approaches that support the development of the limited notions of engagement and debate around emerging technologies currently provided by practitioner accounts of speculative and critical approaches (Seago \& Dunne, 1999). This literature frequently deals with participation as a platform for the public discussion and re-imagination of alternative technologies, rather than seeing participation as enabling designs that support specific and immediate requirements of use. The literature discussed below has been described as complimentary to Scandinavian collective resources approaches (Asaro, 2000). Forms of participatory design relating to workplace settings, where workers took responsibility for the design of new technologies (Ehn, 1988) were certainly adopted via the unionism and activism of alternative technology discourses of in the UK (A. Smith, 2005). However, as described above, I am prospecting for material that is local to the development of critical and speculative approaches in UK academia. Furthermore, while the relationship between Scandinavian participatory design and speculative and critical design approaches is usefully 
discussed elsewhere (Jönsson, 2014), the material introduced below offers something of an opportunity, providing a scale and heterogeneity not well accounted for, nor captured in historical accounts of design research and histories of education 4 . I provide two views into the material to provide firstly an impression of its breadth and vitality and secondly to emphasis a particular strand of design participation in relation to the Alternative Technology movement.

\section{An overview of the material}

A turn to participation in Design Studies was enabled by taking on a wide range of methods and approaches from outside of the disciplines of design. Bayazit for example sees that a participatory agenda "obliged design professionals to collaborate with social scientists as well as anthropologists" (2004, p. 22). Elsewhere Broadbent sees a flight from forms of disciplinary expertise that the designer would "bring to bear in overriding the wishes of those he is supposed to be designing for" (Broadbent, 1984). Nigel Cross expands on this issue in his preface to proceedings the Design Participation conference:

There is mounting pressure for wider sections of society to participate in the processes of planning and design. This pressure ranges from protest groups fighting undesirable side effects of technological development, through calls from Government committees for citizen participation in planning, to proposals from designers themselves for adaptable environments that the users may modify directly... The end result of the changes underway and reported at the conference may well blur the current distinctions between 'designer' and 'user': designing may not always continue to be the exclusive prerogative of the professionals (Cross, 1971, p. 62)

Broadbent and Cross emphasise the need for a move away from disciplinary expertise. Nonetheless, contributors to the Design Participation conference include academics from the fields of architecture, urban planning, computer science, industrial design, a political science, architectural engineering, mechanical engineering and fine art. So while Cross would rhetorically encourage the participatory association of designer and user, or the professions and the laity, it's business as usual in terms of the professional identity of the delegation. This leads Reyner Banham to open his contribution by noting "one wonders whether we have not got the same old Design Conference, but with the new wonder ingredient 'participation'" (Banham, 1971). It is possible to see this group as a coterie of exclusively male academics, reflecting upon a crisis of professionalism within their

\footnotetext{
${ }^{4}$ McIntyre's account of the department under Bruce Archer's leadership for example provides a standard text on the dissolution of the department under Archer's personality (McIntyre, 1996), that does not do justice to the breath of activity in and around a department which at one stage comprised over 30 staff.
} 
respective disciplines. Nonetheless, the conference seems to be something of a challenge to the deeply conservative culture of the institutions of design prior to this period.

Turning to the proceedings, there is a range of approaches for design to take into account the public. Jeff Nutall sees the failure of modernism in the imposition of the designer's individual vision, which gives rise to hygiene, sterility and uniformity. For Nutall the design of buildings and products should respond to the improvised and emergent nature of behaviour:

...We are going to have to join the people in a in a situation of mutual improvisation. We should look at what people currently make for themselves the Facteur Cheval's Garden, the Shanty Towns, the allotment sheds, the drop cities, the strange encampments that spring up at pop festivals - and we should sympathetically read and conjoin the aesthetic of these maquettes. Having done that we should redefine ourselves as technical advisers, providing a vast and subtle range of methods, so that under the instructions of the prospective use, houses and goods re-inforce and amplify the idiosyncrasies and fantasies of that individual.

There is a line that links the accumulation of "incalculably varied behaviour" in Nutall's designed artefacts to current design interests in everyday material improvisations ${ }^{5}$. However, these user improvisations might be dealt with more carefully, whereas the tendency of Nutall's aesthetics is to flatten the social. Here slums and festivals are aligned, and reduced to maquettes that celebrate psychic idiosyncrasy. In this way they no longer refer to their own conditions but become fixed in a schema of the kind the author rails against.
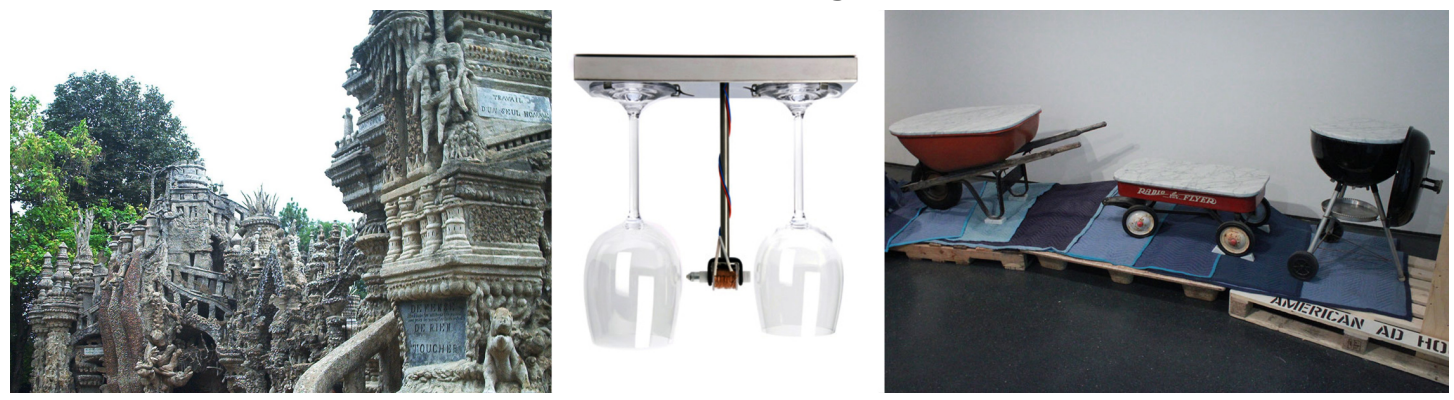

Figure 12: Facteur Cheval's Garden, van der Dagts “bottoms up", Parsons and Charlesworth's Adhocism installation.

\footnotetext{
${ }^{5}$ For a current example of this theme see Tim Parsons' and Jessica Charlesworth's Adhocism installation at the Museum of Contemporary Art in Chicago. In a pamphlet published alongside the exhibition, Parsons and Charlesworth offer a brief history of adhocism in product design including Droog's designer Peter van der Jagt's "doorbell built from two upturned wine glasses with an electrically operated hammer that rings them as if being clashed in a toast" (Parsons \& Charlesworth, 2011).
} 
Brian Smith's polemic on Conceptual Design was delivered as a part of the Design for Need conference at the RCA in 1976. Like others before him, and most notably Thomas Markus at Design Participation (Markus, 1971), Smith suggests there are degrees of commitment to participation, here he outlines reformist versus revolutionary design:

The former, typically from a middle-class leftish background, try to make the design process transparent to the public gaze, and to provide ranges of alternative solutions so that compromises may be effected. But the revolutionary rejects both this and the conservative/patronage-oriented way, in favour of working for a real transfer of power. His clients are the end users and his work is often voluntary. He is not afraid of value judgements and he often rejects 'participation', not least for its potential for political manipulation. (B. R. Smith, 1977, p. 110)

Smith and previously Markus deploy the categories of conservative, reformist and revolutionary approaches in terms of participation and the distribution of power in design. Their typology echoes Emilo Ambasz's curatorial model in an exhibition at New York's Museum of Modern Art in 1972 (Ambasz, 1972). Ambasz describes the practitioners in the show as either conforming, reforming or contesting. Designers who contest, "conceive of objects and of their users as an ensemble of interrelated processes" which materialise arguments drawn out of the contemporary critical milieu (Ambasz, 1972, p. 21). Smith also makes the case for the designer as an activist, whose designs materialise arguments with an ambition to prompt reflection and action in others:

So Conceptual Designers will produce devices, tangible or not, that will bring other peoples' problems within our range... They will design procedures rather than designed objects per se, so that what people do with them is a product of their own experience, circumstances and needs. They should be rich in analogy, so we can generate our own procedures and hence the objects, events, systems, organisations and structures that we need. (B. R. Smith, 1977, p. 113)

Here the designer is cast as a facilitator, where their practice enables public deliberation. The approach is echoed in recent ambitions for design to stimulate discussion (Dunne \& Raby, 2001, p. 58) to stage a debate (Auger, et al., 2003), or project issues (DiSalvo, 2009), either within a community of product designers through pedagogy and academia, or within a broader public community through exhibition and publication.

Other contributors take a more political approach to participation. Of particular note is Mike Cooley's social constructionist account of science and technology. Cooley proposes that socially useful design "not merely exposes, criticises and challenges" industrial society, but "presents constructive alternatives" (Cooley, 
1984, p. 51). A key case study for Cooley's paper is the Lucas Plan, a proposal for socially useful products presented as an alternative to redundancy plans at Lucas Aerospace. The drawing up of an alternative corporate plan included 150 socially useful products and initiated a debate amongst unionised staff, which Cooley reflects on:

What was perhaps most significant about this product range was that it opened a debate about ways of using new technology which would enhance human intelligence rather than diminish it. (Cooley, 1984, p. 53)

This debate was discursively staged, establishing relationships with international trade unions groups and disseminated through "literally hundreds of articles, television and radio programmes" as well as being the subject of two plays and an opera (Wainwright \& Elliott, 1982, p. 140). Cooley's paper is illustrative of the vitality of design research around this time, and provides some vivid material concerning the engagement of the public over the politics of technology that encourage a fresh look at the methods and ambitions of speculative design and upstream engagement.

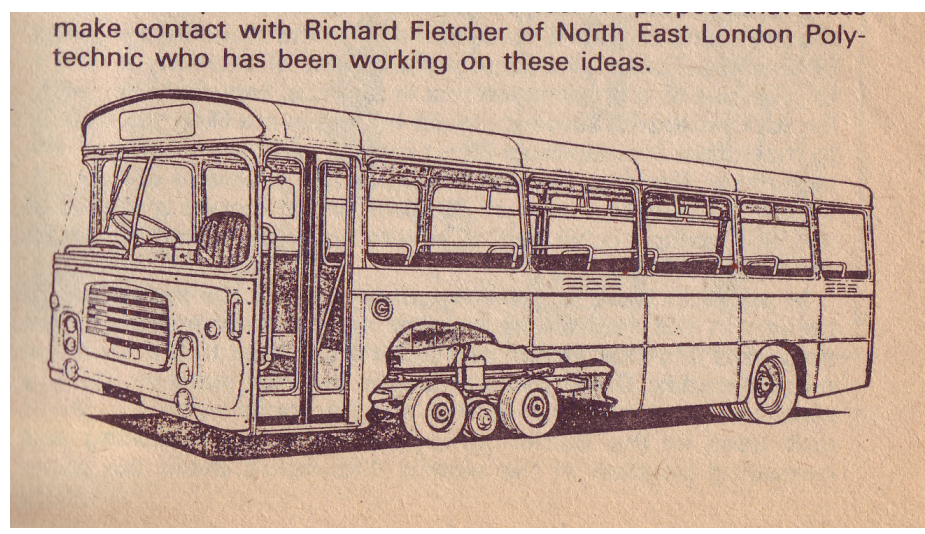

Figure 13: Rail-Road vehicle proposal from the Lucas Plan

While Cooley was a trade unionist activist, Robert Jungk worked in the field of technological forecasting. For Jungk the economic recession of the early 1970s is an opportunity for participation, where those out of work or on short time can use their "idle time" to attend workshops and prognosticate about "doing it better next time". Jungk continues:

People with a lack of knowledge may be able to look at things in a more original, more creative way... What one has to do, is establish an atmosphere of confidence and trust in which you can honestly say to people, "your ideas may be better than mine"... If people get used to contributing ideas to society, then this would make the decision process richer and more varied, it would be possible to draw from a larger pool of possible conceptions. (J. C. Jones \& Jungk, 1971) 
Despite his paternalism, Jungk has something to say about public participation in the field of technological forecasting. Drawing on Calder's discussion of science and democracy (Calder, 1970) Jungk discusses a set of methods for "opening up a sphere which was up to now the exclusive domain of the scientific and technical expert" (Jungk, 1969). The endeavour to introduce lay opinions into technical settings is discussed in more detail in the following chapter as a feature of upstream engagement. However it is appropriate to consider this approach in relation to participatory design.

Jungk's methods are discussed at some length by Robin Roy in his typology of public participation formats (Roy, 1971). In Jungk's "future creating-workshops" Roy sees an approach that allows the public to have a role alongside professionals in imagining the impact of, and making decisions about technologies that have yet to be developed or implemented, in contrast to a public survey which he sees as capturing attitudes towards existing technologies. Roy turns to Junk's more ambitious goal for a broad platform for public participation in technology choice:

Realisation of this goal of a continuous dialogue between laymen and experts implies that adults and children be informed about "scientific, artistic and philosophical work in process, anticipated crises and possible future answers to these challenges", through the mass media and the education system... just as important would be the training of thousands of interpreters to act as gobetweens when experts, laymen and politicians meet. (Roy, 1971)

It may seem here that Roy unknowingly anticipates in Jungk's platform the reach and ubiquity of current public engagement formats. In his outlook we might recognise the lobbying of journalists by institutions like the Science Media Centre, a curriculum focus on STEM subjects and the outreach of science museums, not to mention the thousands of professionals facilitating processes of public engagement ${ }^{6}$. For Roy, the value of Jungk's platform is the opportunity it affords designers and planners in democratising decision making regarding "new products and systems".

\section{Activism and Alternative Technology}

Alongside these varied participatory strategies for the democratisation of technology through engagement, design adopted a politics of independent action focused on the "radical technology-practice" of the Alternative Technology movement (Willoughby, 1990, p. 183). Those associated with Alternative Technology (AT) believed that technology, and control of the production of technology in particular, provided a key context for political struggle and social

\footnotetext{
${ }^{6} \mathrm{PSCI}-\mathrm{COM}$ is an online mailing list "for discussion of any matter relating to public communication of science and public engagement with science", which provides some indication of the breadth and scale of those involved in this area. It has around 1800 mainly UK subscribers, more at http://www.jiscmail.ac.uk/lists/psci-com.html.
} 
change (Elliott, 1984). In this respect AT has been described as a movement in search of a route to access and influence technological decision making:

Significantly, the university research system offered a relatively open point of access for the development and propagation of AT ideas. Architectural schools, for example, allowed students and faculty to experiment with (and even live in) radical autonomous housing. University courses incorporated AT ideas into their teaching materials, e.g. the Man-made Futures course at the Open University's Technology Faculty introduced AT to over 900 technology and design students each year. (A. Smith, 2005)

In the following section I discuss the ways in which this Open University course as configured AT commitments as a pedagogical programme. I then draw a parallel with earlier descriptions of critical design, which I argued offered a disciplinary critique for product and interaction design that emphasised the role of design for debate.

The course Man-Made Futures: Design and Technology (MMF) was produced by Nigel Cross, Robin Roy and Dave Elliot and launched in 1975. MMF comprised four core modules including Technology and Society, and Policy and Participation, along with workbooks introducing Shelter, Food and Work as contexts for design, and a design methods handbook. Additionally eleven television and eight radio programmes were broadcast by the BBC, with topics including The Future of Alternative Technology, and the Biotechnic Community. Set textbooks were a reader edited by Cross, Eliott and Roy (1974), along with David Dickson's Alternative Technology and the Politics of Technical Change (1974). The preface to student course materials begins:

Somehow, and from somewhere, new machines, new techniques, new products - in short new technologies - like new courses at the Open University, emerge into society and influence our lives. By putting some of the skills of design in your hands, and some knowledge of the role of design as part of the technologysociety relationship in your mind, we, the course team, hope that you may better understand and better contribute to both the emergence and influence of new technologies. 


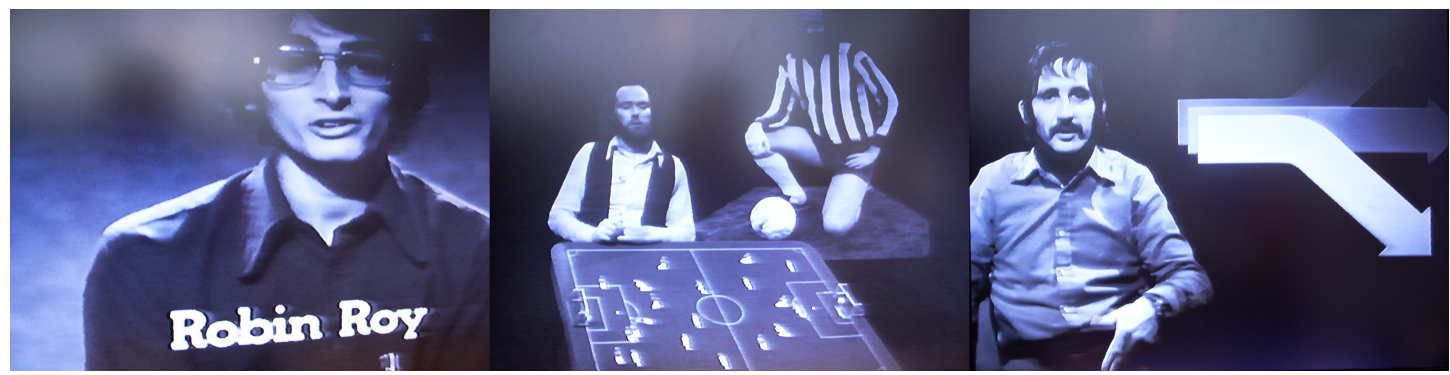

Figure 14: Robin Roy introduces Ways of Seeing the future, Nigel Cross deploys football as a metaphor in Design Strategies and Dave Eliott on The Future of Alternative Technology, three programmes broadcast on $\mathrm{BBC} 2$.

Learning material comprised of output from political theorists, philosophers, environmental activists, scientists, designers and social scientists, many of whom were then featured or interviewed in, or co-hosted the broadcast programmes. While MMF brought these materials to a student base, the course established itself as one of many platforms that were building AT activism, as described by Smith:

The AT movement developed its ideas through manifestos, illustrations, books, exhibitions, festivals, magazines (most notably, 'Undercurrents'), conferences, university courses, plans, campaigns, and projects. (A. Smith, 2005)

To formulate a design approach responsive to the AT agenda, MMF emphasised the practical and material outcomes of independent technology practices. Faculty drew substantially on Murray Bookchin's theme of Liberatory Technology (Bookchin, 1974), Ivan Illich's discussion of Convivial Technology (Illich, 1975), and a broader concept of Soft Technology informed initially by a New Scientist article by Robin Clarke (Clarke, 1973) as the theoretical bases for these technology practices. Cross contextualises this material for the student reader:

I want now to go on to consider some more radical proposals for design activity that is essentially outside of the conventional mainstream of industrial technology. These more radical proposals inevitably include some discussion of post-industrial society as well as post-industrial technology. (Cross, 1975, p. 44)

Cross sees design as a practice for the materialisation of AT agendas. In this respect the methods and processes that comprise design are precisely those capacities that would realise Clarke's soft technologies. In this way MMF aligns with what Adrian Smith has described as an R\&D Lab for Utopia:

Activists tried to create communities of intent, in the sense that they sought social movement opportunities and alliances into which their AT projects could be incorporated and advanced. Activists in this second stream engaged in political lobbying, created community projects, worked with trades unions, set up small AT businesses, and became involved in education and research; all 
tactics that challenged technocratic forms of development and sought technologies open to greater social control. (A. Smith, 2004)
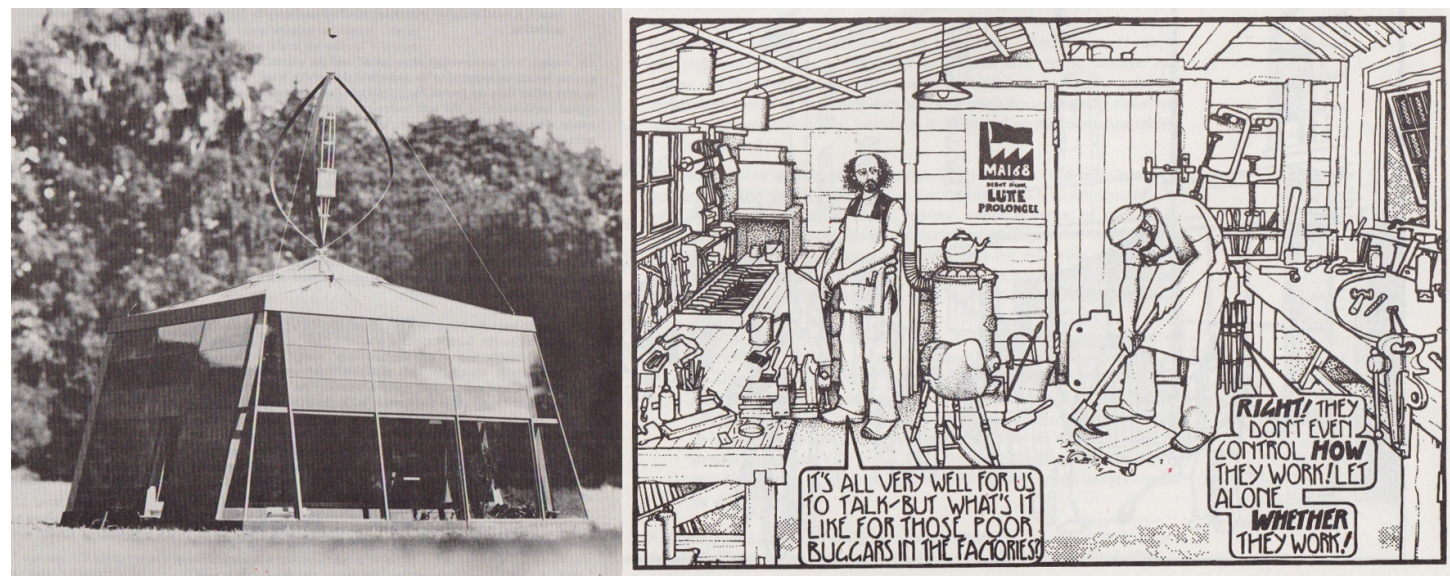

Figure 15: An "autonomous" house as an example of soft technology, illustration of a design workshop as a convivial setting.

These historical accounts of the AT movement demonstrate how ambitions for political intervention with emerging technology become configured as a programme of design pedagogy. I argue that there is a rich connection between the literature, ambition and strategy of this programme and the trajectory of critical design described earlier, from its origin as disciplinary critique, to its identification with the institutions and discourse of public engagement with science and technology, and on to the partnerships and programmes that are the topic of this thesis. In particular, this parallelism offers a rich literature with which to develop the ideological background of critical design, to compliment the reviews made by Ramia Mazé and Simon Bowen in their respective theses. However, the fullness of this historical account acts as a reminder that there is still work to be done in establishing a literature that provides traction on the contemporary scene of speculation and engagement.

\section{Summary}

This chapter opened with some reflection about the appropriation of an implantable biosensor in a design scenario that envisaged the forgery of healthy data. I questioned the value of this design scenario, which seemingly misused this research platform rather than contributing to its development and delivery. To make sense of this provocation I discussed a variety of practices and literature where design is driven by a desire to bring about a public discussion regarding the coming together of technology, issues and people. However, while I hope to have demonstrated the motivation for a speculative approach to design, I have also suggested some weaknesses in this practice and literature in relation to the project that I bring to the thesis. These problems are taken forward as core questions that 
will be addressed through a discussion of Material Beliefs. What are these questions?

In the first section of this chapter I traced a concern for debate in critical design to the entanglement of speculative forms of designs with upstream engagement. I started with a moment of crisis in product design, where a focus on poetic and non-functional electronic prototypes encouraged a move whereby academic forms of value were eschewed for a programme of public value. Here critical design was shown to be developed through a network of exhibitions and related publications, online and printed, which espoused a model of design for debate. Crucially, through the funding of design projects by scientific research councils and science institutions, debate then became reframed as public engagement with science and technology. While the coming together of design and engagement is made possible through some cooperative aims, there is a range of objectives being accomplished here, which deserve to be more rigorously unpacked. Who and what does a speculative approach to design bring together, where does speculative design go, and what is the nature of the encounters that it affects? A discussion of Material Beliefs will show that the divergent and sometimes conflicted aims of speculative designers, biomedical researchers and members of the public, along with the variable performance of the technologies being researched, and the demands of the institutions where engagement events are convened, will offer a rich palette for discussion that will challenge and extend the existing rhetoric of design for debate.

The second section provided a focus on participation and the politics of technology in design literature. These were largely historic accounts of an association between design studies and the politics of technological change. What is the value of this literature to the thesis? Firstly this material is not well represented in current design studies literature, and so to excavate it and consider it in relation to current practice restores a concern in design studies with politics, participation and engagement. Additionally, by locating an appropriate literature for an analysis of speculative design, there is opportunity for a meaningful repartition between practice and theory, and the gallery and the academy, a dispute that initially enabled a critical approach and then left it remote and unqualified, and vulnerable to accusations of elitism and opacity. Finally there is an opportunity to revaluate the theoretical underpinnings of design politics and participation, where determinism holds sway over the articulation of the relationship between technology and society. 


\section{CHAPTER 3: THE PRACTICE AND ANALYSIS OF PUBLIC ENGAGEMENT WITH SCIENCE AND TECHNOLOGY}

\section{Introduction}

I've now established why and how speculative design and upstream engagement became mixed. Where I discussed the basis for this mixing, I focused on the orientation of designers to the idea of public engagement, for example through statements from designers about developing public debates around emerging technology, along with designers' reflection on the upstream as a particular mode of engagement that was identified with. However, the phrase public engagement with science and technology has remained largely undeveloped. The aim of this present chapter is to establish a set of literature that deals with both the practice of public engagement and its treatment as research object.

This chapter is divided into two sections. In the first I provide some historical and cultural context for public engagement with science and technology (PEST), along with an overview of its modes and approaches. Here I start with the policy landscape in the UK as it relates to PEST, and move to an overview of different modes of public engagement as they have been developed over time. I follow with a description of engagement mechanisms, the aims and broader settings of these instruments and their modes of evaluation. In the second half of this chapter I introduce literature where PEST is an object of analysis. In particular I look for a critique of PEST from Science and Technology Studies (STS) in order to acquire some analytical and conceptual resources for the thesis. Here I focus on critical accounts of PEST and upstream engagement in particular. There is also a discussion of methodological innovations in STS that are outside of the scope of PEST literature but relevant to the development of empirical speculation as a form of design research.

\section{Organisations and practices of PEST}

Prior to starting PhD. studies, my initial ambivalence at dealing with a discussion of PEST in relation to design practice was partly due to its scale and complexity. What is it PEST, and where does it come from?

\section{Engagement/Understanding/Awareness, in/with/of, science/engineering/technology}

PEST is one label used to denote a set of practices, institutions and activities concerned with public engagement, and before I look at what those denotations are, it needs to be said that labels other than PEST are used, and that identification with those labels varies over time and across organisations. I'll start with the 
Engineering and Physical Sciences Research Council (EPSRC), who convened the workshop where the proposal for Materials Beliefs was conceived. The nature of the EPSRC's commitment to public engagement has changed over time. At Proposal time, alongside the specific sandpit activities that included the Engineering Ideas call, the EPSRC delivered the Partnerships for Public Engagement programme (PPE), which replaced Partnerships for Public Awareness (PPA), which in itself undated the Partnerships for Public Understanding (PPU) (Johnson, 2008, p. 7). The EPSRC is of course one of many organisations that identify with what I have been referring to as PEST. Organisations including the Department for Business Innovation and Skills and Sciencewise refer to science and not technology as the object of public engagement and previously public understanding, and so their reports refer to PES and previously PUS (Stilgoe \& Sykes, 2009, p. 9). Yet more detailed semantic differences exist to describe public engagement as being variously in, with or of Science (Turney, 2006; Stilgoe, 2007; EU, 2008).

Additionally the role of engagement is often a subset of activity within an overarching commitment to Science and Society (DIUS, 2008), or indeed Science in Society (Bhattachary, 2004) which seems to take in a broader set of activities that include lobbying and legislating along with engaging. This broadening of public engagement takes us back to the EPSRC, where in 2010 the PPE as a separate strand of programming ceded to public engagement as a common priority for research across all UK research councils, designated as The Research Councils UK Public Engagement with Research Strategy, or RCUK PER (RCUK, 2013c) ${ }^{7}$. It is PER that stands as the most recent and wide-ranging description of public engagement activity, a term legitimised by the Concordat for Public Engagement with Research that was developed by the RCUK and is currently supported by over fifty signatories, including government departments, museums, societies and charities (RCUK, 2013a). However I will continue to use the term PEST to indicate the full range of science and technology activities that identify with public engagement, in order to emphasise the historical moment when Material Beliefs was conceived and delivered. I use the term upstream engagement to refer to particular programmes of activity that identify with engagement practices that take place during the early stages of science and engineering research.

While PEST is clearly one of many labels, the practices that identify with that label are also diverse, and so PEST has been described as "a wide and ill-defined area" (Wynne, 1995) . Indeed it has been suggested that the activities that identify with PEST might be considered on a case-by-case basis, rather than taking the label as a meaningful indicator of what activity might consist of:

${ }^{7}$ RCUK PER is seen as one strand of the 'pathways to impact' that should inform the design of all research proposals seeking funding, and as such 'increasing public engagement with research and related societal issues' is a subset of activity where Impact is seen as an overall aim (RCUK, 2013b). 
Part of the challenge of understanding and analysing this field of public engagement is that there are so many different purposes being pursued by institutions (public, private or charitable) and individuals (scientists or other members of the public) in the course of their public engagement activities. These varied purposes may reinforce each other or conflict. In their turn, they depend on different institutional or individual priorities, motivations, and assumptions. (BIS, 2010, p. 6)

The Science for All report provides something of a benchmark for the breadth of institutions currently taking roles within this field, with those reviewed for the report grouped broadly into four sectors; industry, academia, public and cultural (BIS, 2010, pp. 30-31). Examples of institutions by sector here include Pfizer and the Association of British Health-Care Industries from the industrial sector, the Biotechnology and Biological Sciences Research Council and King's College London as examples of academia, the Technology Strategy Board and the Human Fertilisation and Embryology Authority as public sector institutions, and the Café Scientifique network along with the Natural History Museum from the cultural sector ${ }^{8}$. Before unpacking in more detail some accounts of what PEST is and what it does, there is perhaps some value in an overview of how this complex landscape came into being.

\section{Key contemporary phases}

The history of PEST is discussed in a range of literature where it is dealt with through a range of lenses including policy (RS, 1985) public opinion (Gregory \& Miller, 1998) and the inclusion of ethnic minorities (Dawson, 2012). In order to manage the scale of this literature so as to support the topic of this thesis, I restrict this review to the contemporary engagement scene, and follow a dominant model that discerns two phases of public engagement, and then focus on upstream engagement as a mode related to the second phase of engagement that has particular relevance. It goes without saying that this model is problematic, and its underlying assumptions have been challenged (Wynne, 2006). Furthermore, the literature and its concerns take a European and frequently a UK experience as a focus. However, this problematic and dominant model reflects the milieu that I drew upon to write the proposal for Material Beliefs was funded. In the second half of this chapter I turn to critical accounts of this model in order to expand upon its problems.

\section{The Public Understanding of Science}

The publication of The Public Understanding of Science by The Royal Society in 1985 (RS) is frequently put forward as a key contemporary moment when science institutions committed to reconsider their relationship with the public (Irwin \&

\footnotetext{
${ }^{8} \mathrm{~A}$ full list of the organisations within each sector reviewed for the Science for All Expert Group is available in a separate report providing a Public Engagement Map (Featherstone et al., 2009)
} 
Wynne, 1996, pp. 4-6; Miller, 2001; Bhattachary, 2004, p. 7; Wilsdon \& Willis, 2004, p. 17; Stilgoe \& Sykes, 2009, p. 9). The report was prepared under the chairmanship of Walter Bodmer, and sought to "show why it matters that all sections of the public should have some understanding of science and to stimulate action by scientists and others to improve this understanding" (RS, 1985, p. 7). Known by the author's name as the Bodmer report, the publication makes a case that science institutions support public understanding of science, and for a programme to be delivered across a number of fronts. The contexts that provide succour for Bodmer's arguments are worth listing here as they provide some sense of the scale of the report's ambition, and the formation of the "many purposes and motivations for public engagement" (BIS, 2010, p. 7) that remain applicable to the current scene:

- National prosperity through technological innovation

- Interpretation and implementation of innovations by industry

- Evaluation and judgement of public issues relating to science

- Joining up scientific expertise with policy makers and voters

- Strategic links between civil service and research

- Citizenship and participation

- Decisions effecting health and wellbeing

- Proficiency and ability with everyday technologies

- Interpreting and assessing risk

- Appreciation of and involvement in culture

- Interleaving civil and scientific cultures

The list builds a case for the extent to which "science and technology permeate our daily lives" (RS, 1985, p. 31), and Bodmer's recommendations are then associated with the different spheres for their delivery, including formal education, mass media, public lectures and museums, industry and the scientific community. Final recommendations are directed inwards to the structure of The Royal Society itself, through the transformation of the organisation's remit to include a prize for the promotion of understanding of science, press seminars and journalist briefings, parliamentary briefings, the formation of a committee for the public understanding of science, and the express encouragement of individual scientists to "learn to communicate with the public, be willing to do so and consider it your duty to do so" (RS, 1985, p. 36).

A direct outcome of the Bodmer report was the formation of the Committee on the Public Understanding of Science (COPUS), comprising The Royal Society, The Royal Institution and the British association for the Advancement of Science. COPUS is seen as a key instrument for the delivery of Bodmer's recommendations, and has been credited with an increase in science journalists, science centres, festivals and popular science books (Stilgoe \& Sykes, 2009, p. 9), and in raising the profile of 
public understanding of science "as an issue requiring the attention of all sectors of society, including Government" (Wolfendale, 1995, p. 1). Perhaps an initial moment for governmental involvement in public understanding is marked by the formation of the Office for Science and Technology (OST) in 1992, and its publication in 1993 of a whitepaper outlining policies and objectives for science, engineering and technology as they impinge upon the economy and society (OST, 1993) though it is the OST's Wolfendale report of 1995 where the language of Bodmer's recommendations become more thoroughly embedded within governmental commitments to engagement with research ${ }^{9}$, anticipating the breadth of the current scene as evidenced in the signatories and leadership of the Concordat (RCUK, 2013a).

\section{From Understanding to Engagement}

A second report seen as being foundational to contemporary public engagement was a policy document referred to as the Science and Society report, which was published by the House of Lords Select Committee on Science and Technology in 2000 (HOL, 2000). While the Bodmer report initiated an institutional reassessment on the relations between science and the public and provided momentum for a range of activities, the House of Lords Select Committee refined the terms of those relations in a way that incorporated analysis of initial activities:

Despite all this activity and commitment, we have been told from several quarters that the expression "public understanding of science" may not be the most appropriate label... It is argued that the words imply a condescending assumption that any difficulties in the relationship between science and society are due entirely to ignorance and misunderstanding on the part of the public; and that, with enough public-understanding activity, the public can be brought to greater knowledge, whereupon all will be well. (HOL, 2000, p. 25)

Here, the confidence and bombasticism of Bodmer's report gives way to a tone of humility. The Science \& Society report argues that the posture adopted by science institutions in their dealings with the public should shift, from one focussing on the transmission of knowledge and the communication of benefits, to one that promoted deliberation and offered two-way discussion. This move is frequently cited as the source of the etymological shift from understanding to engagement (Miller, 2001; POST, 2001; Wilsdon \& Willis, 2004, p. 17; Stilgoe \& Sykes, 2009, p. 9). The report takes in a range of evidence that leads it to describe a "crisis of trust" in civil society's relationship with science, linking public mistrust to a range of factors including the "disquieting possibilities" of biosciences, allegations of

\footnotetext{
${ }^{9}$ While there are strong links to the language of the Bodmer report, the conclusions and recommendations of the Wolfendale report primarily position public understanding of science and technology as a priority for science researchers and students, rather than cultural institutions.
} 
conspiracy and cover-up, and incidents of technological failure. The case for engaging the public then, is put forward from a position of crisis:

We have argued above that public confidence in science and policy based on science has been eroded in recent years. In consequence, there is a new humility on the part of science in the face of public attitudes, and a new assertiveness on the part of the public. Today's public expects not merely to know what is going on, but to be consulted; science is beginning to see the wisdom of this, and to move "out of the laboratory and into the community"... (HOL, 2000, p. 37)

While the report developed a number of themes that support a range of activities, reparation of public trust would be largely accomplished by moving the locus of scientific accountability from lab to community. The Science and Society report advanced this ambition with two themes, one was a general appeal for "democratic science", the other a specific argument for the "lay involvement" in scientific advisory groups (HOL, 2000, pp. 42-46). Report recommendations were then supported through partnership and funding, across a range of programmes which included the GM debate steering board, the Radioactive Waste Consensus Conference, the ESRC Science in Society research programme and the Leverhulme Trust's Programme on Understanding Risk (POST, 2003).

\section{Upstream Engagement}

I move to a discreet approach that followed on from the context of engagement, and which I have previously linked to the milieu that informed the proposal for Material Beliefs. The term upstream engagement became applied to science and technology in 2003 to describe a particular form of PEST that related to policymaking around Nanotechnology, and designated activity that would take place during the early stages of research:

Much nanotechnology is at an equivalent stage in R\&D terms to biotechnology in the late 1970s or early 1980s. The forms and eventual applications of the technology are not yet determined. We still have the opportunity to intervene and improve the social sensitivity of innovation processes at the design-stage to avoid the mistakes that were made over GM and other technologies. (Willis \& Wilsdon, 2003, p. 218)

Where the Science and Society report supported the need for engagement following a loss of public trust wrought by widespread and negative attitudes to genetically modified organisms, the vitalisation of upstream engagement in Willis and Wilsdon's paper is motivated by the mitigation of similar circumstances anticipated for Nanotechnology. Reflecting on this approach in a report for the Nanodialogues project, the report author emphasises that an atmosphere of openness and transparency enables participants to offer suggestions for scientific applications: 
Upstream engagement works when it is genuinely open, an opportunity for members of the public to explore, with scientists, what the future could and should look like. By shining a public spotlight on systems of science, we can see new concerns and possibilities that would otherwise have been ignored. Some of these have been about risk... But most have been about the direction of innovation and the broader public value of science. (Stilgoe, 2007, p. 73)

However, where scientific research is aligned with economic growth, upstream engagement is seen rather as a mechanism for soliciting public support of future technologies:

The Government will also work to enable the debate to take place 'upstream' in the scientific and technological development process, and not 'downstream' where technologies are waiting to be exploited but may be held back by public scepticism brought about through poor engagement and dialogue on issues of concern. (HM-Treasury, 2004a, p. 105)

The two accounts above see the early stages of research as a ground for public engagement where two markedly different goals are achieved, firstly the active participation of non-experts in decision making, and secondly the mitigation of public perceptions of risk so as to encourage the uptake of technology. Here is a vivid example of how differing institutional commitments can motivate programmes of engagement in distinctive and seemingly incommensurable ways, and given that such issues clearly have implications for Material Beliefs due to its investment in the upstream, I develop this discussion of in later sections of this chapter.

\section{Formats for engagement}

I turn to literature that describes procedures for the delivery of public engagement, starting with the Science and Society report, which in addition to providing a case for engagement over understanding, described a set of methods for delivery. Here are the "principal options" for engagement outlined in the Science and Society report (HOL, 2000, p. 37):

- Consultations at national level

- Consultations at local level

- Deliberative polling

- Standing consultative panels

- Focus groups

- Citizens' juries

- Consensus conferences

- Stakeholder dialogues

- Internet dialogues

- The Government's Foresight programme 
These options represent a range of approaches through which engagement can become a "normal and integral part of the process" of an organisation, where "no one method is perfect; and which is the best will depend on the context" (HOL, 2000 , pp. 44,43). In order to support adoption of these options by organisations, the report includes examples drawn from UK engagement contexts, and I focus on two that have particular relevance for a discussion of speculation and upstream engagement.

The report frames a description of stakeholder dialogues with an enquiry into management of nuclear waste where a balanced shortlist of 500 interested parties contributed to series of options for contractors to develop proposals, which were then subsequently filtered back through stakeholder assessments (HOL, 2000, p. 45). Stakeholder dialogues have been applied as an activity in programmes that identify with upstream engagement, for example the Nanodialogues project convened a "three-day stakeholder workshop" with scientists and community representatives in Harare to discuss applications for nanotechnology in the purification of water supplies for villages (Stilgoe, 2007, p. 39). In characterising these workshops, the author describes how members of the public explore the future of nanotechnology, where "experts take part as guides" (Stilgoe, 2007, p. 78). This notion of a facilitated dialogue which dealt with the potential capabilities of early stage research, provides some background to the form of engagement activity anticipated in the Material Beliefs proposal.

A second option reviewed in the Science and Society report that is useful in introducing the approach of upstream engagement, is the Government's Foresight programme. The report describes the role of this programme, which aimed to explore "the future in a systematic way" in order to create a "vision for different sectors of society and the economy" (HOL, 2000). Since 2005 government foresight activities have been led by the Department for Business, Innovation and Skills (BIS) through partnerships with a range of organizations, and in this respect are best considered as a set of programmes that incorporate a range of engagement methods. Amongst these programmes, an initiative that dealt specifically with the exploration of possible futures was Sciencehorizons from BIS's Horizon Scanning Centre. A core aim of Sciencehorizons was to "discover views about the issues raised by possible future directions for science and technology" (Warburton, 2008, p. 66), and to do this a series of public dialogues were carried out using discussion packs where image and captions provided prompts for discussion:

The scenarios showed how personal individual situations could be affected by new scientific and technological developments. For example, under Mind and Body, the four scenarios were George and the Jogging Cap (a man with Alzheimer's Disease, whose clothes are electronically tagged and his cap directs him so he never gets lost); Ruth and the Tests (computer software for health 
checks); Roy and the New Heart (a new heart is grown so Roy can have a heart transplant); and Katie and the Doctors (a single mother with a daughter who is a wheelchair user but who could consider premium or standard 'enhancement' therapies with different costs attached). The stories were illustrated with pictures and quotes from the main characters and, on the back of each scenario, background information was given on the current state of the technology ('where are we now'), and where developments were happening. (Warburton, 2008, p. 14)

Here is an emphasis on people, artefacts, settings and issues as elements within a narrative composition dealing with the future outcomes of technology that has something in common with speculation's focus on the potential for design outcomes to enable a debate about the issues of technology.

\section{Evaluating engagement practices}

While the Science and Society report included a large amount of detail from witness statements that qualify the value of these engagement strategies, there is very little detail on how to implement and evaluate these mechanisms. It is through subsequent reports these approaches are procedurally framed, for example in the Open Channels report by the Parliamentary Office of Science and Technology (POST, 2001), and through a set of practical guidelines for researchers compiled by Research Councils UK (RCUK, 2002). Elsewhere, in a comprehensive typology of public engagement mechanisms, Gene Rowe and Lynn Fewer assemble a broad literature, taking in the general scene of public involvement in the "agenda setting, decision making and policy forming activities of organizations" (2005). In their initial consideration of over 100 mechanisms drawn out of their material, the authors suggest that three overarching categories can be used to identify the flow of information between participants and sponsors. Communication marks a flow from the sponsor to the participants, while a consultative mechanism offers the reverse, while participation is a form of public engagement that implies an exchange, where "dialogue and negotiation serves to transform opinions in the members of both parties" (Rowe \& Frewer, 2005, p. 255). Elsewhere a number of mapping exercises have been conducted to solicit features for the overall aims and methods of evaluation of PEST. These provide snapshots of the distribution of various PEST mechanisms, the scale and variation of PEST by sector, the role of the individual who leads the engagement activity, and their objectives. A publication commissioned by the Wellcome Trust offers clear mapping of "science communication activity" types and provides some sense of the variety of channels through which science communication is delivered (Kazimirski, 2000), recalling the earlier Bodmer report in terms of the detail of the various mechanisms that support the communication of science. More recent reports include Connecting Science from the British Association (Kean et al., 2005) a report from the Center for Advancement of Informal Science Education (McCallie et al., 2009) and a Public 
Engagement Map from the Science Communication Unit (Featherstone, et al., 2009) to accompany the Science for All review from BIS (BIS, 2010). The BA report summarises commitment to the practice of PEST as being either normative, instrumental or substantive, with a majority of activities continuing to provide a top-down model of science communication (Kean, et al., 2005, p. 86). The CAISE report focuses on informal education, and applies a range of criteria to 14 case studies to map content based on engagement focus (McCallie, et al., 2009, p. 46). The BIS report explores different motives for doing PEST, with networks from the science industry sector most frequently reporting economic reasons, and public sector networks citing democratic reasons (Featherstone, et al., 2009, pp. 8, 16). Such reports reflect the scale of interest in PEST, which through the most recent policy recommendations is arguably becoming further disciplined, for example through calls for formal competency frameworks (BIS, 2010, p. 35). The last four years have seen a reemphasis of engagement in line with the five workstreams Media, Science for All, Learning, Careers and Trust - identified by BIS in 2010 (CST, 2010). In 2010 there is was marked change regarding the provision of public engagement, as described above, here support for engagement moved out from programmes to become embedded as a cross council provision for researchers. Here RCUK guidance sees engagement as an aspect of the impact of research (RCUK, 2013c). PEST is configured variously to reflect the needs and styles of the organisation leading the activity, where outcomes are evaluated within a framework defined through norms of that organisation.

\section{Two cases of practice}

I turn to two examples of practice in order to extend themes and approaches introduced in the discussion of engagement methods above. The first is the SocioTechnical Integration Research (STIR) project that has its methodological roots in research by Dave Guston and Dan Sarewitz on real-time technology assessment, the second case is the Social Dimensions of Nanotechnology project led by Mark Welland and Robert Doubleday. Both projects foreground the capacity for external partners to intercede in the practices of science researchers working in laboratories in order to generate alternative accounts of the research. These two cases establish some background to the role of the designers in Material Beliefs, who are tasked with initiating collaborative practices with biomedical researchers.

$\underline{\mathrm{STIR}}$

STIR was a three-year project running from 2009 and funded through the Social and Economic Sciences division of the National Science Foundation, a public funding body in the US. The proposal orientated itself to moves internationally for laboratory researchers to reflect upon the broader societal dimensions of their work $^{10}$. Eric Fisher and other colleagues pursue this through a framework for

${ }^{10}$ See a summary of the proposal for the STIR project, NSF award number 0849101 online at: http://www.nsf.gov/awardsearch/showAward.do?AwardNumber=0849101 (accessed 30/06/10) 
scientists and engineers to consider the ethical, legal and social aspects (ELSA) of their work as it is being carried out, by embedding humanists and social scientists in laboratory settings (Fisher, 2007; Fisher \& Miller, 2009).

STIR and its methodological predecessor, Real-Time Technology Assessment (RTTA) draw links to constructive technology assessment (CTA), a European methodology for technology development (Guston \& Sarewitz, 2002). A key aspect of CTA is the co-evolution of technical objects through the modulation of science and society relations (Rip, 2002). Rip frames modulation as an approach where science and culture inform each during the development of a technology:

Co-evolution denotes an open, and certainly more integrated, system of sciencesociety interaction which enhances the generation of variety, whether in the choice of scientific problems, colleagues or institutional designs, on the one hand, or the selective retention of certain choices, modes or solutions on the other hand. (ibid. , p. 6)

In this way STIR's embedded humanists are a direct response to Rip's notion of modulating the co-evolutionary aspect of technology development through reflexive practices. One example is a project based at the Thermal and Nanotechnology Lab at the University of Colorado, where an embedded humanist worked with three science researchers:

Midstream modulation is a means of incrementally influencing a technology during the "midstream" of its development trajectories. It thus asks how research is to be carried out, which is within the purview of engineering research, rather than whether a research project or product should be authorized, approved, or adopted, which is largely beyond the purview of engineering research... research decisions might be monitored and broadened to take advantage of otherwise overlooked opportunities to weave societal factors into engineering decisions. (Fisher \& Mahajan, 2006, p. 3)

For Fisher the midstream is "the phase of research and development before scientific results are translated into products or services", and after funding is approved. This approach has also been implemented by Daan Schuurbiers as part of the STIR project at the Department of Biotechnology at Delft University ${ }^{11}$. While Fisher's approach to reflexive practice aimed to empirically "ascertain the utility" for integrating social and ethical concerns and stops short of identifying, accessing or promoting particular reflection (Fisher \& Mahajan, 2006, p. 2), Schuurbiers' approach looked for evidence of "social responsibility in science" as a result of his

\footnotetext{
11 These studies were precursors to STIR, and funded through the Center for Nanotechnology in Society at Arizona State University, established through NSF grant 0531194 providing $\$ 6.2 \mathrm{M}$ over five years as a part of the National Nanotechnology Initiative, see http://www.nsf.gov/news/news_summ.jsp?cntn_id=104505 for a NSF press release (accessed 06/07/10)
} 
interventionist fieldwork. Here he found that his participants considered the social implications of their work, including what he describes as the conscience value of the effects of their work beyond more obviously ethical topics (Schuurbiers \& Fisher, 2009, p. 426).

\section{Social Dimensions of Nanotechnology}

In the UK the Social Dimensions of Nanotechnology project was part of an interdisciplinary research collaboration (IRC) with partners comprising the Universities of Cambridge, Bristol and University College London ${ }^{12}$. Led by Mark Welland a scientist and Robert Doubleday a geographer, the project has overlap with the STIR project, particularly in terms of embedding an academic as a laboratory interlocutor:

The project envisaged employing a social scientist to work in the nanoscience laboratory at the University of Cambridge exploring the social implications of nanotechnology, teaching scientists about the social and ethical aspects of nanotechnology, and supporting public engagement activities. (Doubleday, 2007, p. 171)

While the organisational aims and the approach of the project are aligned with upstream forms of public engagement, Doubleday problematizes these expectations in his empirical analysis. For example, rather than enabling a distributed model of accountability that would see lab and society as variously mixed, he describes situations and conversations where there is an expectation that the social scientist is "taking on the role of protecting an inner experimental core from wider complexities of the public meanings of nanotechnology research" (Doubleday, 2007, p. 173). And so Doubleday recognises three roles that are expected of the social scientist as a lab based interpreter:

- Preparing public for the outcomes of research

- Advising scientists on responsible development

- Facilitating exchanges between public and scientists

These two cases provide different roles for humanities and social science scholars as lab-based intermediaries. The STIR project is a form of real time technical assessment, and is seen to embed responsibility in order to optimise the social impact of a technical system, without recourse to explicit public engagement activities. Meanwhile the Social Dimensions of Nanotechnology project is associated with methods of dialogue that are seen to enable the solicitation of public knowledge, but where the intermediary is in effect seen to be a valve that enables research to continue flow in one direction. Indeed both the midstream

12 This IRC was largely a science and engineering exercise and was supported with some social science work http://gow.epsrc.ac.uk/ViewGrant.aspx?GrantRef=GR/R45680/01 for details of the EPSRC grant (accessed 06/07/10) 
modulation of STIR and the upstream engagement of the Nanotechnology project conceptualise science and technology as a one directional flow.

\section{Where does speculation fit in?}

Here is a shifting landscape of organisations with a broad and diverse range of commitments to the policy, governance, provision and evaluation of public engagement with science and technology. I have characterised speculative design as something of an enthusiastic incomer, seeking to find a way of aligning itself with this landscape. This is certainly the case with Material Beliefs, which adopted the discourse of upstream engagement and aligned it with speculation's aim to enable debate. Currently though, there is a danger that in seeking to provide an analysis of what was accomplished in this case of mixing, I take on the evaluative mechanisms of PEST, and upstream engagement in particular. At this point then, I move beyond a description of the methods and evaluation of engagement practices in order to develop a mode for the analysis of speculation.

\section{PEST as an object of critical analysis}

The accounts above are predominantly articulated through roles bound to the practice and evaluation of PEST, and are in this respect tied to normative procedures including the communication of scientific utility, assessment of risks or governance of technology. For example, taking one of Bodmer's criteria where the role of PUS is to support the public in interpreting and assessing scientific risk, there are a number of underlying assumptions. These include judgements about what constitutes a crisis and indeed what is optimal, who the public are and what they think, what the objects of science are and are not, how trust should be restored and what forms that restoration might take. In this second section I move to analytical accounts of PEST from social science, and thereby aim to resource a move outside of the frame where PEST is practiced in order to reconsider its features.

\section{The 'right kind' of analysis}

The involvement of social science in PEST can be considered historically, alongside the key phases of engagement practice described above. For example, Irwin and Wynne note an explicit "role for social science research" (Irwin \& Wynne, 1996, p.

6 ) in the Bodmer report, which recommends that the Economic and social Sciences Research Council fund a programme of research "into ways of measuring public understanding" and of "assessing the effects of improved understanding" (RS, 1985, p. 12) and which leads to the ESRC's Public Understanding of Science (PUS) programme. Later, the establishment of the Science and Society programme by ESRC can be interpreted as a direct outcome of the House of Lords report of the same name (POST, 2003). There is a sense here of policy support bringing ESRC funding programmes into being, and mobilising social scientists as analysts, alongside communicators and scientists (Burchell, 2009). However, the 
relationship of social science to PEST as an object of and a topic for research is varied and complex, and needs refining in relation to the present requirements for an analysis of PEST.

Social science has applied a range of methodological approaches to PEST research, and at times it feels that PEST is a backdrop for disciplinary friction. One example is a discussion about styles of research activity enabled by the ERSC Public Understanding of Science (PUS) programme between 1986 and 1991 (Durant, et al., 1998). One approach deals with public attitudes and perceptions of science, and is supported by quantitative methods including surveys (Durant, et al., 1998; RAEng, 2009a). However, elsewhere it has been argued that survey-work has sustained what has been described as a deficit model of public understanding, with its focus on the problem of public ignorance (Wynne, 1995). An alternative methodological style sees ethnographic approaches applied to a diverse range of fieldwork where public understanding of science is reconsidered through empirically grounded considerations of authority, identity, and knowledge (Irwin \& Michael, 2003). Examples of work here include interviews with Cumbrian sheepfarmers effected by government restrictions on livestock trade following the Chernobyl reactor failure (Wynne, 1992), a discourse analysis of respondent statements from a survey of understanding of radon (Michael, 1996), and a year long ethnographic study with the makers and visitors of an exhibition at a science museum (Macdonald, 1996). These studies emphasise the "reflexivity of laypeople" in ways that undercut and challenged assumptions about the cognitive failings of the public (Wynne, 1995). For Wynne and Irwin, these studies articulate an approach that is sceptical of some innate assumptions of this 'first wave' of PUS following the Bodmer report (Irwin \& Wynne, 1996). Firstly they challenge the assumption that controversies at the root of a crisis of trust are "created by public understanding rather than the operation of scientists and scientific institutions" (ibid., p. 6). Secondly the authors identify in PUS, commitments to a rhetorical position that frames science as an "important force for human improvement" by neatly solving a huge range of problems. Thirdly they identify science as an unchallenged framework of "value-free and neutral activity" sanctioned to produce legitimate knowledge (ibid., p. 6).

These anthropological and critical approaches saw the public understanding of science located in the mixed discipline of Science and Technology Studies (STS). Wynne aligned the ethnographic turn in PUS research with social constructivist approaches in STS established through a variety of studies during the late 1970s and onwards in the fields of medical sociology, women's studies and environmental controversies (Wynne, 1995, p. 375). Where the quantitative methods of attitudinal surveys take a respondent out of social context, STS provides a framework that emphasises the "reflexivity of laypeople in 
problematizing and informally negotiating their own relationship with science" (Wynne, 1995, p. 385).

I mentioned that friction between these different approaches to research within the PUS programme is a disciplinary one, and it speaks to the methodological and theoretical commitments of social scientists. However, for the purposes of focusing social science literature in relation to my topic of speculation and engagement, it is useful to develop a distinction between the quantitative and qualitative treatments of PUS introduced above. The quantitative approaches, which conduct surveys into public attitudes of the objects and outcomes of scientific research like Biotechnology and Nanotechnology, seem to me inexorably linked to a non-critical and, though Bauer et al. seek to escape this judgement, administrative form of PEST (Bauer et al., 2007, pp. 79-80). In the first chapter of this thesis I introduced the variety of data that I will be drawing on in order to make an analytical account of Material Beliefs, and this included transcripts from interviews and focus groups, along with photography of engagement events and documentation related to design process. Quantitative approaches to PEST do not align well with an analysis of these types of data. Additionally I feel that it is the administrative atmosphere of public engagement, of evaluating workshops and surveying attitudes etc., which has cast PEST as such an uninspiring discussant of the specific issues relating to speculative design's entanglement. And so my subsequent alignment with research associated with qualitative and critical PEST, is underpinned by optimism and excitement around the potential opportunities for speculative design offered by the methodological and conceptual innovations of STS, which I see as a tool for escaping PEST ennui.

\section{PEST and STS}

The model of PEST outlined in the opening half of this chapter depicts two phases, where an initial focus on public cognition of science is later modernised as a twoway engagement process. This model is contested in STS literature, and the claims made for upstream engagement in particular are challenged on various fronts. Frequently its is seen that enabling an open and equal dialogue is complex, and becomes undercut by the authority and knowledge of experts, so that scientific expertise takes precedence over lay knowledge (Kerr et al., 2007; Burchell et al., 2009). Elsewhere Brian Wynne has argued that the upstream is largely a rhetorical posture that makes minimal changes to existing institutional commitments:

The practices so far developed for public engagement with science fall well short of the needed mark. For all their fashion-following language of upstream public engagement, they remain rooted in attention only to downstream impacts, and not to making upstream driving purposes, about the human ends of knowledge, not only its instrumental consequences, more accountable and humane. (Wynne, 2006, p. 218) 
As an example, Wynne cites the Governments' 2004-2014 Science and Innovation framework discussed earlier, where the document emphasises that the successful exploitation of technologies will be 'held back' by 'poor engagement and dialogue on issues of concern' (HM-Treasury, 2004a, p. 105). Here, Wynne sees that technological pathways are clearly set, and engagement merely seeks to account for and negotiate the risks associated with predetermined paths of innovation:

There is no room left for constructive negotiation of possible alternatives, multiple trajectories, and different technologies, including of different social ends. Nor is there room for negotiation of the proper conditions under which an otherwise unacceptable technology might be acceptable... Yet it is important to note that this is imposed upon society, without deliberate intent, but no less rigidly so, by the prevailing institutional scientific culture in virtually all international innovation and regulation processes. Yet sadly, this occurs in the name of avowedly post-deficit model, enlightened public engagement with science. (Wynne, 2006, p. 218)

Similarly Irwin characterises a new form of scientific governance that responds to stinging accounts of "institutional failings and official aloofness", with a strategy of increased openness and centralised control of risk-management (Irwin, 2006, pp. $300,307)$. In considering this new yet familiar nexus of "old technocratic aspirations with the public construed as an obstacle to progress" (ibid. , p. 316) it is not difficult to see how the promise of the upstream conflates technology assessment and public engagement in such energetic and problematic programmes.

These critiques of upstream engagement help sharpen an analysis of practices in Material Beliefs. While the proposal did not respond to the complexities and problems of upstream engagement unpacked above, there is clearly scope for an empirical discussion to reflect upon these arguments.

\section{Other STS topics}

I have argued that STS's conceptual and empirical engagement with PUS, along with its more recent sceptical encounter of upstream engagement, helps an analysis of speculative design's entanglement with the upstream. However, there are other approaches and topics in STS that connect to features of the Material Beliefs case specifically, and more generally with critical and speculative design tropes.

\section{Expertise, knowledge and power}

In the previous chapter, a commitment that underwrote critical and speculative approaches was that society operated along technocratic lines. The designer is here seen to make interventions, and to challenge a dominant mode of design as a form of production that would incorporate new technologies in an unquestioning 
manner. I argued that there was scope to reconsider this model, which is tied to Critical Theory and Marxist social theory, and to reconsider the conceptualisation of expertise and knowledge that these framings are tied to. These essentially linear models of the development of technology in expert settings have been empirically challenged with multidirectional models where the technological object becomes linked to the "wider socio-political milieu" (Bijker, 1987, p. 46). Elsewhere technology artefacts are seen to be co-produced as outcomes of heterogeneous arrangements or actor-networks (Callon, 1986). Recent accounts have explored the composition of expert and lay identities within these networks, along with the ways particular voices are made stronger or underplayed as the technical artefact becomes stable. Jasanoff 's account of co-production emphasises the interdependence of social and natural idioms, where the "social dimensions of cognitive commitments" and the "epistemic and material correlates of social formations" are assembled symmetrically (Jasanoff, 2004, p. 3). In terms of the implications for science and society relations, the pluralism of co-production opens up discussions of accountability, and in this context Jasanoff has argued for "technologies of humility" to address the "lack of perfect foresight" afforded by this opening up of certainty:

These are methods, or better yet institutionalized habits of thought, that try to come to grips with the ragged fringes of human understanding - the unknown, the uncertain, the ambiguous, and the uncontrollable... They call for different expert capabilities and different forms of engagement between experts, decision-makers, and the public. (Jasanoff, 2003, p. 227)

Technologies of humility are here enacted through a framework with four focal points, framing, vulnerability, distribution and learning. These foci are developed deliberatively through engagement mechanisms that asks of technological enterprise, "what is the purpose; who will be hurt; who benefits; and how can we know?" (ibid. , p. 239). Crucially:

The issue, in other words, is no longer whether the public should have a say in technical decisions, but how to promote more meaningful interaction among policy-makers, scientific experts, corporate producers, and the public. (ibid., p. 238)

Meanwhile Nowotny et al. have discussed the transformation of knowledge production in scientific research cultures, stressing a movement from the autonomy and segregation of academic settings, to a distributed model with an interplay of 'multiple accountabilities' (Nowotny et al., 2006). In earlier work the authors mention five characteristics of 'Mode 2' knowledge production (Gibbons et al., 1994); that it is generated from a context of application, it mobilises perspectives and methodologies from a ranges of disciplines, it takes place through distributed and also virtual sites, it is reflexive and epistemologically diverse, and 
it is evaluated and accredited with multiple definitions of quality. These characteristics are later reformulated through their impingement on science and society relations (Nowotny et al., 2001), in particular the concept of the agora is put forward, to suggest an extended environment for Mode 2 interactions:

The agora is the problem-generating and problem-solving environments in which the contextualisation of knowledge production takes place. It is populated not only by arrays of competing 'experts' and the organisations and institutions through which knowledge is generated and traded but also variously jostling 'publics'... The agora is in its own right a domain of primary knowledge production - through which people enter the research process and where 'Mode 2' knowledge is embodied in people, processes and projects. The role of controversies in realising scientific potential is also played out in the agora. (Nowotny, et al., 2006)

This description of the agora relates to Jassanof's technologies of humility, by extending and mixing the political attitude of expertise by enacting "plural viewpoints and collective learning" (Nowotny, 2003). For Notworthy, this plurality leads to socially robust knowledge which "pushes the epistemological and institutional initiative 'up-stream', into the research process and to the research sites where new knowledge is generated" (Nowotny, 2003, p. 155).

These accounts of expertise, knowledge and power provide more nuanced and conceptually rich registers for an empirical discussion of project activity, and help to move analysis on from critical design's version of critique and public engagement's model of dialogue.

\section{Promising and imagining}

A claim made for speculation is that its use of narrative acts to subvert or challenge what is seen as the principal trajectory of a technology. Speculative designs are seen to generate discussion about alternatives. I previously discussed overlap between the narrative approaches of speculation and the practices of technology forecasting, however there is also scope to open up such practices to analytical topics in STS.

The sociology of expectations provides an analysis of the enrolment of future scenarios in order to enrol others in networks of innovation (Brown et al., 2000; Michael, 2000a). Elsewhere it has been argued that technology innovation is supported by the production of 'imaginaries', in order to foster co-ordination between organisations and to mobilize resources (Joly, 2010).

Regimes of innovation describe the development of a technology when tied to frameworks of governance, and are characterised in terms of "economic impact or competitiveness" along with properties including "distribution of power and 
agency, collective learning, social relations" (Wynne et al., 2007, p. 22). Such regimes are inflected in various ways, and a core characteristic is whether a regime is led by technology promises, or builds upon experimentation with broader collectives of actors (ibid, p. 24):

We will indicate the promise-push elements in the regime of economics of technoscientific promise, and how this (re-)introduces the linear model. And indicate our concern about how the emerging regime of collective experimentation is overshadowed by the economics of technoscientific promises

Here, promissory led regimes act to create fictions that reinstate a linear model of technology development. A further set of issues for consideration here is the interaction between the research trajectories and lay attitudes in the making of unfinished technologies through narratives about the future. Macnaghten offers a methodological account of a governance of nanotechnology study ${ }^{13}$ as a site for 'intense future politics':

Given that the technology exists largely in terms of future-oriented promise rather than as material reality, the methodological requirement for the research outlined in this paper was to produce a space in which lay technoscientific citizens could be produced through an innovative public engagement exercise, able to offer opinions, discuss the issues, and reflect on future politics and their contingencies. (Macnaghten, 2010, p. 24)

Such reflections upon future technoscientific outcomes by scientists and engineers have been described as imaginaries. In Macnaghten's nanotechnology study, the opportunity for authorship of this "socially and culturally embedded sense of the imaginary" (Marcus, 1995, p. 4) has been passed from scientist to citizen. In this respect, a core method in the study was to develop five focus groups drawn from lay constituencies that each met twice, followed up with a third meeting with a selection of 12 drawn from those groups along with 'nonoscientists' (Kearnes et al., 2006, pp. 43-44). Transcripts from these sessions show "considerable concern" over the social impacts of nanotechnology, compounded by feelings of a "lack of power" in shaping research trajectories, and perceptions of "large unaccountable actors" behind the scenes (ibid. , p. 46). Such beliefs are supported through the mobilisation of narrative tropes, including the "bodily invasion" of substances that violate biological function, and "artificialist" projections that see the mechanisation of everyday life (Macnaghten, 2010, p. 33). In terms of science and society

\footnotetext{
13 "Nanotechnology, risk and sustainability: developing upstream models of public engagement" (award no: RES-338-25-0006) was funded by the ESRC and continued from 01/01/2004 until $31 / 07 / 2006$, further details are available online at http://www.esrcsocietytoday.ac.uk/ESRCInfoCentre/ViewAwardPage.aspx?AwardId=3019 (accessed 22/06/10)
} 
interactions, the significance of such enduring themes being transposed upon unfamiliar technological contexts perhaps lies not in the composition of these themes, as utopian or dystopian, or in foregrounding bodies or corporations, but in the value of lay prospecting as a resource for initially bringing research activities into lay domains.

Crucially for this thesis, Macnaghten puts forward a case for 'critical public engagement studies' where a curiosity about methods for characterising and demonstrating lay sensibilities and imaginations is an end in itself, rather then a precursor to the 'institutional governance of emerging technologies' (Macnaghten, 2010, p. 32). This is relevant to a discussion of Material Beliefs, which aimed to elaborate and render lay responses to emergent technoscience as speculative design, rather than pursue a formal link to policy. I turn now to literature that accounts for the social as it operates at these smaller scales of such critical public engagement studies.

\section{Materials have agency}

In order to provide an account of speculative engagement that amounts to more than a description of the designer's intention, or an account of the curator's interpretation of designer's intention, I have been arguing for a broader conceptualisation of the scene in which the empirical episodes of this thesis take place. For example, I have spoken about the institutions that make funding available, the organisations that provide evaluation guidelines, and the scientists who want to communicate their work. The rhetorical idea of speculation is interfered with by the standards and expectations of these other entities, which present themselves at various stages including the planning of a proposal or the delivery of an engagement event. These entities have different scales, some are evident while others are more difficult to grapple with and incorporate into an analysis of practice. STS offers theoretical accounts of PEST practices, and these provide strong models for the analysis of practice in Material Beliefs. Michael provides an account of a 'disastrous interview episode' during fieldwork for a public understanding of science study into conceptual models of ionizing radiation. (Michael, 2004). While the original fieldwork can be seen as in relation to PUS work of the time ${ }^{14}$, the author revisits his data in order to theorize the role of the nonhumans in the shaping of an account of the social; in this case this includes the interview equipment, the interviewee's pets and the furniture in the interview setting:

What we have then is a complex set of interactions where humans, animals, and technologies are involved in a process of constituting orderings and disorderings by virtue of the various relations into which they enter, relations

${ }^{14}$ Michael's original fieldwork around the public understanding of radon was delivered as part of ESRC's PUS programme discussed earlier. 
that at one level might generate disruption (as parasites), but on another reproduce certain configurations (or prepositions)... It sensitized us to the heterogeneous disciplinary work that must be carried out in the production of social data, social order, and macrosocial entities. (ibid. , pp. 18-19)

In this account local, material contingencies resist the collection of data that would be useful for the public understanding of radon study. Uselessness in this respect 'sensitises' the author to otherwise hidden processes of co-agency between humans and nonhumans at microsocial scales that are intrinsically part of the orderings of larger scales of phenomena. In this respect, Michael's co(a)gents are part of an analytical model that privileges the material and the immediate, while demonstrating their role within the institutional and the political.

While an initial case has been made for a confluence of local and global settings within descriptions of the science and society, in what ways do humans and nonhumans combine to have effects? One example Michael proposes for the radon study is the PITPERCAT - an admixture of pitbull, person and cat - as a co(a)gent that conspires to disrupt attempts by the INTERCORDER (Interviewer and recorder) to order the setting for the benefit of the radon study. The co(a)gent has similarities with Latour's notion of hybrid networks (Latour, 1993) and Harraway's account of cyborgs (Haraway, 1991) in terms of restating a fluidity amongst objects that for Latour have been historically purified as either natural or social, human of technological. Callon and Law foreground the performativity of these networks, action established as a 'collectif' is an emergent effect, a heterogeneous set of relations that perform, and in doing so express a particular from of agency (Callon \& Law, 1995).

While the focus here is upon links and processes that form around the entities, be they people, technologies, texts or buildings, there is perhaps scope to consider the characteristics of the nonhuman entities, as these surely have a bearing on the relations that are then able to come into play. Akrich is particularly interested in describing the role technical objects play within these networks, particularly the capacity of such actors as to encode or rather inscribe expectations:

Designers thus define actors with specific tastes, competences, motives, aspirations, political prejudices and the rest, and they assume morality, technology, science, and, and the economy will evolve in particular ways. A large part of the work of innovators is that of "inscribing" this vision of (or predication about) the world in the technical content of the new object. I will call the end product of this work a "script" or a "scenario". (Akrich, 1992, p. 208)

In this way the de-scription of the technical object brings about a negotiation with the user as the two come together, and for Akrich there may be a tension between 
the control of the user and the use of the technical object (ibid. , pp. 216-217). The ability of technical and indeed mundane artefacts to perform a disciplinary role upon the user through their materiality has been a focus for Winner (1986) Latour (1992) and Michael (Michael, 2000b, 2006) and also Yaneva (2009) and Wilkie (2010). Latour describes a hydraulic device for automatically closing doors, where rather than disciplining those who don't close the door, that task is delegated to a mechanism:

Prescription is the moral and ethical dimension of mechanisms... How can the prescriptions encoded in the mechanism be brought out in words? By replacing them by strings of sentences (often in the imperative) that are uttered (silently and continuously) by the mechanisms for the benefit of those who are mechanized: do this, do that, behave this way, don't go that way you may do so, be allowed to go there. (Latour, 1992, p. 232)

These concepts have considerable implications for establishing a methodological perspective for speculative design and PEST. These assemblages are responsive to the micro and macro scales within which science and society relations are enacted, while also being sensitive to the material and immanent concerns of design literature. Of interest here is the potential for interventionist forms of PEST in "redistributing competences and performances of actors in a setting" (Akrich \& Latour, 1992, p. 262). This might be through designs that combine social and material properties in novel ways, or activities that reassign the agency of nonexperts as 'enscripters' of technical objects.

\section{Anticipating the empirical chapters}

A view frequently met during informal conversations with other designers whose practice is to some extent resourced by PEST projects, is that we do not associate what we do with PEST, or we do not identify features of a design approach with specific aims of PEST. I believe that this is to some extent due to disciplinary ambivalence to one of the practices that identify with PEST, for example, reluctance that design should act as a communicator of science. However, the expediency of designers' encounters with PEST as a resource for funding, and the opacity and complexity of PEST as an umbrella for so many activities and commitments, mean that these concerns are not easily overcome. In this chapter then, I provided a review of practitioner-led and analytical literature for PEST in order to address these issues. In providing a sceptical account of institutions and practices, and then developing some conceptual resources for thinking about engagement practices, I hope to be in better shape to move beyond the provisional and normative descriptions of PEST that would otherwise characterise the following account of my own interaction with those activities. 
In the following three empirical chapters of the thesis I will not evaluate design episodes in terms of their success as occasions for engagement, rather I will make a heuristic account of what occurred there. This account will speak to the sorts of models I have been introducing, particularly where PEST is conceptualised as a network of technologies, settings, people, materials, processes, accountabilities and roles that come together in particular ways when activated by a speculative approach to design.

\section{Summary}

In this second review chapter I have discussed literature where PEST is the substantive topic, to complement the previous chapter dealing with speculative design. Firstly PEST has been discussed as set of organisations and practices that share a common though disputed history, to become delivered through a range of styles with various commitments from different actors. The case of speculative design discussed in this thesis was aligned with upstream engagement, and contemporary practices of this ilk were presented to expose features that the Material Beliefs proposal identified with. In the second half of this chapter I turned to literature that took PEST as an analytical subject, where I emphasised PEST's handling by STS scholars and identified a range of additional topics that extended the theoretical tropes drawn upon by critical and speculative design. 


\section{CHAPTER 4: SITUATING BIOTECHNOLOGY}

\section{Introduction}

The Material Beliefs proposal intended that speculative designers take biomedical and cybernetic research as a start point for projects. Designers were encouraged to visit labs where research was done, in order to photograph equipment, to see new materials and processes, and to experience in tangible ways early stage activities whose downstream outcomes might otherwise be encountered in science blogs or popular science magazines. This chapter is the first of three empirical chapters, and discusses data generated during the activities that took place in and around biotechnology labs during the Material Beliefs project. The lab features across the duration of the project, both as an actual location for activity, and also figuratively, by virtue of its representation in design outcomes or as a topic of discussion at a museum event. Additionally, I will demonstrate that the lab is a venue for particular forms of PEST that take place well in advance of the design outcomes that might otherwise be seen as the basis for engagement.

I start by considering the lab as it features in the Material Beliefs proposal, where design for debate, upstream engagement and biomedical research are brought together to build a case for funding. I then follow with episodes from the project, starting with two interviews led by designers with biomedical researchers, and following with a discussion of two workshops, one where a patient, scientist and doctor meet to discuss an artificial pancreas, and the other where a group of postgraduate design students visit to a biomedical lab. Following these episodes I provide a summary of key findings drawing upon literature from the review chapters.

In the following sections of this chapter, and also in chapters five and six, I frequently use the terms 'designers' and 'researchers', often together and at times separately, without qualifying the types of designer or researcher I am referring to. Here I mean the speculative designers and the biomedical and cybernetic researchers who are undertaking activities together as part of the Material Beliefs project. This convention is adopted from the project funding proposal and the project publication, where designers (often with academic and research backgrounds) were contracted to undertake design roles through collaborations with biomedical and cybernetic researchers. Therefore, I do not mean to suggest that the terms are mutually exclusive, and that designers do not also perform research roles, or that researchers do not undertake design activities. Additionally, a core contention of the thesis is that speculative designers should make accounts of their practice as a variety of design research, so it would indeed be a problem to suggest otherwise. 


\section{Expectations of the lab}

In this section I discuss the ways in which laboratories were considered prior to project funding, and to do this I consider three expectations of labs at proposal stage. Firstly labs were seen as the locus of biomedical and cybernetic research activity, providing topics and issues that would be start points for the designs of Material Beliefs. Secondly the lab was imagined as a place for interdisciplinary collaboration, where biomedical researchers and speculative designers would come together to do activities in order to advance the project. Thirdly, the research done in that lab, and the implications of future outcomes of that research, were taken to be a matter for public engagement, where non-experts would be invited into the lab for engagement activities. I draw upon the project case for support (Kerridge, Custead, et al., 2006), documentation from an EPSRC workshop where the proposal was shaped up (Nelson \& Jones, 2006) and related literature to discuss these three expectations.

\section{Biotechnology as a field of research}

Underwriting the relationship of the project to the lab was an intention to get at particular forms of technology in the making (Kerridge, Custead, et al., 2006). Biotechnology and cybernetics research were selected as a focus for various reasons, partly due to the existing cases of speculative practice in these fields (Ashcroft \& Caccavale, 2004; Thompson \& Kerridge, 2004) but primarily due to features of an EPSRC workshop call. This was a call for participation in a proposal scoping workshop, which asked "are there issues in public engagement that pertain particularly to engineering" and which encouraged approaches that would "enable new thinking between the disparate players involved" (Nelson \& Jones, 2006). In response, the Project proposal identified biotechnology and cybernetic research as a project theme, drawing upon a Royal Society report to support such a focus. This report makes a case for an interdisciplinary research programme "to investigate the social and ethical issues" associated with emerging technologies, emphasizing civil liberties as a key issues:

The expected convergence between IT and nanotechnologies is likely to enable devices that can increase personal security on the one hand but might be used in ways that limit individual or group privacy by covert surveillance, by collecting and distributing personal information (such as health or genetic profiles) without adequate consent, and by concentrating information in the hands of those with the resources to develop and control such networks. (RS, 2004, pp. 56-57)

The proposal additionally drew upon descriptions of nanotechnology in popular science (Drexler, 1986; R. A. L. Jones, 2004), philosophy of science around the topic of human and machine hybrids (Channell, 1991) and engineering and humanities literature about cybernetics (Gray et al., 1995; O'Mahony, 2002) to develop a 
thematic context for the project. In this way, a theme was established around research in UK university laboratories relating to technologies that provided an interface between biotechnology, data and human bodies, where issues including liberty and security were likely to be a concern. The proposal also responded to a report from the Royal Society, which made a case for the failure of research councils and policy makers to make good on promises to engage the public around nanotechnology (R. A. L. Jones, 2006). To this end the proposal mobilised Royal Society arguments, by articulating a need to "communicate and democratise recent innovation in UK engineering" taking place in academic labs (Kerridge, Custead, et al., 2006).

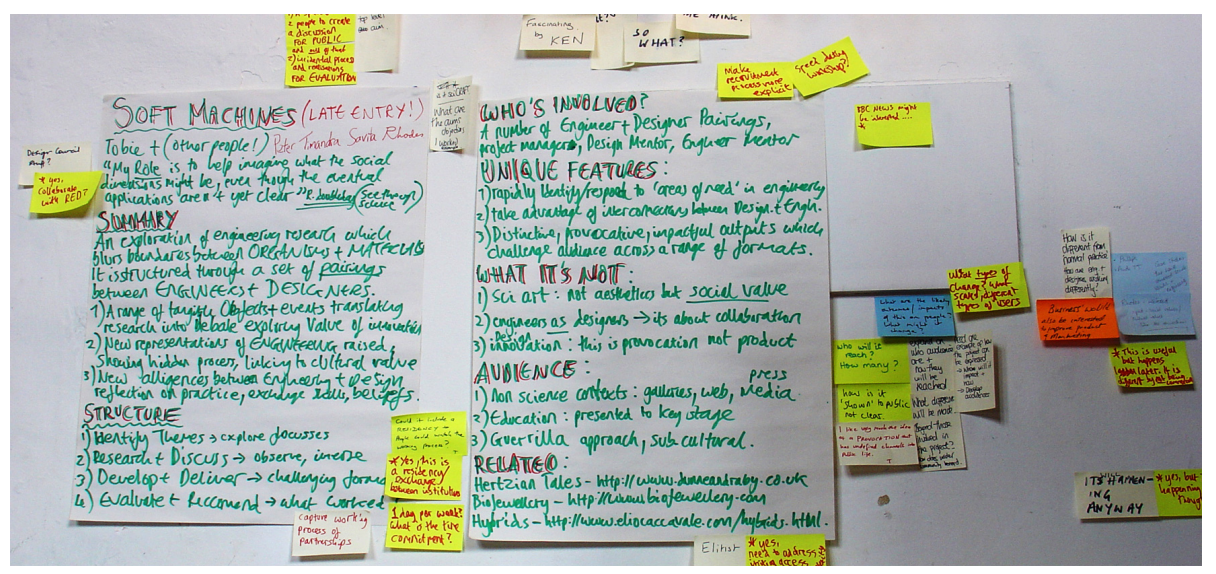

Figure 16: The initial proposal for Material Beliefs at EPSRC Ideas Factory in May 2006

\section{Collaboration}

In order to conduct activities with bioengineers engaged in related research programmes, the proposal anticipated a series of partnerships for collaborative association between designers and researchers. The case for support described how the project would draw upon relationships with engineering departments at UK universities in order to negotiate a period of collaboration:

The first seven-month block is about observation, immersion, discussion and shared reflective activity during which designers and engineers obtain a deep sense of each other's roles, interests and values, and a sense of the broader interests and activities within the department. (Kerridge, Custead, et al., 2006, p. 5)

There is an emphasis in the proposal on 'innovative' forms of collaboration, delivered through design methods that offer "new perspectives for the engineers". While there is some sense that project activity will entail a broader interdisciplinary mix including scientists, artists, policy makers and sociologists, the emphasis is primarily upon the innovative features of bringing together the practices of engineers and designers: 
Both groups deal with the translation of knowledge innovation into a material context of use, they turn ideas into things. The mutual aspects of what they do provides a unique context in which to explore and challenge the mechanism of this translation of institutional innovation into everyday use. How do new things become embedded into a cultural and social space, and how can we effectively discuss the profound effect these things have upon society, our values, belief systems. (ibid., p. 7)

While identifying mutual interests, there is also a clear demarcation in terms of the sensibility of the respective activities of these would be collaborators. The biomedical researcher is focused on the innovation of systems that go out into the world to enable products and applications that then have social effects, while the designer is determined to discuss and to an extent anticipate those effects through the rhetorical capacity of speculative design.

\section{Upstream engagement}

In addition to seeing biotechnology research being done in labs as a starting point for speculative projects, and proposing a model of collaboration as the basis for accessing those labs, the proposal sees that an association with labs provides opportunities for public engagement. Here, it was seen that the lab provides a venue for engagement activities that are responsive to an "emerging culture of joining up scientific, policy, critical and communication disciplines" (ibid., p. 2). To provide examples of these innovative forms of engagement, the proposal aligns with a Demos pamphlet (Wilsdon \& Willis, 2004) and a report on the social dimensions of Nanotechnology (Welland \& Doubleday, 2005) in order to build a case that the project will provide a platform for upstream engagement. A presentation at the EPSRC workshop where the proposal was developed opens with the following quote from an interview with Robert Doubleday in the Demos pamphlet:

My role is to help imagine what the social dimensions might be, even though the eventual applications of the science aren't yet clear.

(Wilsdon \& Willis, 2004, p. 55)

Here Doubleday is being interview by the authors regarding his role as a social scientist seconded to a Nanotechnology laboratory in Cambridge. The Material Beliefs proposal sees the designer as a substitute for the social scientist, acting as an intermediary who helps frame potential implications that the research might have once it leaves the lab. While a speculative approach is aligned with upstream engagement, the mechanism for accomplishing this is somewhat undeveloped. Instead the lab is a like an expanded design studio, where collaboration leads to a set of designs that will embody "perceptions and expectations of future applications arising from the engineers' research area" (Kerridge, Custead, et al., 
2006 , p. 5). Once complete, these speculative designs leave the lab and then go into exhibitions and other public settings in order to do public engagement (ibid., p. 6).

\section{Moving beyond expectations}

These expectations of biotechnology, collaboration and upstream engagement at proposal stage offer an impression of the commitments that gave shape to the project. The proposal is not clear about how these aspirations will be delivered, and in particular the alignment of speculative design with upstream engagement seems to be anticipatory, particularly as the different types of activity that would support these ambitions are not described in any detail. However, these expectations of the lab are a substantial element of the case for support that went to the EPSRC, and as such these expectations were built into plans that were translated into action once the project was underway. I move now to a discussion of key episodes from the project in order to develop this discussion of the lab.

\section{Designers interview biomedical researchers}

The proposal described a network for delivering a public engagement project focused on collaborations between designers and bioengineers. However, collaborations were not formally in place at the outset of the project. The project was administratively based in a design department, it was led by a designer, and proceeded with the recruitment of four designers. In this respect, at the outset the project was somewhat design heavy, and the nature of the mechanisms by which the collaborative features of the project would be delivered were largely aspirational. In order to move from proposal to delivery, a set of activities to build associations with biomedical and cybernetic researchers were conducted.

Initially, project members spoke to colleagues at Goldsmiths University, contacts from other universities, and participants from the EPSRC grant workshop to identify likely researchers, who were approached and referred to the project. In addition, online searches for relevant biomedical research were undertaken, where members of research groups were contacted. Interested researchers were then invited to a workshop in April 2007, where a set of activities developed the theme of the project, and established a provisional model under which collaboration could take place. A key outcome was a strategy where designers recruited to the project would visit researchers at work, where interviews about their roles would serve to elaborate project themes, and also provide something like a matching process for potential collaboration (Kerridge \& Robinson, 2007). Subsequently, the four recruited designers each took a lead on setting up a collaborative cluster, with interviews as an initial activity. Between the period following the April 2007 workshop and September, nine interviews took place. Here, interviewees included participants from the April workshop, along with those that were invited and could not attend, and those who were referred to the project at a later date. 
While the interviews were part of a strategy for developing the collaborative requirements of the project, these conversations also established themes and directions for later design activity. Visits to researchers by designers took the form of unstructured interviews that were filmed using a digital video camera, and also documented with a digital still camera. Prior to a meeting the interview format was discussed and agreed with the researcher, and designers referred to the research pages of websites, and related material including academic papers, press releases and news articles in order to prepare. For each interview one or two designers visited the researcher at their workplace for between one and three hours. Below I refer to transcripts from two interviews and in order to establish an account of their features.

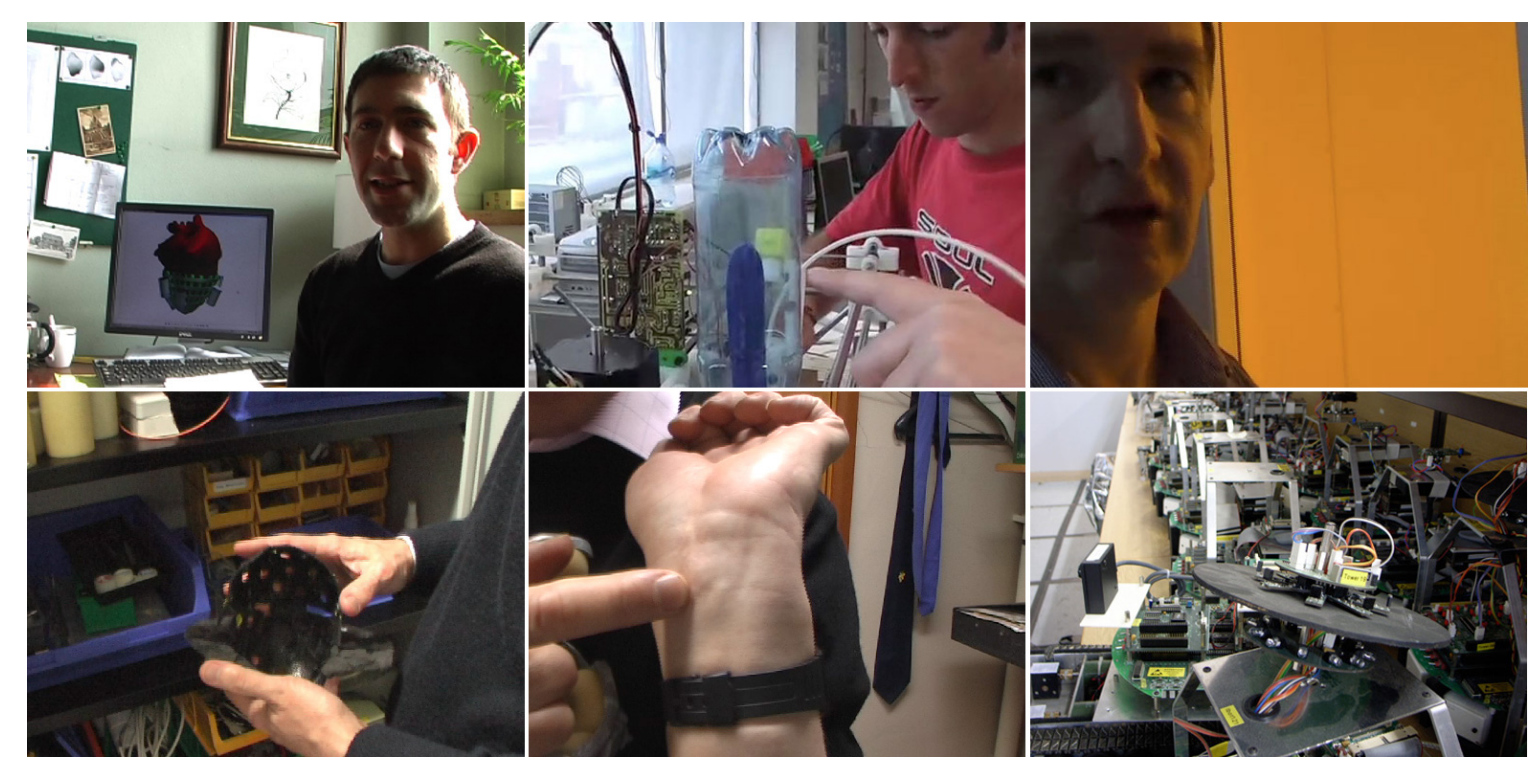

Figure 17: Frames from six of the filmed interviews with engineers and scientists

\section{Interviewing a director of research at a biomedical institute}

With another designer (d3) I conducted an early interview with the director of a biotechnology institute in London, whom I refer to as researcher 1 (r1). The interview with $\mathrm{r} 1$ was conducted alongside a tour of facilities, and the $\mathrm{r} 1$ covered a range of topics including an overview of research underway at the Institute, an assessment of the relationship between scientific research and public engagement activity, the benefit of interdisciplinarity across science disciplines, and the development new technologies for healthcare applications. 

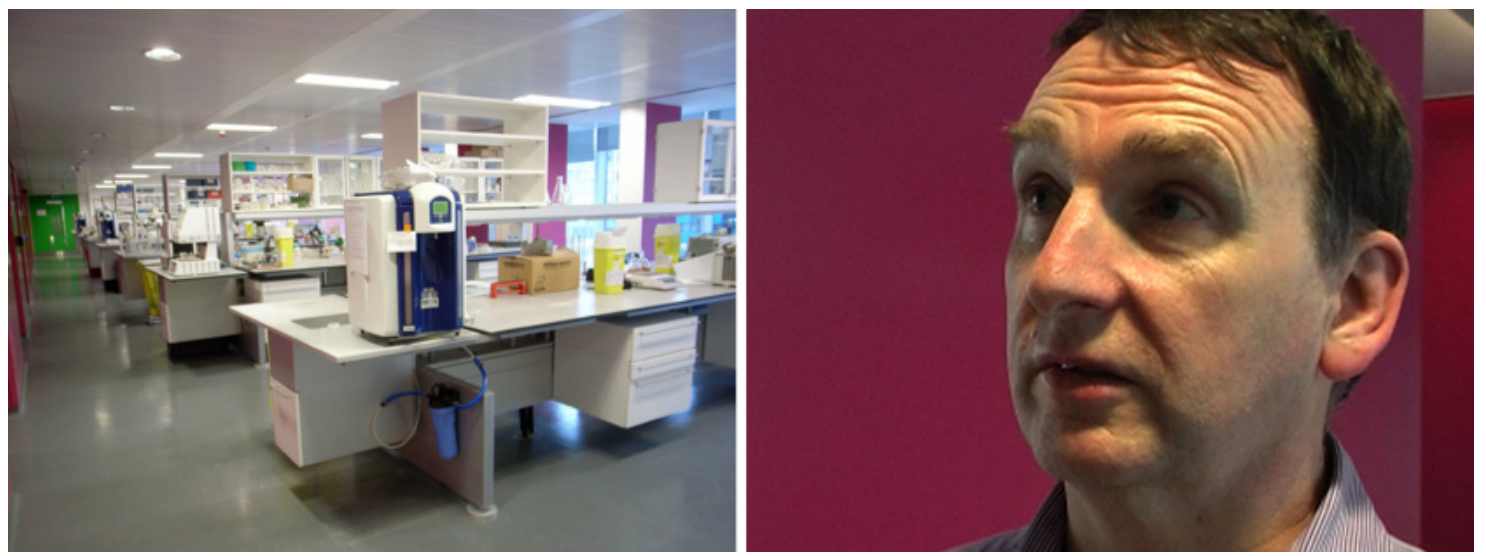

Figure 18: View of the biomedical institute, still from an interview with researcher 1

\section{Silicon and cells}

A particular interest to the two interviewer-designers at this time was research that related to a formative project theme of technologies and bodies, and so one line of questioning sought to establish descriptions of research that would elaborate this notion of 'hybridity'. In respect of this theme, r1 described research that brought together fields of research that included tissue engineering, medical robotics, bionics and nano-scale applications (Kerridge \& Caccavale, 2007). The researcher spoke about advances in bionics derived from "understanding how to make biology and electronics talk to one another", which led to the development of biomedical devices for healthcare applications. The researcher offered this overview of the research:

The idea a few years ago of having a biological silicon hybrid was science fiction, but now because silicon technologies are getting smaller, and our understanding of the organization of biological systems is getting better, you can start to see how you can put the two together. (Kerridge \& Caccavale, 2007)

For the designer-interviewers, comments such as this were seen to offer clarity and insight, helping them conceptualise biomedical research, and leading to use of the quote within design materials. Where statements from interviewers became established as having value in this way, they were drawn upon repeatedly in order to articulate design territories and communicate themes. For example, the quote above from r1's interview was incorporated into a poster for a public event around the theme of bioethics (see Figure 19). This treatment of interview material is seen to confer scientific authorisation on design concepts, and in this way develops approaches taken in critical design where the facts or statistics of experts verify design narrative, as was the case with Audio Tooth Implant (Auger \& Loizeau, 2001). Following the interview, r1's quote was used in a series of design materials, including posters and also captions that accompanied final designs in exhibitions. There were occasions where these supporting quotes from researchers became refined as a result of scrutiny and advice from other researchers. In this way, due 
to the on-going nature of the collaborations, where scientific quotes are displayed in design material in order to provide veracity and authority for design scenarios, these quotes became challenged and were subject to change due to discussions with researchers. Here is an example of how the scenarios of speculative design are open to and therefore shaped by the responsibilities of collaboration.
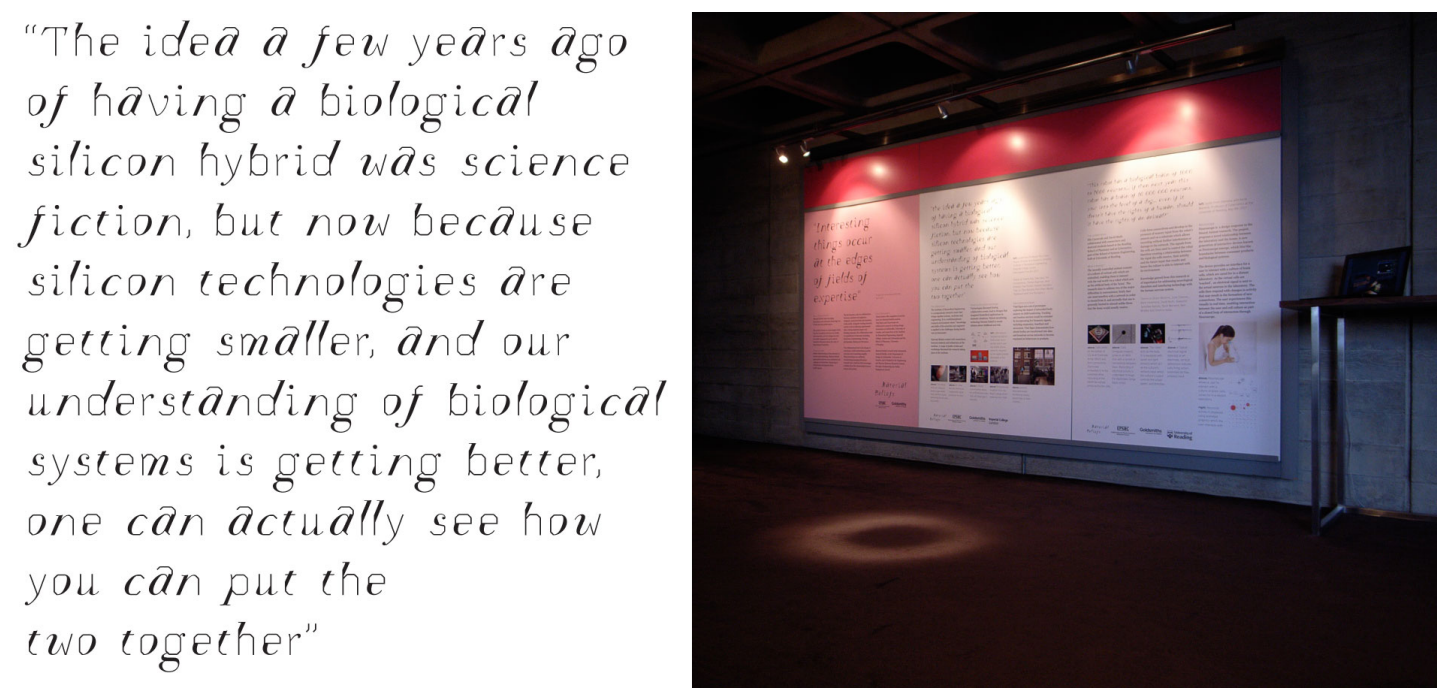

Figure 19: The central panel of this display for an engagement event at the National Theatre features an transcript excerpt from an interview with a researcher

\section{Turning research into narrative}

The proposal made a case for designs that would provide a ground for the public discussion of issues related to biotechnology. In this respect the two interviewers were sensitive to comments from $\mathrm{r} 1$ that provided an impression of the milieus that the outcomes of research related to, as these could be treated as start points to inform design scenarios. A feature of r1's account that aligned with the designer's expectations were his own speculation about likely applications for areas of research that would otherwise be difficult to apply to social settings. Research at the institute was on one hand seen to be discreet and specific, and included algorithm design, the fabrication of silicon, or material innovation for biosensor devices. At other times the researcher emphasised the application contexts that would be enabled by these objects, as they became function and stable, and then brought together in combination as biomedical devices. For example, r1's description of technical difficulties regarding the development of a skin worn biometric sensor, gave way to a wide-ranging discussion related to the eventual use of such a biotechnology. This included reflection about making devices for the 'worried well' - that is those without acute conditions who self-monitor excessively and frequently misdiagnose ailments - along with the implications of a shift in the portfolio of biomedical device makers from healthcare to other industries including sports and gaming, which was characterised by r1 as "the medical pull and the technology push" (Kerridge \& Caccavale, 2007). The designers encouraged these moments of reflection, where technical explanations of research gave way to 
extended accounts of application and use, particularly those examples that dealt with the misappropriation or the recontextualisation of features. I argue that the designers were seeking these exceptions in order to reconsider the configuration of biotechnology within their own proposals. In this way, interviews can be seen as occasions for researchers to identify for designers potential speculative treatments for biotechnology.

\section{Establishing expectations around PEST}

A later section of the interview saw $r 1$ address the role of PEST within the institute and beyond. R1 saw PEST as one of the responsibilities of his role at the institute, alongside the proposing, doing and reporting of research. He believed that PEST allowed the potential hazards of a technology to be communicated, and that PEST also promoted the health benefits of new biotechnologies. These comments were made in relation to nanotechnology, which the lab is recognised as doing, and also a historic case regarding public attitudes to genetically modified organisms, where it was seen by $r 1$ that there was a failure in the regulation of commercial organisations:

The public can be people you meet at parties, and conversations you have, or it can be a select committee in the House of Lords... and so I think we're all very conscious, that even if on a technical, scientific level the concerns are unfounded, they have to be treated with respect and with understanding. And so I don't think in the nanotech area, you'll see the same mistakes made as were with GM crops, GM food. (Kerridge \& Caccavale, 2007)

These early discussions establisheded r1's interests in PEST, and these interests were developed in subsequent project activity. In this way, the project provided a mechanism for $r 1$ to extend a commitment to PEST. An example is r1's later involvement in 'My Space, My City, My World', an engagement event with young people at the Stephen Lawrence Centre in London where r1 and I delivered a workshop that encouraged attendees to design their own applications using biomedical sensors (Kerridge, 2007b). While r1's participation aligned with his commitments to PEST regarding communication and also education, which I have only discussed lightly here, I can say that my participation had more to do with experimenting with the role of speculative approaches applied as workshop formats. So while there are clearly differences in the expectations that $\mathrm{r} 1$ and I have about the aim of this event, here is an example of how interview identified topics such as the public engagement of nanotechnology, which acted as start points for later public activities, despite differences in expectations of those involved regarding the value of that activity.

\section{Showing process}

The films, photos and transcriptions generated during and after the interview with r1 were also edited and published online, providing an impression of the research 
contacted at the institute (Kerridge \& Caccavale, 2007). These film clips are lowquality 'sketches' rather than technically accomplished documentaries, and drew on a method established by Bas Raijmakers where he used filmmaking to support the reflection of designers and research participants upon their activities, and also as a way of documenting practice based design to support research and publication activity (Kerridge et al., 2005). On the Material Beliefs website clips are organised by topic, and in the case of clips from r1's interview, topics include patient self-monitoring, consumer centred approaches to healthcare and nanofabricators. My experience of preparing interview material for these webpages was that is supported reflection on these topics, and provided another opportunity to find relevant or resonant material amongst the footage. Additionally, designers saw the online publication of these interviews as delivering on project commitments to PEST. However, I would argue that these resources are better understood as Raijmakers intended, as a format for capturing and publishing design processes, and in the case of Material Beliefs, this enabled the design activities that supported a speculative approach to be more accountable and legible.

\section{Interviewing a biomedical research fellow}

In the following example I discuss a set of clips that were filmed and edited by designer 2 (d2). As such this is a lighter analysis, which demonstrates that designers took different approaches when researchers were interviewed. In contrast to the interview above, this second interview with two researchers in a biotechnology lab is informal and conversational, and shot from the point of view of $\mathrm{d} 2$ as he talks to the researchers while they are engaged in lab work or while they are demonstrating and handling lab equipment (Loizeau, 2007).

In one sequence the $\mathrm{d} 2$ edges the camera into a container of pigs' hearts, from which useful cells are to be extracted for experimental work. A rapid back and forth between the $\mathrm{d} 2$ and the $\mathrm{r} 2$ ensues:

D2: This is a bag of hearts?

R2: Yes, they were killed today.

D2: Really?

R2: Yes.

D2: Oh no! 

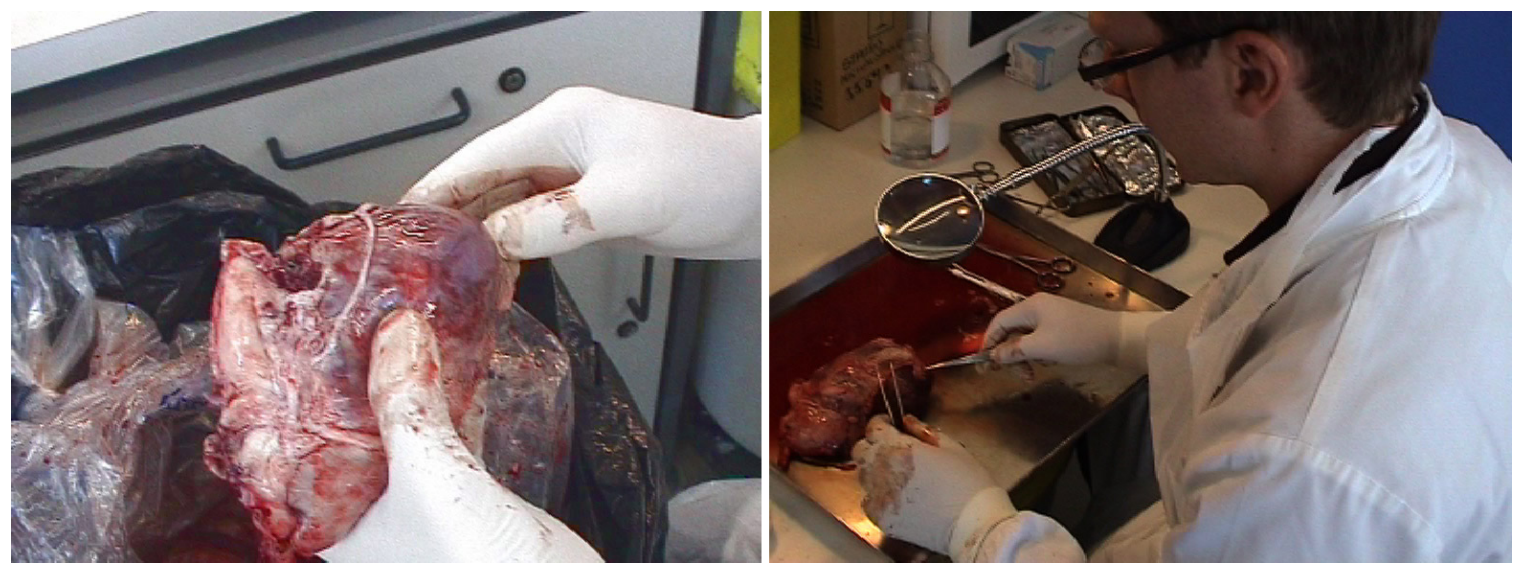

Figure 20: A heart is taken from a container, useful tissue is cut away from fat layers (Loizeau, 2007)

D2 assumes what he described as an "eager dumbness", and so rather than pursuing a line of questioning that would lead to a technical description by r2 of the task at hand, there is a playful exchange that is perhaps somewhat at odds with the activity taking place. The approach of $\mathrm{d} 2$ demonstrates that with very light preparation and by taking a more improvisational approach, more topics are covered, more equipment is seen, and conversation can be guided to make the most of unexpected tangents.

In another sequence from the same visit, researcher 3 (r3) holds up an eviscerated pig heart valve to the camera. R3 describes how, 'rinsed' of its original cells, it is able to act as a neutral scaffold for culturing stem cells from another source, and then leads the designer to a machine that compels the sample to undergo small repetitive movements, whereby the introduced stem cells are coaxed to differentiate as functioning heart tissue in and around the flexing valve:

D2: So is this almost like an exercise machine for the materials that you use then?

R3: Yes

D2: I think in furniture they use similar machines for chairs, to test the stresses...

R3: Yea

D2: And it will do it 100,000 times...

R3: This wont test them, it will just get them used to seeing the things that they would see

D2: right ok

R3: if they were implanted back into the body 

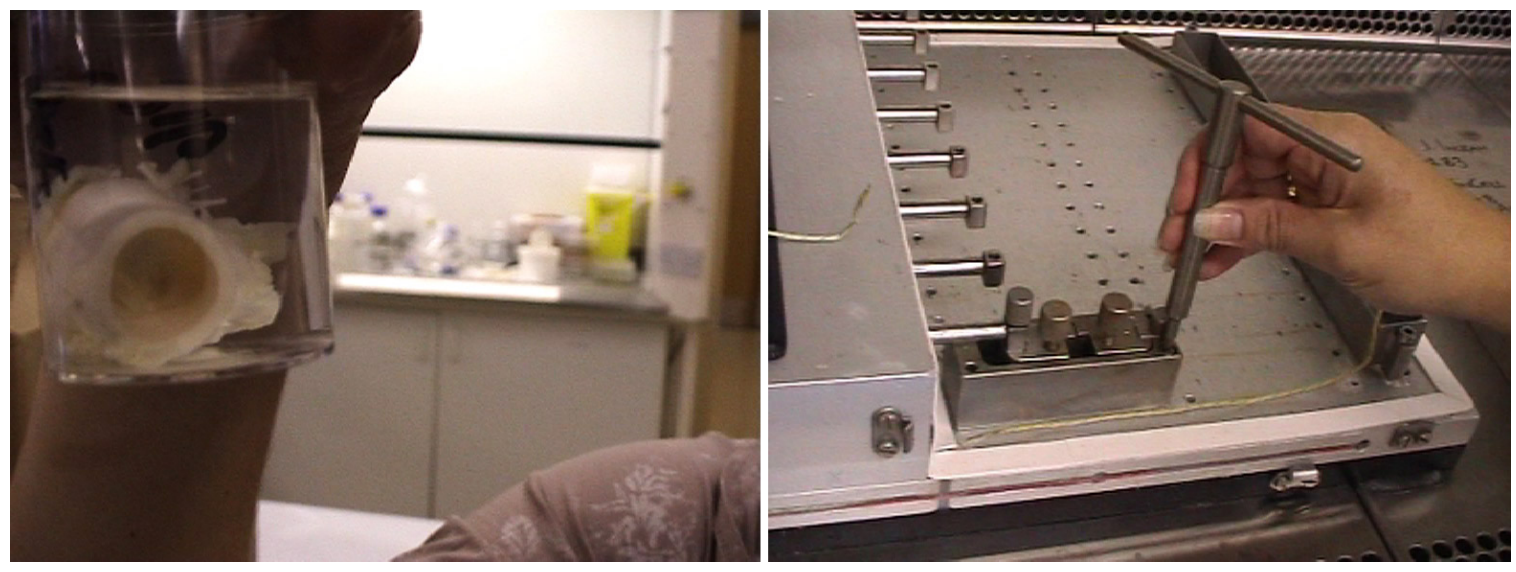

Figure 21: A rinsed pig heart valve, and a device for mechanically encouraging heart tissue growth from cells seeded onto the valve (Loizeau, 2007)

In drawing a comparison between the biomechanical device and equipment for stress testing furniture, the provisional quality of earlier chat gives way to something that generates new representations. Machines are reimagined doing different kinds of work, for industrial design rather than biomedical research. Here it seems that the designer is not trivialising the research, or the commitment of the researcher to the experiment. While the interviewer seems earnestly interested, these enquiries do not seem predicated on full comprehension, but on uncovering enough detail to offer a basis for an intervention from the designer upon interview findings. To accomplish this, the designer takes the materials and technologies under discussion to an unrelated yet mechanically similar setting, where the recombination of elements starts to suggest an aesthetic. And so in the lab becomes a studio for biotechnical furniture, where chairs would have muscles rather than springs. In this way the reordering provides a vignette from which specific designs can then be developed.

\section{The value of the interviews}

These two cases demonstrate different approaches taken be designers when interviewing researchers about their work. I suggest that each designerinterviewer's approach is derived by individual expectations about the sort of data that might be of value for scoping and identifying a design project, which is in turn underwritten by individual approaches to designing and also expectations of PEST. I have shown that interviews are initial meetings between designers and researchers that sometimes support subsequent shared activities, including engagement events. Additionally I have argued that interview topics can deal with the detail of core research and also provoke researchers to anticipate effects or implications of research and in doing so provide detail that aligns productively with a speculative approach to design. At other times researchers sought to mix the work of the lab with the everyday, leading to playful confusion which led to the 
function of lab processes being reimagined so as to support early ideas about the behaviour of later designs.

\section{Workshops at a biomedical institute}

Following the interviews, different forms of continued association took place between designers and researchers. I discuss these differences in the following chapter, while in this present section I focus on two workshops relating to a visiting researcher role I took at a biomedical institute. This role was arranged with researcher 1 (r1) whose interview was discussed above, and supported ongoing contact with researchers and technicians based at the institute. This extended period supported a variety of activity including the arrangement of workshops hosted at the institute. I describe how one workshop developed out of a series of events around a biomedical platform, while a second workshop was arranged for a group of postgraduate students as part of a design brief.

\section{A workshop with biomedical researchers and a patient}

Before discussing this first workshop, it is necessary to summarise a set of activity that took place during my residency at the institute. I continued to interview staff at the institute in order to identify themes for project activity. The digital plaster emerged as a core research platform at the institute. The technology comprised of a microprocessor, miniature sensing devices and a radio transmitter embedded in a small package and worn like a plaster, to transmit biometric data to remote clinical services via the wearer's mobile phone (Toumazou \& Lee, 2005). I published a design overview of this platform on the project website (Kerridge, 2007a), including material from interviews with a clinician seconded to the institute and interested in medical applications related to component technologies of the digital plaster ( $\mathrm{r} 4$ ) and a researcher involved in developing the technical platform (r5). These interviews led to the planning and delivery of a session as part of an engagement event at the Dana Centre, a public engagement venue in London (Kerridge, 2007f). At this event $r 4$ and I led a discussion about the platform with a group of 20 members of the public. Topics arising during that discussion included data privacy and the design of technical systems for patients. Here, participant 1 (p1) spoke about her experiences using a sensor controlled insulin pump:

I have to still be quite inventive about how I wear this, so that people don't know that I'm wearing it, so I have to have a little pocket sewn into my clothes and things... what processes are you using to get the designers in early enough, and particularly the patients, because we don't tend to get asked about which features we think are important. (Kerridge, 2007f) 

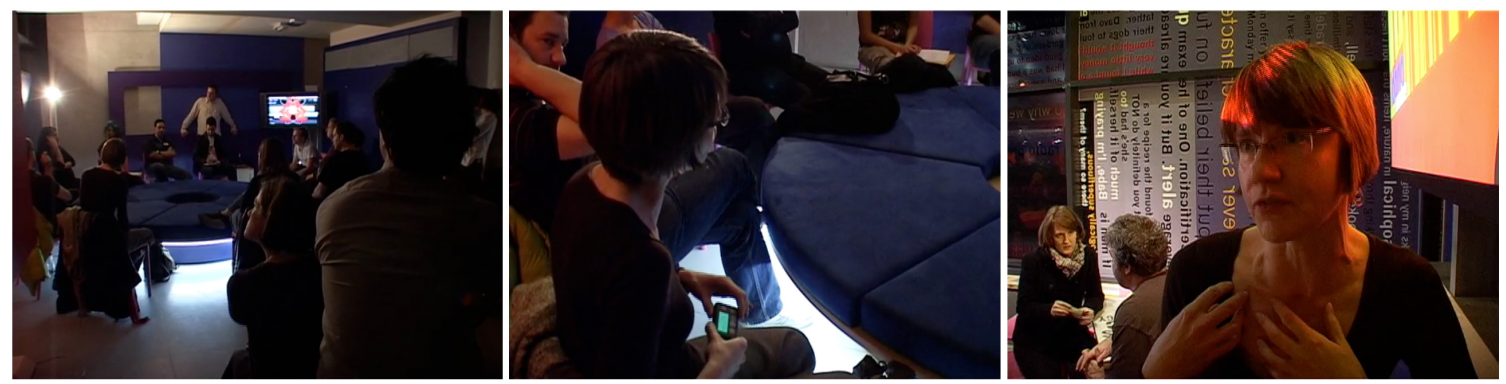

Figure 22: Digital Plaster discussion at the Dana Centre, p1 during and after the session

Back in the Institute, sensitized to user perspectives of biotechnology by p1's account of her insulin pump, r4, r5 and I discussed research of an artificial pancreas "for real-time glucose sensing and insulin release for diabetics" (Pantelis Georgiou \& Toumazou, March 2007). The device became the focus of a discussion between the clinician and I concerning the tendency of such a platform to establish a relationship between individuals, systems, devices and data. Subsequently these issues became discussed in relation to an academic paper on hybrid communities and participatory design, which emphasises the role of technologies "in the construction and the functioning of those collectives" (Callon, 2004). The notion of hybrid communities seemed to align with recent experiences at the public engagement event, and a decision was made to convene a workshop that supported the informal network of discussants described above including p1, who all shared an interest in a common technology for different reasons. An aim for the workshop was to allow these different perspectives to be shared, elaborated and documented, and from my own perspective these elaborations were seen to support a speculative design process. In this way, the initial design exploration of a biomedical platform and its applications, developed into a public engagement event where a participant identified her interest in biotechnology research, which guided a conversation between $\mathrm{r} 4$ and I where technical descriptions and theoretical perspectives were discussed, and led to a workshop being arranged.

Mind the Loop: a workshop

Mind the Loop was a half-day workshop convened at the institute in March 2008. For the workshop I invited a small group that included the clinician researcher (r4) and the Dana Centre participant (p1) who was also a patient of $\mathrm{r} 4$. Additionally we were joined by a researcher who was developing the artificial pancreas (r5), and a filmmaker. Prior to our workshop I circulated a document introducing the theme of the day, providing an outline structure, and offering something of an objective for the session:

The aim of this meeting at [the institute] is to discuss new treatments of type 1 diabetes together and in more detail, to ask questions and have ideas challenged, and make a short documentary film so others can look in upon these combined perspectives. (Jackman, 2008f, p. 1) 
The event's title, Mind the Loop, conflated patient experience and technologist ambition. For while the aim of artificial pancreas research is to provide algorithmic control of insulin delivery for 'closed loop' management of type 1 diabetes without the need for patient intervention (Pantelis Georgiou \& Toumazou, March 2007), p1's account at the Dana event made it clear that responsibility for disease control currently lies with the patient, whose roles as interpreter and manager of data generated by insulin pumps, puts human mediation at the centre of existing diabetes technology. While the event was convened at the institute, and as the meeting would feature technologies being developed there, there was an intention to introduce patient experience alongside technical and functional descriptions of the research platform. This aspect was foregrounded in the briefing document by recalling p1's unplanned role at the Dana session on the digital plaster:

By offering an everyday experience of diabetes, p1's contribution provided an opportunity for a public discussion about the digital plaster, which was complimentary to the designerly and medical descriptions of the platform.

There seemed to be something worth exploring, in terms of this combination of perspectives. (Jackman, 2008f, p. 1)

The session began with introductions and planning, followed by a description of the artificial pancreas by the researcher, and a tour of the institute to see live experiments related to the development of the platform. I then led brief interviews with p1, r4 and r5 about existing and future technologies, leading to a group discussion about what had been seen, and the workshop closed with individual reflection about the session. The filmmaker followed these proceedings and captured most of the session so that short films could be edited and published to provide documentation of the session (Kerridge, 2007c). I use excerpts from transcripts of the films in the following description, followed by a discussion of the data in relation to the concerns of the thesis.
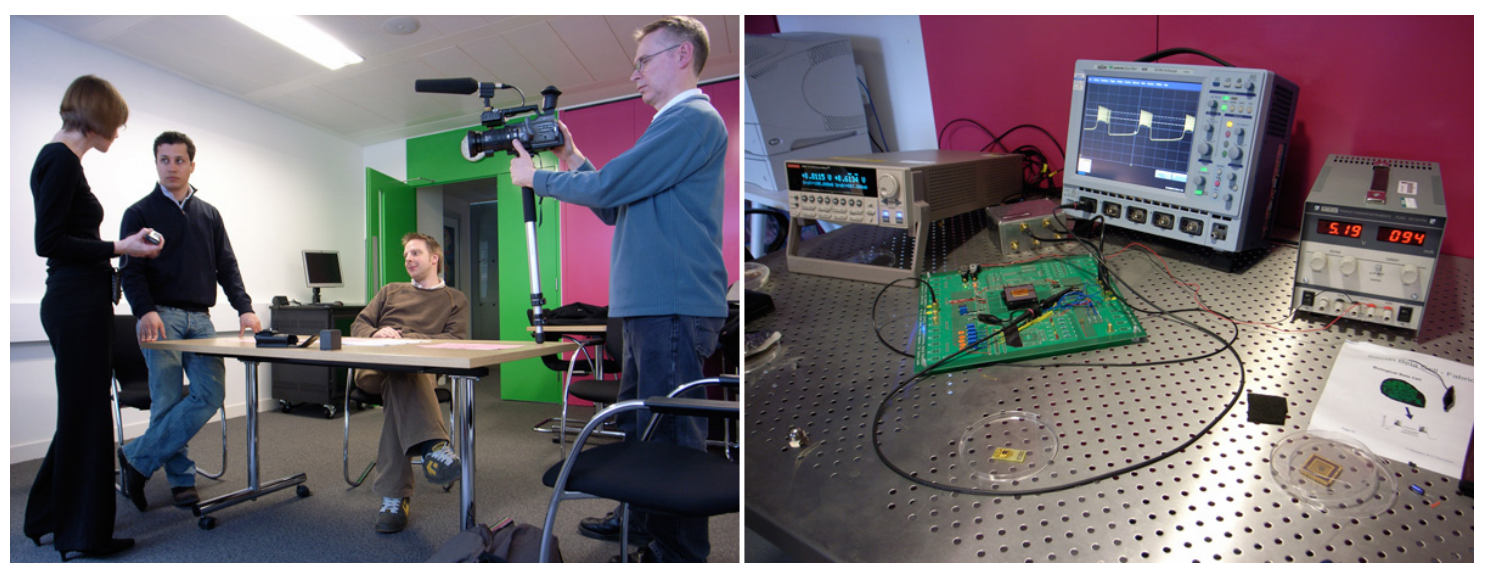

Figure 23: Participants of Mind the Loop meeting, the test bench for the artificial pancreas 
Some data from the workshop

In the introductory session $r 5$ contextualised the artificial pancreas in relation to other biomedical research projects at the institute, including a silicon cochlear and a digital retina. He describes an approach whereby "modelling the way our biological organs work, we can create systems with the same efficiency as the human body" (Jackman, 2008e). In this respect the artificial pancreas aims to mimic the biological release of insulin, in order to regulate blood sugar levels in bodies that lack that function:

We've looked at the biology of the pancreas, and questioned what happens when the pancreas sees glucose, and releases insulin, and what we've found is that the cells inside the pancreas, the beta cells, when they see glucose, they do some sort of intelligent algorithm internally, and they release insulin. (Jackman, 2008e)

This algorithmically derived behaviour was demonstrated with a prototype of the silicon beta cell, running on a test bench in an electronics lab. R5 showed how the test silicon responds to changes in the level of an input voltage - representing levels of glucose in the blood as determined by a sensor - resulted in fine grained changes in the output of a voltage level, which would in turn control the release of insulin. To support the demonstration r5 compared technical function to human behaviour:

When you eat some food and blood glucose rises, we get bursting from the beta cell. By boosting the equivalent blood glucose levels of the chip, you can see that the microchip bursts in a similar fashion to you beta cell... Each spike is responsible for introducing some insulin into your blood that lowers in turn your blood glucose. (Jackman, 2008e)

Following the technical demonstration p1 reflected on her experience of using an insulin pump:

I realised I was using the word "feel" about the pump... this is technology, and it's absolutely amazing, but when you have to live with it day in day out, you do actually have feelings about this technology because it makes a difference to how you feel, it affects your self-esteem how you wear it, so I realised that how I feel about the technology is actually really complicated. (Jackman, 2008f)

During the reflection session, p1's account of using an insulin pump was recalled by the $\mathrm{r} 4$, who is 'fascinated' about the extent to which the technology effected $\mathrm{p} 1$ outside of a clinical context:

Before the pump, $\mathrm{p} 1$ found it easy to hide the diabetes because she had insulin pens, and subsequently has been forced into an attitude change by a piece of technology, that has benefited her in many ways but leads into the conflict for 
her as someone that has been forced to become 'out 'as a diabetic. (Jackman, 2008b)

A recurring feature of the session is the proliferation of data by the current open loop system. Towards the end of the session p1 presents a 17-page document that was generated and exported as a pdf from her smart insulin pump. The device collates and formats the data that it generates, in this case over a 14-day period, for interpretation by $\mathrm{p} 1$ and in order to further configure its behaviour. The demands on patients, doctors and nurses for the interpretation of this data is a focus of the closing discussion. For the clinician the reams of data produced during the five month period between visits for the patient is overwhelming, so he looks to the patient to 'be a filter', and suggests to p1 that "it's data mining, that you're doing". p1 responds:

I'm quite motivated and I've spent a lot of time on this, but I think there is a need for more sharing about how to interpret data, what to do with it, some of that might be self help groups with patients, it might be the diabetic nurse and their role... but I don't get the feeling that the skill sets aren't keeping up with the technology. (Jackman, 2008b)

Mind the loop as speculation

While the aim of the digital pancreas is a closed loop system for the control of blood sugar levels in the body, this workshop at the institute reveals that disease management with a biotechnical platform entails a fairly large set of people, technologies, data and processes. Even then, it was demonstrated that the system has effects that are additional to the control of the disease, and unwanted, including the demands of data interpretation upon the patient and clinician, and the affective nature of the use of the pump upon the patient.

What does speculative design make of and do with this data? This surely speaks to a participatory or co-design approach, as there are opportunities here for a methodology that would respond to the issues that have been identified through a discussion between different stakeholders. For example, the interface and the software functions of the insulin pump could be re-designed, or services that better manage patient and healthcare relations might be proposed. It is through analysis of the processes undertaken during project work that the speculative designer becomes exposed to forms of knowledge that challenge two core operational tenets that characterise the critical inheritance of their approach. These are the formulation of a monolithic and controversial scenario for emerging technology, and the assumptions inherent in the rhetorical intentions of that scenario about the forms of debate that are seen to be enabled. In the episode above, the designer becomes sensitised to a variety of accounts that deepen their encounter with a biotechnology and therefore challenge these tenets. But crucially, I argue that empirically derived detail provides an opportunity to develop a 
version of speculative design that does not converge with participatory approaches. For my interpretation of participatory design is that it does not reflexively examine the assumptions of the programmes that support its projects, whereas a reflexive critique of public engagement programmes and approaches is an explicit aim of this thesis. Rather, the extended speculative practice that I am seeking, sees the designs as only partial concrescences of the data generated through a trajectory of practice, where these materialisations are complemented and also unbalanced by the accounts of the broader activities that attend their making, and where those accounts deal reflexively with the programme and practices of, in my case, upstream public engagement. In this way, both the artefact and its critical, empirical account take the place of the artefact and its publicity rubric (critical design) while resisting the urge to incorporate the products of participation in an instrumental outcome (participatory design). While a critical approach rejects empiricism, and participation is seen be enabled through it, I consider that both these approaches support the materialisation of artefacts as settlements of 'problems'. I would characterise empirical speculation as opening up the settings in which technologies are made, and of problematizing the artefacts that would come out of those settings.

\section{A workshop with postgraduate students}

An objective of Material Beliefs at proposal stage was to resource upstream engagement in labs. However, the proposal does not provide examples of what this would entail, or who would be engaged. In this section a workshop convened at a biomedical institute for a group of postgraduate students provides an example of upstream engagement in the lab. I provide some background to the workshop, and then discuss what was accomplished, and how its features align with other examples of upstream engagement.

\section{Setting the context}

The workshop was seen by researchers as an opportunity to undertake public engagement activity. The potential to arrange public engagement events in the institute had been discussed with $\mathrm{r} 4$, who described two existing models. The first were research demonstrations for funders and other partners, and were generally arranged by a member of the institute. The second were tours and presentations for schools and college groups, which were organized by an educational outreach unit with a remit across the university. In this respect, a workshop for design students would provide an additional mode of engagement that would be distinctive both in terms of the activities undertaken and the motive for doing those activities.

During the residency at the institute, I delivered a postgraduate design brief at a London university. The brief had developed over a five-year period, initially framed so as to encourage students to take emerging biotechnologies as a start 
point for a speculative approach to product design. The professor of this programme offered some refection on the development of the brief, and the nature of his students' approach:

Early on, I think people mistakenly thought the projects that looked at the social or political implications of scientific knowledge were critical of scientists and science. This was never the case. The projects do not function as public communication exercises, but neither do they critique scientific advances. They are simply taking exciting scientific discoveries and fast-forwarding to see how they might impact on our daily lives in the near and not so near future. (Beaver, et al., 2009, p. 64)

As a key part of the brief, the workshop aimed to provide a robust encounter with biotechnology research for the students. Ward and Wilkie discuss such a strategy for the teaching of critical design at undergraduate level, where the critical studies canon of "Baudrillard, Derrida and de Certeau" are challenged by empirical paradigms inspired by STS accounts of technology and society (Wilkie \& Ward, 2008, p. 1). Students are instead encouraged to get amongst the phenomena and practices that excite them; "to go out, open the black boxes and untangle the complexities and novelty they encounter and in doing so provide their own situated and partial descriptions and new design contexts" (Wilkie \& Ward, 2008, p. 2). My role at the institute provided an opportunity to support the postgraduate brief by providing a direct encounter for the students with the biotechnologies being researched there.

With the help of researchers at the institute I devised a workshop that provided a pedagogical experience for these students that complemented the detail of the brief. Biotechnologies being researched at the institute were to be objects of provocation for the design students, whose orientation to the brief would now become grounded through direct encounters, rather than as the result of desk based research. Additionally, while the workshop would have a pedagogical function in relation to the project brief, it also supported the aims of Material Beliefs in delivering upstream engagement events in labs, and furthermore complemented models of educational outreach already established at the institute.

\section{About the workshop}

The workshop initiated a four-week design project for the postgraduate design students and provided an extended project briefing, offering a full day of activities for 16 students, starting with meetings and introductions and an orientation presentation from the tutors. The presentation included slides depicting two ongoing projects from Material Beliefs that the tutors were involved in, highlighting their interactions with researchers and the speculative treatment of research. The final slide offered a set of bullet points providing key features of Material Beliefs: 
- combining science \& engineering, public engagement, social science and design

- design as a structuring tool for emergent practices

- situating the work, putting it out there in society

- testing and challenging ways of working

- documentation of process as well as outcomes

- making new technology contingent and messy

Figure 24: Summary slide from introductory presentation for students

These points provided something of a ground for students to consider the workshop activities that would follow, while offering a start point for the development of individual approaches to the brief.

The presentation was followed by an overview of the Institute from the director of research that included a short slide presentation of the research projects being undertaken and a background to funding and the interdisciplinary nature of the research, which included staff with backgrounds from physics, chemistry, biology and engineering. A tour of facilities at the Institute included an electronics workshop, anechoic chamber, a lab for testing medical robotics and a biology workshop. Other workshop sessions included two research presentations, to provide a deeper impression of biotechnology being put together at the institute. The presentations were about the SAW, an implantable blood pressure monitor, and the artificial pancreas. Additionally students conducted an experiment in the biology workshop where they extracted DNA from cheek cells. A final session was the presentation and discussion of the project brief tiled "Science And Society", which asked the students to make a design responding to biotechnology research:

How can designers situate this research into broader society? By setting up interventions with engineers and scientists, along with publics, bioethicists and sociologists, design can create products, services and events which stage sophisticated conversations, by plotting original paths through this crossdisciplinary space. (Kerridge \& Caccavale, 2008) 

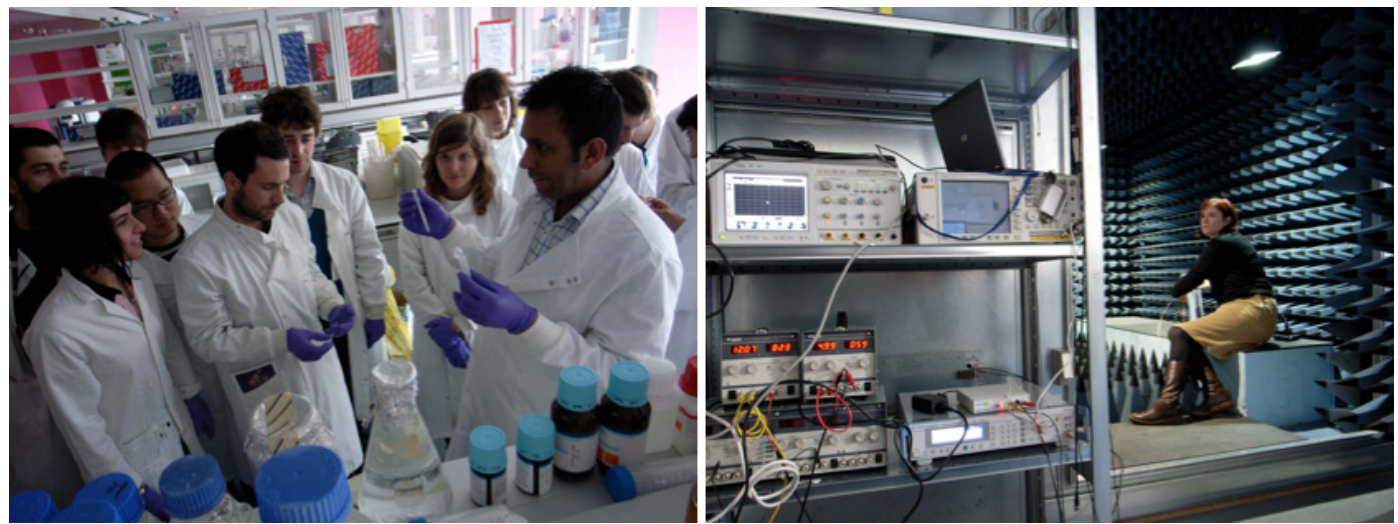

Figure 25: Workshop for students at IBE, testing an implantable blood pressure monitor

\section{Extending the Lab}

In order to provide an account of the outcomes of this workshop, I include three related events. These are a student tutorial in the second week of the brief, a pedagogical reflection session convened following the four-week brief, and an evaluation meeting at the institute towards the end of the Material Beliefs project.

Following the workshop, researchers from the institute and also from a second research lab, took roles as visiting tutors at the students' university studio. Individual tutorials are a feature of projects, while the inclusion of the researcher was fairly novel and aimed to provide the researcher with an entirely different interpretation of familiar research, and to offer the student an external perspective on their design concepts. A short film was made of one such tutorial, in which a student (s1) presents a theme that combines a biometric sensing platform and tiredness at work. S1 describes the concept:

I found this hormone, orexin, related to maintaining a normal sleep pattern, and people with narcolepsy have got a reduced amount of it... Then I was looking at the nano-needles, for monitoring levels of hormones in the bloodstream, specifically for this hormone. (Jackman, 2008a).

This background is then developed by s1 though a discussion of the culture of patient activism and patient expectations of doctors in particular. A fictional interview with a doctor about workload and patient relations provides background for a proposal where the doctor's identity badge becomes a display for their alertness. Elsewhere, students undertook fieldwork and conducted interviews. One project took biomedical technology presented during the workshop at the institute as a start point; an implantable blood-pressure monitor for patients with chronic disease, which incorporated a passive radio system to transmit data to an external unit. A follow up meeting between a student (s2) and a researcher (r6) developing the implantable sensor, featured discussion of techniques for blocking or faking the signal sent from the implant. In a project titled Cathy the Hacker, s2 explored and visualised techniques for data evasion. This included designed props and short 
films documenting how to hack an implant to provide fake, healthy data to deceive a hypothetical insurance company that is monitoring a fictional user's lifestyle, thereby intruding upon her daily activities. Through an interview and follow up conversations with the researcher, s2 devised hacks which included attaching a sensor to an energetic pet cat, in order to generate a surrogate data set, while "The closing spin cycle of the washing machine also does a good job"(Hayoun, 2008). The themes of the project are deepened by s2's conversations with $\mathrm{r} 6$, and $\mathrm{r} 6$ reflects on her experiences with s2 during a focus group session:

I would have assumed, "Oh of course this is everybody's benefit" like you, you may not want one you know, people's civil liberties and everything and, and it was s2 who first raised the issue of, well, what, what if your insurance company will make you have an implant or else won't cover your hospital expenses. (Dawson, 2008)

These encounters provided s2 with technical insights to develop a speculative design scenario, while the 6 takes an active role within an alternative description of her own research. In this respect, the workshop with postgraduate design students was something of a departure from the tours and demonstrations provided for partners and schools groups described earlier. The partner demos build peer and partnership networks and provide economic support for the institute, while educational outreach is related to university recruitment and policy commitment to maintain the uptake of science subjects at undergraduate level. In contrast, through a conversation with $\mathrm{s} 2$, it seems that $\mathrm{r} 6$ is considering other forms of knowledge in relation to the biotechnology she is developing.

\section{Summary}

This chapter is the first of three empirical chapters, and focused on biotechnology labs as sites of project activity. The chapter opened by considering the lab as it featured in the project proposal, where design for debate, upstream engagement and biomedical research are brought together to build a case for funding. I followed with episodes from the project, firstly with two interviews led by designers with biomedical researchers, and secondly with a discussion of two workshops, one where a patient, scientist and doctor meet to discuss an artificial pancreas, the other where a group of postgraduate design students visit a biomedical lab. I now take interdisciplinarity, collectives, and knowledge as three core themes to summarise this material.

\section{Interdisciplinarity}

The laboratory is a frequent feature of both the historical and analytical literature of public engagement discussed in chapter three. A key feature is the conceptualisation of activities that support the association of people from outside 
the lab with researchers based there. Activities that bring together biomedical researchers and non-experts in the lab are seen to be configured by a range of features, including the motivation for the activity, the agencies of the researcher and non-expert, and the characteristics of their association. For the SciArt initiative, interdisciplinarity supports the translation of issues around biomedical research into creative outputs for exhibition, where the researcher and the artist are experts who offer distinct insights around biomedicine, and whose collaborative effort emerges through the artist's extended residency in the lab (Arends \& Thackara, 2003). Elsewhere interdisciplinarity is conceptualised as a range of logics, at times making research accountable, but also providing an ontological function, or doing innovation (Barry et al., 2008). Both versions of interdisciplinarity are useful for considering interactions between the speculative designer and researchers in the lab, in particular the transformative effects upon the pathways that the research follows.

However, interdisciplinarity tends to emphasise the value of designer and researcher pairings, and does not adequately support the agency of others coming into the lab to do activities. For example when the patient and the students participated in the workshops, their conversations with designers and researchers affected the trajectory of the project. What goes on in the lab then is not reducible to interdisciplinarity, rather the attempts of designers and researchers at various times to do interdisciplinarity - perhaps during the curation of an event that is shaped with language from the proposal, and as a feature of project evaluation for the funder - is one of the ways that activities can be made sense of. Like engagement, public relations, or education, interdisciplinarity helps action be framed, structured and reported upon, but does not necessarily get at the features of what is done there.

\section{Collectives}

While I have argued that it is richer to consider design activities in the lab as coming together through the actions of people other than the designer and the researcher, it is also clear that it is not only people who have agency. P1 describes how her glucose monitor effects how meals are arranged and eaten, a photo of the Queen on the wall of the institute started a conversation about science and empire. I have discussed a range of literature that helps consider how other objects have been seen to have agency, and most relevant to the episodes in the lab are Callon's hybrid collectives for the design of technical systems, and a Irwin and Michael's discussion of assemblages in PEST settings. Callon has discussed how technical knowledge are co-produced in collectives of patients and scientists, with the participation of non-human objects:

Technologies, and particularly ICTs, must be considered and managed as authentic actors who shape collectives and open new ways of thinking and acting. (Callon, 2004, p. 7) 
From the outset, the project conceived that a broad network of people, materials, methods, processes and equipment would be brought together under the auspices of public engagement of biotechnology. There was also an expectation that the lab would be in some way 'opened up' through the establishment of these mixed networks. The episodes above provide grounded examples of how these sets of objects come together. But what are the features of the ways in which these relationships are made? Irwin and Michael have drawn attention to the process of doing PEST as one where new alliances and identities are established and combined:

...These assemblages are a means of expanding the range of entities, actors, processes and relations that get blurred and mixed up... ethno-epistemic assemblages are about renewing and refashioning the agenda of public understanding of science. (Irwin \& Michael, 2003, p. 114)

This sense of mixing and blurring provides a way to productively consider the way that a design approach permits novel interrelations between objects. There are certainly moments where project limits the scope of activities, and I have mentioned expectations about interdisciplinarity as an example where activity is framed in ways that curtail action. However, a speculative approach tends to generate unexpected alignments. Comparing tissue engineering to furniture testing, being suspicions about the organisational use of biometric data, and discussing the emotive features of a silicon prototype in a lab are three examples. Rather than trivialising these moments as irrelevant to understanding technical features, or delimiting them as anecdotes about disciplinary difference, here is a way of dealing with people and technology that draws attention to the flexible nature of their arrangement. By attending to such details, it becomes possible to demonstrate the ways in which a speculative approach generates activity that helps reconsider what is meant by debate. In the following chapters it will be seen that as the designs come together, and as those designs are then exhibited, there is continual pressure upon these mixings to be made coherent by various organisations.

\section{Knowledge}

In the episodes above, activity can be characterised as following a variety of plans. A researcher discusses public engagement as a form of public relations around the benefits of Nanotechnology. An activist patient seeks to improve the development of biomedical devices. A group of students look for inspiration for their speculative design projects. A researcher hopes to demonstrate the value of her work to those students. And all the while, designers try to initiate a public engagement project. I have characterized a speculative approach as an extension of critical design, where a critical impulse for debate has become aligned with engagement. Having argued for a fuller description of the activities enabled by mixing speculation and engagement, it seems that the activities that are revealed have antagonistic aims. 
How can interdisciplinary collaboration, science communication, public relations, and product innovation be reconciled?

In my discussion of the digital pancreas workshop, I argued that the richness of the data emerging from the activities undertaken there was not easily transformed into a speculative scenario. Furthermore, I am concerned that the treatment of such empirical data as an object of speculation is irresponsible. Is it reckless to forgo the opportunity to shape and innovate better biomedical devices? This issue is sharpened by a practical problem. I have argued for speculation's events to be lightly framed, so that the outcomes of activities are not foreshadowed by requirements. This does not help participant expectations, which can lead to confusion about the aim of the activity. It might be taken that an implicit goal of the workshop, as participants other than the designer understood it, was to somehow come up with a set of recommendations for the improvement of a technical system. Here features of the data that provide value for a speculative approach are taken forward at the expense of insights that would contribute to core biomedical research, of making better diabetes treatments for example. I would suggest there is indeed a problem when outcomes fall short of expectations, and argue for more clarity about the aims of a speculative approach. The persistent issue going forward is a methodological one, regarding the intransigence of a speculative approach in relation to empirically derived knowledge. 


\section{CHAPTER 5: DESIGNING SPECULATIVELY}

\section{Introduction}

The review of speculative design emphasised that while accounts of this practice do much to establish and promote final outcomes, the process of designing is not well articulated. This gives the impression that when a speculative design is exhibited and publicised, it is as if it had spontaneously appeared in the world. This chapter will provide an empirical discussion of making designs in Material Beliefs, emphasising the manner in which issues, materials, processes and strategies are materialised. I start by describing three cases of design in Material Beliefs, Neuroscope, Carnivorous Domestic Entertainment Robots and Vital Signs. Then, In order to develop a discussion about making, I propose three aspects related to the mixing of speculative design and upstream engagement as lenses for thinking about project activity. Firstly I discuss how speculative designers' association with biomedical researchers is conceptualised and managed in various ways, and that this has implications for the format of the design regarding expectations about engagement. Secondly I will demonstrate that delivering functionality in a design enables experimental forms of practice, and also places demands upon project management. Thirdly, I discuss how a speculative designers' ambition to provide alternatives to the biotechnologies encountered in the lab, displaces the variety and complexity that already exists in the researchers' own accounts of their biotechnologies.

\section{Three speculative designs}

In this section I provide a description of three prototypes that were designed as a result of the Material Beliefs project, Neuroscope, Carnivorous Domestic Entertainment Robots and Vital Signs. I draw on the project publication and associated documentation including interviews with researchers and designers, along with photography, written documentation prepared for the project website, and personal correspondence with the designers.

\section{Neuroscope}

The Neuroscope is a design outcome of a collaboration between researchers and doctoral students at a pharmacy and cybernetics lab, along with creative technologist (c1) and led by a Material Beliefs designer (d3) (Beaver, et al., 2009, p. 96). The prototype was presented as a speculative response to a research project being carried out at the lab, where a small mobile robot with sensors is controlled by a culture of neuronal cells embodied on a silicon substrate (Warwick et al., 2010). As the robot moves, its sensors detect obstacles, and a signal is sent to the cell culture where they are electrically stimulated. Responsive behaviour from the neuronal cells are detected and transformed to a control signal to the robot, 
creating a loop of control between the cells and the robot. While the underlying research is discussed in relation to medical applications including smart prosthetics, Neuroscope is seen to reimagine how this core technology would enable novel features in domestic products, in order to provoke "questions about the possibility of linking objects in the home to material in the lab" (Beaver, et al., 2009 , p. 96). A documentary by a filmmaker at the lab depicts the movement of the robot and the preparation of the cells, along with equipment including a microscope which provides images of the neuronal cells connected to tiny wires upon a silicon surface (Jackman, 2008d). D3 see that this equipment and in particular the microscope provide a product design language that can be expressed in the form of the design in order to provide a visual relationship with the lab:

We focused on the microscope, something that is familiar to a lab environment, but using that language, and transforming it and adapting it for a domestic environment. (Jackman, 2008c)

The form of the design was rapid prototyped and then finished by a model maker to a high standard, so that the object appeared to be manufactured. The design incorporated an eyepiece at the top, which revealed a digital display embedded inside. Graphics on the display are controlled by software that was developed by c1, and a button on the base of the Neuroscope enabled interaction with the software. The graphics were visual representations of the behaviour of the cells in the lab, and so the by combining product design, interaction and software, the Neuroscope aimed to provide "an interface that had a meaningful relationship with the behaviour of the cell culture", d3 continues:

As you interact with it you will be sending signals to the cell culture, which then will feedback into the virtual environment, so there is a loop between what you do with the Neuroscope and the cell culture. (Jackman, 2008c)

The Neuroscope was described by d3 as originating from a diagram depicting a range of possible future products enabled by technologies linked to research at the lab, which were discussed and mapped during a workshop arranged by $\mathrm{d} 3$ and attended by researchers (r7, r8, r9) based at the lab (Jackman, 2008d). For d3 the prototype mixes up of the design languages and the functionality associated with the home and the lab in order to provoke a discussion:

We were interested to explore ideas around rituals and relationships with objects. The closest example is the Tamagotchi, which involved children taking them to school because they could die in less than half a day from lack of care. Neuroscope was designed to explore the possibility of a new emergent class of objects linked to biological systems, thus provoking questions about what sort of new relationships would emerge between the user, the object and its living components. (Beaver, et al., 2009, p. 106) 
To communicate these features, the prototype is depicted in a photograph with a young user in their home, and this image is accompanied by a diagram of the system, showing a loop of interaction that links the Neuroscope in the home with the neurones in the lab. In terms of its function, the design was developed to the extent that software linking the interface and display in the Neuroscope to the technology controlling the signal processing of the neuronal culture in the lab was prepared and in place for a public demonstration at an event in London.

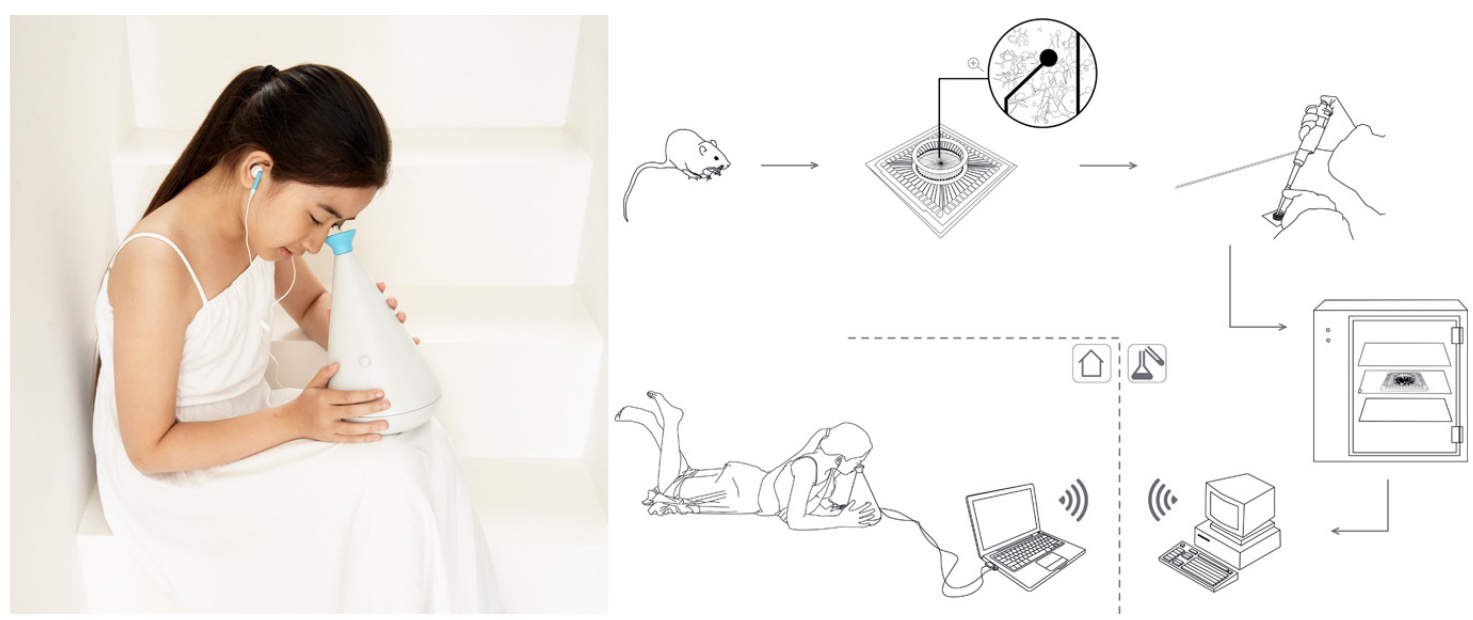

Figure 26: Image of the Neuroscope with a user, and a diagram of the underlying system

\section{Carnivorous Domestic Entertainment Robots}

Carnivorous Domestic Entertainment Robots (CDER) were designed by d 2 and $\mathrm{d} 4$, and supported by interviews with researchers at a robotics lab and conversations with a Professor of Biomimetics (r10), and with development assistance from a mechanical engineer ( $\mathrm{r} 11$ ). CDER is a set of prototype furniture with biological stomachs. Research being conducted at robotics lab regarding the development of a robot which generates its own power through the digestion of organic matter (Ieropoulos et al., 2003) became a focus for the designers. During an interview by $\mathrm{d} 2$ with a group of researchers at the robotics lab, a researcher (r12) described the autonomous robot project:

We're interested in developing artificial agents, which can extract their energy from the environment. And in doing so, we are employing the microbial fuel cell technology, which uses bacteria to break down organic substrate and produce electricity from that. It's basically a bio-electrochemical transducer. (Kerridge \& Loizeau, 2007)

Research at the robotics lab research gave expression to this core biotechnology through a practical application called SlugBot, which is an autonomous slug-eating garden robot. Having seen SlugBot presented by a researcher (r13) at a public engagement event, $\mathrm{d} 4$ described the potential for design to give expression to alternative forms of autonomy, where the behaviour of the robot becomes a compelling spectacle: 
The idea of these robots roaming around in your garden at night whilst you're sleeping, eating slugs, didn't engage us very much. But there were certain elements within that we thought that were potentially hugely engaging. So we were concentrating on how people might get more out of that interaction. As a way of communicating and exploring the technology, CDER are entertainment through the spectacle of these predators. With this we are making accessible the underlying technology, by virtue of it becoming an entertainment format, where it was previously a research discourse. (Dawson, 2009c)

CDER is a set of five prototypes, Flypaper Robotic Clock, Lampshade Robot, Mouse Trap Coffee-Table Robot, Fly Stealing Robot and UV Fly Killer Parasite Robot. These prototypes are partially operational, including mechanical and digital behaviors to demonstrate how they capture and convey insects or mice to their microbial fuel cells, which is a model that provides visual detail. For example the Flypaper Robotic Clock has a vertical belt of honey covered latex, on which flies are caught and conveyed to a blade at the base of the device which scrapes the files from the belt and into a microbial fuel cell. The belt is turned by rollers driven by motors controlled by an algorithm compiled onto an embedded microprocessor, while the fuel cell is a model, constructed from layers of laser cut plastic.

The designers commissioned r11 to develop the CDER movements, and worked with an animator and photographer to document the prototypes. The designers used the film and photographic documentation, along with short descriptions of each robot, to promote the project with curators.
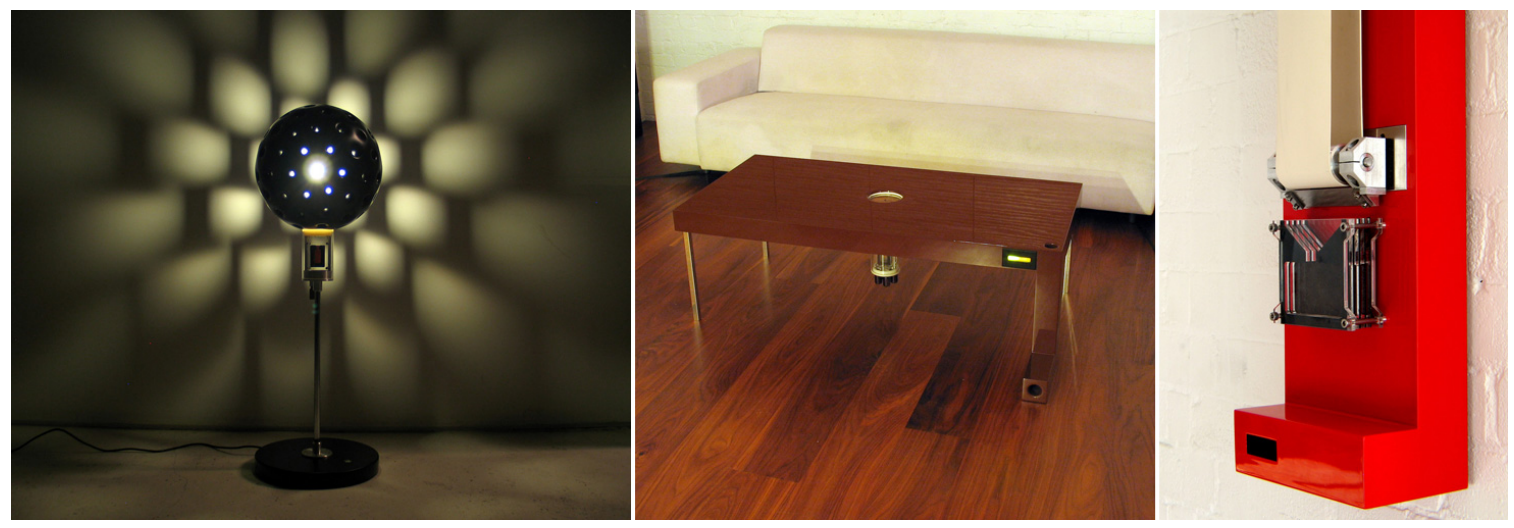

Figure 27: Images of three of the CDER prototypes, Lampshade Robot, Mouse Trap Coffee-Table Robot and Flypaper Robotic Clock

\section{Vital Signs}

Vital Signs is a set of three prototypes made during a period of fieldwork I undertook at a biomedical institute. Researchers demonstrated a range of medical biotechnology including miniature, low powered biometric sensors and silicon circuit designs that simulated human biological functions. Of particular interest was the Digital Plaster, an adhesive skin-worn patch with embedded sensors and 
wireless communications, where biometric data would be transmitted to the wearer's mobile phone and to a remote medical service (Toumazou \& Lee, 2005). Following discussions with researchers, and during visits to the lab by a patient and a group of design students, I became interested in roles for these biotechnologies in application areas other than healthcare. In particular these discussions demonstrated "curiosity about how medical technologies move into other contexts of use" (Beaver, et al., 2009, p. 69).

I was given a news article that featured new products being used by parents to monitor the comfort and safety of their child, and saw a documentary film where a parent sought advice from an engineer about tracking her daughter using a transmitter and a mapping application (Neale, 2008). In addition, a recurring topic in news media at that time was the loss of liberty for young people to enjoy public space, and a report from a UK think tank discussed technology in relation to these issues (Madge \& Barker, October 2007). I imagined a scenario where the biometric platform being developed at the institute enabled a set of products for the parent in the documentary:

Responding to discussions about surveillance and risk, a set of prototypes was designed. Vital Signs took research into biometric monitoring for chronic health conditions, and repositioned the technology as a system for an anxious parent to monitor their child. (Beaver, et al., 2009, p. 66)

There was an intention that such a scenario would provide the basis for a discussion around the use of biometric data, the ways in which data generated by bodies inhabits technical objects, and the ways that data collection and transmission might impinge upon a persons privacy (Jackman, 2008h).

I designed and developed a set of prototypes, which moved and displayed graphical patterns. These three devices contained motors, printed circuit boards (PCBs), an LED display and were controlled by code residing in microprocessors on the PCBs. There were plans to link the devices in real-time to data broadcast from the digital plaster, though the final behaviours were derived from archived biometric data. These were considered to be "a hypothetical but fully working set of prototypes" (Jackman, 2008h). Two sets were built using cases printed using rapid prototyping machines, then finished by hand. Finally a set of photos was taken where a friend and her son posed with the devices in order to provide an explicit visualisation of the prototypes in use. 

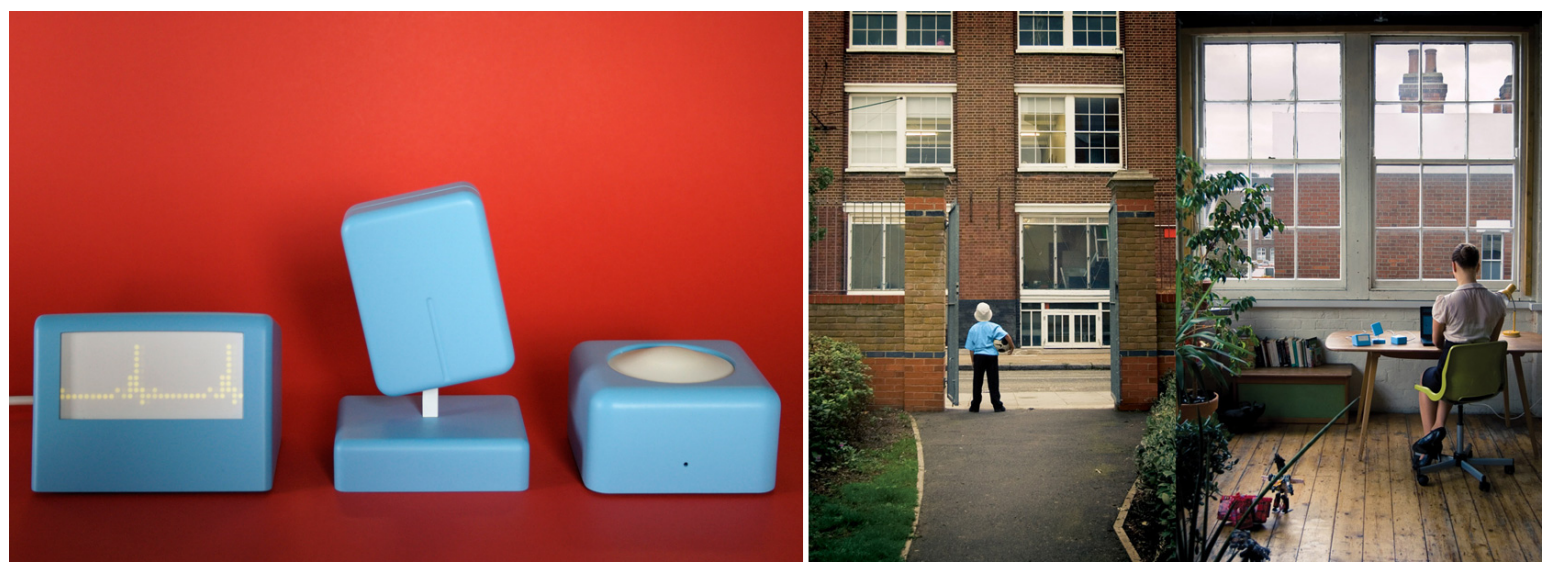

Figure 28: Vital Signs prototypes in blue, a photograph establish a scenario for the devices

\section{Features of designing speculatively}

In the following section I take episodes of design activity from these three projects as a basis for discussion. I draw on transcripts of short films shot and edited for the Material Beliefs publication and website, and interviews with speculative designers and biomedical researchers led by a public engagement professional (e1) for her summative evaluation of the project. I use data relating to Neuroscope and CDER to discuss designers' association with researchers and the implications of designing functionality, and use data from Vital Signs project episodes to discuss the consequences of a designer's ambition to provide alternative uses for the biotechnologies.

\section{Association with biomedical researchers}

Association between designers and researchers is a core expectation for the project in the EPSRC proposal. In the previous chapter I took early project activity at a biomedical institute as an example of how association was initiated. In this section I take two cases of collaboration between designers and researchers in order to consider the design of prototypes. In the first case, the designer and researchers met at the beginning of the project and set a course for subsequent and frequent association. The second case provides a contrasting approach where designers work relatively independently, with researchers providing periodic advisory input.

\section{Brainstorming the Neuroscope}

Towards the end of the first year of Material Beliefs, d3 convened a workshop with researchers at a pharmacy and cybernetics lab that featured a group discussion about the design of a speculative prototype. The discussion was conceived by $\mathrm{d} 3 \mathrm{as}$ an opportunity for 'both sides' of the collaboration - that is the designer leading the build of the prototype, and the researchers working on the underlying biotechnology - to reach a consensus about the themes which be addressed by the design (Jackman, 2008d). 
During the workshop d3 led a sketching and mapping activity. Hypothetical products that might result from the Animat research were discussed, and sketches made during the session provided visually rich records of discussion topics. These provided initial mappings, where discussion topics were applied to design themes. For example 'sophisticated products' designated a set of products with embedded biological brains, including toys with pet-like behaviour. Other topics included human sensory enhancement capabilities, which offered a range of capabilities for speculative devices, including human embedded communication networks that would provide 'extra sensory perception'. The documentation also established a temporal dimension for these products and features, where developments would eventually lead to moment of parity between the capabilities of technologies and humans described as a 'technological singularity'.

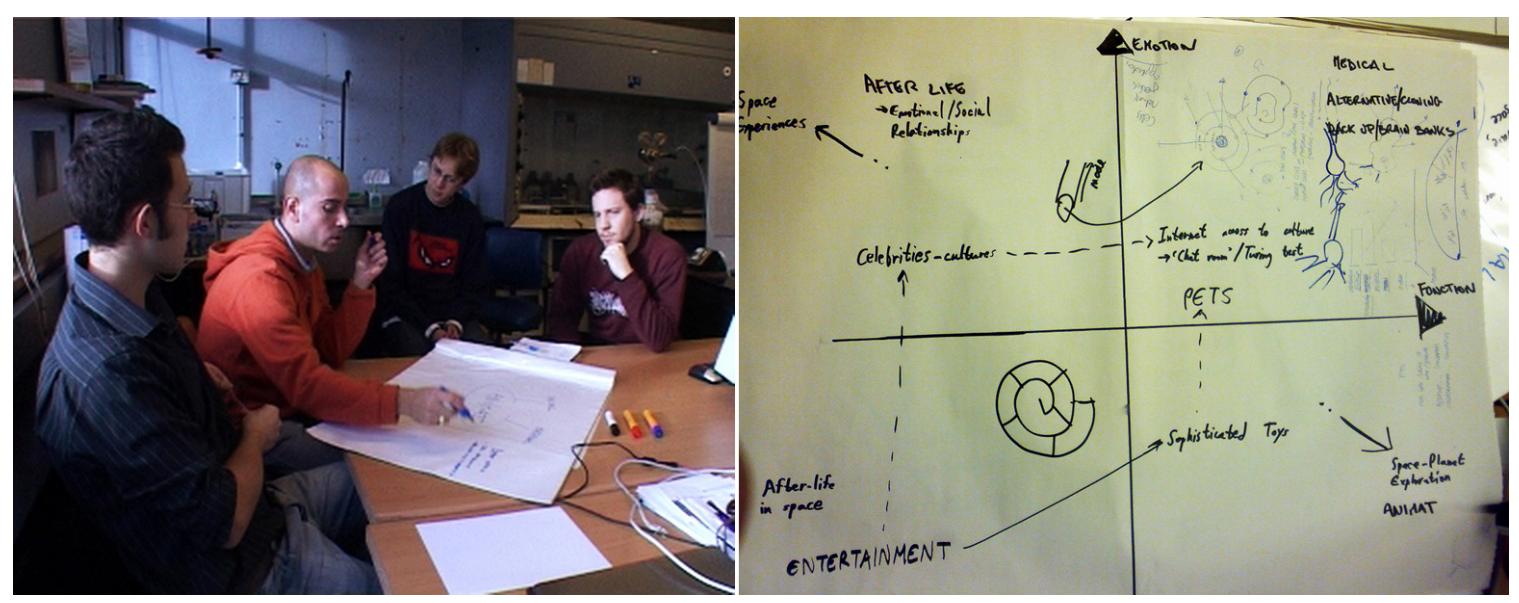

Figure 29: A discussion about potential applications for a biotechnology and a diagram of those applications

Following the discussion, $\mathrm{d} 3$ developed the content of these documents as an illustration that provided a conceptual framework for design activity. The illustration depicts biotechnology leaving the lab as a series of product groups, ranged across a horizontal axis representing some combination of time and certainty. 


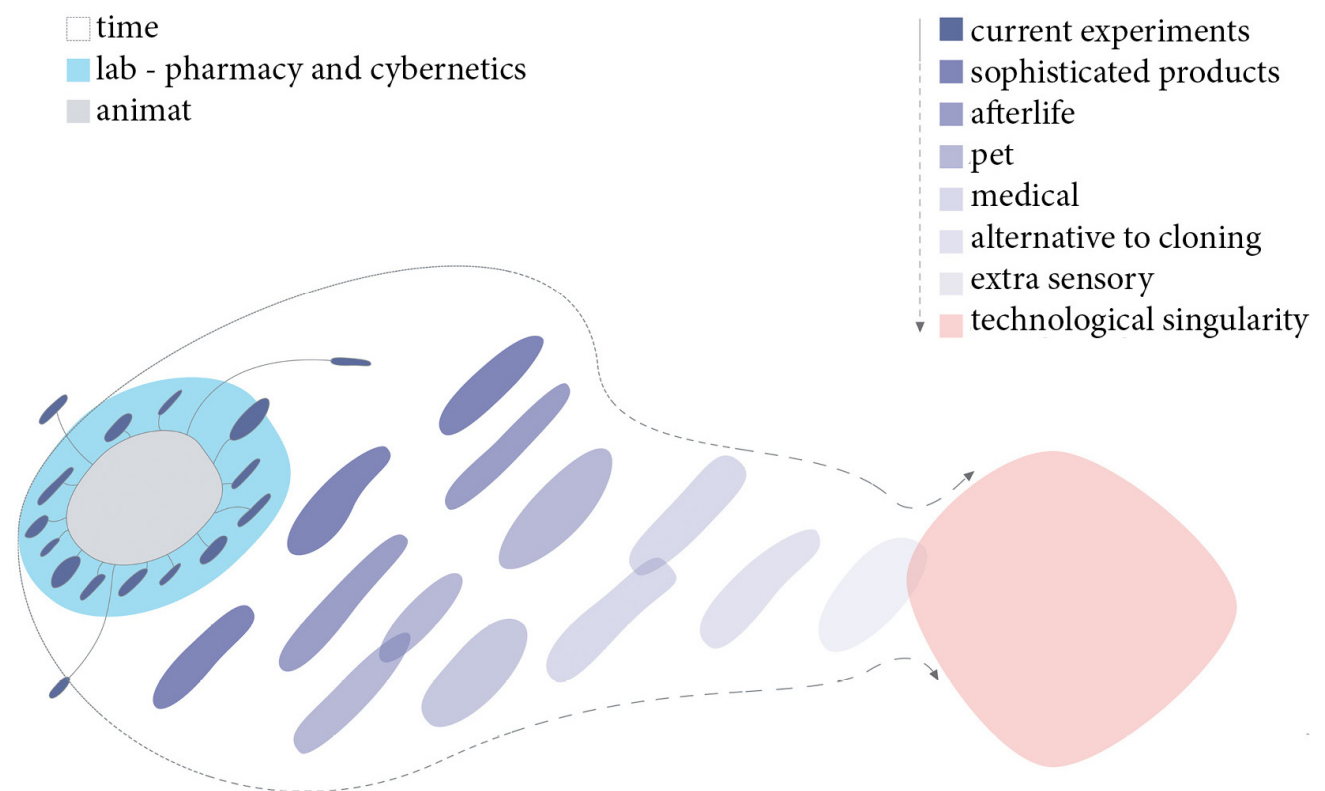

Figure 30: Potential applications, including 'sophisticated products' and 'extra sensory' are shown moving from the lab to the everyday, towards the far right is 'technological singularity'

The designer then drew upon the diagram and other details generated during the discussion to develop a design proposal where he focused on making 'an interactive device which is similar to a game or a toy' (Jackman, 2008c). The Neuroscope supported both the researchers' interest in the embodiment of the neuronal behaviour in a networked robotic device, and his own curiosity about the bringing together functions and aesthetics derived from domestic products and scientific equipment in a speculative manner.

The conceptual and functional design of Neuroscope can be characterized as emerging through this mapping activity. Sketches and other representations of technical knowledge were sketched, expectations and ideas about the outcome were shared, and then supported through on-going discussion including further short meetings and email correspondence. However it remained the responsibility of the designer, who then either executed design processes himself or commissioned work from others, to implement or manage activity and the delivery of a design outcome. In this respect, the incorporation of requirements for the prototype coming from the researchers placed demands upon the practice of $d 3$, which $\mathrm{d} 3$ reflected upon during an evaluation session at the end of the project:

I had some thoughts about - because of my background and my practice as a designer - setting up speculative projects in order to expose some of the social and cultural issues around biotechnology. I remember going away from one of these [meetings with researchers] with this big headache, "How on earth am I going to make everybody happy?" which was highly frustrating for me, and that made me step back a little bit and be quite reflective rather than, I don't know if you remember at the beginning, I used to be quite fiery. (Dawson, 2009a) 
On one hand the difficulty of incorporating the various concepts of the researchers are attributed to practical issues, including the limited time and resources of the designer. At other times there is reflection upon disciplinary differences, conceptualised as the 'looseness' of a design approach, and the 'specificity' of scientific approach. The perception of design's looseness is expressed by researchers in terms of the conceptual development of the outcome, particularly the open-ended nature of the interpretation of that design, and also its evaluation. These issues are somewhat compounded by a lack of clarity about what 'type' of a designer $\mathrm{d} 3$ is, and $\mathrm{r} 8$ reflects on this issue:

That's something we could have benefited from. A sort of "well what is a designer supposed to do" up the front, at the start. If some sort criteria had been suggested, by which we can measure it by. So we know, "Oh OK. In the design world, that's good". Because the criteria for measuring things in the design world might be completely different to the science world. And I think we just didn't know what to expect. (Dawson, 2009a)

Ambiguity about the nature of the designer's approach and role play-out in two ways. The researchers see design as enabling the positive promotion of the research by bringing additional features outside of their competencies, and ascribing what is described as a "wow factor" to their research. From the perspective of the designer, his role becomes restricted by expectations that design 'packages' the research in order to provide publicity, which is seen to compromise a speculative approach so that the outcomes "becomes a decoration of science" and where the designer "could have become your PR" (Dawson, 2009a).

Nonetheless, during the conceptual development and the design of the Neuroscope, the designer takes an experimental approach to his practice by setting up occasions for co-authorship of design materials, including the brainstorming session about future products. However, a later discussion between the designer and researchers demonstrates that the collaborative generation of such material exposes differences in disciplinary approaches regarding scientific rigour and design open-endedness, and exposes expectations around design communicating the value and utility of research.

\section{Consultancy}

The two designers leading Carnivorous Domestic Entertainment Robots (CDER) took microbial fuel cell research at a robotics lab as a technological start point for a design trajectory. Like $\mathrm{d} 3$ there was a focus on the transformation of the underlying technology. During a short documentary about the design of CDER, d2 discussed the nature of this intervention as he reflected on a presentation by r13 on the robotics lab's SlugBot - a slug eating robot that used a microbial fuel cell to provide power from the slugs - at the Dana Centre: 
The raw formula of the machine eating an animal is hugely interesting. And what the robotics lab was suggesting missed all that, and missed all the observation and questioning of that. That's why we wanted objects that would not just have the machine and the animal, but it would have the human watching it and talking about it, discussing it and interrogating it as an entity. (Dawson, 2009b)

For $\mathrm{d} 2$ and $\mathrm{d} 4$, human spectatorship offers the potential for the underlying biotechnology to be communicated in stronger ways. The development of this scenario is seen by $\mathrm{d} 4$ to be established through design's reimagination of the biotechnology:

We're taking new ingredients from what's happening in labs and imagining the very near future... Therefore people can understand it, they can imagine it in their lives and that's really what we're trying to do, translate some existing or emerging technologies into tangible and believable and hopefully desirable things people can imagine living with. (Dawson, 2009b)

The process of repositioning the microbial fuel cell to support a design scenario for CDER is undertaken independently, without further association with researchers at the robotics lab. This is partly due to time constraints on managing collaboration, but also ties in to a broader approach taken by $\mathrm{d} 2$ and $\mathrm{d} 4 \mathrm{where}$ their association with scientists and engineers is largely instrumental. This includes the view above, that core biotechnologies provide a source of 'ingredients' for design, along with the role of researchers as informal consultants, and the commissioning of engineers with specific skills.
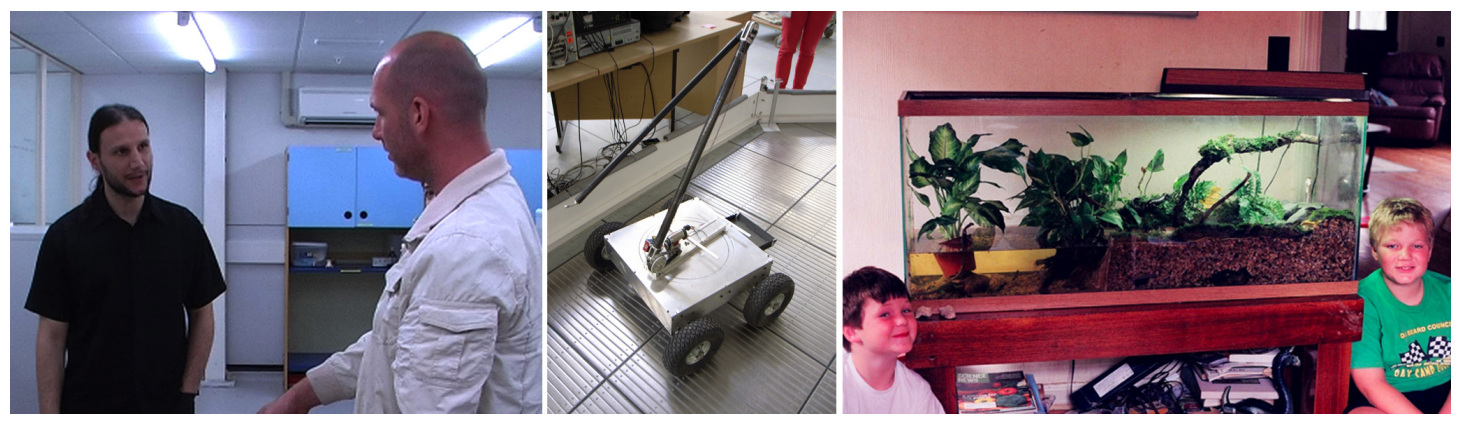

Figure 31: $r 12$ and $d 2$ at robotics lab, the SlugBot and an image of a vivarium used by the designers to discuss the spectacle of life and death

In common with $\mathrm{d} 3$ 's experience with the design of Neuroscope, $\mathrm{d} 2$ and $\mathrm{d} 4 \mathrm{discuss}$ researchers' expectations about the role that a collaborating designer would perform:

You see it all over the TV, Linda Baker and celebrity designers working for MFI and then it's difficult for us to get our feet in the door, because all they think that we're doing is to be maybe taking their sort of wonderfully engineered things 
and packaging it in pretty ways. And if that's what they think then of course it's problematic. So that's worth saying, that misunderstanding, how do you give them a better idea about what we're doing, that we are serious about what were doing, its much, much deeper and more profound that just putting paint on things.

Here, $\mathrm{d} 4$ argues that a speculative approach would have been better understood by researchers if the boarder aims of the Material beliefs project were reframed so that design and research were equally valued.

\section{Entanglement and Independence}

In her evaluation of Material Beliefs for the EPSRC, e1 outlines two modes of collaboration. The first where "people from different disciplines, and the public, work together" to produce a public engagement project, the second the where "one discipline 'uses' another" (Dawson, 2009c). Taking these models as a start point, there are certainly features in the cases above where disciplinary modes become instrumentalised by both designers and researchers through the requirements of their own practices. There is also a sense from designers that the role of researchers is to provide accounts of and access to biotechnology in order to resource design concepts. These are moments where there is less experimentation with disciplinary roles, and where encounters between disciplines are shaped to align with professional expectations of the designers or the researchers.

In the case of CDER, there are perceived benefits to non-collaboration and in following an independent design process. The designers attest that the cohesive nature of their design narrative results from targeted and informal consultancy regarding a single scenario. In contrast the design of Neuroscope leads to a more complex entity, where the designer takes responsibility for the contributions and the expectations of the researchers. There is an entanglement and richness here, though certainly the story about the design is more complex and less easily managed as an exhibitable object.

Looking forward, the opportunities and incompatibilities arising from an experimental and risk taking approach to collaboration with the Neuroscope becomes further nuanced as the prototype moves into public settings. Meanwhile the instrumental and cohesive features of the CDER designs are better suited to the management of a publicity network that allows the design to 'travel'. I develop these accounts in the following chapter, which deals with public events.

\section{Designing functionality}

I have demonstrated that speculative designers doubt that the stories researchers tell about biotechnology will communicate with non-experts meaningfully, and that in order to provide engaging formats for the public, speculative design is seen to generate compelling alternatives. Decisions about the design concept are made 
by the designer against a background of instrumental or experimental modes of association with the researchers and others. In this section I take two episodes where the features of association discussed above lead to two different versions of functionality in the designs. Firstly I discuss interactive features of Neuroscope planned for an engagement event, where the design is intended to use a network to share data in real time with a culture of neuronal cells at the pharmacy and cybernetics lab. Secondly I consider the mechatronic features of CDER that enable the designs to behave realistically when they are exhibited.

\section{Networking and Interaction}

A short documentary about the Neuroscope featured d3 in his studio in London (Jackman, 2008c). In this film, the designer describes features of the prototype, almost complete at the time of filming, which takes place about eight months after the Neuroscope workshop at the pharmacy and cybernetics lab. The designer shows enthusiasm for researchers' willingness to implement features of their research in the Neuroscope, and remarks that this functionality means that design is able to do more than "engage with their work on an intellectual level" (Jackman, 2008c). For the designer, the status of the device as "a working prototype" (Jackman, 2008c) was enabled by workshop activities, including drawings that supported the translation of technical aspects of the research into a set of design features. Two of those drawings (Figure 32) follow d3's description of their origination:

This is one of the initial sketches developed with $\mathrm{r} 7$ who is the neuroscientist working on the project, in order to understand how to represent the cell culture in the virtual environment, first of all to develop something meaningful in terms of behaviours, but also visually, a meaningful relationship with the cell culture... Here's another one for example where I remember $r 7$ trying to explain to me what happens when a cell fires, and you have this branching, things branching out, and how the different cells are linked together or networked, and these spikes which are when the cell culture fires. (Jackman, 2008c) 

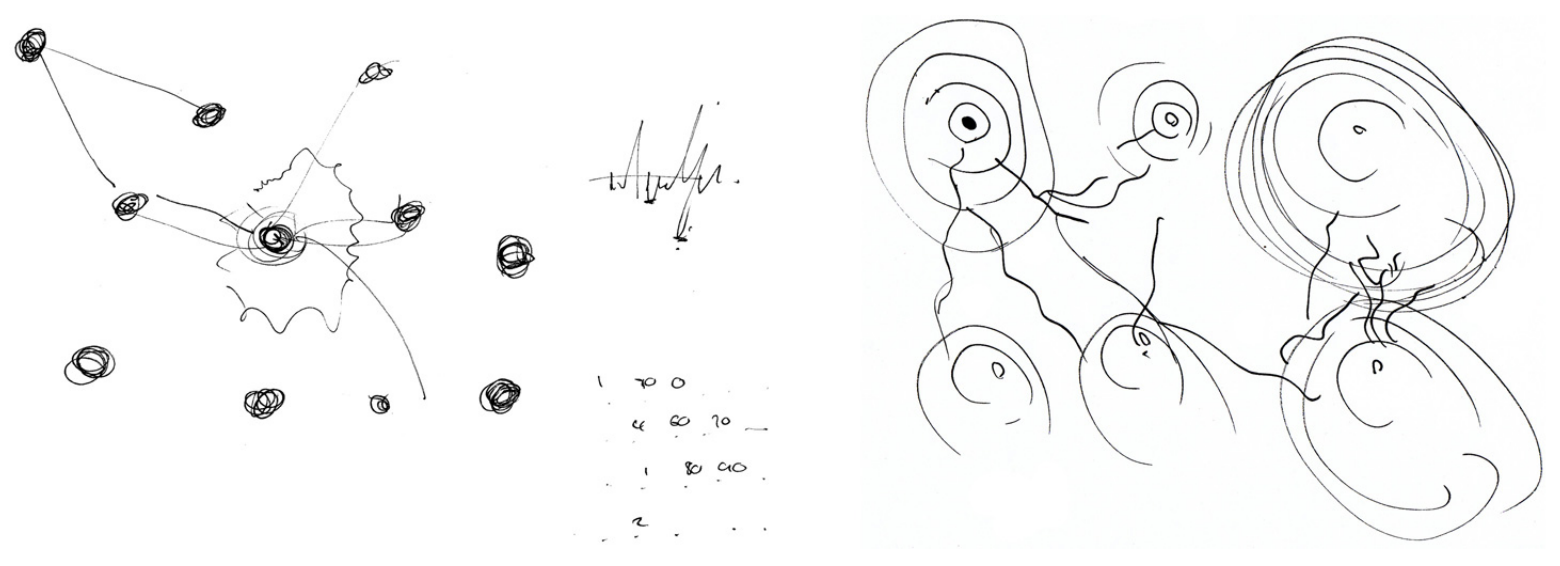

Figure 32: Two drawings depicting the arrangement of cells on the array of electrodes and the branching structure of connections being made.

In order to support the stimulation of the behaviours recorded in these illustrations, d3 designed the Neuroscope with a user interface that allowed interaction with a digital visualisation of the neuronal cells, which was commissioned from c1. C1 worked with r8 and others at the pharmacy and cybernetics lab on a software protocol so that the digital visualisation in the Neuroscope and the embodied neuronal culture were able to communicate in real time over a network connection. This enabled user interaction with the Neuroscope to electrically stimulate the cells at the pharmacy and cybernetics lab, and for changes in the activity of those cells to be presented to the user of the Neuroscope as they peered into its aperture.

This rich functionality created something of a challenge for the speculative nature of the design. Reflecting on the project with researchers from the pharmacy and cybernetics lab during their exit interview with e1, d3 described two constraints that arose from the incorporation of this advanced functionality into the design phase of the Neuroscope:

My practice in the past few years been very much about collaborating with people and looking at the way you use design in order to discuss specific social cultural issues around scientific research and about producing often quite highly provocative projects. I immediately learned it was not possible, but of course I came with an assumption that I was going to repeat something that I was familiar with... One of the things that made me really question what I was doing, or what I've done, was your willingness to let me actually be involved with your research. And also hands on, to actually implement your scientific research in a way that could be used. That was extremely exciting for me, but I think it also provoked conflict. Coming from a perspective that's only engaged in an intellectual level, as with thought experiments, the moment that you have a hands on approach then you have to justify why you're doing that, and that was a massive learning curve for me. (Dawson, 2009a) 
There are two constraints here. D3's first point about not being to repeat the familiar practice of designing a 'controversial' speculation, relates to perceived issues of illegality regarding the human tissue act and the features of research being embodied in the Neuroscope, which I unpack shortly. The second relates to a dilemma $\mathrm{d} 3$ has as a designer with a speculative approach. Given the opportunity to develop his practice through incorporation of the functions described above, he is faced with new forms of responsibility. The principal investigator of the research (r16) summarised the situation as a conflict between the speculative scenario of the Neuroscope and the responsibility of function:

There had to be a distinction, if you're going to do something practical it's got to be legal. Or you could do something that's entirely theoretical but it can't involve the tissue itself. And that's just the way it is. If we want to continue carrying on any work at all and not find ourselves behind bars, then that's the way we've got to do it. (Dawson, 2009a)

In order to deliver a design for Material Beliefs, d3 saw that he two options. Firstly, to disengage from the opportunity for function, and instead make a model with hypothetical behaviours. Secondly, to deliver a functional prototype that was not made controversial by virtue of its speculative context, in particular the conceptualisation of the device as a domestic toy, a treatment was seen to trivialise and challenge the ethical context of the research.

\section{Demonstration and dissemination}

A short documentary shot by filmmaker in June 2008 features $\mathrm{d} 2$ and $\mathrm{d} 4 \mathrm{in}$ a studio surrounded by the CDER prototypes at various stages of completion. Two sets of five robots have been designed and fabricated, and three robots have mechanical behaviours to demonstrate how pests are captured for digestion by the microbial fuel cells that are at the heart of each device. D2 reflected on the current state of the prototypes and their future plans:

R10 wants to take one of the robots to the robotics lab, and present it to them and say, "Let's get this working" for real. Which would be fantastic. These robots that we've made, they work to a certain point. Obviously the time and the budget didn't allow for a fully functioning prototype, but it allowed for the representation, which for a gallery is fine, but these robots will really come to life when they're placed in a home and we start recording and observing the behaviour of people using them. (Dawson, 2009b)

The designer briefly mentions plans for a further iteration of the prototypes. There is an ambition to work with the robotics lab in order to link the prototype behaviours to real microbial fuel cells, and plans for those functioning prototypes to be deployed and tested in people's homes. In their current form though, the CDER are designed to a specification that supports being exhibited. For example, 
the embedded code that controls their mechanical movements run in loops in order to demonstrate behaviour repeatedly. In contrast to the Neuroscope, where the designer was granted access to features of biotechnology research, functionality for the CDER is primarily formatted through the designers' professional experiences of exhibition.

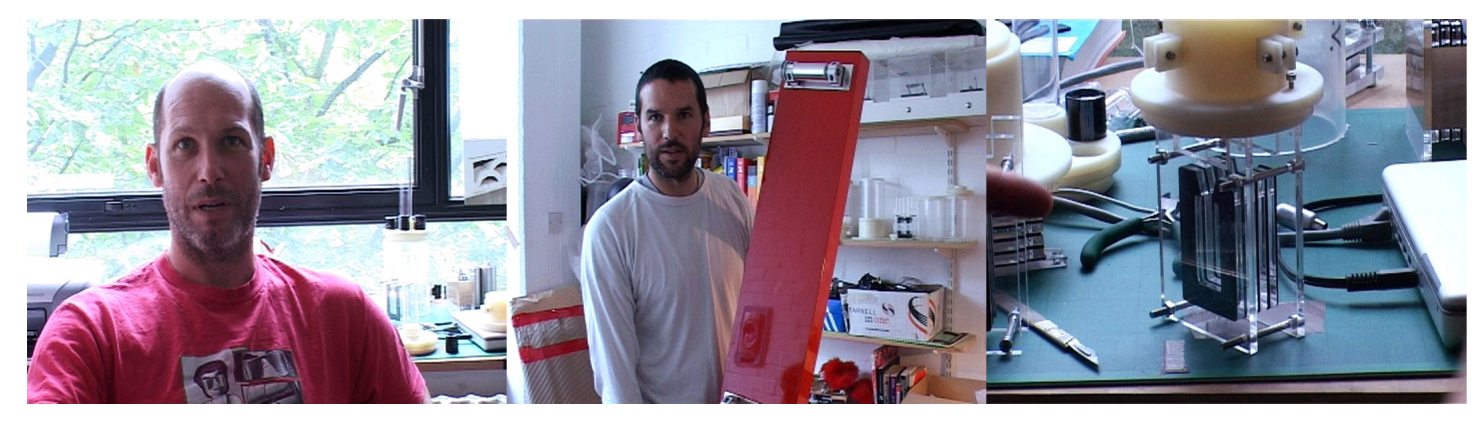

Figure 33: $\mathrm{d} 2$ and $\mathrm{d} 4$ interviewed by a filmmaker surrounded by CDER prototypes

Exhibition behaviour is predicated on clear communication of the broader speculative scheme of the designs, rather than true functionality that would enable the deployment of a prototype in someone's home. For example, during exhibition, the arm of the fly catching robot can repeatedly be seen moving through an arc to an aperture where a fly would be deposited for digestion, without a viewer needing to wait for a fly to actually be caught, or indeed without the control algorithm needing to be developed so that a fly can be caught. This is in contrast to the kinds of functionality required for Neuroscope. Where d3 commissioned a visualisation tool that that would support a network protocol to link remotely to research software, $\mathrm{d} 2$ and $\mathrm{d} 4$ commissioned algorithms that allow smooth mechatronic movements. The former is to enable system level integration while the later is immediately visual.
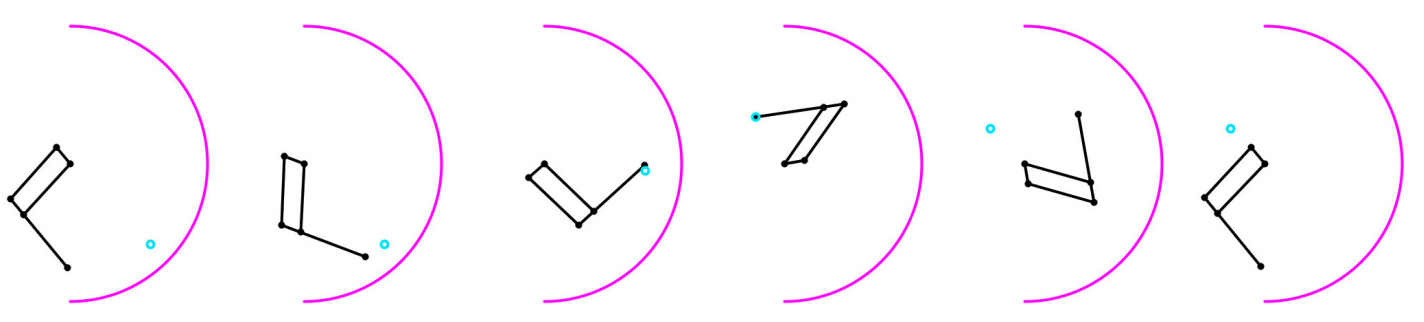

Figure 34: Frames from r11's visual algorithm to help develop movement of the arm of the fly stealing robot

For $\mathrm{d} 2$ and $\mathrm{d} 4$ resources are focused on features that enable the communication of the project with future audiences. In this respect the devices themselves are just one part of a set of design activity, as described by $\mathrm{d} 4$ : 
If you're trying to reach a wider audience you can't be there in person with a physical object, so it's going to be done through things like the Internet or magazines or newspapers. So we try to feed the journalist, or whoever is doing it, good information. That's through trying to write a decent body of text and having quite high-resolution images. ... What we have now are fairly well resolved objects, but the communications side of it is still premature. It needs quite a lot more work doing. And what we've learnt over the last few years of doing this is that it's not point hitting the world prematurely with ideas, because then people don't quite grasp them fully. (Dawson, 2009b)

By working with researchers as consultants for specific behaviour, $\mathrm{d} 2$ and $\mathrm{d} 4$ are largely focused on applying their experience to tailoring the format of the design in order to support the publication of the work. This approach aligns closely with features of critical design discussed in the design review section.

\section{Providing alternatives}

In an earlier discussion regarding a workshop at a biomedical institute, I described how the designer, researchers, a patient and a group of postgraduate students participated in activities that treated biotechnology research at the institute in an open-ended manner. Student interactions with researchers led to a conversation about the appropriation of biomedical implant by organisation other than healthcare, including insurance services. Vital Signs developed these thoughts about alternative uses for biotechnology, through a scenario where a parent monitored their child's biometrics using devices that embody data through movement and other behaviours. Despite all the energy that went into these activities, I have a sense that key representations of the biotechnologies that came out of researchers' accounts of their work, have not been addressed. To help me grapple with this absence, I revisit the biotechnology underlying the Vital Signs design, which is the biomedical institute's Digital Plaster.

\section{A range of application trajectories for research}

During an interview with the researcher at the institute, he discussed the value placed on innovation, which included "getting something into commercial production that will ultimately be used clinically, and generating intellectual property" (Kerridge \& Caccavale, 2007). I later described the Digital Plaster as a "monitoring platform for people with acute health problems" and followed with a provocation about "how this might move into other markets" (Jackman, 2008h). In treating the Digital Plaster as a specific and defined biotechnology, I was able to suggest that once the platform leaves the lab, the underlying technology becomes reconfigured to support market driven applications including biometric surveillance, which might have dubious implications for liberty.

However, in order to support innovation as discussed by $\mathrm{r} 1$, and while the underlying protocols and digital circuits were being researched and tested, the 
Digital Plaster had been presented not as a single application but as various applications. These versions exist in texts including whitepapers, technology briefs and company financial reports. For example, SensiumVitals is a product of Toumaz Healthcare, a business created to exploit technologies developed from research at the institute (Toumaz-Group, 2013a). While patient monitoring in hospital wards is the most prominent technology being developed, the Sensium platform is described as supporting a wide range of applications including elderly assisted living and elite athlete monitoring (Burdett, 2009). The application portfolio of the parent company, Toumaz Group, shows even greater variety, where an underlying expertise in low cost, ultra-low power wireless communications technology support medical monitoring and internet-connected consumer devices (ToumazGroup, 2013b). Common descriptions of technology, diagrams of the system and product photography are shared across academic papers (Pantelakis Georgiou et al.), promotional whitepapers (Toumaz-Group, 2013c) and product marketing material.

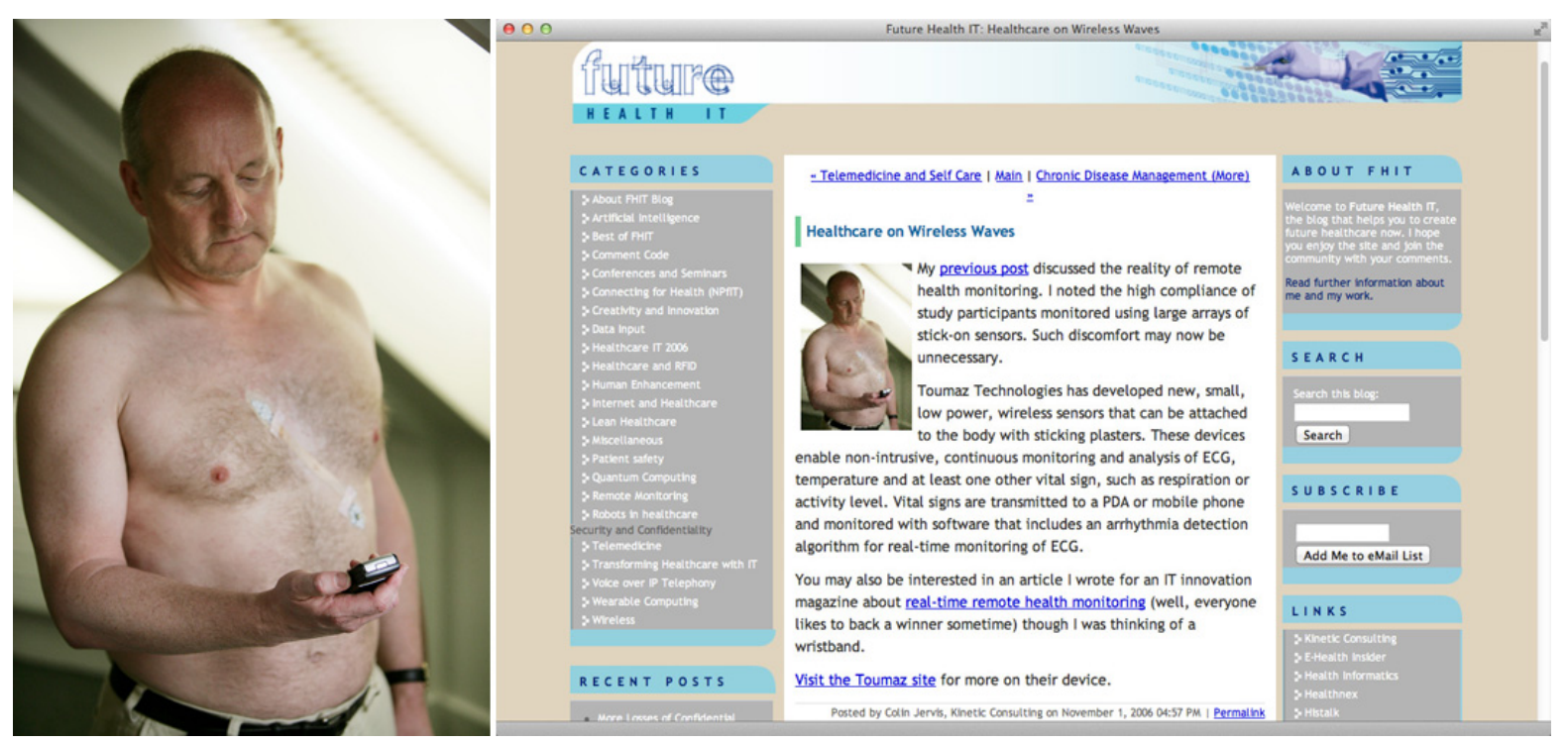

Figure 35: Photo depicting a user wearing a digital plaster and monitoring biometric data on a mobile phone, and a description of the application on a health technology website

The format of innovation aligns with the approach of speculative design publicity, for example a hypothetical self-monitoring phone app comprised of a description and photographs of a model used by Toumaz Healthcare for press releases (see Figure 35). These materials are circulated, and networks are made. Flip-flopping between elite athletes, the elderly, the chronically diseased and the music enthusiast, the variety of scenarios for the Digital Plaster can be seen is evidence of the flexibility with which biotechnologies are made. It is also indication of the manner in which - through early prototypes and cohort studies, along with 
markets and investors - biotechnologies in the making are being both concretely and speculatively tied to entities 'outside' of the lab ${ }^{15}$.

\section{Promising or problematizing?}

Returning now to the third speculative design case, two transformations were made to the material that emerged from the collaboration in order for Vital Signs to be proposed as an alternative. Firstly, a complex set of research entities were treated as a discrete biotechnology (the Digital Plaster for healthcare), against which the speculative alternative could then be proffered. Those earlier encounters with biotechnology at the biomedical institute, and the variations of the Digital Plaster, were put to the side so that a design story could be told.

Secondly, research at the biomedical institute was treated as a 'scientific' endeavour aseptically restricted to the lab. That research is then seen to be made social through design speculation. Here the scenario of the prototype and the public nature of its exhibition is seen to provide social agency, so that the research can be taken 'out of the lab and into the studio' (Kerridge, Stott, et al., 2006) and from the designer's studio into the 'real world' (DiSalvo \& Lukens, 2009). Yet the biotechnology of the Digital Plaster is described and publicised in multiple ways by its researchers in order to attempt to innovate. Rather than being somehow independent, an innovation strategy proposes specific models for biotechnology and people. Like the designer, the researcher is actively engaged in the production of scenarios. The practice of biotechnology research is social. Then what are the differences between the stories being told by research and those being told by design, and what is the intention for their respective storytelling?

The innovation narratives of the Digital Plaster and the design scenario of Vital signs are both imaginaries, presenting a case for a beneficial innovations and a platform for speculative design respectively (Joly, 2010). Joly's imaginaries are elsewhere discussed as 'promissory regimes', where innovation is enabled through a focus on persuading organisations able to provide material, financial and political resources of the technical and commercial viability of the technology (Wynne, et al., 2007). This form of innovation has consequences for the demarcation of lay audiences in relation to a technology:

Space for public deliberation quickly becomes reduced to polarised interactions for or against the technoscientific promise... policy makers can fall in the trap of seeing civil society, under the rubric of "the public", as outsiders, to be taken into account, for sure, but as "irrational", prone to be scared without reason, and always to be monitored by opinion polls. (ibid., pp. 25-26)

\footnotetext{
15 This experimental variety is also a feature of other biotechnologies explored by other Material Beliefs prototypes, for example, research at the pharmacy and cybernetics lab around neuronal cultures and robotics is seen as an enabler of intelligent prosthetics, but also as a technology that would support defence applications (Xydas et al., 2008).
} 
An effect of a promissory regime is the separation of the researcher and their research from civil society, and it is in this context that public engagement becomes instrumentalised as a tool for the positive promotion of the biotechnology to a lay audience, in order to address that deficit. Then where are the forms of engagement that enable discussion about the variety of biotechnology in the making? This question is asked by Stirling, who proposes that reflexive form of appraisal would open up seemingly locked-in innovation pathways and expose variety:

Instead of focusing on unitary prescriptive recommendations, appraisal poses alternative questions, focuses on neglected issues, includes marginalized perspectives, triangulates contending knowledges, tests sensitivities to different methods, considers ignored uncertainties, examines different possibilities, and highlights new options. Here, the relative lack of structured constraints on modes of expression may present a vulnerability to strategic behaviour on the part of participants. (Stirling, 2008, p. 280)

Stirling is challenging the mode of technology appraisal in order to better inform policy and governance choices, yet the spirit of the engagement he proposes is in opening up technology, rather than in presenting a single object for approval. This brings me back to the beginning of this detour, to Vital Signs as a scenario about biometric surveillance, and a feeling that this dealt with encounters at IBE in an unsatisfactory manner.

\section{Multiples rather than alternatives}

The Digital Plaster is a complex entity, comprising a range of commercial, academic and public organisations, along with technologies and materials, and different human actors who are seen to determine or be supported by the application. This assemblage is anticipatory and experimental in nature, and the relationship between science and society is one of co-production. People already relate to biotechnology in the making, as patients of medical monitoring services, as contributors to government funding of underlying innovations, as beneficiaries of new products in associated markets, and as readers of articles about medical innovations.

Weak speculation might, by virtue of a desire for debate that aligns with deficit engagement, develop any one of those under-articulated relations as narrative antagonist to the 'official' story of a given biotechnology. Productive speculation gives rise to a series of reorderings around a biotechnology. Here the prototype becomes analytically secondary to the open framing of association that encourages comparison and reinvention. 


\section{Summary}

In the previous chapter I discussed four episodes where designers initiated interviews and devised workshops with biomedical researchers, a patient and a group of students. I suggested that a speculative approach to design might be characterised by such forms of association, and when the designer takes such an approach, that is where design themes and design processes develop in relation to a programme of interaction with non-designers, their approach can be seen to extend the largely disciplinary concerns of critical design. However, while a speculative approach features fieldwork and reflexivity, a focus on an issue based prototype and engagement events as outcomes, is distinct from participatory and user-centred design, which emphasise the iteration of a product or service in response to the requirements of the user.

In this chapter, an empirical and conceptual discussion of making prototypes in Material Beliefs has fostered a reconsideration of the emphasis placed by critical design on the exhibition of a finished design as the locus debate. I have emphasised the process of design as giving rise to a series of open-ended encounters between a variety of actors around biotechnologies in the making. Here association is enabled not through an encounter with a finished design artefact, but through a mixed range of objects including the literature around a biotechnology application, the silicon circuits and nano-printers that fabricate an application's underlying devices, and individual responses to these devices and their capabilities.

Nonetheless, while these smaller encounters speak to the disaggregation of power attributed to the design exhibition as gatekeeper of debate, those events indeed came about by virtue of the execution of a design project, and in this sense can be attributed to design activity. The key shift is that rather than debate being attributed to an encounter with a finished design, it is now linked to the process of designing. Furthermore, while the design process is nominally about the successful organisation of a prototype - comprising activities such as CAD modelling, circuit design, software development etc. - the activities that are thereby enabled are somewhat reflexive and disaggregating in character. In this way they do not clearly speak to either the design logics or the engagement tropes that might be expected, for example there is no evidence of the inductive solving of problems that would lead to a satisfactory outcome for design for social innovation, nor are there the core mechanisms of evaluation or links to policy that would be the expected outcomes of science engagement or governance. Rather the analysis is an elaboration of what a speculative approach to design entails, where design can now be seen as a shared accomplishment rather than the achievement of a sole designer. I have demonstrated ways in which the contributions of others are either materialised in the design, or elaborated as a result of design activity [briefly recall 2 examples]. 
However, it remains that the designer executes an influential role as a prototype comes together, through the direction of their energy in the identification of key concepts, the organisation of processes and the management of activity. The designer intervenes, exploits opportunities, executes on the basis of taste and habits of training. However, at times the design emerges through the substantial contribution of others, and value is seen by the designer to reside in their expertise and opinion. On these occasions the designer deals constructively with the exclusivity of practice and the unaccountability of method that I have associated with critical design as it moves into the professional settings of scientists and engagers, and to see a speculative approach as the reconnection of criticality to forms of design where cooperation and contribution are emphasised. 


\section{CHAPTER 6: CIRCULATING DESIGN}

\section{Introduction}

In the introductory chapter of this thesis I described how the project proposal for Material Beliefs presented a trajectory for activity, which led to a series of exhibitions and other events, where public encounters with project outcomes enabled engagement around issues related to biotechnology and society (Kerridge, Custead, et al., 2006). In a discussion of the proposal I then argued that these expectations for the project were largely rhetorical, and so in the preceding two chapters I moved beyond a rhetorical frame to an empirical account of episodes from the project. I contended that deliberation about biotechnology between speculative designers, biomedical researchers, technicians and others takes place before and during the making of speculative designs. These insights demonstrated that while speculative design is seen to enable debate though its outcomes, the processes that led to the publication of outcomes are valuable, and warrant attention. However, it remains the case that circulation of designs in exhibitions, at engagement events, and through a publication, were a core activity of the project. In this chapter I turn to the dissemination of outcomes and also designs in an unfinished state, to connect activity related to the public circulation of designs to the forms of accountability established in the preceding two chapters.

In this chapter I discuss three pairs of episodes from the project where designs go into public settings. Firstly I discuss two exhibitions, one at LABoral in Gijón, Spain and the other at the Royal Institution in London, where project designs were included with the designs of others in group exhibitions. Secondly I take two events at the Dana Centre in London, where designers from Material Beliefs worked in partnership with staff from that venue to deliver public engagement events. Thirdly I discuss the aggregation of project documentation on a website and in a book as examples of publication.

\section{Three formats for circulating speculative designs}

Over the course of Material Beliefs, designers and their associates participated in a series of public events. A full listing of these events is available on the project website, and included there are workshops, conferences, exhibitions, schools visits, lectures and debates (Kerridge, 2007b). While these events were diverse, a common element was that production and delivery was conducted through partnerships with other organisations. The weight of the role taken by Material Beliefs in relation to the overall content of an event ranged from the project having a minimal presence, for example a one hour workshop in a small marquee at large 3-day music festival in Cambridgeshire (Kerridge, 2007e), to situations where project content was the exclusive focus, an example being an evening debate in a 
public events space in London (Kerridge, 2007f). The form taken by the content used to support the role of the project at these events was varied, and included presentations and films for projection, card and clay and other materials for hands on activities, and objects and posters for exhibition.

These public events took place over the project time frame, and so content included final designs and also featured material relating to early design processes and research activity. Given the commitment of the project to do public engagement activity, speculative designers and biomedical researchers acted responsively to opportunities as they became available, and as the project developed the network of partners that were worked with broadened, these opportunities to undertake partnerships increased. Given that participation in public events were being offered to project members on the basis of the proposer's interests, rather than being sought in accordance with our own expectations of project aims, the formats that project members were invited to deliver became more surprising and diverse.

In this chapter I discuss exhibitions, workshops and publications as three formats for the circulation of design material in public settings. I take a pair of examples for each format in order to derive insights that make the most of the breadth of activities undertaken during the project. For each pairing I provide some general background to the approach for that format, then with each event I establish some initial context including the setting of the event and the aims of the partner, before discussing the event empirically and establishing some key issues, and finally I discuss each pairing in order to establish features.

\section{Exhibitions}

In the design literature review I suggested that exhibitions are seen to be a core activity for speculative designers, conceived as being the final stage of a designer's work, and considered an initial point of contact for everyone else. Exhibitions are seen to be places where the public encounter speculative designs in the flesh, and where debates happen. While I have disputed the assumption of debate, it cannot be doubted that exhibitions are intensively resourced, meticulously planned and professionally valued. It is perhaps a surprise then that while their documentation is lavish, practitioner accounts of what goes into and what happens at design exhibitions is so sparse. I introduce two exhibitions from Material Beliefs in order to discuss their features and characterise their role in the project.

\section{A contemporary design exhibition in Gijón}

Projects from all four of the Material Beliefs clusters were included in Nowhere/Now/Here, a large group show of contemporary design curated by Roberto Feo and Rosario Hurtado (Feo \& Hurtado, 2008). The exhibition was installed at LABoral, a public arts and industrial design venue in Gijón, northern Spain in 2008. Following a period of some months where the curators developed 
the material for the publication and the format of the exhibition, four of the five designers involved in Material Beliefs travelled to Gijón to set up their work. Along with other participating designers and following the fit-out of the venue, there was a two-day period to allow for the installation of work leading to an opening event to which a variety or project partners, journalists and others were invited. Following the opening on October $9^{\text {th }} 2008$, the exhibition was open daily until $20^{\text {th }}$ April 2009, where the exhibition is the core component of a programme that included workshops and tours.

I have previously described three of the projects exhibited at Nowhere/Now/Here, these are CDER led by $\mathrm{d} 2$ and d4, Nueroscope led by d3, and Vital Signs which I lead. The fourth project We Live What We Eat was led by a product designer (d5), who took research and journalism around the positive effects of calorie restriction on longevity as focus for a project which "reinterprets these tensions through tableware and palate enhancing utensils to contrive new interactions at mealtimes, which affect our eating habits" (Feo \& Hurtado, 2008, pp. 84-85).

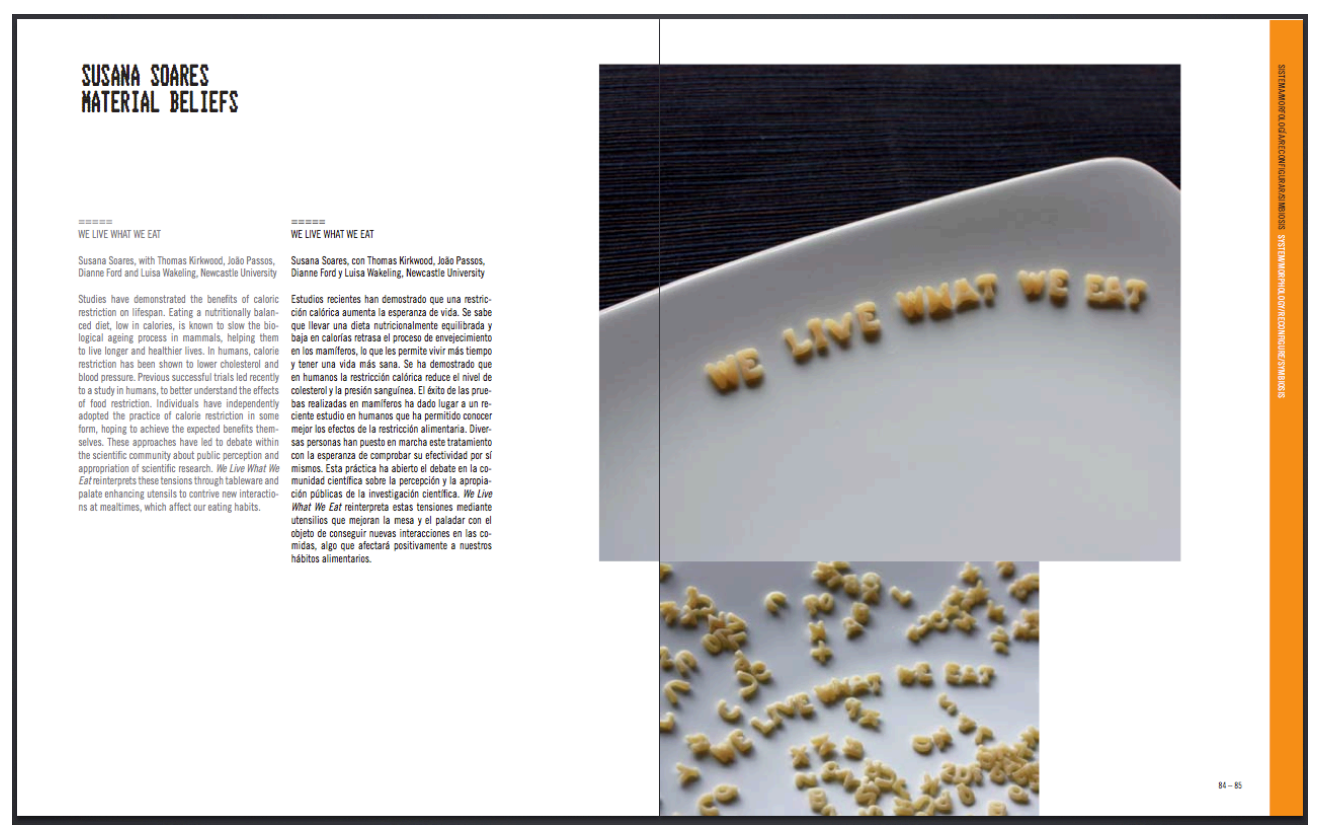

Figure 36: Layout of d5's We Live What We Eat in the exhibition catalogue

For all four projects, the exhibited elements included the prototypes, which were either mounted on hexagonal cardboard plinths or fixed to walls, and photographs mounted on aluminium and fixed to walls. The mounted photography provided context for each exhibit, for example with a depiction of the prototype being used, or with a diagram of the technical system supporting the function of the device. Each exhibit was supported by a caption providing the name of the designer and partners, and reproducing the text from the catalogue that described each individual exhibit, a format used throughout the exhibition. Additionally there was a screen displaying a looping slideshow comprising of all four exhibits and the Material Beliefs title in order to associate the four projects with a common theme. 


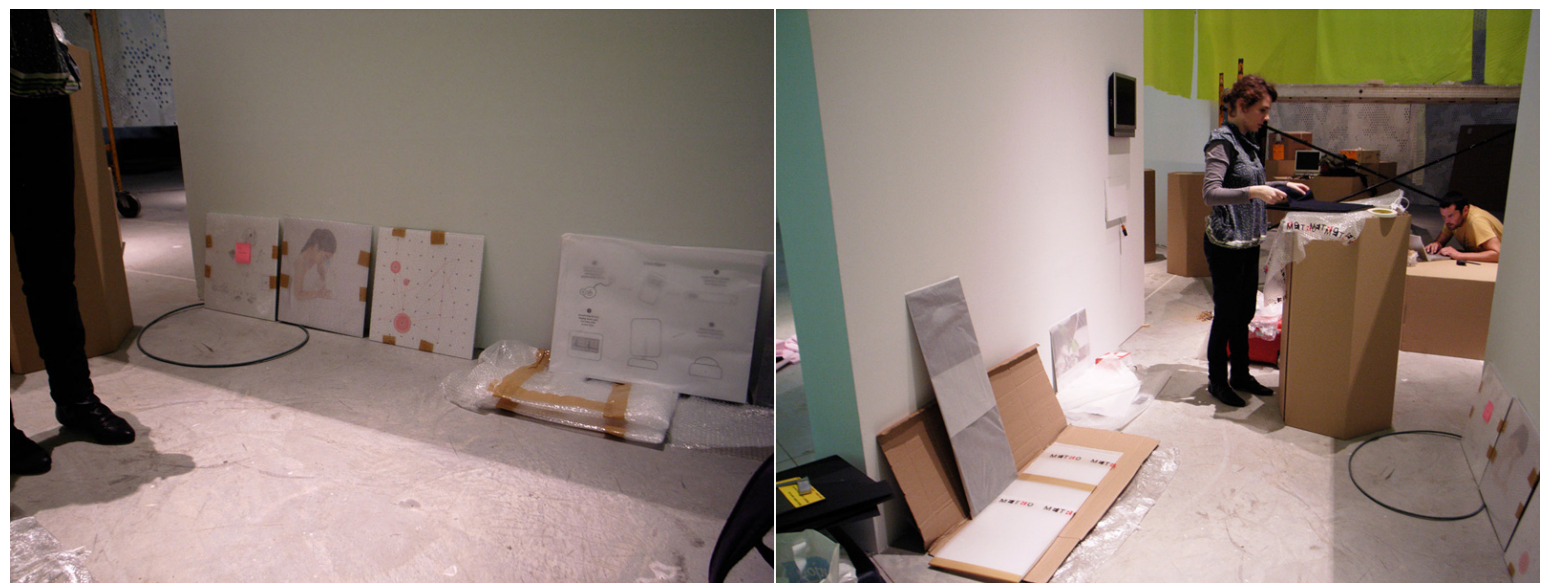

Figure 37: Installing exhibition materials at LABoral

\section{Bio-design at an art exhibition in London}

The second case for this section on exhibiting speculative design is a show titled Crossing Over - Exchanges in Art \& Biotechnologies, which took place between $2^{\text {nd }}$ October and $21^{\text {st }}$ November 2008. Crossing Over was a group show at the Royal Institution in London, an organisation that is perhaps recognised for its programme of scientific research including the experiments of Michael Faraday (James, 2000) and public engagement activities including the Christmas Lectures (Harrison, 2014). The exhibition at the Royal Institution was conceived and produced by Artakt, a team of arts and humanities researchers and curators based in the Research and Innovation group at Central Saint Martins College of Art and Design, and focused on the innovative communication of art, science and culture (Wallace et al., 2012).

Marking the reopening of the premises following refurbishment, Crossing Over brought together a group whose output was associated with a range of creative practices, seen to come under a broad banner of contemporary art:

Crossing Over is an exhibition of contemporary art bringing together art, design and biotechnologies. Integrated in the fabric of the Royal Institution building, artworks by eleven artists and designers investigate the metaphors, potentialities and anxieties of genetic manipulation and bioengineering. (Albano, 2008) 


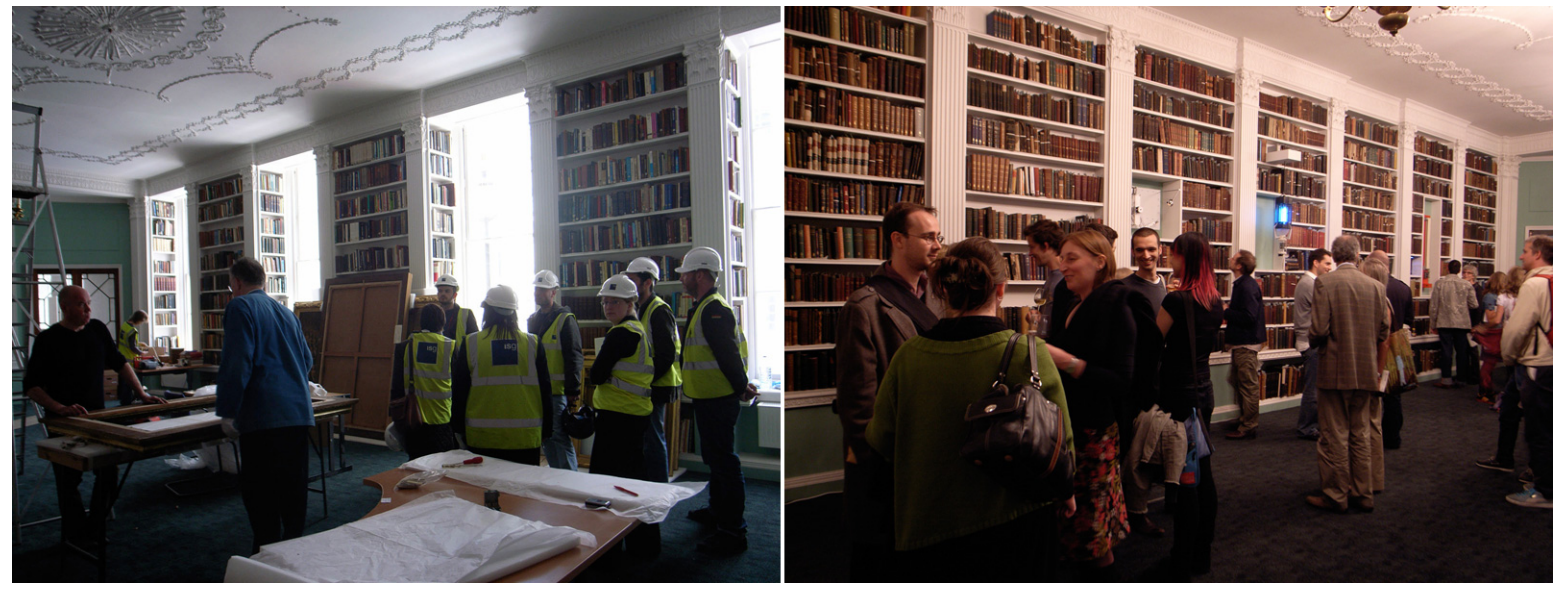

Figure 38: Designers visiting the Library at the Royal Institution during the removal of material to make way for their work, and the opening event for Crossing Over

The artworks were installed throughout the Royal Institution premises, amongst the displays of scientific apparatus used in historic research, and in the corridors and stairways that connect these spaces. The outcomes of the four Material Beliefs projects included were installed in the library, where books and shelves were removed to provide voids for the objects. The installed designs are largely the same as those exhibited at LABoral, including CDER, Neuroscope and Vital Signs, though instead of We Live What We Eat, d5 here exhibited a different design called Bonsai Cells, where adult stem cells are cultured to generate patterns. Collectively these four exhibits were described by the curator Caterina Albano as being biodesign, which is seen to be "an innovative field where cutting edge scientific and technological experimentation meet speculative design" (Albano, 2008, p. 37).

\section{Discussing exhibitions}

The LABoral and Royal Institution exhibitions have some common features. Firstly, both are group shows supported by printed material, including an invitation, an exhibition leaflet and a press release, and principally a printed catalogue featuring photography and descriptions of individual projects and essays that establish curatorial themes (Albano, 2008). Secondly, an opening event is followed by a period of daily admission and a programme of occasional events, including a gallery tour by curators and an evening panel discussion of relevant themes with exhibition participants.

There are also key differentiating features between these two exhibitions. Beyond formal features like the scale, duration, budgets and locations of the exhibition, one primary difference lies in the discourses that respective curators draw upon to establish a theme for a group show. Nowhere/Now/Here is a contemporary design show that fosters a curatorial agenda about the role of designers in driving cultural change (Feo \& Hurtado, 2008). On the other hand, Crossing Over is a contemporary art exhibition where artists are credited with rearticulating the characteristics of biomedicine (Albano, 2008). How are these curatorial themes balanced with the 
character of individual projects that make up these group shows? There was a case during preparation for one of these exhibitions where the partner's perception of a designer's desire to communicate the "scientific relevance" of biotechnology was at odds with the artistic and cultural values of the curatorial stance (Kerridge, 2008). Certainly the broader aims of Material Beliefs as a project proposal, with an alignment to the idea of upstream engagement, are somewhat as odds with these curatorial discourses, where action and vision are attributed to the individual energy and insight of designers and artists. Undoubtedly, with both these exhibitions negotiating 'project fit' is an intractable feature of planning processes that support the arrangement of multiple artefacts in an exhibition with a particular theme. There is a point to be made here about the invisibility of the process of negotiation that takes place between partners during the arrangement of an exhibition. While the idea of discussion and debate around the meaning and implication of a design is largely associated with general expectations regarding public encounters, it is also a feature of the negotiations of event partners that take place during planning.

Elsewhere, in their accounts of these exhibitions, designers and researchers express some doubt about the value of these events as forums for public engagement (Dawson, 2009c). Firstly d3 reflects on the exhibition at Royal Institution in relation to project aims for public engagement, and for the claims that speculative design in an exhibition accomplishes debate:

I always struggle to find the purpose of an exhibition, you know. Is it for the sake of having to tick a box, "I had a show, it's good for my CV"? And quite often what works well is the opening, you are there and you can engage with all sorts of people... But then you know what happens afterwards? There are some visitors but you're not there to explain the work. (Dawson, 2009a)

This theme is also established in the project evaluator's interview (e1) with the designer (d5) and the researchers (r14 and r15) as they discuss the Royal Institution exhibition and forms of participatory engagement:

r15: We went to see the exhibition, and there weren't any members of the public there when we went so it's difficult to gauge how they perceived the exhibition.

d5: I mean in, it works in the opening, because it's the opening, you bring and invite people. In the opening you are there, the people that did the work are there...

e1: So it's much closer to that discussion participation model?

d5: But then even the model of the exhibition, the complaints that I had from my side was like there wasn't enough explanation to the projects. 
r14: Yeah.

$\mathrm{d} 5$ : You had the text, but there was nothing there, and the projects were really complex.

r14: You can't ask questions at an exhibition unless there's somebody there to ask the questions to. Whereas the public event, if you had any questions or suggestions, you could bring it up and cause a discussion.

d5: So I think in that way, exhibitions are great, but they don't really....

r15: It's limited isn't it?

d5: Yeah. They're very limited I think. (Dawson, 2009d)

D5 continues to question the effect of exhibitions as proscribing the innovative features that might come about as a result of the collaboration and the broader agenda of the project:

Because for me that's the normal design thing. You know, you do an object, and then you might be exhibiting at the fair or at the exhibition space, and you just do it for yourself, that's the traditional design role, and what we would like to explore is different design roles, and how design can contribute to research and to raise awareness, and do public engagement. So I think if you take that traditional element and put it there it just loses the whole meaning I think. (Dawson, 2009d)

While the designers in Material Beliefs took a range of approaches, it can be said that a core expectation going into the project was to work on a single speculative outcome for exhibition. However the structure of the project, with ambitions for multiple exhibitions and also other types of public events where the designs would feature, challenged that anticipation of a final exhibition. The requirement to undertake a series of events led to reflection about the syndication and iterative refinement of the design outcome, for example $\mathrm{d} 3$ and $\mathrm{d} 4$ planned to make two sets of designs, and then made improvements to the behaviours of exhibited designs over time (Dawson, 2009b). However, d5 sees that exhibitions can act as points of focus for an on-going trajectory of related activities that are characterised as involving different partners with various research interests. D5's approach seems to be distinctive in terms of working with an evolving set of partners related to a developing theme, in her case therapeutic biotechnologies. In this way, $\mathrm{d} 5$ sees exhibitions as pressure points for the materialisation of a continually evolving set of activities giving rise to a series of overlapping projects. These are depicted below in a d5's illustration and include We Live What We Eat, which featured at Nowhere/Now/Here, and Bonsai Cells exhibited at Crossing Over (see Figure 39). 


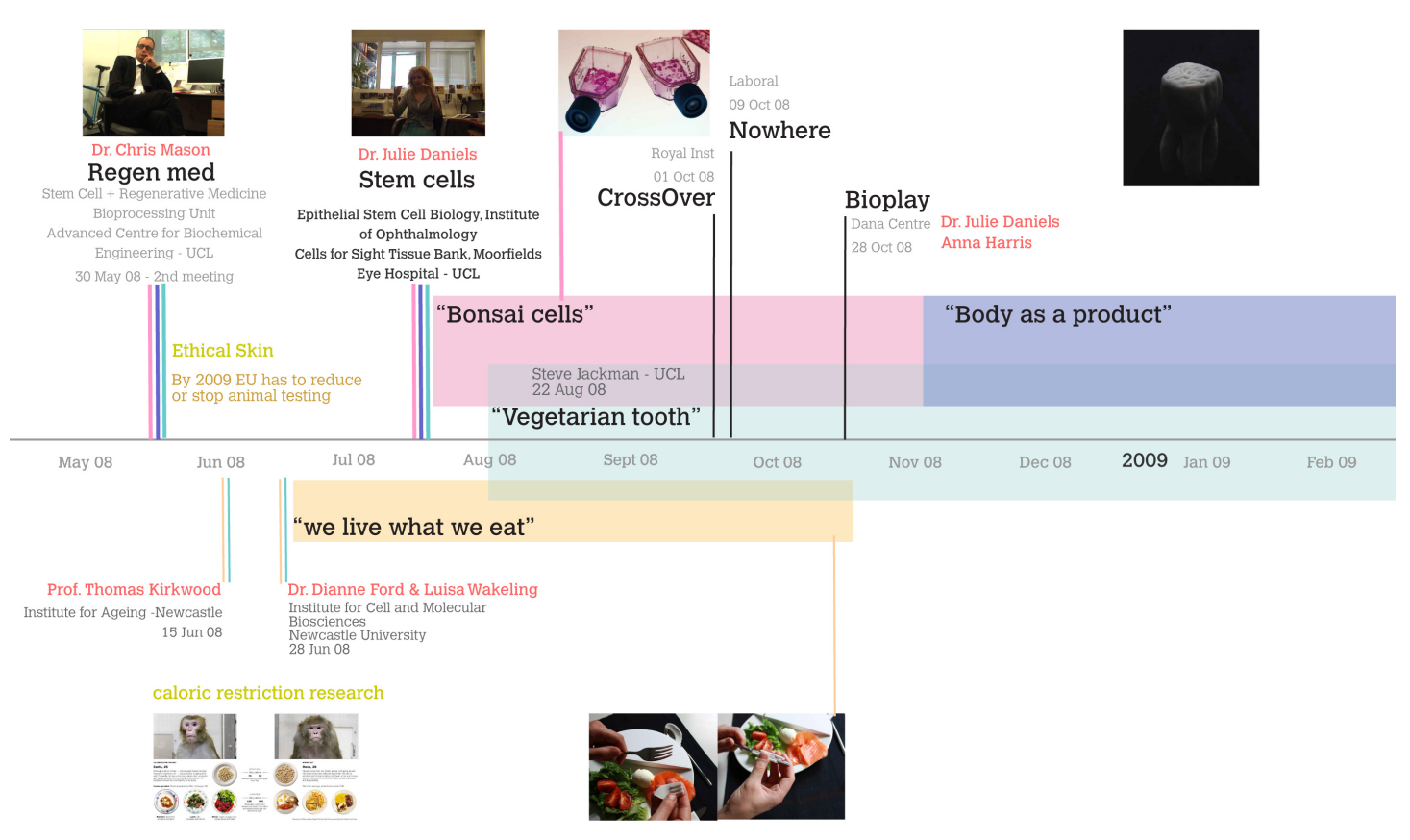

Figure 39: The right-side portion of $\mathrm{d}^{\prime}$ 's timeline of project activity for Material Beliefs detailing later interviews, projects and events.

Elsewhere $\mathrm{d} 5$ is quite concrete about the role of speculative design's multiple outcomes in relation to the project aims for upstream engagement:

I'm interested in research that is connected to therapy, medicine or biomedicine. That kind of research interests me because I think I see a use; what could be applied as a therapy in the future. I can participate in that. So I feel you could be interested in politics or economics because it interferes with your life. I think these fields [of therapy] also interfere with my life, and everyone's life. So I'm interested in having knowledge about that, and I think that's the main reason that you do public engagement, so you become more aware and you know more about what other people do, and also their methods. Also I think until recently science was like this kind of bubble, untouchable, and it was like almost like a dogma. You couldn't discuss or argue about what science does, you couldn't argue, and I think now it's very healthy that you can actually argue and discuss. Because what I see, they [researchers] are normal people like us, perhaps they have some doubts in their work also. Even if we are talking about very important things that perhaps are applied to you and will change you and your body, sometimes you are not sure what's going to be the outcome.

(Dawson, 2009d)

Biomedicine is seen by $\mathrm{d} 5$ as a form of expert knowledge that can become situated by speculative design in public settings so that research and its role can be discussed and contested. It seems fair to say that the exhibition of speculative 
design, where designers and researchers are largely not present, does not align well with the live-ness and the participatory nature of d5's ambitions. This view seems at times to be supported by other designers and researchers involved in these two exhibitions, as evidenced above. It's certainly more useful to talk about exhibitions as enabling the promotion and dissemination of design and its themes. Exhibitions enable designs to be promoted and for professional networks to be built, but it's very tricky for designers to provide an account of the public debates that are accomplished there. As I have argued above, designers' experiences of exhibitions come during the arrangement and production of these events, through conversations with the curators and other partners, which include venue owners, the administrators of programmes that resource those venues, and the policies and charities that resource those programmes.

The success of an exhibition is commonly evaluated using metrics relating to visitor numbers and the readership figures for news items generated by the event. In the case of Crossing Over, an email was circulated by the curator to participating designers and artists details Royal Institution visitor numbers over the period of the exhibition. Elsewhere, a journalist contacted by a press officer at LABoral attended the exhibition opening of Nowhere/Now/Here and was introduced by the officer to designers so that they could describe their work. The journalist subsequently published an article about Neuroscope and CDER in Spanish newspaper El País (Bosco \& Caldana, 2008), a national newspaper with the largest daily circulation in Spain, which was a notable outcome for the designer, the curator and the venue administrators. These metrics certainly align with a designer's ambition to have their work promoted, and depending on how good the results are, would seem to reward the private efforts of the professional partnerships that the designer undertook. However, I have demonstrated a need to move to a more nuanced account of public encounters with speculative design, and for this I move to other forms of circulation that take place in and around the exhibitions.

\section{Workshops}

While at proposal stage workshops were seen to be ancillary features of the broader programming that supported exhibitions, through reflection upon project activity by designers and partners, these live events have emerged as preferable formats for a speculative approach, at least in relation to designers' own conceptions of public engagement. The term workshop is here taken to indicate a set of structured activities that designers and researchers have jointly prepared for a group of attendees at a public event. The two workshops described here are evening events, made up of multiple sessions of activities that are repeated and run in parallel, and where the programme commences with an introduction and a closes with a plenary. 
In this section I present and discuss a pair of events at the Dana Centre. This is a venue in Albertopolis, an area of museums and academic campuses in Kensington conceived and commissioned by Queen Victoria In memory of her late Husband Albert following the Great Exhibition in 1851. This includes the Royal Albert Hall, Natural History Museum, Imperial College, Science Museum, Royal College of Art and the Victoria and Albert Museum (Hobhouse, 2002). The Dana Centre is based in the Wellcome Wolfson Building, part of recent redevelopment in the area, and whose lead partner is the British Science Association, discussed in the earlier engagement review chapter as a key player in the report for the public understanding of science (RS, 1985). Indeed the area is mentioned in the Science and Society report:

The golden age of popular science was surely the Victorian era, when Faraday lectured at the Royal Institution and the Great Exhibition led to the establishment of the national museums in South Kensington. (HOL, 2000)

This brief cultural and historical context provides some background to current activities at the Dana Centre, primarily formed of a programme of evening events for informal adult education, and whose format and tone align with the approach of Café Scientifique. While the Dana Centre's formal alignment with Café Scientifique has been through a subset of its evening activities, the organisations own guidance identifies with common strategies for planning, delivery and evaluation. Speaking as a founder of Café Scientifique, Duncan Dallas articulates an approach very much in line with contemporary, post-Bodmer public engagement where informal and deliberative formats are emphasised:

Public engagement receives support for many reasons, and many critics have explained that these reasons are self-serving... Academics politicians and educators all say that they want to 'listen' to the public but they are only 'listening to responses to their own questions... Within the Cafés, there is no brief to defend science at all costs, which provides a free and unconstrained agenda allowing people to ask awkward questions. Cafés consist of direct, faceto-face contact with scientists positioned as a part of the community. (Dallas, 2008, pp. 178-179)

Duncan sees Café Scientifique as an informal organisation that operates through a "bottom-up" remit, as a network without central resources, where groups informally associate themselves with this ethos. Due to an existing relationship with the Dana Centre from an event around Biojewellery, the venue was identified as a partner in the original funding proposal, and I subsequently contacted programme organisers there to arrange the two events described below. With support from staff from the Dana Centre, each event was planned in advance to take place over 90 minutes from 19:00 - 20:30, followed by a social event in the bar area. A common format was an introduction and concluding plenary to take 
place in the main bar area, with parallel and repeated workshops in between, with those workshops delivered in separate breakout rooms and taking a range of formats including brief prompts then discussion, and longer presentations followed by a question and answer session. There were four parallel workshops during the first event, with two at the second, and in both cases each workshop was run twice. Each event had about one hundred attendees, and in addition to the presenters and organisers, a film-maker and photographer attended on behalf of Material Beliefs to document the evenings, along with two or three science communications evaluators from various related partners including Material Beliefs, Talking with Robots, and the Science Museum.

\section{Techno Bodies}

The first evening event was titled "Techno Bodies; Hybrid Life?", and took place on $22^{\text {nd }}$ January 2008, at a stage in the project after collaborations had been established but before design work had started. This was conceived as an opportunity for the designers and scientists who made up the four projects clusters in Material Beliefs to come together in a public setting, and where the designer was cast as a discussant for the scientist's research, for example to invite questions from the floor whereby alternative applications for the research would be imagined. Each of the four projects were brought into an event setting earlier than the designers were accustomed to, and in order to participate in unfamiliar formats. It can be said that this led to innovation on the part of the designers, who became interpreters or provocateurs for the research, and who made early associations between features of the research and their own approaches. The title and theme of the event was a development of the Material Beliefs theme of silicon and cell hybrids, and the promotional description for the event that was published on the Dana Centre website framed a series of questions:

Meet engineers, designers and thinkers who are blurring boundaries between technologies and your body. What counts as a hybrid life form and how might it affect you?... Will the biological features of our future appliances make them more like pets? ... Is it sustainable to mend and replace our frail bodies? ... How might this body network connect to the internet, will we be monitoring each other's activity? ... Have your say as we discuss these new hybrids: are we becoming our own products? (Wong, 2008) 


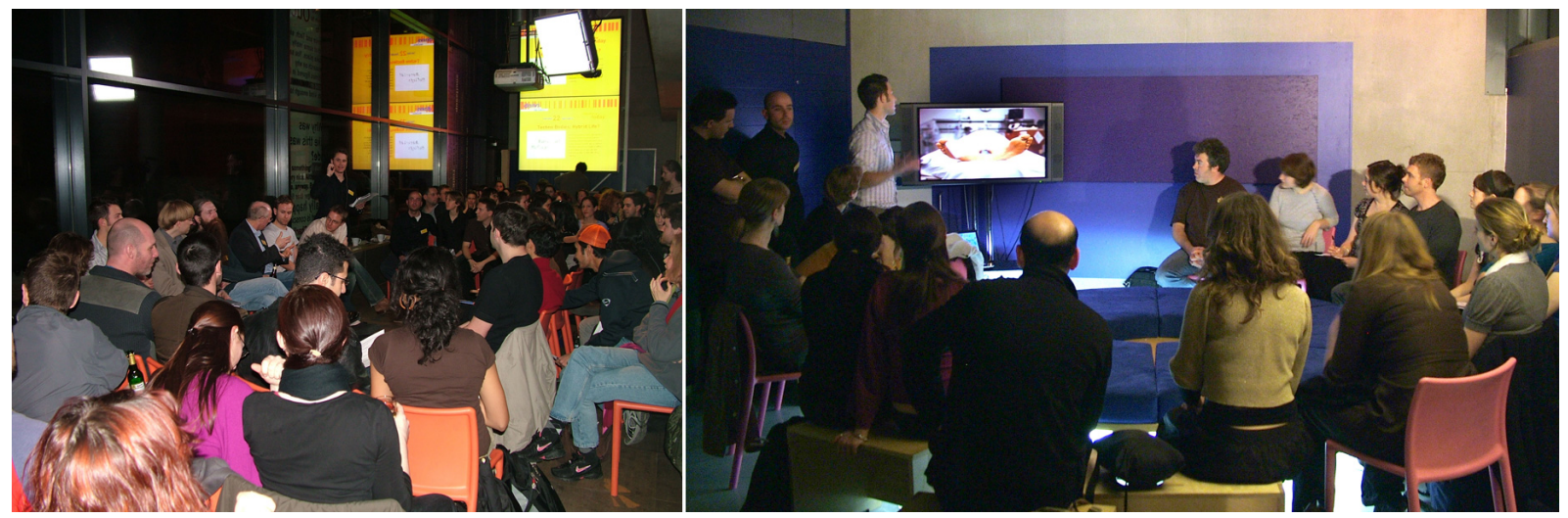

Figure 40: Techno Bodies, Hybrid Life - event introduction in the main space (left), and breakout discussion with $r 7, d 3$ and $r 9$ (right).

Researchers and designers were encouraged to both make active and overlapping contributions in order to frame discussion with the group who had attended each session. The four workshops can be characterised as either offering a structured (though presentation heavy) synthesis of research and design framings, or as providing an opportunity for the presentation of a research theme by the researcher that was then lightly reinterpreted by the designer.

\section{Bio Play}

The second Dana Event was tied "Bio Play" took place nine months after the first, on $28^{\text {th }}$ October 2008 . At this time designs within the project clusters were coming together, and so the event provided a public opportunity to present and discuss unfinished outcomes, ostensibly so that ideas could be tested and comments responded to in subsequent activity. As mentioned, this evening featured two projects rather than four, with the reduction in the scale a response to attendee feedback from the first event that expressed disappointment at being randomly allocated only two of the four workshops. And so the second evening provided a format that was less busy, and where attendees could experience the entire programme. The title of this event was Bio Play, and the theme was the inquisitive and open-ended treatment of bioengineering research, as framed by the description on the Dana Centre web page:

How can playfulness expand horizons in bioengineering? What happens when we open up laboratories to the whim of undefined ends, exploration and wonder? By expanding current laboratory research through speculative designs, Material Beliefs aim to create prototypes that redraw the intersection between science, engineering and design and lead to new realms of thought. (Bell, 2008)

There were initially plans for the evening to showcase the Neuroscope as a live and functional system for the first time. However as discussed in the previous chapter, 
it was seen that the topic of the evening created problems for the underlying research around the ethics of using animal cells.

The final programme for the evening featured sessions that focussed on $\mathrm{d} 5$ 's Bonsai Cells and d2 and d4's CDER. Each session was run twice for twenty five minutes, where Bonsai Cells split the group across three tables where project materials used to lead short discussions about the collaboration, and where CDER took the format of a presentation and Q\&A session.
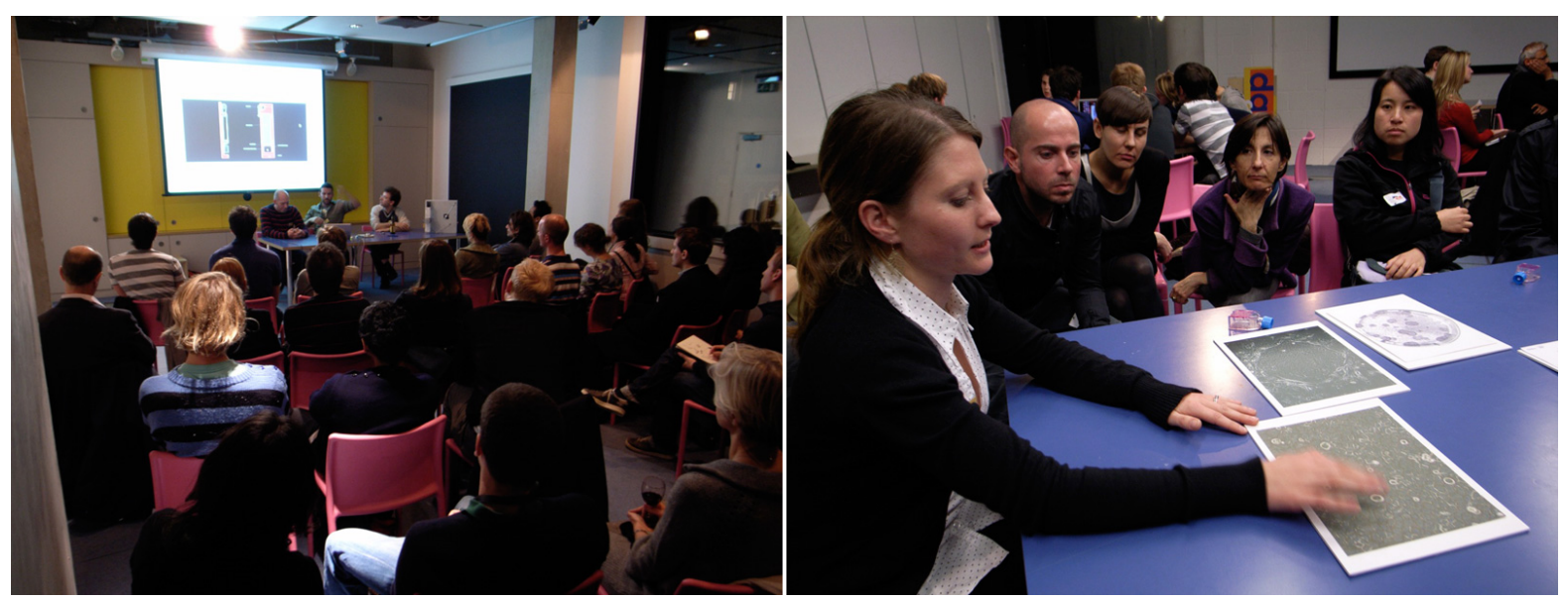

Figure 41: CDER being presented by $d 2, d 4$ and $r 11$ (left), r14 with photography of adult stem cells from the Bonsai Cells project (right)

\section{About Workshops}

The format of the workshop sessions at these two evening events conformed to two types. The first type was where the accounts by scientists of their research and the recontextualisation of that research by designers became synthesised, the second where a monolithic account was delivered either by the scientist or the researcher. To discuss these two types I focus on the workshops that took place at the first evening event, Techno Bodies; Hybrid Life?.

The workshop sessions that featured the clusters that lead to Neuroscope and Vital Signs were led by a pair of short presentations from a researcher and then a designer, followed by questions and answers with workshop attendees. In this way, alongside the presentation of a core trajectory for the research, some social implications for potential outcomes were introduced through design scenarios that diverged from the research narrative. For example, a design treatment of the biomedical institute's Digital Plaster that I presented, suggested that the collection and publication of biometrics might lead to surveillance and analysis of our personal data by organisations that we did not initially allow access to. Elsewhere, the Animat from the pharmacy and cybernetics lab was reconsidered by $\mathrm{d} 3 \mathrm{as}$ a domestic product, leading to a provocation that if embodied neuronal cells in appliances or toys led to perceptions of intelligence, what new status would be granted? 
Overall the discussions were considered by participants to be too short, with too much information delivered across the sessions. However, the theme of the discussions in these two cases were broadly in line with conveners expectations, which is probably not surprising given that the framing was so tight. Participants who agreed to be briefly interviewed on camera towards the end of the evening provided a lively snapshot of the atmosphere that evening, and while the attitudes being expressed there are clearly not generalizable as evidence of what the event accomplished, comments were sympathetic to the intended approach of the evening, for example:

In general I think that design is a strategy for questioning culture... and I think these guys are questioning culture and generating new scenarios. (Jackman, 2008g)

Both sessions offered a format where speculative treatment of biotechnology research suggested that the potential outcomes of research are not necessarily constrained to the applications anticipated by the researchers. Discussion was brought about by widening the application scope of the research through the introduction of an alternative outcome, which provided an opportunity for lay opinions to emerge. These alternatives enabled a space for speculation that did not serve to undervalue or directly criticise the effort of individual researchers. At times a discussion of alternative applications for the research were limited to topics connected to the instance presented by the designer, rather then ranging widely and being generated spontaneously by virtue of the speculative format. At other times, discussions that were had did not deal with the controversies envisioned, but impinged upon practical issues, for example the embarrassment of using biomedical technologies in the workplace. At these times, the ability of the workshop format to generate and sustain a variety of topics for discussion is a departure from the formats of the exhibition where design outcomes and their supporting materials are unitary.

The second tendency to which individual workshops conformed was for proceedings to be driven substantially by a monolithic presentation, and in the case of the first event this was by designers' invited partners. These cases speak to the provisional nature of collaborations at this early stage in the project, and perhaps also the perceived experience of the partner in delivering public engagement formats, leading to an achievable and therefore familiar format. In both cases, there was a sense from designers that the topic of the session drifted away from their speculative interests and the themes of Material Beliefs. This raises an issue about the stewardship of the debate that is had during a workshop, where engagement events enact the topics and the agenda of a particular engager. Here concern lies not with a public debate being had per se, or even the quality of the debate that is had, but in whether an event features a particular subject that 
aligns with the engager's interests. The first event can be characterised as a set of overlapping and at times confusingly divergent intentions for engagement, including for example 1) the Dana Centre's broad interest in informal adult education around contemporary science research, 2) the communication and promotion of research from the robotics lab featuring artificial intelligence in robots, and 3) design and biomedical collaborations where speculative designs raise social implications for silicon and biological hybrids (Material Beliefs). In short, a general aim for deliberation gives way to the right kind of deliberation with the right kind of indicators, as conceived by various schemes of the engagers.

Nowhere was the competitive ownership of engagement's framing concern so direct, than in an instance where a workshop session effectively became focussed on the topic of life extension in humans, and through that content, the promotion of a research group dealing with this topic. The session was led by the spokesperson for a Transhumanist foundation. However, while the topic of Transhumanism displaced the specific debate that the designer intended, questions were raised and discussion were had, as recorded in this summary participant's summary of the session:

As a human race we're part of an ecosystem and so if we prolong life to the point where people can live indefinitely, then the population will rise and rise and eventually we'll run out of resources. (Jackman, 2008g)

With these reflections of activity at two evening events, I've demonstrated that workshops offer a format for the circulation of design ideas that act as prompts for questions and discussion and where the content of format provides immediate feedback for the designer. However, given that the features of the debate that is had often misalign with the designer's expectations, I wonder if concerns about having the 'wrong' kind of debate points to a challenge raised by the core features of workshop formats for speculation, and why for designers the publication of finished outcomes at exhibition and in catalogues might be preferable. For sure the live-ness of the workshop format sees the designer as part of an extended set of ideas and proclivities that are not exposed by rhetorical accounts of debate.

Another feature of design's alignment with engagement is its rejection of goals that would otherwise be outcomes of particular engagement tropes - recommendations for the regulation of biometrics, more women scientists, public understanding of nanotechnology. In e1's exit interview with $\mathrm{d} 5$, e1 questions the motive as a designer doing public engagement:

So to gain knowledge, is to gain knowledge so that with knowledge you're in a better position to discuss or to argue, and is that the end of the story? Is discussing and arguing an end in itself, or would you want that to go further? And for the people involved with the discussions to kind of take those views 
away back to their work, or let that be the end of it. Because, what's the end point of that process? (Dawson, 2009d)

In the case of a speculative approach to design being applied to public engagement mechanisms like the café scientific format of these two events, there was certainly little interest from the designers in 'going further' in terms of learning about engagement from the forms of evaluation conducted by the partner, though for e1 such responsiveness would be seen as a programmatic goal for engagement practice. For the designers that developed a mode of doing workshops that moved beyond a monolithic presentation style, the discussions that were generated at these workshops through design materials can be seen as generating forms of activity not directly linked to a core design trajectory. This was the case with the discussion about an attendee's personal experience with diabetes technology, following the Digital Plaster session, which led to an interdisciplinary workshop at the biomedical institute, discussed in chapter 4 . These ancillary activities thicken, challenge and extend the core ambition of speculative design, and I argue that a description of those activities benefits speculation's account of itself. Finally, while these workshops are not taken further in relation to the evaluative mechanisms of public engagement, they are certainly not endpoints either, in the same way that exhibitions are not endpoints, rather these events should be seen as part of an ongoing process of design.

\section{Publications}

In this third section I briefly discuss a website and a book as two examples where written, photographic and film materials generated during the project were published. Both the website and the book are compilations of material that aimed to make good two intentions of the proposal, firstly to make the project generally accountable by illuminating the processes that were undertaken during its execution, and secondly that published material would in itself constitute engagement in relation to particular biotechnologies (Kerridge, Custead, et al., 2006). I discuss how these ambitions for transparency and engagement became mixed with a speculative impulse for the circulation of designs to enable promotion and debate, and reflect upon how the role of design publications might be reconsidered in the light of this mingling.

As well as sharing content, both the project website and book were unified through common presentational elements. A graphic designer was commissioned to establish an identity for the project, which was applied initially to stationery and cards for project members, then to templates for online content including website pages and the Wordpress blog. Additionally the same graphic designer later laidout the book and organised its printing. This visual continuity provided project publications with a cohesive identity and established a consistent design language, which was also applied to occasional and less substantial printed matter including posters for events and delegate packs for workshops. Both website and book drew 
substantially upon the same material, including interviews with biomedical researchers, the process of designing artefacts and the exhibitions and public events of the project. However, the publications display features that are specific to the medium and its role. For example, the website was responsive to project processes and was updated frequently and as activities occurred, whereas the book was produced at the end of the project and dealt retrospectively with an archive of material. In this respect, the website was formative in character and so a blog became a distinctive feature, whereas the summative nature of the book supported indexes and essays that surveyed the project and its themes.

\section{Project website}

The website was described in the proposal as being one of the ways that public engagement would be conducted, and the architecture of the website reflected this will to engage. For example it incorporated sections that featured a series of clips from interviews with scientists and engineers approached by designers and a blog where the minutiae of project activity could be published in order to fulfil an ambition for transparency and to provide a mechanism for contribution from users through the use of comments. In addition, a section dealing with the development of prototypes included interviews with the designers about the planning of their designs and their intention for these objects, along with a set of drawings and models of initial designs.
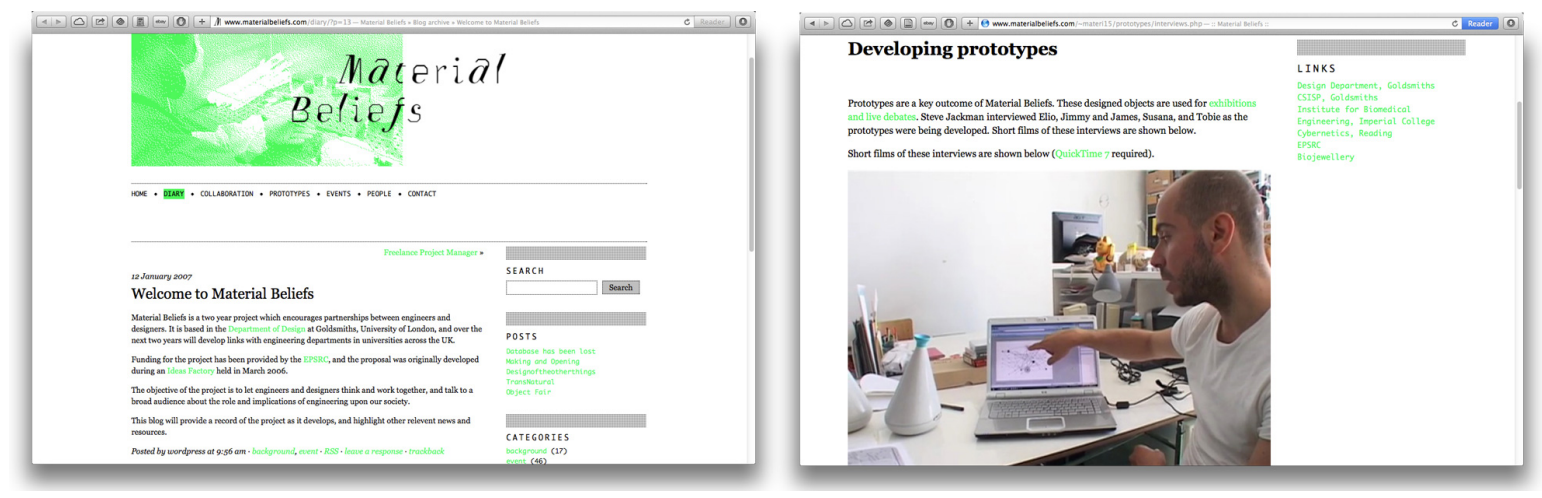

Figure 42: Images of project website showing logo and blog post, and screenshot of section featuring interviews with designers about their projects..

\section{Project book}

The Material Beliefs book provided comprehensive documentation of the project, structured chronologically (Beaver, et al., 2009). The text starts with scanned reproductions of the EPSRC project proposal and ends with an appendix of events, with four book sections that deal with scoping the project, engaging people, developing designs, and provoking debate. These sections are descriptive rather than analytical, and include photography, sketches, annotations and quotes as a series of mixed materials that provide a detailed impression of project activities. Additionally there are three short essays dealing with the topics of engagement, 
speculation and collaboration that contextualise the core features of the project. The publication also includes a DVD that contains the documentary films that were shot and edited by Steve Jackman.

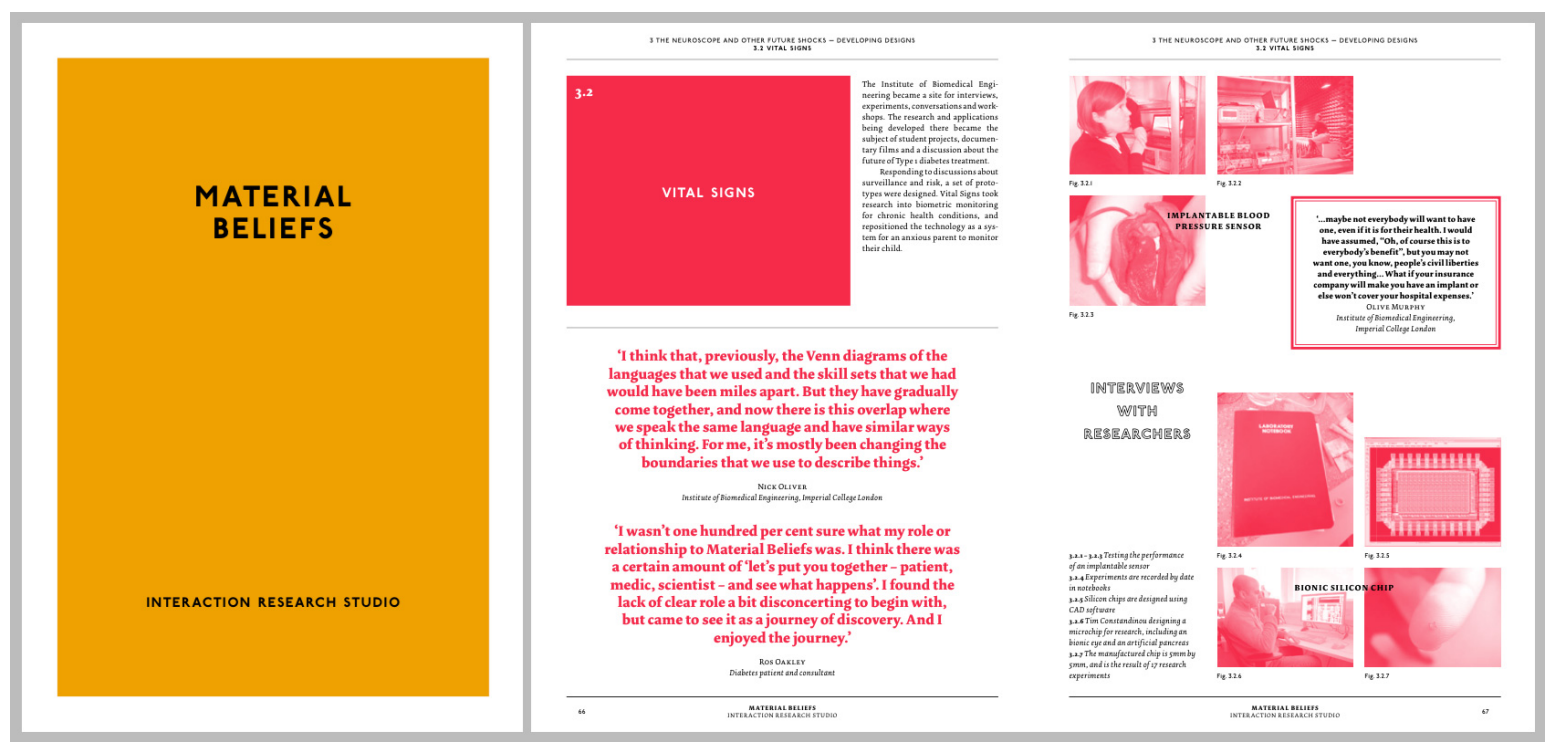

Figure 43: Cover (left) and a spread (right) of the Material Beliefs book.

I believe that the book performs a range of roles, in relation to the project and this thesis. Firstly, shortly after it was printed the book was given to participants, partners and an extended network of colleagues and professional associates in order to disseminate the project. I have heard from colleagues that the text has been used for pedagogy, particularly as a resource for discussion about the methods of speculative design in postgraduate teaching. Secondly, in writing this thesis and providing a scholarly account of Material Beliefs, I've grappled with the status of the book as the core textual mode for the project. As discussed in the introduction of the thesis, I now see the two as complimentary, and I remind the reader to download it ${ }^{16}$, or contact the author for a printed copy.

\section{About publications}

In order to discuss these publication formats, I focus on the website's responsiveness and the book's comprehensiveness. Firstly, where the website supported a responsive form of publication that responded to proposal aims of for transparency of practice and continual engagement, I discuss an episode where online documentation presented a challenge to the effective formation of a design outcome. Secondly, the comprehensiveness of the publication supports a discussion about the types of content that should be shared with the public, and I discuss what kinds of outcome are appropriate for speculative design.

\footnotetext{
${ }^{16}$ A PDF version of the Material Beliefs book can be downloaded at www.materialbeliefs.com/pdfs/materialbeliefs-book.pdf
} 
I have mentioned that the website aimed to make the project transparent by providing snapshots of processes and the development of individuals projects, and in doing so make the methods of speculative design visible to the public.

Additionally the website acted as a resource for journalists, editors and curators, and initially these professionals were contacted directly in order to generate interest in the work so that there was an awareness of the project and its potential for public engagement events. In this way, the editor of a popular design blog was contacted and sent a set links to the project website, which led to an interview about Material Beliefs that included a description of the aims of the project along with documentation of individual projects at a fairly early stage (Debatty, 2008). In this case, an ambition for design process to be published as a form of engagement becomes conflated with more familiar strategies for speculation's promotion, as reflected on by $\mathrm{d} 4$ in his response to the appearance of early stage design material on the blog:

There are pictures of the robots on that, and very brief and quite poor explanations. So they have already now to hit the world, they going to be blogged and they've been seen by a lot of people, but misrepresented slightly or not with a link to a really full explanation. So we've lost that initial impact a little bit. And now we've lost control of the public image of that because of copying and pasting. And these are things that are important but very hard to manage. (Dawson, 2009b)

Responsiveness is in this case seen to diminish the impact of the design as a finished proposition, particularly as the blog incorporates what are seen to be partial and unfinished versions of the design. Additionally, the importance of the control of the design is raised, and here the idea of a stable 'public image' seems at odds with speculation as a format that encourages debate and discussion, which would seem to entail versions and opinions rather than a single agreed format. On one hand d4's concerns can be seen as a response to what is seen to be premature and badly executed promotion, rather than a rejection of an experimental approach to engagement, and this is due to the somewhat strange conflation of promotion and engagement enabled by the website. However, there is also an opportunity to see this conflation, and the confusion that it entails around control versus variety in the representations of a design, and the muddling of expectations about types of audiences that are neither exclusively professional or public, that sees the primacy of the designer as sole arbiter of the terms of debate give way to an extended and distributed set of agencies. Certainly an ambition for a responsive mode of documentation of design processes interferes with the focus on the exhibition of finished designs that has been inherited from critical design's version of public debate. 


\section{Summary}

This final empirical chapter dealt with three formats for the circulation of speculative design in public settings; exhibition, workshop and online. I focused on a pair of episodes for each format, and through these empirical accounts I challenged and extended the rhetorical and articulated notions of debate and the public present in accounts of speculative design practice. I developed a series of analytical points that arose from the discussion of these episodes, including the refinement of speculation's relationship with upstream engagement, and pressed on with the rehabilitation of speculative design as a form of practice based research by discussing the methods and process of a speculative approach alongside final outcomes.

These various cases about the circulation of design have been opportunities to examine the underarticulated features of a speculative approach where the conception, execution and evaluation of project activities have, through the auspices of the proposal and subsequent funding, become mixed with public engagement and an idea of upstream engagement in particular. It is my intention that these specific cases offer a model for empirical discussion, which might be productive for other formulations of a speculative approach, within healthcare or innovation for example. However, as a secondary concern I also take the circulation of designs in Material Beliefs as opportunities to discuss how attention to speculation's features might refresh the idea of engagement practices that I have demonstrated to be challenged by critical accounts from STS.

While I am using the term circulation to challenge the primacy of finished design outcomes as the currency of exchange, there is equally a requirement to reconsider assumptions around those involved in that exchange. The idea of the public has been shown to connote a range of entities, and therefore it might be more useful to think of publics, as being a series of constituencies coming together in particular settings and also as being an effect of those contexts rather than an existent entity to be dipped into. Circulation is a term used to describe encounters with speculative design where materials and processes that are unfinished, and where the format of the event is planned and where participation is ostensibly open.

\section{A range of outcomes}

I have argued for an account of speculative design that takes focus away from the exhibition and the publicity of the finished prototype, in order to attend to the encounters that are enabled by the processes of design leading up to, and occurring during and after the exhibition of a speculative prototype. Furthermore, a trajectory of activity that starts in the lab and ends in society is also at odds with the mixings that I have discussed. This helps understand design's interaction with other disciplines and practices, and allows a speculative approach to make itself understood as a form of design research. A second key move is to challenge 
assumptions about the form of public engagement with which speculative design has becomes aligned.

This chapter featured episodes from Material Beliefs that extended the notion that public encounters with speculative design are necessarily about confrontations with finished outcomes. Indeed I question the notion of speculation - a design approach where 'use' is predicated on discussion - as ever being finished. And so, while at first glance this final empirical chapter concluded a linear sequence for the execution of speculative design, where fieldwork with experts leads to studio making leads to public exhibition, I have shown that public workshops can be considered to be fieldwork, and the publication of material online has much in common with processes of making.

\section{Publics of speculative design}

In the forms of circulation discussed above, 'the public' are specific and diverse, but share common characteristics. Firstly, publics are imagined and anticipated by designers and their partners as participants in events where the presentation of materials are planned and choreographed, and where the presentation of the material is delegated through particular presenter roles, particularly in workshops. The delivery of planned materials necessitates a distinction between the roles of presenter and participant, and happens despite an expectation that there will be an unplanned debate about the features of those materials. Looking back at the episodes dealt with in the previous two chapters, while these features of planning and explicit choreography set the public events in this chapter apart from earlier episodes such as informal conversations that took place in a meeting, or from discussion with colleagues about technical features of a design process, they are common to what might be though of as non-public events, for example doing interviews with researchers, and delivering a small internal workshop at a lab. So what makes one planned event public, and the other not? One answer is that the forms of circulation dealt with above support the idea of an encounter where participation is in principle open and available to all. 


\section{CHAPTER 7: CONCLUSIONS}

\section{Introduction}

As a preface to the topics of this thesis, I offered snapshots of my involvement in two funding workshops. With the first workshop I aimed to introduce the design project Material Beliefs and provide an overview of the proposal's ambition to bring a speculative approach to upstream engagement. The second workshop framed a sense of inertia and repetition regarding the modes of writing enabled by this mixing of speculation and engagement. A decision to take up $\mathrm{PhD}$ studies came specifically from the inability for the forms of writing supported by that practice, which amounted to curatorial captions and online publicity, to deepen and analytically extend speculation's account of itself, which in turn precluded the practice from making a contribution to design research. With this thesis I have moved beyond rhetorical and promotional modes of writing about the activity and outcomes of Material Beliefs, and provided an analytical account of that project as design research.

In this chapter I provide a review of the key findings related to the principal chapters of this thesis, starting with the two literature review chapters that covered speculative design and public engagement, and then move on to the three empirical chapters that discussed situating biotechnology, designing speculatively and circulating design. Following the review section I reflect on some key issues raised by the thesis in relation to the contributions anticipated in the introduction. Finally, I reflect both on the experience of undertaking PhD studies, the strengths and weaknesses of this thesis, and anticipate activity that will follow its completion.

\section{Review of key findings}

\section{Practicing speculative design}

In the first half of the second chapter I demonstrated that a speculative approach to design had inherited from critical design an ambition to infuse technology with narrative, to generate debate rather than provide utility, and to move from an academic environment into public settings. However, I argued that critical designs' intention to enable a debate about technology is at times conflated with a desire to successfully promote this novel design practice. Nevertheless, a blurring of the idea of engagement and with the ambition for the promotion of practice, does not problematize a core tenet of critical design which is the production of a network where "design thinking can be encountered by the public"(Dunne, 1999), as an alternative to academia which is seen to confine the appeal of the work (Debatty, 2007). 
Meanwhile, new objects of concern, including biotechnology, drive design's association with public engagement organisations, which in turn compels the refinement of design commitments to public debate. For example, I see Bioland's prototypical network of "scientists, ethicists, museum and arts organisations, the public and designers" (Dunne \& Raby, 2003, p. 3) as a precursor for early speculative design and public engagement projects like Biojewellery (Thompson \& Kerridge, 2004) and Hybrids (Ashcroft \& Caccavale, 2004), which are funded by the EPSRC and Welcome Trust. These projects see versions of debate rooted in disciplinary notions of criticality challenged by versions of public engagement that are responsive to the interests of science educators and funding councils, and which also invite the vicarious demands of the public. The model of practice where the designer is an isolated critic of technology in society is thereby challenged, for design no longer has the authority to set the terms of the debate in which the public, scientists and policy makers are then engaged. Rather design becomes more of a ground for staging these encounters, and of building formats through which the outcomes of these encounters coalesce.

Here emerges a clear sense of speculative design, which is informed by notions of debate developed in critical design, and remains focused on framing emergent science and technology as hypothetical products and services. However, responsibility for identifying and materializing issues is now distributed across the network that has come together through a project of public engagement. Through their funding proposals and project reporting, I argue that designers' unqualified notions of public engagement become refined through the rubric of upstream engagement. For designers, the upstream provides an opportunity for dialogue about early stage scientific research and supports their envisioning of hypothetical futures through design alternatives. However, I argue that rather than engendering debate, due to under-articulation of this mode of practice, speculative design currently does little more than enable the programmes of the organisations that sponsor its exhibitions. There is an opportunity to articulate the value of speculative design as a generative activity where technology, people and issues are brought together in experimental ways.

\section{Analysing speculative design}

Having discussed a trajectory for critical design where an emphasis on public debate led to professional and epistemic association with public engagement with science and technology, it was not clear how to go about an analysis of this mixing. This was due to the lack of clarity about how design research might grapple with public engagement, compounded by an under-articulation of speculative practice as a form of design research. My first move in the second section of chapter two was to establish some links between speculative design and research literature in order to resource empirical analysis. 
I noted an emerging literature where critical approaches are applied either as methods of practice-based design research or evaluated in relation to conceptual schemes, including a discussion of critical making by Matt Ratto (2009), and Matthew Malpass's taxonomy of critical design (2009). More recent developments include the integration of critical approaches and participatory design (Lenskjold \& Jönsson, 2013), a formal analysis of the approaches taken in a case of design for debate (Mollon \& Gentes, 2014) and a feminist discussion of normativity in speculative and critical design (Prado de O. Martins, 2014). I then took the PhD. theses of Ramia Mazé (2007), and Simon Bowen (2009) as two analytical cases.

Mazé and Bowen provide two very different accounts of critical design that align with and support distinct methodologies for critical practice, where their treatments of criticality are motivated by different literature reviews. In Bowen's case design criticality is initially a reified and patronising exercise that is then put to constructive work solving real design problems as a form of participatory design. Meanwhile Mazé expands an initial focus on product design with histories of radical architecture, and shows how design artefacts can go into a wider range of settings to act as prompts of discussion between designers and prospective users. These analytical approaches offer models for the empirical treatment of speculative design. However, their approaches do not treat the commitments of partners sceptically, rather the partner's formulation of a problem that needs to be solved is adopted as the start point for design's inductive problem solving. I resolved that a discussion of speculation and engagement's mixing in the case of Material Beliefs would proceed out of a sceptical treatment of the idea of the upstream, so that rather than evaluating design activity as a normative mode of engagement practice, there would be scope to discuss the extent to which speculation in fact challenged and reformulated the claims made for upstream engagement.

The notion of applied criticality was then developed with a discussion of the design research projects Switch! (Mazé \& Redström, 2008), and Zapped (DiSalvo, 2009) where workshops that provide public encounters with speculative representations of technology are seen to support the emergence and discussion of issues. However the authors do not develop a full account of what happens at these events. There is an opportunity for the empirical sections of this thesis to extend the account of peoples' experiences of these events, including the experiences of biomedical researchers, members of the public and designers themselves. I argued that one way to support this would be to move away from a style of writing that sought to evaluate speculation as a mode of public engagement. Opening the account to consider perspectives, values and outcomes other than those tied to the normative evaluation of upstream engagement, would allow a richer and potentially more illuminating discussion of activity. 
In order to develop the conceptualisation of politics by designers, I looked to Design Studies and found a model that sees society as largely determined by technological development, and where it is the responsibility of the designer to consider how their role can contribute to and intervene with how choices are made. I argued it would be useful to articulate a less direct relationship between design and society, and take into account forms of agency other than that of the designer. Nevertheless, given that a deterministic model of technology and society underwrites practitioner accounts of critical and speculative design, I surveyed this literature further.

I argued that a core strand of design research in the 1960s sought to establish a methodological account of practice that reconciled the sensibility of the designer with a positivist framework (Cross, 2001; Bayazit, 2004; Krippendorff, 2006; Cross, 2007). In contrast to this literature, the approaches adopted by industrial and architectural design through a turn to participation, support a reconsideration of the ways in which critical and speculative design currently marks its own difference from 'affirmative' and 'commercial' design. For example, it seemed that this literature on participation, a variety of design research that had been somewhat excised from the canon, saw design as a medium for generating discussion, which had much to contribute to speculative design's emphasis on exhibitions and workshops.

In an overview of conference proceedings from this period, I emphasised that a crisis in expertise drove a model of participation that saw the designer as the facilitator of events, organisations and structures that enabled others to take action (B. R. Smith, 1977). Political activists saw in designers the potential to deliver programmes of change that enabled constructive technological alternatives (Cooley, 1984), though not as independent actors but as part of a network of trades unions, universities and public organisations. Elsewhere, it was seen that the designer's participatory methods would enable the laity to access planning and decision making that would otherwise be restricted to technocratic elites, where the public would imagine the impact of, and advise upon technologies that have yet to be developed or implemented (Roy, 1971). Here are models of design echoed in recent ambitions for design to stimulate discussion (Dunne \& Raby, 2001, p. 58) to stage a debate (Auger, et al., 2003), or solicit issues (DiSalvo, 2009), either within a community of product designers through pedagogy and academia, or within a broader public community through exhibition and publication.

I then focused on an Open University programme that sought to deliver an Alternative Technology agenda, enabling its design graduates to control the production of technology, and engage in a political struggle for social change (Cross, et al., 1974). Faculty drew substantially on Murray Bookchin's theme of Liberatory Technology (Bookchin, 1974), Ivan Illich's discussion of Convivial 
Technology (Illich, 1975), and a broader concept of Soft Technology informed initially by a New Scientist article by Robin Clarke (Clarke, 1973) as the theoretical bases for these technology practices. I argued that there is a rich connection between the literature, ambition and strategy of this programme and the trajectory of critical design described earlier, from its origin as disciplinary critique, to its identification with the institutions and discourse of public engagement with science and technology, and on to the partnerships and programmes that are the topic of this thesis. In particular, this parallelism offers a rich literature with which to develop the ideological background of critical design, to compliment the reviews made by Ramia Mazé and Simon Bowen in their theses.

\section{Organisations and practices of PEST}

In chapter three I provided a review of the practice and analysis of public engagement with science and technology (PEST). Having established in the previous chapter how speculative design became mixed with upstream engagement, a subset of PEST, I reflected that the meaning of the term PEST had so far remained largely undeveloped in the thesis. I then provided some background, including variations of the term used by different organisations and the varieties of activity that are thereby denoted. I emphasised that PEST has been described as "a wide and ill-defined area" (Wynne, 1995) as a result of the diversity of purposes being pursued in its name and the variety of "institutional or individual priorities, motivations, and assumptions" being enacted there (BIS, 2010, p. 6). A government report provided a benchmark for the breadth of institutions from industry, academia, public and cultural sectors currently taking roles within this field (BIS, 2010, pp. 30-31).

Having conveyed the institutional variety of PEST, I moved to a dominant historical model of its development in order to provide some context and detail of its various purposes (Gregory \& Miller, 1998; Bauer, et al., 2007). However, before proceeding I noted that the neatness of the model, and its implicit assumptions regarding the development of styles had been challenged (Wynne, 2006) and that while the history predominately reflected a UK experience, this was commensurable with the funding context and delivery of Material Beliefs. I then reviewed three sets of material, including two historical phases of public engagement followed by upstream engagement, which I introduced not as a historical phase per se but a PEST style with particular relevance for topic of the thesis.

Starting with Bodmer's report for the Royal Society (RS, 1985), the Public Understanding of Science is seen as mobilising a broad commitment from science institutions to reconsider their relationship with the public (Irwin \& Wynne, 1996, pp. 4-6; Miller, 2001; Bhattachary, 2004, p. 7; Wilsdon \& Willis, 2004, p. 17; Stilgoe $\&$ Sykes, 2009, p. 9). The report made a comprehensive case for the extent to which "science and technology permeate our daily lives" (RS, 1985, p. 31), including national prosperity, participation, policy making, risk assessment and 
scientific culture. Following the report, the formation of organisations including Committee on the Public Understanding of Science (COPUS) are seen to delivery Bodmer's recommendations, through its support for science centres, festivals and popular science literature (Stilgoe \& Sykes, 2009, p. 9), and in raising the profile of public understanding of science as a policy concern (Wolfendale, 1995, p. 1) leading to the formation of the Office for Science and Technology (OST) in 1992.

Following broad, institutional momentum of public understanding of science, I argued that the subsequent Science and Society report appeals for a refinement in focus from the transmission of knowledge and the communication of benefits, to a model of deliberation and discussion (HOL, 2000). The report describes a "crisis of trust" in civil society's relationship with science following the "disquieting possibilities" of biosciences and incidents of technological failure including the Chernobyl explosion, and is frequently cited as the source of the etymological shift from understanding to engagement (Miller, 2001; POST, 2001; Wilsdon \& Willis, 2004, p. 17; Stilgoe \& Sykes, 2009, p. 9). The report made a series of recommendations to support organisations in delivering programmes of shared decision making with non-experts, where a subsequent review of activity included the GM debate steering board and the ESRC Science in Society programme (POST, 2003).

I then emphasised an engagement trope that I have previously linked to the milieu that informed the proposal for Material Beliefs. I showed that the term upstream engagement became applied to science and technology in 2003 to designate activity during the early stages of nanotechnology research when the "forms and eventual applications of the technology are not yet determined" (Willis \& Wilsdon, 2003, p. 218). However I then foreshadowed a critical treatment of engagement's rhetoric, noting that commitments to the upstream differ across organisations, and so while engagement practitioners might seek the active participation of nonexperts in decision making (Stilgoe, 2007), economic actors might look to the mitigation of public perceptions of risk so as to encourage the uptake of technology (HM-Treasury, 2004a). I noted that these seemingly incommensurable treatments of upstream engagement underlined the need for careful and critical handling in my analysis of its adoption by speculative design.

Moving to the more general scene of PEST, I then provided an overview of public engagement methods, taking the principal options for engagement described in the House of Lords' Science and Society report (HOL, 2000). I offered a brief overview of two options, namely stakeholder dialogues and foresight activity, in order to provide some background for options that related strongly to the adoption of upstream engagement in Material Beliefs.

The stakeholder dialogues of the Nanodialogues project were characterised by the technique of using experts to facilitate public discussion, and by the intent of 
establishing themes about the potential capabilities of early stage research (Stilgoe, 2007). Both these features align with the expectations about engagement activity anticipated in the Material Beliefs proposal, where it was seen that biomedical researchers would provide expertise, for design imaginations and at public events. Additionally the Sciencehorizons project was seen as providing a model for public dialogue about technology futures (Warburton, 2008), where the narrative style of information packs helped frame speculation's focus on design outcomes as material prompts for debating biotechnological issues. In establishing continuity between engagement practices and techniques of speculation, I wished to draw attention to my anticipation of Material Beliefs' alignment with upstream engagement in the proposal. Furthermore, these continuities establish some detail regarding the accounts that I made to others regarding the aims and features of Material Beliefs activities, during planning and delivery.

I concluded this section by reflecting that while the preceding review of the practice and evaluation of PEST provided insight into the rhetorical alignment of speculation with upstream engagement in the project proposal, there was an opportunity to introduce analytical approaches that supported a broader and more critical conceptualisation of the design activity that followed.

\section{PEST as an object of critical analysis}

In the second half of the third chapter I argued that the accounts in the first half were motivated by the specification, delivery and evaluation of PEST programmes, and in this respect are tied to normative activities, for example a poll to determine public perceptions of nanotechnology. In the second half of the chapter I signalled a shift in focus to analytical accounts of PEST from social science. I introduced a set of research supported by funding from the Economic and Social Research Council (ESRC), whose programmes were seen to align with key moments of governmental support for public engagement initiatives (Irwin \& Wynne, 1996, p. 6), namely periods following the publication of the Bodmer report (RS, 1985) and the Science and Society report (HOL, 2000). I distinguished two methodological approaches to PEST in these research programmes, the first dealing with public attitudes and supported by quantitative methods including surveys (Durant, et al., 1998; RAEng, 2009a), the second where ethnographic approaches are applied to a diverse range of fieldwork where public understanding of science is reconsidered through empirically grounded considerations of authority, identity, and knowledge (Irwin \& Michael, 2003). The later, anthropological and critical approaches to PEST, saw the public understanding of science located in the mixed discipline of Science and Technology Studies (STS).

For the purposes of focusing social science literature in relation to my topic of speculation and engagement, I argued that an analytical account of Material Beliefs would not be best supported by quantitative methodologies, and felt that it was the administrative atmosphere of survey work which had cast PEST as such an 
uninspiring discussant of the specific issues relating to speculative design's entanglement. I then emphasised that for design writers, the methodological and conceptual innovations of STS offered a route of escape from PEST ennui.

I noted that STS literature problematizes the historical model of PEST'S progression from deficit model to more enlightened and participatory styles of engagement (Irwin, 2006; Wynne, 2006). The claims made for upstream engagement in particular are challenged, for instance the upstream is seen to be a rhetorical posture that merely seeks to account for and negotiate the risks associated with predetermined paths of innovation (Wynne, 2006, p. 218). I emphasised that while the Material Beliefs proposal incorporated upstream rhetoric, there was scope for empirical discussion of design activity to deal critically with the proposals' identification with the upstream.

I then discussed three sets of STS literature beyond the immediate scope of PEST, that I believed would support analysis of Material Beliefs as a case of speculative design. Firstly I looked to move beyond the tradition of Critical Theory and Marxist social theory in order to reconsider the speculative design's conceptualisation of expertise. Linear, technocratic models expertise have been empirically challenged with multidirectional models where the technological object becomes linked to the "wider socio-political milieu" (Bijker, 1987, p. 46), and engagement can expose uncertainties of science and technology by problematizing linearity and provoking questions regarding purpose and risk (Jasanoff, 2003, p. 239). Such accounts of expertise, knowledge and power provide more nuanced and conceptually rich registers for an empirical discussion of project activity, and help to move analysis on from critical design's version of critique and public engagement's model of dialogue. Secondly, I related speculative design's focus on imagining future instances of biotechnology to STS topics that dealt with science and technology's capacity to imagine and persuade. Here, the potential for innovation practices to be experimental and generous is seen to be put under pressure from regimes that seek simple fictions in order to reinstate a linear model of technology development (Wynne, et al., 2007). Clearly, how technology innovation is conceptualised within a laboratory will shape expectations about what PEST activity should accomplish, be it public dialogue or public relations.

Elsewhere the notion of critical public engagement studies expressed a curiosity about methods where the characterisation and demonstration of lay sensibilities and imaginations was seen as an end in itself, rather then a precursor to the 'institutional governance of emerging technologies' (Macnaghten, 2010, p. 32). I argued that dealing with design's intervention in sites of engagement can be seen as an end in itself, rather than seeing it as partial or precursory process to a policy outcome. This emphasis on the value of the procedure of design activity vitalises a discussion of speculative design that focuses on descriptions of its processes and 
the theorisation of empirical detail. Finally, a third set of literature considered how to move beyond the agency and intention of the designer in order to grapple with the diverse accountabilities of speculative engagement. Following a disastrous interview episode where a respondents dog sits on a audio device and destroys an audio recording, Michael is prompted to instead treat the scene itself as his data, leading to rich set of reflections regarding heterogeneous actors and the emergence and nature of the disaster (Michael, 2004). Elsewhere, Akrich describes how designers' inscribe expectations into technical artefacts, and that there may be a tension between the user and the intended use (Akrich, 1992). I emphasised that the competences and performances of biotechnologies might be seen to be redistributed (Akrich \& Latour, 1992, p. 262) by way of speculative designs that intervene with and upset intended configurations.

\section{Situating biotechnology}

In chapter four I discussed biotechnology labs as sites where designers interviewed researchers about their work, and where workshops were convened to provide others with encounters of biotechnologies in the making.

\section{Expectations of the lab}

Prior to moving to episodes of project activity in actual labs, I described how the proposal for Material Beliefs imagined that biotechnology and cybernetics facilities were at the centre of a programme of activity, where it articulated three core expectations of labs (Kerridge, Custead, et al., 2006). Firstly, extending the relationship between biomedical research and design established in earlier speculative projects (Ashcroft \& Caccavale, 2004; Thompson \& Kerridge, 2004), labs were seen as the locus of biomedical and cybernetic research activity. A thematic concern for biotechnologies that mixed with and extended the function of human bodies was established. Such labs were seen to offer early access to research whose likely future applications would entail controversy, for example privacy of data (RS, 2004), and would therefore offer potent start points for design projects. Secondly, labs were seen to be venues that would host interdisciplinary collaborations between designers and researchers. The proposal characterised both designers and researchers as turning "ideas into things", where researcher's things were technologies and applications, and where designer's things were hypothetical provocations (Kerridge, Custead, et al., 2006). It was seen that a programme of collaboration would enrich their respective approaches, and challenge their ways of working. Thirdly, it was envisioned that these collaborations would make the lab available as a venue for public engagement. In particular, the issues and topics identified by the designer as a result of their association with researchers would become developed through the delivery of events in the lab, an expectation that aligned with models of upstream engagement discussed elsewhere (Wilsdon \& Willis, 2004). Here the designer is seen to be an 
intermediary who convenes activity that encourages others to imagine the implications of lab research.

These three expectations provide an impression of how biomedical and cybernetic labs were characterised at proposal stage. The imagined lab shaped subsequent activity, as the proposal document became a resource for planning and project management.

\section{Designers interview biomedical researchers}

I described how a set of initial project activities sought to build a network of designers and biomedical researchers to undertake the aims of the proposal. Four designers were recruited to the project, and researchers were contacted by designers and initially invited to a workshop that set some initial expectations about the theme of speculative engagement around biomedicine and cybernetics, while the ambition for designers to collaborate with researchers was also introduced. Subsequently a series of interviews were undertaken, where designers visited researchers to discuss biotechnologies and see the facilities where the researcher worked. These interviews were filmed and activity was photographed, and I referred to this documentation in order to discuss two interviews in some detail.

At times designers anticipated that the interviews would provide start points for the development of speculative designs. The interview with $\mathrm{r} 1$ provided insights about biotechnology research, and extracts from the transcript were selected by $\mathrm{d} 1$ and reproduced in design material including posters and exhibition captions. While these quotes were intended to verify design scenarios, in the same way that expertise is performed by critical design in order to suspend disbelief (Auger \& Loizeau, 2001), the quoted material became subject to discussions between designers and researchers, and at times modified or even withdrawn. In this way, speculative design's adaption of biomedicine became negotiated, due to the accountability of the design concepts to the requirements of on-going association between designer and researcher. Elsewhere, designers encouraged the researcher to elaborate upon discursive contexts of biotechnologies rather than technical aspects of research. For example, a discussion about biomedical implants led to chat about the 'worried well' and other features of the market for healthcare. These tangents were seen by $\mathrm{d} 1$ and $\mathrm{d} 3$ to provide anecdotal treatments of biotechnology that supported the conceptualisation of design scenarios. In this way while researchers might be expected to act as technical consultants, or as experts who can verify and authenticate the biotechnology which is seem to be extended by the design, they in fact contributed to discursive and imaginary treatments of research that supported design speculation.

The interviews also acted in various ways as start points for public engagement activity. In the case of the interview with $\mathrm{r} 1$, a discussion about the public 
controversies of genetically modified organisms led to reflection from the researcher on the need to communicate the value of nanotechnologies, with which he aligned his own research. The conversation led to $r 1$ 's participation in a public event with d1 (Kerridge, 2007d), despite divergences in their respective expectations of the event, which was for the researcher an opportunity for educating young people about nanotechnology, and for the designer a chance to develop a workshop activity that allowed biotechnology to treated imaginatively. Elsewhere, the online publication of the data generated during the interviews, including films and photography, was notionally seen by designers to be in itself an occasion for public engagement. However, while online publication of project content aligns with the proposal's strategy for the project website to be a mode of engagement, these short films might more usefully be considered as design documentaries (Raijmakers, 2007) that act to make speculative method more accountable.

\section{Workshops at a biomedical institute}

I reflected upon a role I took as visiting researcher at the biomedical institute, and discussed two workshops that I convened there. The first workshop emerged out of a series of events that took a biomedical platform as a focus, while the second workshop was arranged for a group of postgraduate students as part of a design brief. These workshops were discussed as examples of project activity where access to research settings was granted to people without biomedical research expertise, including a patient at the first workshop and the group of fourteen students at the second.

Mind the Loop was a half-day workshop convened at the institute for a small group that included a clinician ( $\mathrm{r} 4$ ) a participant from a previous public event (p1) who was also a patient of $r 4$, a researcher who was developing an artificial pancreas (r5), and a filmmaker. An aim for the workshop was to allow the participants' diverse perspectives on an artificial pancreas to be shared, elaborated and documented. It was demonstrated that such biomedical therapies are likely to have effects that are additional to the control of the disease, including the demands of data interpretation upon the patient and clinician, and the affective nature of the technology upon the patient. I reflected that these types of insight challenged my own expectations about the workshop as a mechanism for generating speculative design concepts. I became exposed to forms of knowledge that challenged the formulation of controversy for debate that I argued characterised the critical inheritance of my speculative approach. I argued that where speculative design is treated as research, it is possible for an account of practice to give expression to, and find value in, forms of activity that are not well aligned with the exhibition narratives that would otherwise be the dominant mode of outcome. 
The second workshop had various aims. Firstly it aimed to provide a robust encounter with biotechnology research for a group of postgraduate design students who would visit the lab for a project brief. Secondly it developed existing types of engagement undertaken by researchers at the institute, which were restricted to providing tours of the facilities for young people to encourage the uptake of science subjects, along with research demonstrations for visitors that were regarded as either exercises in public relations or pitches for funding development. Thirdly the workshop supported the aims of Material Beliefs in delivering what was seen at the time to be upstream engagement events in labs. Through their encounters with researchers the students devised design projects that challenged the researcher's accounts. In one example where the data produced by a biomedical implant became hacked in order to produce fake, healthy data, the researcher was surprised by the reinterpretation of her work by others. These interactions can be seen to interfere with researchers' expectations about engagement, which had previously been seen to provide educational and promotional functions.

\section{Designing speculatively}

This chapter provided an empirical discussion of making designs in Material Beliefs. I opened with a description of three cases of design in Material Beliefs; Neuroscope, Carnivorous Domestic Entertainment Robots and Vital Signs. I then discussed three aspects of designing prototypes, related to the mixing of speculative design and upstream engagement. Firstly I discussed how designers' association with researchers is conceptualised and managed. Secondly I demonstrated that the functionality of a design enables experimental forms of practice. Thirdly I examined how my ambitions to see design as providing alternative for biomedical research acted to displace existing variety.

\section{Association with researchers}

I contrasted two cases of collaboration between designers and researchers, in the design of Neuroscope and CDER. In the first case, the designer and researchers met at the beginning of the project and set a course for subsequent and frequent association. Here the designer takes an experimental approach to his practice by setting up occasions for co-authorship of design materials, including a brainstorming session about future products. However, a later discussion between the designer and researchers demonstrates that the collaborative generation of such material exposes differences in disciplinary approaches regarding scientific rigour and design open-endedness, and reveals expectations from researchers that d3's design will communicate the value of their research. The second case provided a different approach where the designers of CDER worked relatively independently, with researchers providing periodic advisory input. Here, the designers see biotechnology as providing raw material for design, where researchers descriptions resource initial design concepts. In contrast the design of 
Neuroscope leads to a more complex entity, though arguably this complexity is not easily presented at exhibition.

\section{Designing functionality}

I argued that features of designers' association with researchers during the making of Neuroscope and CDER shaped the development of functionality in the prototypes. Design functionality for Neuroscope became challenged through the technical requirements of system integration, while for CDER there was a focus on behaviours that demonstrated function in order to communicate the design proposal. Both design processes are mindful of the status of the prototype as a public entity, though different forms of publicity are anticipated and embodied in the design, including dissemination, demonstration, debate, promotion, education and ethics. I characterised the trajectory of CDER as being fairly independent and aligning strongly with the designers' initial ambition, where a substantial set of speculative work was produced, and where approaches align with the format of critical design. In contrast, the Neuroscope followed a deep and complex association with researchers, where the speculative nature of the design was challenged by functional integration with biotechnology, and the outcome was experimental and risky.

\section{Providing alternatives}

I discussed Vital Signs as a speculative alternative to the digital plaster, a biotechnology platform being researched at a biomedical institute. However, I expressed concern that in proffering such an alternative, the design acted to displace expressions of variety that already existed in researchers own accounts of their work. In treating the digital plaster as a specific and defined biotechnology, I was able to suggest that once the platform leaves the lab, the underlying technology becomes reconfigured to support market driven applications including biometric surveillance, with dubious implications for liberty. However, while the underlying protocols and digital circuits were being researched and tested, the digital plaster had been presented as enabling a range of applications including assisted living for the elderly, elite athlete monitoring and the internet of things (Burdett, 2009). In this way biotechnologies in the making are being both concretely and speculatively tied to entities 'outside' of the lab by researchers. Like the designer, the researcher is actively engaged in the production of scenarios, and the practice of biotechnology research is inherently social. However, the intrinsic flexibility of biotechnology is expressed primarily through networks of innovation that are comprised of actors able to provide material, financial and political resources (Wynne, et al., 2007). This network sees the public as outsiders, who are characterised as irrational in their misunderstanding of the value of these biotechnical innovations in the making. It is in this context that public engagement becomes a tool for the positive promotion of emergent biotechnology to a lay audience, and at that point the variety and instability of biotechnology becomes 
fixed (Wynne, 2006). I argued that through the provision of an imaginary alternative to lab biotechnology, and despite an ambition to provide debate, there is also potential for speculative design to tidy away the instability and sociality of research, and inadvertently align itself with a network of innovation that sees civil society as an external and deficient public, and where biotechnologies follow fixed trajectories from the lab to the consumer.

\section{Circulating design}

In this chapter I discussed three pairs of project episodes where designs went into public settings. Firstly I discussed two group exhibitions, one at LABoral in Gijon, Spain and the other at the Royal Institution in London. Secondly I reflected on two evening events at the Dana Centre in London, where designers worked with venue staff to deliver public workshops. Thirdly I considered the compilation of project documentation on a website and in a book as examples of publication. These examples of design circulation are a small but fairly representative selection of the public-facing activity delivered over the duration of the project (Kerridge, 2007b).

I noted that public events took place over the project time frame, and so disseminated content included final designs and also featured material relating to early design processes and research activity. Given project commitments to do engagement activity, designers and researchers acted responsively to opportunities as they became available. As the project developed the network of partners that were worked with broadened, and opportunities to undertake partnerships increased. Given that participation in public events were frequently offered to project members on the basis of the proposer's interests, rather than being sought in accordance with our own expectations of project aims, the formats that project members were invited to deliver became more surprising and diverse.

\section{Exhibitions}

I have argued that exhibitions are seen to be a core activity for speculative designers, conceived as being the final stage of a designer's work, and considered as the settings where the public encounter speculative designs in the flesh, and where debates happen. I cautioned that an assumption of debate at exhibitions be treated sceptically, and expressed surprise that given the value placed on exhibitions, accounts of what goes into them and what happens there are so sparse.

I introduced two exhibitions from Material Beliefs in order to discuss their features and characterise their role in the project, Nowhere/Now/Here at LABoral in Gijón and Crossing Over at the Royal Institution in London. While there were similarities between the configuration of displayed work and some core strategies of these two exhibitions, there were some key differences that effected the presentation of the designs. For example, the curators draw upon different discourses to establish a theme for a group show. Nowhere/Now/Here is a contemporary design show that 
fosters a curatorial agenda about the role of designers in driving cultural change (Feo \& Hurtado, 2008), while Crossing Over is a contemporary art exhibition where artists are credited with rearticulating the characteristics of biomedicine (Albano, 2008). These curatorial themes at times aligned with the topics of individual projects and elsewhere required compromises to be made. Therefore while the idea of discussion and debate is largely associated with general expectations regarding public encounters of a design, it is an explicit yet under articulated feature of the negotiations of event partners that take place during planning.

Meanwhile, I showed that designers and researchers raised doubts about the value of exhibitions as a mode of public engagement. D3 disputed the idea of debate happening at exhibitions given the absence of the designer and their partners, a subject echoed by r14 who commented "you can't ask questions at an exhibition unless there's somebody there to ask the questions to". Elsewhere, d5 saw that in contrast to live events like workshops, exhibitions tend to emphasise role of the designer(s) exclusively, and that therefore the features of collaborations and partnerships become displaced (Dawson, 2009d).

\section{Workshops}

I discussed a pair of evening events delivered by designers, researchers and partners at the Dana Centre in London. This venue provided a programme of informal adult education, and identifies with the ethos of Café Scientifique and its variety of contemporary, post-Bodmer public engagement where informal and deliberative formats are emphasised (Dallas, 2008). The first event, Techno Bodies; Hybrid Life?, took place in January 2008, after collaborations had been established but before design work had started, while the second event Bio Play, took place nine months later, when designs were well established though not complete. While initially seen as marginal, or as the poor relation of the exhibition, I argued that over the course of the project, workshops emerged as preferable formats for some designers, at least in relation to their own conceptions of public engagement.

I argued that the individual workshop sessions at these events conformed to a format where accounts by scientists about their research, and the recontextualisation of that research by designers became synthesised, or contrastingly where a monolithic account was delivered either by the scientist or the researcher. In the first case, alongside the presentation of a core trajectory for the research, some social implications for potential outcomes were introduced through design scenarios that diverged from the research narrative, demonstrating that the potential outcomes of research are not necessarily constrained to the applications anticipated by the researchers. These alternatives enabled a space for speculation that at times was limited to topics connected to the 
instance presented by the designer, rather then ranging widely and being generated spontaneously by virtue of the speculative format. At other times, discussions that were had did not deal with the controversies envisioned by designers, and instead related to practical and personal issues, for example the embarrassment of using biomedical technologies in the workplace. Here, the workshop format exposed variety and generated discussion, in contrast to d5's comments on exhibitions, where the range of views taken by the designer and the researchers as a result of their association become collapsed.

The second format that the workshop activities conformed to was where proceedings were driven substantially by a monolithic presentation. Here I argued that public events support a variety of sometimes divergent sensibilities about the means and purposes of engagement. For example, at the first workshop there was the Dana Centre's broad interest in informal adult education around contemporary science research, versus Material Beliefs' speculative design of biological hybrids for upstream engagement around issues of liberty and privacy, versus the vociferous promotion of a gerontology foundation that identified with the ambitions of transhumanism. At times a particular mode of engagement prevailed, and activity became largely framed by the concerns of a particular presenter. In this respect, where designers see that their interventions set the terms for a debate, we should also recognise that such an approach is just one aspect of a variegated scene of engagement.

\section{Publications}

In the third section of this chapter I discussed a website and a book as two examples where written, photographic and film materials generated during the project were published. These publications supported aims of the original proposal to make the project process visible to others and provide engagement in relation to the biotechnologies being explored (Kerridge, Custead, et al., 2006). Both website and book drew substantially upon the same material, including interviews with biomedical researchers, the process of designing artefacts and the exhibitions and public events of the project. However, the website was formative in character and so a blog became a distinctive feature, whereas the summative nature of the book supported indexes and essays that surveyed the project and its themes.

I discussed an episode where, due to its formative nature, online documentation presented a challenge to the effective formation of a design outcome. Early stage drawings of the CDER designs were posted on the project website, and the editor of a popular design blog was contacted and sent a set links to this content, resulting in an interview about Material Beliefs accompanied with the CDER drawings (Debatty, 2008). This was seen by $d 4$ to diminish the impact of the design as a finished proposition. Here, the idea of a stable 'public image' seems at odds with speculation as a format that encourages debate and discussion, which 
would seem to entail versions and opinions rather than a single agreed format. However, $\mathrm{d} 4$ 's concerns can be seen as a response to what is seen to be premature and badly executed promotion, rather than a rejection of an experimental approach to engagement, and this is due to the somewhat strange conflation of promotion and engagement enabled by the website. Nevertheless, there is also a sense that a designer's control of the representations of a design, and the role of a designer as sole arbiter of the terms of debate, become challenged by attempts to connect design practice to public engagement. Certainly an ambition for a responsive mode of documentation of design processes interferes with the focus on the exhibition of finished designs that has been inherited from critical design's version of public debate.

\section{The contributions of empirical speculation}

In this thesis I have treated speculative design empirically, in order to make a reflexive analysis of a case of practice. In this final section I argue that the thesis makes three core contributions.

Firstly, I have emphasised that without robust analysis, speculative design is tied to modes of writing that offer limited and rhetorical accounts of its features. In moving beyond descriptions that support the promotion and exhibition of their projects, speculative designers can become responsive to the features of the settings in which their work operates. Secondly, given the association of my speculative design case with PEST and upstream engagement in particular, the thesis provides a distinctive and critical lens for the idea of upstream engagement. Thirdly, given that the processes of making and circulating speculative design artefacts provide the grounds for a reflective analysis of practice, the thesis encourages speculative designers working with partners in professional settings to treat the activities they undertake as research. I expand on these areas of contribution below.

\section{Developing the rhetorical claims of speculative design's practitioners}

From the outset I have argued that the idea that speculative design engages the public and enables debate is not grounded in the analysis of actual events. These claims are rhetorical and anticipatory, and are not supported by analysis of the circumstances of making, installing, exhibiting, and promoting designs. I am therefore sceptical of claims made for the effects of speculative and critical design by its practitioners, which often suggest that the creation of a network for exhibitions and other public events, enable the critical discourses that inform their design work, to become more widely available as a form of public debate (Dunne \& Raby, 2003; Kerridge, Custead, et al., 2006; Debatty, 2007). Coupled with this notion of establishing a network for the circulation of speculative design is the idea that exhibitions enable a broad medium for the discussion of critical ideas, where those concepts in their original form are seen by designers to be inscrutable, 
scholarly and remote. However, I contend that the discourses used by curators and practitioners to make rhetorical accounts of design projects are not somehow unshackled from disciplinary and specialist knowledge, indeed the languages and conventions of the network that critical and speculative design has established is opaque and mysterious. In making a case for empirical accounts of speculative design, I have demonstrated an analytical mode of writing tied to encounters with these designs, as they are made and circulated in various ways, amongst a diverse yet specific constituency, in order to make the features of those encounters accountable.

I have demonstrated that an empirical analysis of speculative practice deals with the process of design as well as the outcomes. In the case presented here, outcomes included the exhibition of designs and their documentation in catalogues and project publications. While these forms of circulation are taken for granted, their features have not been described. Additionally a range of activities took place during the trajectory of the project, including proposal writing, interviews, workshops and the making of prototypes. Treating these various processes as episodes for reflection and analysis requires an account of speculative design that includes positions other than the designers. In taking focus away from the intent of the designer, and considering the role of others, a richer picture of the design setting has been captured, and the claims made for the effect of a design have become challenged and show to be multiple and at times contrary.

\section{Speculative design's enchantment with upstream engagement}

In the thesis I have grappled with speculative design's attraction to the idea of upstream engagement. I identified my own practice with the upstream following the publication of a Demos pamphlet, which described a public engagement with nanotechnology project (Wilsdon \& Willis, 2004). The text included reflection from geographer Robert Doubleday regarding his role in a nanotechnology lab. Here, he supported activities involving scientific researchers and the public, where the outcomes of early-stage nanotechnology research were imagined. The notion of a social scientist embedded in a lab, leading interpretive and imaginative activities with publics, aligned with my own ambitions for speculative design as tool for public debate. The vignette of an external interpreter provided a model for the partnerships anticipated in the Material Beliefs proposal, where I contended that speculative designers would work with biomedical researchers to establish a collaborative and mutual programme of upstream engagement.

As a consequence of writing this thesis, these preliminary ideas about the compatibility of speculation and engagement have been challenged and developed through analytical accounts of project activity. I now see that in the Demos pamphlet, a social science researcher's notion of lab intervention becomes normatively tied to a policy-focussed discussion around public participation in science and technology research. In the policy-focused discourse of Demos, the 
geographer's role is mediated by the narrative of upstream engagement, and despite paying lip service to the idea of democratic participation, this discourse reintroduces problematic and patronising models of engagement (Wynne, 2006). The thesis has enabled a reflexive examination of the bases of association between speculation and engagement, and this has enabled an articulation of design practice on its own terms. This mode of writing has more in common with researchers own accounts of practice (Doubleday, 2007; Horst, 2007), where researchers speak reflexively about project activities in which they have had a hand.

I have argued that the term public engagement is not useful, mobilised as it is through divergent and incompatible energies including education, public relations and deliberative policy, none of which align with the core questions of this thesis. I have endeavoured to provide an alterative to articulations of speculation that would align it instrumentally to one or another of these schemes, particularly where the designer is seen to be the creative, imaginative collaborator of an entrepreneurial, scientific innovator. Here, speculation becomes reduced to being a communicator of the beneficial impacts of biotechnology, transmitting scientific value and knowledge to the public (RS, 1985). I appreciate though that there are superficial similarities between the hypothetical scenarios of speculation and engagement projects that associate with upstream approaches. For example, the Sciencehorizons workshop packs are conceived to bring together "citizens, scientists and other experts, policy makers and other stakeholders" in order to discuss "issues raised by possible future directions for science and technology" (Warburton, 2008, p. 8). This sounds and looks something like speculative design, particularly in respect of the use of scenarios to link biotechnologies to practices and issues through hypothetical technologies.

There are however big differences in how these upstream scenarios are devised, how they are deployed, and in particular with the forms of public interaction they anticipate. Crucially, the events of speculative design are ends in themselves. Speculation does not explicitly link into some later mechanism, whereas Sciencehorizons is explicitly about guiding the formulation of policy. Elsewhere, Phil Macnaghten describes ethnographically inflected depictions of engagement practice as critical public engagement studies. Therein he characterises the development of lay imagination an end in itself, rather then a precursor to the 'institutional governance of emerging technologies' (Macnaghten, 2010, p. 32). This self-contained and generative mode of practice aligns well with the episodes that I have discussed, where speculative design offers a practical critique of public engagement's assumptions.

I feel that a potential strength of speculative design is that its disengagement from engagement keeps the conceptualisation and evaluation of technology talk loose, 
whereas upstream engagement ultimately conceptualises discussion in relation to a linear model of technology development (Stirling, 2008). The notion of a 'stream' of activity that can be navigated goes against the open-endedness that is established in forms circulation described here. Michael has written about the multiplication of versions of technology in speculative projects, which "Spiral out in many conceptual directions, raising questions about a multitude of indistinct issues surrounding science and technology" (Michael, 2009). I have argued that rather than talking about creating debate, designers could admit to a less authoritative and central role, accept the proliferation and indeterminacy of their concepts, and enjoy providing an account of the versions that their designs take.

\section{Speculative designers as practitioner-researchers}

At the outset of the thesis I appealed to speculative designers to attend to their practice as research, and to provide analytical accounts of the activities they undertake, so that knowledge about their practice can be shared with others. Those who identify with the label of speculative designer may not be seeking partnerships with biomedical researchers, though they will probably be working with partners from some other professional setting. They might not be conducting interviews in labs, but there will likely be processes of discovery within partner settings where ideas are generated and outcomes are designed. Those outcomes might not be encountered by particular publics and responded to in ways that are characterised as challenging the configuration of biotechnology, but no doubt there will be an emphasis on the imaginative reaction of a particular community or participant. This thesis has provided an example of how the features of a particular case of speculative design can be captured and shared.

Having argued for the accountability of practice through analytical writing, I would like to dispel what might be a persistent doubt in the minds of some speculative designers about doing practice-based research. I am mindful of a conversation with Maja Horst about the productive tension that arose when she took up seemingly conflicting roles as a public engagement practitioner and as a researcher of those practices. Here I paraphrase Horst's reflection on her involvement with a public engagement installation in a city centre, where the responses of those who encountered the project was at times sharply at odds with her intentions for it (Horst, 2007):

I am much more considerate of practitioners now that I have been one. What I learnt is that I am a researcher, and I don't want to take responsibility for the kinds of effects that practitioners have in the production of persuasive fictions.

Horst's reflection speaks to an experience of exposure related to taking part in a mode of practice that would otherwise be the object of her research activity. For speculative designers the discomfort comes when crossing over in the opposite direction, where there is perhaps a sense that analysis would diminish the 
assurances and prestige granted by the design. There is even perhaps a sense that the treatment of design as research acts as an obstruction to the making. Certainly the speculative designer becomes exposed to a variety of positions that challenge features of practice inherited from critical design. These include the formulation of a controversial and monolithic scenario that frames a future outcome of emerging technology, along with a set of assumptions about the forms of debate that are seen to be enabled by that scenario. However, I contend that the discomfort experienced by the speculative designer as they adopt an analytical mode is in fact productive. In Horst's case, the experiences of practice go on to resource conceptually rich forms of analysis. In the case of empirical speculation, the core outcomes of design can be seen as partial concrescences of the data generated through a trajectory of practice. These outcomes of practice are then complemented and also unbalanced by the reflexive accounts of the broader activities that attend their making.

\section{To the future}

I have found $\mathrm{PhD}$ studies and writing up this thesis to be incredibly challenging and immensely rewarding. During this time, the two topics I have been discussing, speculative design and public engagement with science and technology, have developed. Designers who associate their practices with a speculative approach have extended their work into a variety of professional settings, and through an uptake in PhD studies, designers have also turned to analytical modes of writing in increasing numbers. I am excited to be a part of this landscape, and look forward to sharing and developing these topics with an expanding and engaged community of design researchers. Meanwhile, the environment of public engagement has become reconfigured in various ways, most significantly through the adoption of Pathways to Impact by the RCUK. I hope these new expressions of engagement provide fresh opportunities for experimental and sceptical design practices.

During my studies I've not been locked in the library. I have enjoyed the collegial and intellectual support of those named at the opening of this document, not only on matters relating to this thesis, but in a range of related activities. Working with colleagues at the Interaction Research Studio, an RCUK energy communities project provided an opportunity to apply approaches from speculative design and inventive STS in ways that incorporated and extended the topics of this thesis. With others in the Design Department at Goldsmiths, I have applied ideas about research and pedagogy explored here to the curriculum of a newly established MA Interaction Design programme. Of course my enjoyment of these activities has inevitably slowed down the completion of this document, which has accompanied me for so long now I can't very well remember life without it. And so as I write these final words, I must say that I'm immensely excited now at the prospect of handing it in, and returning to this network of colleagues and ideas. 
Designing Debate: The Entanglement of Speculative Design and Upstream Engagement 


\section{REFERENCES}

Adorno, T. (1991). The Culture Industry. London, New York: Routledge.

Akrich, M. (1992). The De-Scription of Technical Objects. In W. E. Bijker \& J. Law (Eds.), Shaping Technology/Building Society: Studies in Sociotechnical Change (pp. 205-224). Cambridge, Mass.: MIT Press.

Akrich, M., \& Latour, B. (1992). A Convinient Vocabulary for the Semiotics of Human and Nonhuman Assemblies. In W. E. Bijker \& J. Law (Eds.), Shaping Technology/Building Society: Studies in Sociotechnical Change (pp. 205-224). Cambridge, Mass.: MIT Press.

Albano, C. (Ed.). (2008). Crossing Over - Exchanges in Art \& Biotechnologies. London: Artakt.

Alexander, C. (1964). Notes on the synthesis of form. Cambridge, Mass.: Harvard University Press.

Alexander, C., \& Jacobson, M. (1971). The Sate of the Art in Design Methods. Design Methods Group Newsletter, 5(3), 3-7.

Ambasz, E. (1972). Italy: the new domestic landscape: acheivements and problems of Italian design. New York: Museum of Modern Art in collaboration with Centro Di, Florence.

Antonelli, P. (2008). Design and the elastic mind. New York: Museum of Modern Art; [London: Thames \& Hudson, distributor].

Archer, B. (1963). Systematic Method for Designers. Design.

Arends, B., \& Thackara, D. (Eds.). (2003). Experiment: conversations in art and science. London: The Wellcome Trust.

Asaro, P. M. (2000). Transforming society by transforming technology: the science and politics of participatory design. Accounting, Management and Information Technologies, 10(4), 257-290.

Ashcroft, R., \& Caccavale, E. (2004). Hybrids: Towards a New Typology of Beings and Animal Products. London: edition of 2000.

Auger, J. (2001). Augmented Animals. London: edition of 1000.

Auger, J., \& Loizeau, J. (2001). Audio Tooth Implant Retrieved November 4th, 2014, from http://www.auger-loizeau.com/index.php?id=7

Auger, J., \& Loizeau, J. (2001 - 2009). Augmented Animals. 2011(21st March).

Auger, J., Loizeau, J., \& Agamanolis, S. (2003). Iso-phone: a total submersion telephonic experience. Paper presented at the Proceedings of the 1st international symposium on Information and communication technologies, Dublin, Ireland.

Banham, R. (1971). Alternative Networks for the Alternative Culture? Paper presented at the Design Participation: Design Research Society's Conference Manchester, September 1971, London.

Barry, A., Born, G., \& Weszkalnys, G. (2008). Logics of interdisciplinarity. Economy and Society, 37(1), 20 - 49.

Bauer, M. W., Allum, N., \& Miller, S. (2007). What can we learn from 25 years of PUS survey research? Liberating and expanding the agenda. Public Understanding of Science, 79-95. doi: 10.1177/0963662506071287 16:

Bayazit, N. (2004). Investigating Design: A Review of Forty Years of Design Research. Design Issues, 20(1), 16-29. doi: doi:10.1162/074793604772933739

Beaver, J., Kerridge, T., \& Pennington , S. (2009). Material Beliefs. London: Goldsmiths, University of London. 
Bell, J. (2008). Bio Play - event Tuesday 28 October 2008 19:00 - 20:30. Dana Centre event Retrieved 2th August, 2014, from http://www.danacentre.org.uk/events/2008/10/28/446

Betsky, A. (2003). The Strangeness of the Familiar in Design. In A. Blauvelt (Ed.), Strangely familiar: design and everyday life (pp. 38-55). Minneapolis, Minn.: Walker Art Center.

Bhattachary, D. (2004). Science in Society: Report 2004. London: The Royal Society.

Bicknell, J., \& McQuiston, L. (1977). Design for need: the social contribution of design: an anthology of papers presented to the Symposium at the Royal College of Art, London, April 1976. Oxford: Pergamon for ICSID.

Bijker, W. E. (1987). The Social Construction of Facts and Artefacts: or How the Sociology of Science and the Sociology of Technology might Benefit Each Other. In W. E. Bijker, T. P. Hughes \& T. J. Pinch (Eds.), The Social Construction of Technological Systems: New Directions in the Sociology and History of Technology (pp. 17-50). Cambridge, Mass.: MIT Press.

BIS. (2010). Science for all: Report and action plan from the Science for All Expert Group. London: Department for Business Innovation and Skills.

Blauvelt, A. (2003). Strangely familiar: design and everyday life. Minneapolis, Minn.: Walker Art Center.

Bookchin, M. (1974). Post-scarcity anarchism. London: Wildwood House.

Bosco, R., \& Caldana, S. (2008, 23rd October). Material Beliefs mezcla biología, diseño y tecnología en nuevos objetos, El Paîs. Retrieved from http://elpais.com/diario/2008/10/23/ciberpais/1224727358_850215.ht $\underline{\mathrm{ml}}$

Bowen, S. (2009). A critical artefact methodology: using provocative conceptual designs to foster human-centred innovation. Sheffield Hallam University, Sheffield.

Brassington, I. (2006). Body art and medical need. Journal of Medical Ethics, 32(1), 13-16. doi: 10.1136/jme.2005.012229

Broadbent, G. (1984). The Developmnent of Design Methods. In N. Cross (Ed.), Developments in Design Methodology (pp. 337-345). Chichester: John Wiley and Sons Ltd.

Brown, N., Rappert, B., \& Webster, A. (2000). Contested futures: a sociology of prospective techno-science. Aldershot: Ashgate.

Burchell, K. (2009). A helping hand or a servant discipline? - Interpreting nonacademic perspectives on the roles of social science in participatory policymaking. Science, Technology \& Innovation Studies; Vol 5, No 1 (2009): The role of social sciences in science policy making.

Burchell, K., Franklin, S., \& Holden, K. (2009). Public culture as professional science: final report of the ScoPE project Scientists on public engagement: from communication to deliberation? London, UK: London School of Economics and Political Science.

Burdett, A. (2009). Pervasive Monitoring Systems for Personalised Healthcare Challenges and Opportunities. Paper presented at the The nineteenth International Conference on Optical Fibre Sensors (OFS), Perth, Western Australia. http://obel.ee.uwa.edu.au/OFS19/technical_programme/ofs19_burdett.pdf

Burton, M., Charlesworth, J., \& Mora, M. (Eds.). (2007). Design Interactions. London: Royal College of Art. 
Calder, N. (1970). Technopolis: Social Control of the Uses of Science. London: Panther.

Calhoun, C. J. (1995). Critical social theory : culture, history, and the challenge of difference. Oxford: Blackwell.

Callon, M. (1986). The sociology of an Actor-Network: The case of the Electric Vehicle. In M. Callon, J. Law \& A. Rip (Eds.), Mapping the dynamics of science and technology: sociology of science in the real world. Basingstoke: Macmillan.

Callon, M. (2004). The role of hybrid communities and socio-technical arrangements in the participatory design. Journal of the Center for Information Studies, 5(3), 3-10.

Callon, M., \& Law, J. (1995). Agency and the Hybrid Collectif. The South Atlantic Quarterly, 94(2), 25.

Channell, D. F. (1991). The vital machine : a study of technology and organic life. New York: Oxford University Press.

Clarke, R. (1973). Technology for an alternative society. New Scientist, 57, 3.

Cooley, M. (1984). Socially useful design. In R. Langdon \& N. Cross (Eds.), Design and society: the proceedings of the Design and Society Section of an international conference on design policy (Vol. 1, pp. 51-54). London: Design Council.

Cross, N. (1971). Preface. Paper presented at the Design Participation: Design Research Society's Conference Manchester, September 1971, London.

Cross, N. (1975). Man-Made Futures: Design and Technology. Milton Keynes: Open University Press.

Cross, N. (2001). Designerly Ways of Knowing: Design Discipline Versus Design Science. Design Issues, 17(3), 49-55. doi: doi:10.1162/074793601750357196

Cross, N. (2007). Forty Years of Design Research. Design Research Quarterly, 1(2), 3-5.

Cross, N., Elliott, D., \& Roy, R. (1974). Man-Made Futures: Readings in Society, Technology and Design. London: Hutchinson Educational in association with The Open University Press.

Crotty, M. (1998). The foundations of social research : meaning and perspective in the research process. London: SAGE.

Crowley, D., \& Pavitt, J. (2008). Cold War Modern: Design 1945-1970. London: V\&A.

CST. (2010). A Vision for UK Research. London: Council for Science and Technology.

Curnow, A. (2009). Engaging with synthetic biology. Agenda and reservation form for a presentation and discussion. Retrieved from

http://www.raeng.org.uk/news/publications/list/reports/Synthetic_biolog y.pdf

Dallas, D. (2008). Will Public Engagement Lead to a Marriage between Science and Society? In A. Miah (Ed.), Human Futures: Art in an Age of Uncertainty (pp. 176-181). Liverpool: Liverpool University Press.

Dant, T. (2003). Critical social theory: culture, society and critique. London: SAGE.

Dawson, E. (2008). Tobie and IBE researchers. Material Beliefs: Focus Group for Summative Evaluation. audio recording. Goldsmiths, University of London. London.

Dawson, E. (2009a). Elio and Reading team. Material Beliefs: Focus Group for Summative Evaluation. audio recording. Goldsmiths, University of London. London. 
Dawson, E. (2009b). Jimmy and James. Material Beliefs: Focus Group for Summative Evaluation. audio recording. Goldsmiths, University of London. London.

Dawson, E. (2009c). Summative Evaluation of Material Beliefs: engineers and designers in collaboration for public engagement. London: Goldsmiths, University of London.

Dawson, E. (2009d). Susana, Julie and Anna. Material Beliefs: Focus Group for Summative Evaluation. audio recording. Goldsmiths, University of London. London.

Dawson, E. (2012). Science and the inclusive society: how do UK minority sociocultual groups experience public engagement with science and technology. PhD, King's College London, London.

Debatty, R. (2005). Augmented Animals. We Make Money Not Art Retrieved 19th January, 2010, from http://www.we-make-money-notart.com/archives/2005/03/augmented-anima.php

Debatty, R. (2007). Interview with James Auger. We Make Money Not Art Retrieved 19th January, 2010, from http://www.we-make-money-notart.com/archives/2007/01/interview-with-6.php

Debatty, R. (2008). Interview with Tobie Kerridge (Material Beliefs). We Make Money Not Art Retrieved 5th August, 2014, from http://we-make-moneynot-art.com/archives/2008/11/if-there-are-images-in.php

Dickson, D. (1974). Alternative Technology and the Politics of Technical Change. London: Fontana.

DiSalvo, C. (2009). Design and the Construction of Publics. Design Issues, 25(1), 4863. doi: doi:10.1162/desi.2009.25.1.48

DiSalvo, C., \& Lukens, J. (2009). Towards a Critical Technological Fluency: The Confluence of Speculative Design and Community Technology Programs. Paper presented at the DAC '09: Proceedings of the Digital and Arts and Culture Conference, University of California, Irvine.

DIUS. (2008). A Vision for Science and Society - A consultation on developing a new strategy for the UK. London: Department for Innovation Universitites and Skills.

DoD. (2010). Design - Postgraduate Handbook. London: Department of Design, Goldsmiths, University of London.

Doubleday, R. (2007). Organizing accountability: co-production of technoscientific and social worlds in a nanoscience laboratory. Area, 39(2), 166-175.

Drexler, K. E. (1986). Engines of creation (1st ed. ed.). Garden City, NY: Anchor Press/Doubleday.

Dreyfuss, H. (1955). Designing for people. New York: Simon and Schuster.

Dunne, A. (1997). Herzian Tales: An investigation into the critical potential of the electronic product as a post-optimal object. Royal College of Art London.

Dunne, A. (1999). Hertzian tales: electronic products, aesthetic experience and critical design. London: RCA CRD Research Publications.

Dunne, A., \& Kemp, S. (2008). HUMAN ENHANCEMENT TECHNOLOGIES: The Role of Art and Design (new tools and methods). Research workshop proceedings. Royal Colleage of Art. London. Retrieved from http://www.rca.ac.uk/Docs/FinalHumanEnhancementProgramme.pdf

Dunne, A., \& Raby, F. (2001). Design Noir: The Secret Life of Electronic Objects. Basel: Birkhäuser.

Dunne, A., \& Raby, F. (2003). Bioland / CONSUMING MONSTERS: BIG, PERFECT, INFECTIOUS. Unpublished. London.

Dunne, A., \& Raby, F. (2004). Consuming Monsters. Cluster 04: Biotech, 76-90. 
Dunne, A., \& Raby, F. (2007). Critical Design FAQ Retrieved 16th September, 2010, from http://www.dunneandraby.co.uk/content/bydandr $/ 13 / 0$

Dunne, A., Raby, F., \& Gorman, M. J. (Eds.). (2009). WHAT IF... Future Form, Future Function. Dublin: Science Gallery.

Durant, J., Bauer, M. W., \& Gaskell, G. (1998). Biotechnology in the public sphere a European sourcebook. London: Science Museum.

Ehn, P. (1988). Work-Oriented Design of Computer Artefacts. Stockholm: Arbetslivscentrum.

Elliott, D. (1984). Alternative Technology: Production for Need. Paper presented at the A.T. in the '80s, London.

Endy, D., Calvert, J., Elfick, A., Schyfter, P., \& Daisy Ginsberg, A. (2010). Synthetic Aesthetics: Call for Participants. In S. University (Ed.). Standford: Standford University.

EPSRC. (2003). Partnerships for Public Awareness: Good Practice Guide. London: People Science \& Policy Ltd for Engineering and Physical Sciences Research.

EPSRC. (2009). EPSRC Delivery Plan 2008/09 to 2010/11. Swindon: Engineering and Physical Sciences Research Council.

EPSRC. (2010). IMPACT! Swindon: Engineering and Physical Science Research Council.

EU. (2008). Report of the Science in Society Session: Public Enagement in Science Portuguese Presidency Conference The FUTURE OF SCIENCE and TECHNOLOGY in EUROPE. Brussels: European Commission.

Facione, P. A. (1990). Critical thinking: A statement of expert consensus for purposes of educational assessment and instruction. Newark, Delaware: American Philosophical Association.

Fallman, D. (2008). The Interaction Design Research Triangle of Design Practice, Design Studies, and Design Exploration. Design Issues, 24(3), 4-18. doi: 10.1162/desi.2008.24.3.4

Featherstone, H., Wilkinson, C., \& Bultitude, K. (2009). Public Engagement Map: Report to the Science for All Expert Group. Bristol: Science Communication Unit, University of the West of England.

Feo, R., \& Hurtado, R. (2008). NOWHERE/NOW/HERE. Gijón: LABoral Centro de Arte y Creación Industrial.

Fisher, E. (2007). Ethnographic Invention: Probing the Capacity of Laboratory Decisions. NanoEthics, 1(2), 11.

Fisher, E., \& Mahajan, R. L. (2006). Midstream Modulation pf Nanotechnology Research in an Academic Laboratory. Paper presented at the Proceedings of IMECE2006, Chicago, Illinois, USA.

Fisher, E., \& Miller, C. (2009). Collaborative Practices for Contextualising the Engineering Laboratory. In S. Hyldgaard Christensen, B. Delahousse \& M. Meganck (Eds.), Engineering in Context. Copenhagen: Academica.

Fuad-Luke, A. (2009). Design Activism: beautiful strangeness for a sustainable world. London: Earthscan.

García-Antón, K., King, E., \& Brändle, C. (2007). Wouldn't it be nice... wishfull thinking in art and design. Geneva: Centre d'Art Contemporain Genève.

Georgiou, P., Shepherd, L., Kwansuwan, P., Arachchige, D., Addis, M., Constandinou, T. G., ... Toumazou, C. Development of an Ultra Low Power Wireless Sensium Platform Providing Personalised Healthcare for Chronic Disease Management. In I. C. London (Ed.). London.

Georgiou, P., \& Toumazou, C. (March 2007). A Silicon Pancreatic Beta Cell for Diabetes. IEEE Transactions on Biomedical Circuits and Systems, 1(1), 10. 
Geuss, R. (1981). The idea of a critical theory : Habermas and the Frankfurt School. Cambridge: Cambridge University Press.

Gibbons, M., Limoges, C., Nowotny, H., Schwartzman, S., Scott, P., \& Trow, M. (1994). New Production of Knowledge: Dynamics of Science and Research in Contemporary Societies. London: Sage.

Ginsberg, A. D. (2010). The Synthetic Kingdom. Second Nature: International journal of creative media, 2(1), 20.

Ginsberg, A. D., \& King, J. (2009). E.chromi - Our work with the team Retrieved 29th January, 2009, from http://www.echromi.com/workshops.html

Ginseng, A. D., Calvert, J. E., Schyfter, P., Elfick, A., \& Endy, A. D. (2014). Synthetic aesthetics: investigating synthetic biology's designs on nature. US: MIT Press.

Glinkowski, P., \& Bamford, A. (2009). Insight and Exchange: An evaluation of the Wellcome Trust's sciart programme. London: Wellcome Trust.

Gray, C. H., Mentor, S., \& Figueroa-Sarriera, H. J. (1995). The Cyborg handbook. New York; London: Routledge.

Gregory, J., \& Miller, S. (1998). Science in Public: Communication, Culture, and Credibility. New York; London: Plenum Trade.

Guillaume, V. (2005). D.DAY - le design aujourd'hui. Paris: Centre Pompidou.

Guston, D. H., \& Sarewitz, D. (2002). Real-time technology assessment. Technology in Society, 24(1-2), 93-109.

Haraway, D. J. (1991). Simians, cyborgs, and women: the re-invention of nature. London: Free Association.

Harrison, J. (2014). Christmas Lectures Retrieved July 22, 2014, from http://www.rigb.org/christmas-lectures

Hayoun, N. B. (2008). Cathy the Hacker Retrieved 28th February, 2011, from http://vimeo.com/2173766

HM-Treasury. (2004a). Science \& innovation investment framework 2004 - 2014. London: HM Treasury, Department of Trade and Industry, Department for Education and Skills.

HM-Treasury. (2004b). A Ten-Year Framework for Investment in Science and Innovation 2004-2014. London: Department of Trade and Industry, Department for Education and Skills.

Hobhouse, H. (2002). The Crystal Palace and the Great Exhibition : art, science and productive industry: a history of the Royal Commission for the Exhibition of 1851. London: Athlone Press.

Hogan, J. (2005, 26 February). With this sample of cultured bone, I thee wed. New Scientist.

HOL. (2000). House of Lords Select Committee on Science and Technology Third Report - Science and Society. London: The Stationery Office.

Horst, M. (2007). Public Expectations of Gene Therapy: Scientific Futures and Their Performative Effects on Scientific Citizenship. Science, Technology \& Human Values, 32(2), 150-171. doi: 10.1177/0162243906296852

Horst, M. (2013). Learning from discomfort - Science communication experiments between diffusion, dialogue and emergence. Developing Capacity in Multimodal Research, Community Engagement and Energy Demand Reduction. Cardiff University.

Horst, M., \& Michael, M. (2011). On the shoulders of idiots: Rethinking science communication as 'event'. Science as Culture, 20(3), 283-306.

Ibars, R. (2003). Self-made objects. Barcelona and London: edition of 2000. 
Ieropoulos, I., Melhuish, C., \& Greenman, J. (2003). Artificial Metabolism: Towards True Energetic Autonomy in Artificial Life Advances in Artificial Life (Vol. Volume 2801/2003, pp. 792-799). Berlin / Heidelberg: Springer.

Illich, I. (1975). Tools for conviviality. London: Fontana.

Irwin, A. (2006). The Politics of Talk: Coming to Terms with the 'New' Scientific Governance. Social Studies of Science, 36(2), 299-320. doi: $10.1177 / 0306312706053350$

Irwin, A., \& Michael, M. (2003). Science, social theory and public knowledge. Buckingham: Open University Press.

Irwin, A., \& Wynne, B. (1996). Misunderstanding science? The public reconstruction of science and technology. Cambridge: Cambridge University Press.

Jackman, S. (2008a). Austin's tutorial at the Royal College of Art. Material Beliefs [Video recording]. London: Goldsmiths, University of London.

Jackman, S. (2008b). A discussion about diabetes. Material Beliefs [Video recording]. London: Goldsmiths, University of London.

Jackman, S. (2008c). Elio describes Neuroscope. Material Beliefs [Video recording]. London: Goldsmiths, University of London.

Jackman, S. (2008d). Neuroscope meeting at University of Reading. Material Beliefs [Video recording]. London: Goldsmiths, University of London.

Jackman, S. (2008e). Pantelis describes a silicon pancreas. Material Beliefs [Video recording]. London: Goldsmiths, University of London.

Jackman, S. (2008f). Ros describes diabetes management. Material Beliefs [Video recording]. London: Goldsmiths, University of London.

Jackman, S. (2008g). Techno Bodies Hybrid Life at the Dana Centre. Material Beliefs [Video recording]. London: Goldsmiths, University of London.

Jackman, S. (2008h). Tobie describes Vital Signs. Material Beliefs [Video recording]. London: Goldsmiths, University of London.

James, F. A. J. L. (2000). Guides to the Royal Institution of Great Britain: 1 HISTORY. London: Royal Institution of Great Britain.

Jasanoff, S. (2003). Technologies of Humility: Citizen Participation in Governing Science. Minerva, 41(3), 223-244.

Jasanoff, S. (2004). States of knowledge : the co-production of science and the social order. London: Routledge.

Jeremijenko, N. (2004). If Things Can Talk, What Do They Say? If We Can Talk to Things, What Do We Say? In N. Wardrip-Fruin \& P. Harrigan (Eds.), First person: new media as story, performance, and game (pp. xiii, 331 p.). Cambridge, Mass.; London: MIT.

Johnson, B. (2008). Evaluation Report - Evaluation of the Engineering and Physical Sciences (EPSRC) Partnerships for Public Engagement (PPE) Grant Scheme. Felton Common: Graphic Science Ltd.

Joly, P.-B. (2010). On the Economics of Techno-scientific Promises. In M. Akrich, Y. Barthe, F. Muniesa \& P. Mustar (Eds.), Débordements : Mélanges offerts à Michel Callon (pp. 203-222). Paris: Presse des Mines.

Jones, J. C. (1970). Design methods: seeds of human futures: London: WileyInterscience.

Jones, J. C. (1977). How my thoughts about Design Methods have Changed During the Years. Design Methods and Theories, 11(1), 50-62.

Jones, J. C., \& Jungk, R. (1971). Closing Comments. Paper presented at the Design Participation: Design Research Society's Conference Manchester, September 1971, London. 
Jones, R. A. L. (2004). Soft machines : nanotechnology and life. Oxford: Oxford University Press.

Jones, R. A. L. (2006). Some reflections on UK nanotechnology policy Retrieved 20/04/2010, from http://www.softmachines.org/wordpress/?p=218

Jones, R. A. L. (2009). Designs for living. Nature Nanotechnology, 4(8), p. 471.

Jönsson, L. (2014). Design Events: On explorations of a non-anthropocentric framework in design. PhD, Royal Danish Academy of Fine Arts, Copenhagen.

Jungk, R. (1969). Technological Forecasting as a Tool for Social Strategy. In R. V. Arnfield (Ed.), Technological Forecasting (pp. viii,417p.,412plates). Edinburgh: Edinburgh University Press.

Kazimirski, A. (2000). Science and the Public: Mapping Science Communication Activities. London: Research International for the Wellcome Trust.

Kean, S., Peacock, M., Russell, C., \& Whitmarsh, L. (2005). Connecting Science: What we know and what we don' 't know about science in society: the British Association for the Advancement of Science.

Kearnes, M., Macnaghten, P., \& Wilsdon, J. (2006). Governing the Nanoscale: People, policies and emerging technologies. London: Demos.

Kerr, A., Cunningham-Burley, S., \& Tutton, R. (2007). Shifting Subject Positions: Experts and Lay People in Public Dialogue. Social Studies of Science, 37(3), 385-411. doi: 10.1177/0306312706068492

Kerridge, T. (2007a). Designing and manufacturing a Bionic Sensor. Material Beliefs [Video recording]. London: Goldsmiths, University of London.

Kerridge, T. (2007b). Material Beliefs - Events Retrieved 22/06/12, from http://www.materialbeliefs.com/events/

Kerridge, T. (2007c). Mind the Loop Retrieved 22/06/12, from http://www.materialbeliefs.com/events/loop.php

Kerridge, T. (2007d). My Space, My City, My World Retrieved 22/06/14, from http://www.materialbeliefs.com/diary/?p=49

Kerridge, T. (2007e). The Secret Garden Party Retrieved 22/06/12, from http://www.materialbeliefs.com/events/sgp.php

Kerridge, T. (2007f). Techno Bodies; Hybrid Life? Retrieved 22/06/12, from http://www.materialbeliefs.com/events/dana.php

Kerridge, T. (2008, 17/07/08). [Personal email with exhibition curator c1].

Kerridge, T., \& Caccavale, E. (2007). Interview with Prof Tony Cass. Material Beliefs [Video recording]. London: Goldsmiths, University of London.

Kerridge, T., \& Caccavale, E. (2008). Science And Society. A design brief for Design Interaction students. Royal College of Art. London.

Kerridge, T., Custead, S., \& Gaver , W. (2006). Material Beliefs - Collaborations for public engagement between engineers and designers. IDEAS Factory, case for support, EPSRC standard proposal. Goldsmiths. London.

Kerridge, T., Law, A., \& Raijmakers, B. (2005). Media Mediators Retrieved March 2, 2012, from http://mediamediators.blogspot.com/

Kerridge, T., \& Loizeau, J. (2007). Interview with Claire Rocks and Emily Dawson from University of the West of England, and Peter Walters, Peter Jaeckel, Paul Bremmer, Chris Bytheway, Craig Chorely and Ioannis Ieropoulos from Bristol Robotics Laboratory. Material Beliefs [Video recording]. London: Goldsmiths, University of London.

Kerridge, T., \& Robinson, A. (2007). Material Beliefs Collaborations: a guide for setting-up collaborations Goldsmiths, University of London. London. 
Kerridge, T., Stott, N., \& Thompson, I. (2006). Biojewellery: Designing Rings with Bioengineered Bone and Tissue (pp. 36). London: Oral \& Maxillofacial Surgery, King's College London.

King, J. (2009). Synthetic Biology \& Speculative Design. Ethical Issues in Synthetic Biology. Garrison, New York: The Hastings Centre, http://www.thehastingscenter.org/News/Detail.aspx?id=4633.

Krippendorff, K. (2006). The semantic turn: a new foundation for design. Boca Raton, FLorida: CRC.

Langdon, R., \& Cross, N. (1984). Design and society: the proceedings of the Design and Society Section of an international conference on design policy. London: Design Council.

Latour, B. (1987). Science in action: Harvard University Press.

Latour, B. (1992). Where are The Missing Masses? The Sociology of a few Mundane Artifacrs. In W. E. Bijker \& J. Law (Eds.), Shaping Technology/Building Society: Studies in Sociotechnical Change (pp. 225-258). Cambridge, Mass.: MIT Press.

Latour, B. (1993). We have never been modern. New York ; London: Harvester Wheatsheaf.

Law, J. (1987). Technology and Heterogeneous Engineering: The Case of Portuguese Expansion. In W. E. Bijker, T. P. Hughes \& T. J. Pinch (Eds.), The social construction of technological systems : new directions in the sociology and history of technology. Cambridge, Mass.: MIT Press.

Lenskjold, T. U., \& Jönsson, L. (2013). A Foray Into Not-Quite Companion Species: Design Experiments With Urban- Animals As Significant Others. Paper presented at the Nordes 2013, Copenhagen.

Levinson, R., Nicholson, H., \& Parry, S. (Eds.). (2008). Creative Encounters: New conversations in science, education and the arts London: The Wellcome Trust.

Lewis, J. (2013). Mind Matters: Working with the Arts to Engage with Public Groups. Developing Capacity in Multimodal Research, Community Engagement and Energy Demand Reduction. Cardiff University.

Loizeau, J. (2007). Interview with Dr Joanne Ingram. Material Beliefs [Video recording]. London: Goldsmiths, University of London.

Lopez, A., \& Milliken, N. (Eds.). (2005). PopNoir - Critical Designs Selected by Dunne \& Raby. Jerusalem: The Israel Museum.

Macdonald, S. (1996). Authorising Science: public understanding of science in museums. In A. Irwin \& B. Wynne (Eds.), Misunderstanding science? The public reconstruction of science and technology (pp. 152-171). Cambridge: Cambridge University Press.

Macnaghten, P. (2010). Researching technoscientific concerns in the making: narrative structures, public responses, and emerging nanotechnologies. Environment and Planning A, 42(1), 23-37.

Madge, N., \& Barker, J. (October 2007). Risk and Childhood. London: RSA.

Malpass, M. (2009). Contextualising Critical Design: Classification Of Critical Design Practices. Paper presented at the 8th European Academy Of Design Conference, The Robert Gordon University, Aberdeen, Scotland.

Malpass, M. (2012). Contextualising Critical Design: Towards a Taxonomy of Critical Practice in Product Design. Doctor of Philosophy, Nottingham Trent University Nottingham.

Marcus, G. E. (1995). Technoscientific imaginaries: conversations, profiles, and memoirs. Chicago; London: University of Chicago Press. 
Marcuse, H. (1991). One-Dimensional Man. London: Routledge.

Margolin, V., \& Margolin, S. (2002). A "Social Model" of Design: Issues of Practice and Research. Design Issues, 18(4), 24-30. doi: doi:10.1162/074793602320827406

Markus, T. (1971). A Dougnut Model of the Enviroment and its Design. Paper presented at the Design Participation: Design Research Society's Conference Manchester, September 1971, London.

Marshall, H. (2007). Public Attitudes to Engineering and Engineers 2007: British Market Research Bureau Limited.

Mazé, R. (2007). Occupying Time : Design, Time, and the Form of Interaction. Blekinge Institute of Technology, Karlskrona.

Mazé, R., \& Redström, J. (2008). Switch! Energy Ecologies in Everyday Life.

Mazé, R., \& Redström, J. (2009). DIFFICULT FORMS: Critical practices of design and research. Research Design Journal, 1(1), 28-39.

McCallie, E., Bell, L., Lohwater, T., Falk, J. H., Lehr, J. L., Lewenstein, B. V., . . W Wiehe, B. (2009). Many Experts, Many Audiences: Public Engagement with Science and Informal Science Education A CAISE Inquiry Group Report (pp. 83). Washington, D.C.: Center for Advancement of Informal Science Education.

McIntyre, J. (1996). The Department of Design Research at the Royal College of Art: its origins and legacy 1959-1988. In C. Frayling \& C. Catterall (Eds.), Design of the times : one hundred years of the Royal College of Art (pp. 58-62). Shepton Beauchamp, Somserset: Richard Dennis Publications/Royal College of Art.

Michael, M. (1996). Ignoring science: discourses of ignorance in the public understanding of science. In A. Irwin \& B. Wynne (Eds.), Misunderstanding science? The public reconstruction of science and technology (pp. 107-125). Cambridge: Cambridge University Press.

Michael, M. (2000a). Futures of the Present: From Performativity to Prehension. In N. Brown, B. Rappert \& A. Webster (Eds.), Contested futures: a sociology of prospective techno-science (pp. xiv, 277 p.). Aldershot: Ashgate.

Michael, M. (2000b). These Boots Are Made for Walking...: Mundane Technology, the Body and Human-Environment Relations. Body \& Society, 6(3-4), 107126.

Michael, M. (2004). On Making Data Social: Heterogeneity in Sociological Practice. Qualitative Research, 4(1), 5-23. doi: 10.1177/1468794104041105

Michael, M. (2006). Technoscience and everyday life : the complex simplicities of the mundane. Maidenhead: Open University Press.

Miller, S. (2001). Public understanding of science at the crossroads. Public Understanding of Science, 10(1), 115-120. doi: 10.1088/0963$6625 / 10 / 1 / 308$

Mollon, M., \& Gentes, A. (2014). The Rhetoric of Design for Debate: triggering conversation with an "uncanny enough" artefact. Paper presented at the Proceedings of DRS 2014: Design's Big Debates, Umeå, Sweden.

Neale, J. (2008). Cotton Wool Kids. Cutting Edge: Princess Productions.

Nelson, J., \& Jones, V. (2006). Engineering Ideas in Public Engagement - Call for Participants. IDEAS Factory. Engineering and Physical Sciences Research Council.

Nickelsen, N. C., \& Binder, T. (2008). Design and Heterogeneous Engineering: Toward an Actor Network Perspective on Design. Artifact, 2(3), 164 - 175.

Niedderer, K. (2007). Designing Mindful Interaction: The Category of Performative Object. Design Issues, 23(1), 3-17. doi: doi:10.1162/desi.2007.23.1.3 
Nowotny, H. (2003). Democratising expertise and socially robust knowledge. Science and Public Policy, 30, 151-156.

Nowotny, H., Scott, P., \& Gibbons, M. (2001). Re-thinking science: knowledge and the public in an age of uncertainty. Cambridge: Polity Press.

Nowotny, H., Scott, P., \& Gibbons, M. (2006). Re-Thinking Science: Mode 2 in Societal Context. In E. G. Carayannis \& D. F. J. Campbell (Eds.), Knowledge Creation, Diffusion, and Use in Innovation Networks and Knowledge Clusters: A Comparative Systems Approach Across the United States, Europe, and Asia. Westport, Connecticut: Praeger Publishers.

O'Mahony, M. (2002). Cyborg : the man machine. London: Thames \& Hudson. OST. (1993). Realising Our Potential: A Strategy for Science, Engineering and Technology. London: The Office for Science and Technology.

Papadopoulou, Z., \& Kramer, C. (2009). About The Cloud Project Retrieved 29th January, 2009, from http://www.thecloudproject.co.uk/about

Polanyi, M. (1969). Personal knowledge : towards \& post-nutical philosophy (2nd ed. ed.). London: Routledge \& Kegan Paul.

POST. (2001). Open channels: public dialogue in science and technology. London:: Parliamentary Office of Science Technology.

POST. (2003). Science and Society: three years on. London: Parliamentary Office of Science Technology.

Potter, N. (2002). What is a designer: things, places, messages (4th ed. ed.). London: Hyphen Press.

Prado de O. Martins, L. (2014). Privilege and Oppression: Towards a Feminist Speculative Design. Paper presented at the Proceedings of DRS 2014: Design's Big Debates, Umeå, Sweden.

Prado, L. (2014). Questioning the "critical" in Speculative \& Critical Design. Retrieved from https://medium.com/designing-the-future/5a355cac2ca4

Prod'hom, C. (2006). Animals with Style: Five Continents Editions.

RAEng. (2009a). Synthetic Biology: public dialogue on synthetic biology. London: The Royal Academy of Engineering

RAEng. (2009b). Synthetic Biology: scope, applications and implications. London: The Royal Academy of Engineering

Raijmakers, B. (2007). Design documentaries: Using documentary film to inspire design. PhD, Royal College of Art, London.

Ramakers, R. (2002). Less + more: Droog Design in context. Rotterdam: 010 Publishers.

Ratto, M. (2009). Critical Making: conceptual and material studies in technology and social life. University of Toronto. Toronto.

RCUK. (2002). Dialogue with the Public: Practical guidelines. Swindon: Reseach Councils UK.

RCUK. (2010). Our Vision For Excellence With Impact: Research Councils UK.

RCUK. (2013a). Inspiration to engage: Concordat for engaging the public with research. London: Research Councils UK.

RCUK. (2013b). Pathways to Impact. London: Research Councils UK.

RCUK. (2013c). RCUK Public Engagement with Research Strategy. London: Research Councils UK.

Reed, T. (2005). Biojewellery - Designing Rings with Bioengineered Bone Tissue. London: press release.

Rip, A. (2002). Co-evolution of Science, Technology and Society Expert Review. Berlin: Berlin-Brandenburgische Akademie der Wissenschaften. 
Rittel, H., \& Webber, M. (1973). Dilemmas in a general theory of planning. Policy Sciences, 4(2), 155-169. doi: citeulike-article-id:460032

Rowe, G., \& Frewer, L. J. (2005). A Typology of Public Engagement Mechanisms. Science Technology Human Values, 30(2), 251-290. doi: 10.1177/0162243904271724

Roy, R. (1971). Choosing the Future. Paper presented at the Design Participation: Design Research Society's Conference Manchester, September 1971, London.

RS. (1985). The Public Understanding of Science. London: The Royal Society.

RS. (2004). Nanoscience and nanotechnologies: opportunities and uncertainties. London: The Royal Society.

Sandhana, L. (2010). Augmenting the Animal Kingdom Retrieved 19th January, 2010, from http://www.wired.com/science/discoveries/news/2005/05/67349

Schön, D. A. (1983). The reflective practitioner: how professionals think in action. Aldershot: Avebury.

Schuurbiers, D., \& Fisher, E. (2009). Lab-scale intervention EMBO Reports, 10(5), 4.

Seago, A., \& Dunne, A. (1999). New Methodologies in Art and Design Research: The Object as Discourse. Design Issues, 15(2), 7.

Simon, H. (1969). The Sciences of the Artificial: MIT Press.

Smart, S. (2007). Engineering and Physical Sciences Research Council Annual report and accounts 2006-2007. Norwich: The Stationery Office.

Smith, A. (2004). An R\&D lab for Utopia? Alternative technology centres in the UK. Paper presented at the European Consortium for Political Research Joint Sessions Workshop - The Politics of Utopia: Intentional Communities as Social Science Microcosms, Uppsala University, Sweden.

Smith, A. (2005). The Alternative Technology Movement: An Analysis of its Framing and Negotiation of Technology Development. Human Ecology Review, 12(2), 14.

Smith, B. R. (1977). Conceptual Design - a Polemic. In J. Bicknell \& L. McQuiston (Eds.), Design for need : the social contribution of design : an anthology of papers presented to the Symposium at the Royal College of Art, London, April 1976 (pp. 108-113). Oxford: Pergamon for ICSID.

Snow, C. P. (1998). The two cultures. Cambridge: Cambridge University Press.

Stilgoe, J. (2007). Nanodialogues: Experiments in public engagement with science. Londonw: Demos.

Stilgoe, J., \& Sykes, K. (2009). The Road Ahead: Public Dialogue on Science and Technology. Didcot: Sciencewise.

Stirling, A. (2008). "Opening Up" and "Closing Down": Power, Participation, and Pluralism in the Social Appraisal of Technology. Science Technology Human Values, 33(2), 262-294. doi: 10.1177/0162243907311265

Storni, C. (2013). Design For Future Uses: Pluralism, Fetishism And Ignorance. Paper presented at the Nordes 2013, Copenhagen.

Thompson, I., \& Kerridge, T. (2004). Biojewellery: Designing Rings with Bioengineered Bone and Tissue (Vol. £66,664). London: Engineering and Physical Sciences Research Council (EPSRC Ref: GR/T26511/01).

Thwaites, T. (2008). Energy Futures Retrieved 13th October 2011, from http://www.thomasthwaites.com/energy-futures/

Toumaz-Group. (2013a). TOUMAZ HEALTHCARE Providing the world's leading wireless healthcare solutions Retrieved 01/07/13, from http://www.toumaz.com/toumaz-healthcare 
Toumaz-Group. (2013b). Toumaz Limited - Annual Report and Accounts For the year ended 31 December 2012. Oxfordshire: Toumaz Group.

Toumaz-Group. (2013c). Towards the improvement of patients' safety with continuous wireless monitoring: Pilot at Saint John's Health Center. London: Toumaz Group.

Toumazou, C., \& Lee, C. Y. (2005). Ultra-low power UWB for real time biomedical wireless sensing. Proceedings of the IEEE International Symposium on Circuits and Systems, 1, 4.

Turney, J. (2006). Engaging Science: Thoughts, deeds, analysis and action. London: Wellcome Trust.

UOL. (2009). University of London - Regulations for the Degrees of MPhil And PhD. London: University of London.

Wagstaffe, C. (2009, October). Explore a world of impact. Connect.

Wainwright, H., \& Elliott, D. (1982). The Lucas plan : a new trade unionism in the making? London: Allison \& Busby.

Wallace, M., Albano, C., \& Wells, T. (2012). Artakt - curating in action: Central Saint Martins College of Art \& Design.

Warburton, D. (2008). Evaluation of Sciencehorizons - Final report. Brighton: Shared Practice.

Ward, A. (1993). Resistance or Reaction? The Cultural Politics of Design. Architecture \& Comportment / Architecture and Behaviour, 9(1), 28.

Warwick, K., Xydas, D., Nasuto, S. J., Becerra, V. M., Hammond, M. W., Downes, J. H., . .. Whalley, B. J. (2010). Controlling a Mobile Robot with a Biological Brain. Defence Science Journal, 60(1), 10.

Welland, M., \& Doubleday, R. (2005). Social Dimensions of Nanotechnology Retrieved 26/04/10, from http://www.nanoscience.cam.ac.uk/irc/theory/21.html

Whiteley, N. (1993). Design for society. London: Reaktion.

Wilkie, A. (2010). User Assemblages in Design: An Ethnographic Study. PhD, Goldsmiths, University of London, London.

Wilkie, A., \& Ward, M. (2008). Made in criticalland: designing matters of concern. Paper presented at the Networks of Design - Proceedings of the 2008 Annual International Conference of the Design History Society, University College Falmouth.

Willis, R., \& Wilsdon, J. (2003). Technology, Risk and the Environment. In A. Giddens (Ed.), The Progressive Manifesto: New Ideas for the Centre-left. Cambridge: Polity Press.

Willoughby, K. W. (1990). Technology Choice: A Critique of the Appropriate Technology Movement. London, England: Intermediate Technology Publications.

Wilsdon, J., \& Willis, R. (2004). See-through science: why public engagement needs to move upstream. London: Demos.

Winner, L. (1986). The Whale and the Reactor: A Search for Limits in an Age of High Technology. Chicago: University of Chicago Press.

Wiseman, E. (2005, April). Human Jewellery. Bizarre.

Wolfendale, A. (1995). Committee to review the contribution of scientists and engineers to the public understanding of science, engineering and technology.

Wong, J. (2008). Techno Bodies; Hybrid Life? - event Tuesday 22 January 2008 19:00 - 20:30. Dana Centre event Retrieved 4th August, 2014, from http://www.danacentre.org.uk/events/2008/01/22/354 
Woolgar, S. (2002). Virtual society? Technology, Cyberbole, Reality. Oxford; New York: Oxford University Press.

Wynne, B. (1992). Misunderstood misunderstanding: social identities and public uptake of science. Public Understanding of Science, 1(3), 281-304. doi: 10.1088/0963-6625/1/3/004

Wynne, B. (1995). Public Understanding of Science. In S. Jasanoff, G. E. Markle, J. C. Peterson \& T. Pinch (Eds.), Handbook of Science and Technology Studies, Revised Edition (3rd ed. / edited by Edward J. Hackett ... [et al.]. ed., pp. 361389). Thousand Oaks, California; London, England: SAGE Publications, Inc

Wynne, B. (2006). Public Engagement as a Means of Restoring Public Trust in Science - Hitting the Notes, but Missing the Music? Public Health Genomics, 9(3), 211-220.

Wynne, B., Felt, U., Callon, M., Eduarda Gonçalves, M., Jasanoff, S., Jepsen, M., ... Tallacchini, M. (2007). Taking European Knowledge Society Seriously Report of the Expert Group on Science and Governance to the Science, Economy and Society Directorate, Directorate-General for Research, European Commission. Belgium: Office for Official Publications of the European Communities.

Xydas, D., Norcott, D., Warwick, K., Whalley, B., Nasuto, S., Becerra, V., ... Marshall, S. (2008). Architecture for Neuronal Cell Control of a Mobile Robot European Robotics Symposium 2008. In H. Bruyninckx, L. Preucil \& M. Kulich (Eds.), (Vol. 44, pp. 23-31): Springer Berlin / Heidelberg.

Yaneva, A. (2008). How Buildings 'Surprise': The Renovation of the Alte Aula in Vienna. Science Studies, 21(1), 21.

Yaneva, A. (2009). Making the Social Hold: Towards an Actor-Network Theory of Design. Design and Culture, 1(3), 21.

Zagers, G., \& Warnier, C. (2008). Designing Critical Design. In J. Boelen, M. Mieke \& G. Zagers (Eds.), ZOOM IN ZOOM OUT. Ghent: MER. Paper Kunsthalle. 